H. S I ADD 
"Maiades of missonin"

Whe I. Uttenback

I. Amarican midlone motenalist vol. 4 , no. 3, of. 41-53, may 1915 .

II $u$ u u vol, , no $4,97-15 \frac{2}{2}, 8$ ly 1915 ,

III $n$ u n Vol 4, no5, 181-20\%.sefft. 1915 .

IV u n u n. Vd4, mo 6, 244-273. Mor, 1915 .

VI u u u vol v mo 7, 311-327. Jom. 1916,

VII u u u Vd4, mo9,387-400, may 1916 ,

VIII 4 a n vol 4, mo 10, $432-460+$ Juky 1916.

Note that there are two congletely different (differently infere set) emata pirnteingt, becouse of $t h$ differences of pagination of tho Jomnal and the sefanato book.

Yexy 1966, 


\section{Josp 1950 pom Hor Laod}

\section{NAIADES Of MISSOURI}

Utterback

I Amer. Midland Nat., Vol. 4, no. 3, pp. 41-53 May 1915,

II Amer. Midland Nat., Vol. 4, no. 4; 97-152 July 191,

III Amer. Midland Nat. Vol. 4, no. 5; 181-204 Sept 1915

IV Amer. Midland Nat. Vol. 4, no. 6; 244-273 Nov. 1915

V Amer. Midland Nat. Vol. 4, no. 7; 311-327 Jan 1916

VI Amer. Midland Nat. Vol. 4, no. 8; 339-354 Feb 1916

VII Amer. Midland Nat. Vol. 4, no. 9; 387-400 May 1916

VIII Amer. Midland Nat. Vol. 4, no. 10; 432-460* July 1916

Note that there are two completely different (type set) errata printings because of page references, etc.

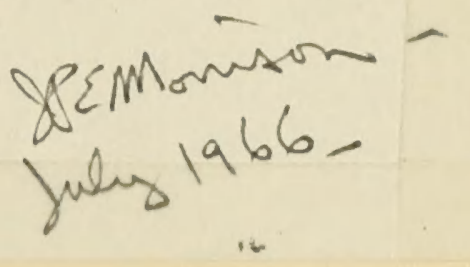


M01818990M 30L.

14021599010306 


\title{
The Naiades of Missouri
}

\author{
By \\ William I. Utterback, B.S., A.M., \\ Author of "Mussel Resources of Missouri," (1914), and "Breeding \\ Record of Missouri Mussels," (1916a).
}

Reprinted from The American Midland Naturalist, Vol. IV.,

Nos. 1-10, with Plates I-XXIX.

\section{SMITHSONIAM}

APR

$$
51091
$$

\section{LIBRARIES}

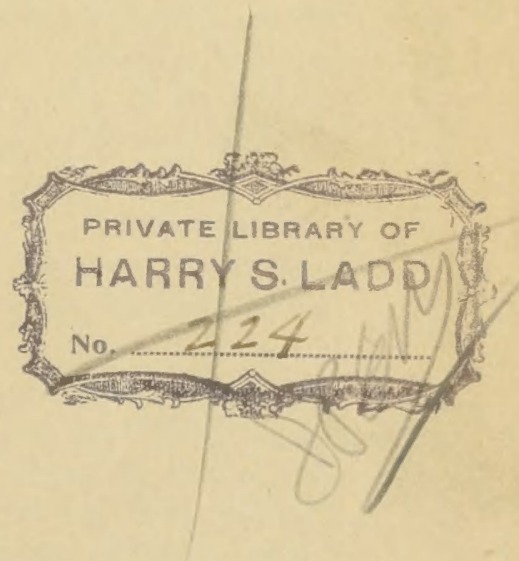

University Press

Notre Dame, Indiana 1916b 
$1408199901 \times 306$ 


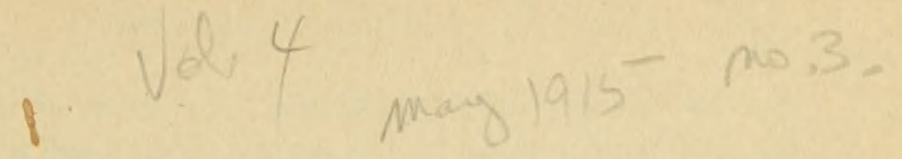

\section{THE NAIADES OF MISSOURI.}

(Plates $i$-xxviii.) New Series.

\section{Introduction.}

After some years of intensive studies in the field, library and laboratory an attempt is made to give a catalogued account of the Naiades, or Fresh-water Mussels, of Missouri. Most of the data for this descriptive and illustrated catalogue have been collected through extensive, personal surveys of the most importtant streams and lakes of the State and now the typical anatomical and shell material from the different localities are preserved in the writer's laboratory. No literature of any consequence, dealing with the Naiades of Missouri, had been produced until the author of this paper made a preliminary report on "The Mussel Resources of Missouri." 'This was, however, a government report, published for economic purposes, the detailed account of the scientific observations of which will not appear until a later date.

The plan of classification, based on anatomical structures, notably those of marsupial characters, has been carefully followed in this work. The many changes in the nomenclature of this catalogue from that of the Simpsonian system are due especially to the recognition of Lindahl's orthographic modification and of the wise scheme of taxonomy for the Naia'des begun by Sterki (I906) and well consummated by Ortmann ( $19 \times 2$ ); and also to the acceptance of Rafinesque's priority as recently revived by Mr. Frierson and accepted by Dr. Ortmann. The writer believes that the ultimate taxonomic system will be based far more upon the anatomical structure of juvenile and adult than upon their shell characters from the fact that the soft parts are more constant 
morphologically and less liable to parallelism and convergence We should not, however, lose cognizance of the importance concerning shell characters. External factors may so shape the shell, as to individualize it, but, under normal conditions, do not often destroy all traces of indentification with some group. Since validity is so dependent upon the examination of both hard and soft structures of large series of individuals, it is felt that the species, as recorded for their extensive and intensive studies herein, are fairly well settled within their genera. Fortunately extensive field work has made this intensive study possible. On one occasion the rare opportunity was given the author to make a mussel survey of three hundred miles down the Osage River in a row boat and ample time was given to the study of one of the richest faunae of Missouri. Two papers, "Mussel Studies Afield" for the years 1913 and 1914 , are now in MS. recorded matter of which is submitted herewith. The ecologic facts secured in these field surveys are especially interesting. For example, in the long trip down the Osage, the largest tributary of the Missouri in the interior of this state, it was found that the flat or compressed forms found at the headwaters, where the water is shallower and swifter, become more swollen and heavier shells further down stream where the water is deeper and more sluggish. The most valuable data gathered from these field excursions are the ecologic as illustrated in Plates $\mathrm{x}$-xiv. Much physiologic and morphologic information, however, has been obtained from these immediate studies in nature that could not be secured otherwise, since actual observation have been made of the animal carrying on the nutritive and reproductive functions there as well as observed through aquarium studies (See Plate ix). More accurate idea of the morphology (especially of soft parts as to color, form, etc.) is obtained while the specimens are fresh and uncontracted as examined afield.

While this catalogued account is rather synoptical as to the text of its animal and shell characters, yet it has been the effort to be more complete than those literary works of somewhat similar character that have devoted more space to the structures of the shell; hence, much description will be found to be completely given for the first time, notably those of $M$. heros (Say), O. quadrula (Raf.), P. Utterbackii Frierson, R. tuberculata (Raf.), U. tetralasma (Say), Las. suborbiculata (Say), Prop. capax (Green), 
Eur. (M.) brevicula (Call), T. Curtisi Frierson and Utterback, and $T$. Lefevrei Utterback. Aside from the morphological synopsis of the nutritive and reproductive parts and also of the external and internal features of the shell the physiological and ecological facts are especially dwelt upon in the miscellaneous remarks. Because of the value of beak sculpture and glochidial characters as bases for classification a special feature is respectively made of the studies of juveniles and glochidia. I,ikewise, for classificatory reasons, a Breeding Record has been kept for the most representative generic types, and, in many instances, more complete records have been made than by other observers due to more detailed observations during the winter season. This Record and also the Zooggeographic account of the Missouri Naiades have been carefully kept in tabulated form, but, as these accounts have been reserved thus for other special papers, they will only appear here in extracts.

In this catalogue eighty species and twenty subspecies are listed. Doubtless this list will be supplemented, although the author has worked the State rather thoroughly in actual field investigations - especially Central and Northwest Missouriand has examined all species catalogued except the following which have been reported by Missouri collectors:- $A n$. Bealii (I.ea). Cy. Aberti Lamarckiana (L,ea), Pleu. plenum (Lea), Lamp. Reeviana (Lea) and Lamp. Powellii (Lea). According to a report from the material sent away for identification, this State can claim another species not yet on the list, - a new and undescribed Lampsilis, near to Lamp. biangulata (Lea), and will soon appear under the authorship of Mr. Frierson.

The author wishes to express his thanks to those who have assisted him in this work. Especially is he thankful to Dr. George Lefevre who assigned and directed this work and rendered it possible through his numerous kindnesses and suggestions. Much credit should also be given Dr. W. C. Curtis, the co-worker with Dr. Lefevre, in the University of Missouri, Department of Zoölogy, where the author gathered much of his data through the facilities of the laboratory, library and museum. Besides the invaluable instructions received from these two gentlemen, who have contributed so much to the Science of Fresh-water Mussels, it was the author's pleasure to receive many valuable hints in person from Dr. R. E. Scammon, author of "Kansas 
Unionidae." For other personal help while attending the University thankful acknowledgements are due to Dr. R. I. Moodie, Messers. G. T. Kline and F. A. Sampson. Under the illustrations of the new species (Plates $\mathrm{v}$ and vi) credit is given $\mathrm{Mr}$. Kline, the University Artist-technician, for his excellent drawings. Through the kindness of Mr. Sampson, author of the "Mollusca of Missouri" (Exclusive of the Unionidae), permission has been given to examine his collections of mussel shells and make use of his list for same in determining geographic distribution and in confirming the reports of other Missouri collectors. Mr. B. F. Bush, a well-known scientist, and resident of Courtney, Mo., has rendered invaluable aid in sending for study immense collections taken mostly from the Ozark region where the author has not been permitted to carry on such exhaustive field studies as in the northern part of the State. Material from Missouri, contributed to the author's collection by Messrs. C. C. Crouch of LaGrange, E. J. Palmer of Webb City and D. K. Gregor of Fulton, has been thankfully acknowledged. The writer is deeply indebted to old collectors and authors, who were former residents of this State, viz:-Messrs. C. T. Simpson, W. A. Marsh, Elwood Pleas and Dr. John H. Britts; also to those students of Naiades for the nearest surrounding States viz:- Dr. F. C. Baker of Illinois, Rev. W. E. Wheeler of Arkansas, Dr. D. H. Wolcott of Nebraska, Dr. Junius Henderson of Colorado, Prof. F. B. Isely of Oklahoma and Drs. R. E. Coker, Thaddeus Surber, A. D. Howard, Prof. H. Walton Clark of Iowa. 'The last four named students are of the personel of the U. S. Fisheries Biological Laboratory, located along the Mississippi at Fairport, Iowa, where the author has done some study and has had pleasant personal contact with these gentlemen who have contributed so much to the science of Fresh-water Mussels. Besides being under obligations to the above-named for their literary and conchological exchanges, as well as for their valued correspondence and actual personal assistance, special mention would also be made of Drs. A. E. Ortmann, V. Sterki, C. B. Wilson, W. H. Dall, Harold Hannibal and Messrs. B. H. Wright, Bryant Walker and L. S. Frierson. The author is most grateful to Dr. Ortmann as an authority concerning the soft parts, to Mr. Walker for his treatment of the shell parts and to Mr. Frierson for his general knowledge of Naiades as well as for his special information concerning the Southwest forms. Through 
very pleasant and extensive correspondence with these last three named gentlemen many problems have been solved and all novelties and changes have passed througl their censorship.

In order to elucidate the references in the text made to the physiography and geography an excerpt of the geographic distribution and also a tabulated Account of the Mussel Faunae of Missouri are given here, although, when it is possible to secure the desired data, it is the intention of the author to give a detailed account of the zoogeography of the Naiades of Missouri and adiacent territory in relation to the restoration of the ancicnt geographic conditions of Contral Mississippi Valley.

In this connection the hydrography of the State may also be given for the sake of clearness in the use of the text. The drainage to the Mississippi is mostly through the Missouri River which flows entirely across the State just above the central line, and because of the loess soil held in suspension, together with its shifting sand bars and mud beds, it forms "a great faunal barrier." Hence we may account for such a distinct mussel fatuna north of the Missouri (known as "Old Muddy") from that south of it. The depauperization of mussel life is remarkable as noted in this river, together with that of the Mississippi from the mouth of the Missouri to a point below the southern boundary line of the State. The chief river basins of North Missouri belonging directly to this faunal barrier are the Chariton, the Grand, the Platte, the Nodaway and other minor ones of the Northwest. A chain of lakes, formed by the changing of the Missouri River channel into "ox-bow cut-offs," are found mostly in the northwestern part of the State along the Missouri in its eastern and northern flood-plains. The largest river basins draining into the Missouri River from the south are the Osage, Gasconade and Black-water. The most important one which drains directly into the Mississippi from this State is the Meramec. The chief basins found on the south slope of the Ozarks are the White, Black and St. Francis Rivers which are drained into the Mississippi through Arkansas. South-west Missouri drains into the Mississippi River partly and directly through the Neosho.

The following is a Classified Account, (although apparently contrary to the geologic facts, yet self-explanatory), showing the distinct mussel faunae of the State that coincide with the different 
physiographic provinces because of their different ecologicai conditions, namely, the muddy, sluggish streams of the north, swift, clear-water streams in the south and the mediocre streams of the Central portion:-

$a=$ Prairies; $b=$ Mo. and Miss. R's (Proper); $c=$ Ozark Uplift. I.-NORTH MISSOURI = Primitive Mussel Fauna.

1.a-New Prairies, or Glacial Plains. (N. and N.W.Mo.)

1.b-Missouri-Mississippi Flood-plains - Mo. Lakes and Miss R.

(Proper) to mouth of Mo. R. (N. E. Mo.).

Mo. R. (Proper) $=$ Depauperated Mussel Fauna.

II.-CENTRAL MISSOLRI = Intergraded Mussel Fauna.

2.a--Old Prairies of W. Central Mo.

r.c-Ozark Border, or North Slope.

III.-SOUTH MISSOURI = Modern Mussel Fauna.

2.c-Ozark Plateau.

3.c-Ozark Center, or South Slope.

2.b-Miss. R. (Proper) below mouth of Mo. R. and Miss.

Lowlands of S. E. Mo. = Depauperated Mussel Fauna.

The Spcries and Sub-Species, listed under the following general Key to the Missouri Naiades, are assigned to the different sub-physiographic provinces where they predominate by employing to the cutreme right after their names the lettered numbers of the above Classified Account: e. g., Amblema rariplicata (Deshayes)1.a., thus indicating the New Prairies Fauna where mostly found.

\section{General Key for Identification of the Missouri Naiades.}

This key is for very general use, being based upon the essential reproductive and nutritive characters of the animal parts for the Families, Sub-Jamilies and Generic Groups. These characters are indicated under the lettering in the Scheme below and the enumeration of all Naiades for Missouri is denoted both by the Roman and Arabic numerals. The geographic distribution of the Species and Sub-Species is indicated by the lettered numbers. The following Scheme of progressive classiffcation is employed:-

A.-FAMILY I.

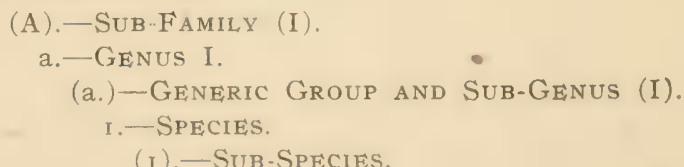

A.-Gills with no water-tubes, septa incomplete, obliquely arranged; gill- 
diaphragm incompletely formed; supra-anal absent, branchial and anal openings suppressed with no tendency to a siphonal form; all four gills both respiratory and marsupial; post-ventral margin of mantle undifferentiated; glochida semi-circular, ventral margin with irregular dentations; tachytictic, or short period ("Summer") breeders.

FAMILY I. MARGARITANIDAE Ortmann.

a.-Gill septa oblique from base of gills, more vertically arranged and shorter ventrad................... CUMBERLANDIA, Ortmann I.-C. monodonta (Say)-(1. c).

B.-Gills always with water-tubes, septa complete and parallel with gill filaments; gill-diaphragm complete; branchial and anal openings usually tend toward a siphonal form; all four gills or only outer, or parts of outer, marsupial; glochida generally suboval, spadiform, geltiform, spined or spine-

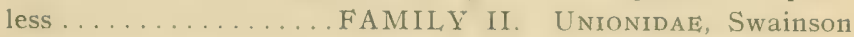

(A).-Connection between anal and supra-anal openings short or absent; inner laminae of inner gills free from visceral mass; post-ventral margin of mantle not specialized; marsupial undifferentiated, not distended when gravid; glochidia suboval, spineless, tachytictic for the most part........ Sub-Family (I), Unioninae, Ortmann

a.-All four gills marsupial.

(a)-Conglutinates club-shaped, pinkish, solid; beak sculpture concentric and slightly nodulated at base of post-umbonal ridge; disk unsculptured....Genus II. Fusconaia Simpson

2. F. undata (Barnes)-(1. b)

(I). F. undata trigona (Lea)-(r. c)

(2). F. undata trigonoides Frierson-(1, a)

3. F. flava (Raf.)-(3.c)

4. F. hebetata (Conrad)-(r. c)

5. F. ebena (Lea)-(r. b)

(b)-Conglutinates leaf-like, compressed, subsolid white; beak sculpture concentric, extending zigzag out on disk which is greatly sculptured.............................. II Amblema (Raf.)

6. A. peruviana (Lamarck)-(1, c)

7. A. rariplicata (Deshayes)-(I. a)

8. A. perplicata (Conrad)-(3. c)

(3). A. perplicata Quintardi (Cragin)-(1. c)

9. A. (plicata) costata (Raf.)-(r. a)

Genus IV. Magnonaias Utterback.

Io. $M$. heros (Say)-(I, a)

Genus V. Quadrula (Raf.)

I I. Q. pustulosa (Lea)-(1, b)

(4). Q. pustulosa Schoolcrafiensis (Lea)-(I, a)

(5). Q. pustulosa asperata (L,ea)-(I. c)

12. Q. quadrula (Raf.)-(1. b)

(6). Q. quadrula contraryensis Utterback-(1. a) 


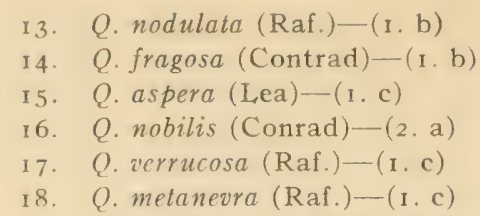

(7). Q. metanevra Wardii (Lea)-(r. b)

19. Q. cylindrica (Say)-(3. c)

b.-Only outer gills marsupial.

(a)-Supra-anal opening absent; beak sculpture zigzag; disk greatly sculptured.................. Genus VI. Rotundaria (Raf.)

20. R. luberculata (Raf.)-(I. c)

21. R. granifera(L,ea)-(1.b)

(b) - Supra-anal present but short; beak sculpture concentric but disappearing toward disk which is mostly unsculptured.

Genus VII. Plethobasus (Simpson:

22. P. Cooperianus (Lea) - (2, c)

23. P. aesopus (Green)-( $\mathrm{I}, \mathrm{b})$

Genus ViII. Pleurobema (Raf.)

24. P. obliquum (Lamarck)-(I. b)

(8). P. obliquum plenum (Lea)--(3. c)

(9). P. obliquum pyramidatum (Lea)-(1. c)

(10). P. obliquum catillus (Conrad)-(ז . c)

(I I). P. obliquum coccineum (Conrad)-(I. c)

25. P. catillus (Conrad)-(3. c)

26. P. coccineum (Conrad)-(3. c)

27. P. missourense (Marsh) - (3. c)

28. $P$. Utterbackii Frierson-(3. c)

Genus IX. Elliptio (Raf.)

29. E. nigra (Raf.)-(2.c)

30. E. dilatata (Raf.)-(2. a)

(12). E. dilatata subgibbosa (Lea)-(3.c)

(13). E. dilatata delicata (Simpson)-(3. c)

Genus X. Uniomerus (Conrad)

31. U. tetralasma (Say)--( 1, a)

(14). U. tetralasma comptodon (Say)-(i . a)

(B).--Mantle connection between anal and supra-anal openings always present, very long and moderate; inner laminae of inner gills usually free from the visceral mass; marsupia occupying entire outer gills only, distended ventrad and with lateral water-tubes when gravid; post ventral margin of mantle not differentiated; glochidia subtriangular, or spadiform, spined; bradytictic or long period ("Winter") breeder ................. Sub-Family II. AnodontinaE Ortmann a.- Inner laminae of inner gills free from visceral mass; beak sculpture coarse, double-looped.

(a)-Mantle connection between anal and supra-anal openings moderately long; hinge rather complete, shell sculptured and

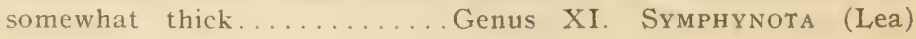


32. S. complanata (Barnes)-(1.a)

33. S. costata (Raf.)-- (3. c)

Genus XII. Arcidens Simpson)

34. 4. confragosus (Say)-(2. c)

(b)-Mantle connection between anal and supra-anal openings very long; hinge completely absent; disk smooth; shell thin.

35. L. suborbiculata (Say)--( 1 , b)

Genus XII. IAASTENA (Raf.)

36. L. ohiensis (Raf.)-( $1 . \mathrm{b})$

Genus XIV. Anodonta (Lamarck)

37. A grandis (Say)-(1. b)

38. A. dakolana Frierson-( - $\mathrm{i}, \mathrm{b})$

39. A. corpulenta Cooper-(I, b)

40. A. Danielsii Lea-(I, a)

41. A. Bealii Lea-(1, 2c)

(c)-Mantle connection between anal and supra-anal openings moderately long; hinge almost absent; shell rather thin, disk unscupltured.............. Genus XV. Anodontordes (Simpson) 42. A. Ferussacianus (Lea) - (1, b-)

b.- Inner laminae of inner gills with tendency to connect with visceral mass; mantle connection between anal and supra-anal openings moderate; beak sculpture, heavy, concentric.

(a)-Marsupium with simple ovisacs; hinge teeth rather well developed with cardinals sharp and prominent

Genus XVI. Alasmidonta (Say)

43. A. calceolus (Lea)-(3. c)

44. A. marginata Say-(2, c)

(b)-Marsupium with transverse ovisacs; hinge rudimentary with cardinals rounded and suppressed. Genus VXII. Strophitus (Raf)

45. S. edentulus (Say)-(2. a)

(C)-Mantle connection between branchial and anal openings present, never very long; inner laminae of inner gills rarely ever entirely free from visceral mass; post-ventral margin of mantle usually highly differentiated with papillae, flaps, etc.; part of outer gills in most genera specialized as marsupia, which, when gravid, bulging beyond original edge of gills, ruptured at ventral edge of ovisacs for escape of larvae; glochidia semi-circular, (LAMPsilis type), or axe-head shape (PROPTERA type), ventral margin rounded, rarely spined; bradytictic.

Sub-Family III. Lampsilinae Ortmann.

a.-Marsupium with subcylindrical ovisacs; post ventral margin of mantle smooth; shell sometimes with disk sculptured, sex dimorphism of shell not distinct.

(a)-Marsupium occupying almost entire outer gill, edges folded, ovisacs several, small, short... Genus XVIII. Fllipsaria (Raf.)

46. E. clintonensis (Simpson)-(3. c)

(b)-Marsupium occupying outer gill in a few, large, long ovisacs.

Genus XIX. Obliquaria (Raf.)

47. O. reflexa (Raf.)-(I. c) 
Genus XX. Cyprogenia (Agassiz)

48. C. Aberti (Conrad)-(3. c)

(15). C. Aberti Lamarckiana (Lea)-(3. c)

b.-Marsupium with compressed and dilated ovisacs; post ventral margin of mantle smooth to papillose; shell generally without disk sculpture, sex dimorphism usually very distinct.

(a) - Inner post-ventral edge of mantles without flap or papillae, but slightly lamellate and crenulated; glochidia elliptic and celtiform, when normal in shape either extremely large or small.

Genus XXI. Obovaria (Raf.)

Sub-Genus (I)-PSEUdooN (Simpson)

49. O. (Pseudoon) ellipsis (Lea)-( $1 . \mathrm{b})$

Genus XXII. Nephronalas (Cross and Fisher)

50. N. ligamentina (Lamarck) - ( I, b)

(16). N. ligamentina gibba (Simpson)-(1, c)

5I. N. ellipsiformis (Conrad)-(I. c)

(17). N. ellipsiformis venwsta (Lea)-(1. c)

52. N. Pleasii (Marsh) - (3. c)

53. N. ozarkensis (Call)-(3. c)

Genus XXIII. Amygdalonaias (Cross and Fisher)

54. A. donaciformis (Lea)-(1, a)

55. A.truncata (Raf.)-(1. c)

Genus XXIV. Plagiola (Raf.)

56. P. securis (Lea)-( $\mathrm{I}, \mathrm{b})$

Genus XXV. Lasmonos (Raf.)

57. L. fragilis (Raf.)-(1. a)

58. L. Simpsoni (Ferriss)-(3. c)

59. L. leptodon (Raf.)

Genus XXVI. Proptera (Raf.)

6o. P. alata (Say)-(I. a)

61. P. purpurata (Lamarack)-(3. c)

62. P. laevissima (Lea)-(1. a)

63. P. capax (Green)-(1. b)

(b) - Inner post-ventral edge of mantle differentiated with papillae and flaps; glochidia normal in shape, medium in size.

Genus XXVII. Carunculina (Simpson)

64. C. parva (Barnes)-(r.b)

65. C. texensis (Lea) - ( 1, a)

66. C. glans (Lea)-(1. a)

Genus XXVIII. EURYNia (Raf.)

Sub-Genus (II). Micromya (Agassiz)

67. E. (Micromya) lienosa (Conrad)-(3. c)

68. E. (Micromya) iris (Lea)-(3. c)

69. E. (Micromya) brevicula (Call)-(3. c)

(18). E. (Micromya) brevicula Brittsi (Simpson)-(1. c)

Sub-Genus (III).) EURyNia (sens. strict.)

7o. E. (Eurynia) subrostrata (Say)-(1, a)

71. E. (Eurynia) recta (Lamarck) - (1, c) 


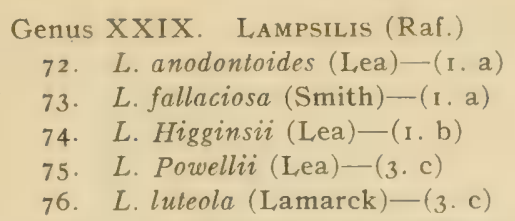

(19). L. luteola rosacea (DeKay)-(3. c)

77. L. Reeviana (Lea)-(3. c)

78. L. ventricosa (Barnes)-(3. c)

(20). L. ventricosa satura (Lea)-(3. c)

Genus XXX. Truncilla (Raf.)

79. T. Curtisi Frierson and Utterback-(3. c)

8o. T. Lefevrei Utterback-(3. c)

ENUMERATION OF MISSOURI NAIADES.

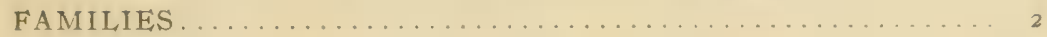

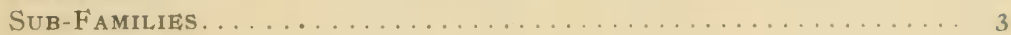

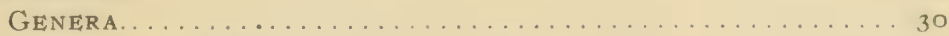

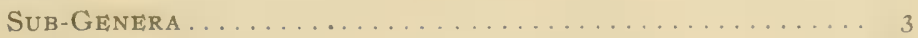

SPECIES......................... 80

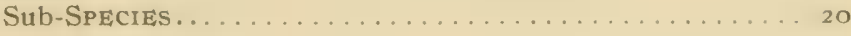

Total of Species and Sub-Species.................

ExplanATION OF FIgURES.--For the purpose of illustrating the characteristic structures of the animal a few text-figures have been inserted immediately under the different Sub-Families. All figures illustrating these characters are about life-size and, while they are drawn from actual specimens in gravid condition, yet the sketches are more or less diagrammatic in or ${ }^{-1} \mathrm{er}$ to emphasize the essential features. The sketches of the glochidia (most of them figured here for the first time) are actual cameralucida drawings by using lenses to magnify 87 diameters. In both sets of these inserted figures, as well as in some of the plates at the close of the text, the following meanings are given to the letters for the labels:-

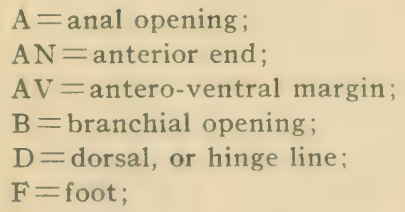

$$
\begin{aligned}
& \mathrm{I}=\text { inner gill; } \\
& \mathrm{M}=\text { marsupium; } \\
& \mathrm{P}=\text { palp; } \\
& \mathrm{PO}=\text { posterior end; } \\
& \mathrm{S}=\text { supra-anal opening; } \\
& \mathrm{V}=\text { ventral margin. }
\end{aligned}
$$

Explanation of Terms, AbBreviations, ETC., Used in the TEXT, BIBLIGGRAPHX AND CHECK LIST.-A few technical terms intro- 
duced here are suggested for general use. Reference to the four sections of the shell or mantle edges, limited by the anterior, posterior, dorsal and ventral extremities, can be expressed adjectively and adverbially by the respective terms, "antero-ventral," "anterorentrad," "post-dorsad," etc. (See Plates I-III). "Spadiform" (shape of a spade head) and "celtiform" (shape of a celt, or axehead) are used as adjectives in describing glochidia. In a few shell measurements adoption has been made of Scammon's term, "umboidal ratio," (um ra.) which is secured by dropping a line perpendicularly from the tips of the beaks to the longitudinal axis and expressing the distance from the intersection of the two lines to the anterior margin of the shell as a decimal fraction of the entire length of the longitudinal axis. The term, "interdentum," is used here for the bridge between the lateral and cardinal teeth. 'The terms, "bradytictic" and "tachytictic," as suggested by Ortmann, are adopted as meaning respectively, "long period" and "short period" breeders. The term "diaphragm," is also used here for the partition between the branchial and anal openings formed by the gills.

All shell measurements are reckoned in terms of millimeters (mm.) and length, height and diameter are considered consecutively. "Diameter" is the distance between the greatest convexities of closed valves. All other usages employed in this work have been in such common adoption as to need no explanation.

To make plain those parts of this catalogue,-especially the Synonomy and Bibliography,- the equalities for the abbreviations are given as follows:-

Am. J. Conch.-American Journal of Conchology.

Am. J1. Sci. and Arts.-American Journal of Science and Arts.

Am. Nat.-American Naturalist.

An. Car. Mus.-Annals of the Carnegie Museum.

Biol. Bull.-Biological Bulletin.

Bull. Wash. Coll.-Bulletin of Washburn College.

Bull. U. S. Mus.-Bulletin of the United States Museum.

Bull. U. S. B. F.-Bulletin of the Unites Stated Bureau of Fisheries.

J1. (or Jour.) Ac.N. Sci. Phila.-Journal of the Academy of Natural

Science of Philadelphia.

J. Cinn. N. Hist. Soc.-Journal of the Cincinnati Historical Society.

J1. Phila. A. Sci-Journal of the Philosophical Academy of Science.

Mal. Soc. Lon.-Malacological Society of London.

Moll. Chicago, Pt. I.-Mollusks of Chicago, Part I.

Monog. Biv, Ohio.-Monograph of the Bivalves of Ohio, 
Naut.-Nautilus.

N. Harm. Diss.-New Harmony Disseminator.

Pr. (or Proc.) Ac. N. Sci. Phil.-Proceedings of the Academy of Natural Science, Philadelphia.

Pr. Am. Phil. Soc--Proceedings of the American Philosophical Society.

Pr. Mich. Ac. Sci.-Proceedings of the Michigan Academy of Science.

Pr. Ohio Ac. Sci.-Proceedings of the Ohio Academy of Science.

Pr. U. S. Nat. Mus.-Proceedings of the United States National Museum.

Tr. (or Trans.) Ac. Sci. St. Louis.- Transactions of the Academy of Science of St. Louis.

Tr. Am. Fish. Soc--Transactions of the American Fish Society.

Tr. Am. Phil. Soc.-Transactions of the American Philosophical Society.

U. S. B. F. Ec. Cir.-United States Bureau of Fisheries, Economic Circular.

U. S. B. F. Doc.-United States Bureau of Fisheries Document. 



\section{CATALOGUE OF THE NAIADES OF MISSOURI.}

\section{Family I. Margaritanidae Ortmann.}

I911-Margaritanidae Ortmann., Nautilus, Feb.

"Diaphragm incomplete, formed only by the outer gills; outer laminae of outer gills only in part connected with the mantle, posteriorly free for considerable distance. Anterior end of inner gills separated from the palpi by a wide gap. The margins of the mantle do not unite or approach each other anywhere and there is no tendency to form branchial and anal siphons and no supraanal opening is present. Gills without water-tubes, inter-lamellar connections forming oblique rows. Marsupium formed by all four gills. Glochidia small, semicircular and globular, without hooks, but with irregular, small teeth at the ventral margin."Ortmann (I9I2 b, p. 223).

This Family presents the most primitive characters of the Naiades and is represented in Missouri by only one species, Cumberlandia monodonta (Say), for which it was necessary to create a special genus because of its peculiar gill structure as determined by histological studies. Even in this Family, shell characters are not constant enough to be considered in the diagnosis. Like the sub-families, Inioninae and Anodontinae of Unionidae, the glochidal discharge is effected through the anal opening.

\section{Genus Cumberlandia Ortmann.}

189 г2a-Cumberlandia Ortmann, Nautilus, XXVI pp 13 and I4.

(Type, Unio monodonta Say.)

Animal Characters:-Diaphragm and supra-anal opening absent; gills long and narrow, inner broader anteriorily than 
outer, inter-laminar connections not irregularly distributed but arranged obliquely parallel to each other, outer lamina of outer gill free from mantle posteriorly, inner lamina of inner gill almost entirely free from visceral mass; all four gills marsupial; anterior adductors reinforced posteriorly.

SHEll ChaRACTERS:- Shell narrowly elliptical, no sculpture on disk, low beaks scuptured with ridges parallel with growth lines; epidermis black; anterior cardinals lacking, posterior ones conical; anterior adductor muscle scar deeply impressed post-dorsad; nacre pearl blue to white.

\section{Cumberlandia monodonta (Say). \\ ("Spectacle Case.") \\ Pl. XV. Figs. $28 \mathrm{~A}$ and $\mathrm{B}$.}

1829-Unio monodonta Say, N. Harm. Diss., IIp. 293; 1830, Am.

Conch I. P1. VI.

I853-Margaritana monodonta Conrad, Pr. Ac. N. Sci., Phila. VI, p 262. 19I ia-Cumberlandia monodonta Ortmann, Nautilus XXVI, pp 13 and 14 .

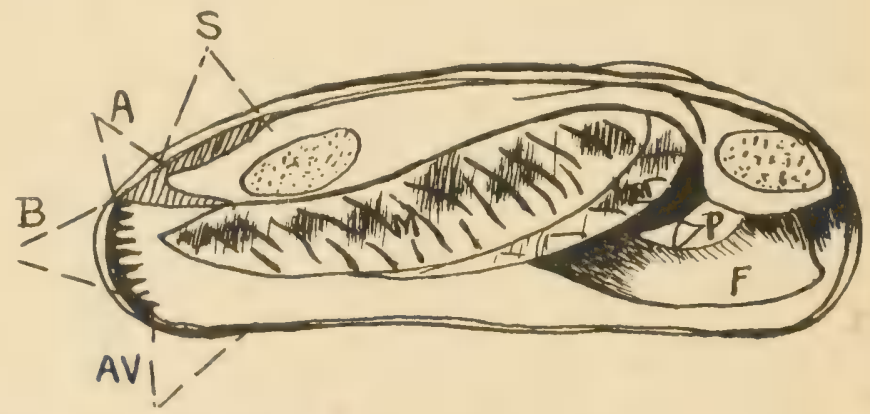

Fig. I.-Cumberlandia monodonta (Say). † Diagram of sterile individual from the Osage River, Sagrada, Mo., showing animal characters in left valve. (Nat. size.)

\section{ANIMAI, CHARACTERS.}

NUTRITIVE STRUCTURES:--Branchial opening with papillae reduced to mere crenulations; no gill partition (diaphragm) between branchial and anal openings; no true supra-anal opening; gills very long and narrow with interlaminar connections regularly arranged as "continuous septa which run obliquely forwards;" inner lamina of inner gill free from visceral mass except at its 
anterior end; outer lamina of outer gill slightly free posteriorly from mantle, all four gills marsupial; palpi, large, comparatively broad, hangs low, united two-thirds of way toward base; color of soft parts soiled white, mantle edge blackish chiefly at the branchial openings.

REPRODUCTIVE STRuctures:- No gravid females found so

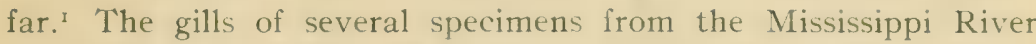
presented no variations of structure; hence this peculiar oblique arrangement of septa may not be a sex distinction.

\section{SHELL CHARACTERS.}

ExTERnAL STRUCTURES:- Elongate-elliptical, arcuate in old specimens, not sexually dimorphic; rounded before, usually more pointed behind; beaks small, low, sculptured by a few coarse concentric bars; lines of growth rough, coarse; epidermis black, shell moderately thick anteriorly, but very thin posteriorly, being disposed to crack easily upon exposure to air.

INTERNAL STRUCTURES:- Cardinals conical, single in both valves, rudimentary to lacking in left; laterals low, single in right, inclined to double posteriorly in left; scars well impressed anteriorly-especially the one taking the position of anterior cardinals in most other Naiad shells; beak cavities shallow; nacre bluish with a slight tint of salmon in umbonal cavity; no vein marking as in most Unioninae.

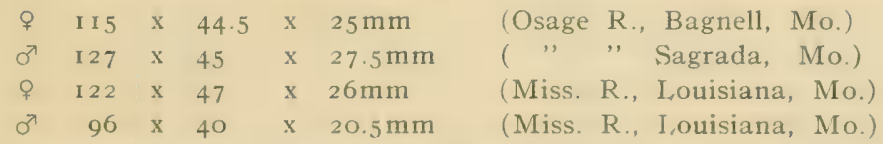

MISCELLANEOUS REMARKS:- $C$. monodonta is most typical in the Mississippi above the mouth of the Missouri. Bryant Walker records it from Tennessee to Ohio, thence Northwestward to Nebraska. From the fact that the author found this primitive species at several points in the Osage and Gasconade Rivers, its known distribution is now carried farther south and west of the Mississippi River, than recorded before. The existence of this, as well as other primitive forms of the Naiades, also in the Cumberland-

1 Dr. A. D. Howard, (Scientific Assistant, U. S. Biological Station, Fairport, Iowa), has however recently discovered that this species bears unusually small glochidia and has the peculiar habit of bearing two broods in a season (Nautilus, XXIX, p. 6, May, ig15.), 
Tennessee basin may furnish some interesting data for the reconstruction of ancient geographical features for the central Mississippi Valley.

\section{Family II. Unionidae Swainson (restricted).}

"Diaphragm complete, formed only by the gills; the outer lamina of the outer gills connected with the mantle at its posterior end. Anterior end of inner gills separated from palpi by a more or less wide gap. Margins of the mantle held together by the gilldiaphragm, but not united, thus separating the anal from the branchial opening, and the anal is generally closed above by the union of the margins of the mantle, (it rarely remains open), and when closed, it always leaves a supra-anal opening (which is very rarely obliterated). Gills always with water tubes formed by interlamellar connections developed as continuous septa, running parallel to the gill-filaments. Marsupium formed by all four gills, or by the outer gills alone, or by parts of the outer gills. Glochidia of various shapes, suboval, or subtriangular, or celtshaped, with or without hooks on the ventral margin."-(Ortmann I 912 b.)

Simpson's terse diagnosis of this family is:- "Hinge with schizodont teeth; embryo a glochidium."

The family, Unionidae, naturally falls, into three divisions on the basis of physiological and morphological characters; however, this family may fall into two sub-divisions on the sole basis of reproductive functions. The Inioninae and Anodontinae would form the first and the Lampsilinae the second group from the fact that the discharge of the glochidia takes place in the former through the primitive and natural way of passage from the ovisacs through natural openings into the suprabranchial canals and then on out through the anal opening and in the latter the discharge is effected in a more direct and seemingly unnatural manner; that is, in the passage from openings forced through the ventral edges of the ovisacs, and thence out through the branchial opening. Yet the two sub-families, Lnioninae and Anadontinae, have morphological differences in marsupial characters and in structures of the glochidial masses that are correlated with physiological differentiation in breeding habits. On the same grounds, Lampsilinae is set aside as well a defined group; however the latter, although the modern group, is related to the primitive one Unioni- 
nae, in that the morphology of the Lampsiline glochidium would indicate a reversion to the primitive type as is the natural course in the cycle of evolution. Thus on the basis of glochidial characters, the Family Unionidae may be grouped as:

I Anodonta, bearing non-conglutinated glochidia, spadi form, spined.

2. PROPTERA, bearing conglutinated glochidia, celtiform. spined or spineless.

3. UNIO-LAMPSILIS, bearing conglutinated glochidia, apronform, spineless.

The key to the whole situation governing the approach to the modern arrangement is in the differentiation of structures for the benefit of the embryos; e. g., large palpi for the Unioninae, marsupial water tubes (secondary) and also large palpi for Anodontinae, but, best of all, an adjustment of marsupium near to a specialized mantle edge in form of flaps, papillae, tentacles, etc., as shown in Lampsilinae.

\section{I-SUB-FAMILY Unioninae Ortmann.}

I9 I a-Unioninae Ortmann. An. Car. Mus., IV, pp. 335-336; I912b

An. Car. Mus. VIII, pp. 236-277.

ANIMAL CHARACTERS:- Branchial opening rather sparingly papillose; anal smooth to finely crennulate; supra-anal usually present separated from anal by very short or moderately long mantle connection; no tendency to form tubular siphonal openings; inner laminae of inner gills free from visceral mass; palpi usually very large and long, marsupium occupying all four gills or by the two outer ones, when gravid not much swollen, ventral edge pointed, never bluntly distended and secondary water-tubes never developed lateral to the ovisacs within; mantle edge anteroventrad to branchial opening, smooth; glochidia of the Lampsilis type, apron-shaped, small to medium, semicircular or semielliptical, ventral margin rounded, without spines; conglutinates well formed.

SHEll Characters:-Forms of shell various, usually thick; disk smooth to very profusely scuptured; beaks usually scuptured with concentric or zigzag ridges; hinge teeth very highly developed, cardinals and laterals never lacking; scars well impressed.

MISCELIANEOUS REMARKS:- The soft anatomy of the species of this subfamily are rather constant. However, its shell characters 
are so inconstant that this subfamily may be termed a great group of intergrades. Having very typical hinge teeth and very closely adhering valves the branchial margins are not well papillosed and the soft parts of the different species are more or less identical. In contrast with the other more modern subfamilies, Anodontinae and Lampsilinae, a greater differentiation of soft parts is noted in the latter, due to their more gaping valves and to a greater adjustment to aeration of the embryos; then, too, Inioninae differs from either of the two in that its breeding season is short (tachytictic), being confined to the summer. In the Inionae the color, form and solidity of the conglutinates can be considered as of greater systematic value than in the other sub-groups. It is to be noted that these summer breeders have the peculiar trait of aborting their conglutinates when they may be disturbed from their natural beds. The fact of the close, or even deciduous, mantle connection between the anal and the supra-anal openings may be a minor character in distinguishing the genera. The connection between inner laminae of the inner gills and the visceral mass may also serve in making distinction. From the fact that there are a great number of variations in shell character for this sub-family it is necessary to admit several genera so that there may not be so much opportunity for the same types of shell to turn up and thus give false impressions of relationships. It is very striking to note the atavism of the spineless, subovate glochidium of this sub-family in the fact of its homologous recurrence under the Lampsilis type. However, this natural reversion to primitive type in the embryo of the Lampsilinae is only an indication of the wide gap between the two sub-families as well as in the fact of its differences of physiological characters in the adult, such as the discharge of glochidia through the anal opening for the Unioninae and through the branchial for the Lampsilinae. However the homologous differences in the soft parts and hard parts of the two groups are still greater than the analogous. Why more species of this primitive group should occur in the more modern region of this state (i. e., N. Mo., the New Prairies) than in that of the more ancient geologic formation (i. e., S. Mo.,-the Ozark I'plift)--this is a problem that the author is trying to solve. 'The unusual variations within the sub-family especially is another problem that would also be solved. 


\section{Genus Fusconaia Simpson.}

rgoob-Fusconaia Simpson, Pr. U. S. Nat. Mus. XXII, p. 784 (as sect.) r $912 \mathrm{~b}-$ Fusconaia (Simpson) Ortmann, An. Car., Mus., VIII, pp. $240-24$ I.

(T'pye I nio undatus Barnes).

Animal Characters:-Branchial opening with dense yellnwish tentacles; anal smooth; supra-anal separated from anal by very short connection, laminae of inner gills free from risceral mass; palpi rather large; all four gills marsupial, ovisacs when gravid subcylindrical; conglutinates same shape, usually reddish, subsolid and discharged whole; glochidium subovate, somewhat small, spineless; colors of soft parts usually brilliant, such as orange or red.

SHELl CHARACTERS:- Shell roundly quadrate or triangular; disk smooth; beaks elevated, sculptured with concentric ridges angled at base of prominent post-umbonal ridge; epidermis reddish to brown with fine, rather interrupted, rays when young; hinge teeth well developed; beak cavities deep; nacre white.

Miscellaneous Remarks:-Dr. Ortmann considers this genus the most primitive of the Lnionidac and limit; it to those species of Simpson's trigond group that possess subcylindrical conglutinates and ovisacs, concentric beak sculpture and smooth disk as the diagnostic features. While the conglutinates of the Fusconaia species may be reddish, yet they may vary from pale pink to white due to their development usually. It is to be noted, however, that when the conglutinates are white all of the anatomy is also white; when the conglutinates are reddish the soft parts will be more yellowish. In this state the following groups may differ morphologically and ecologically as follows:

I. F. undata: swollen, high beaks, mostly greenish-black epidermis ......................... Rivers

2. F. trigona: swollen, lower beaks, mostly reddish epidermis.

Medium Rivers

3. F. flava: flat, low beaks, always reddish epidermis

Small Rivers

The second group is not found in very typical form in this State, but is represented by intergrading forms. In fact none of these Species, representing the above names, are very often found typical in Missouri, since this State seems to be the home mostly 
for intermediate forms not only for Fusconaia, but for other Genera of this Sub-family, Inioninae, especially. All Fusconaia of this State are strictly fluviatile. For the most part the Species of this Genus are hermaphroditic, for all localities.

\section{Fusconaia undata (Barnes). \\ (" "Pigtoe.") \\ Pl. xv. Figs. 29 A and $B$.}

I823-Unio undatus Barnes, Am. Jour. Sci., VI, p. I2I, pl., IV, fig. 4. I831-Unio trigonus Lea, Tr. Am. Phil. Soc., IV, p. I Io, pl XVI, fig. 40. 1 goob-Quadrula trigona, Simpson, Proc. U. S. Nat. Mus., XXII, p.,787. 1900-Quadrula undata Walker, Nautilus, XXIV, pp. 5-1 I and 16-24,

Plates I and I.

I9 2 b-Fusconia undata (Barnes) Ortmann An. Car. Mus., VIII, p. 24 I.

ANIMAL CHARACTERS.

NUTRITIVE STRUCTURES-Branchial opening with short brownish papillae; anal slightly papillose, separated from supraanal by very short, - even deciduous - mantle connection; i:ner gills larger, inner laminae free from visceral mass; outer gill undulate antero-ventrad, palpi moderately large, connected over half of their length antero-dorsad; most of soft parts yellowish or cream colored.

REPRODUCTIVE STRUCTURES:-Marsupia formed bv all four gills, when charged not distended, lumen of ovisacs subcylindrical; conglutinates same form, light red--even to white-according to age of embryos; glochidium semicircular, medium size, hinge line nearly straight, length and height, (O.I60 x 0.155 $\mathrm{mm}$ ), about same.

SHELI, CHARACTERS.

EXTERNAL STRUCTUREs:- Shell trigonal, thick, heavy anteriorly, disk smooth; beaks high, full, pitched slightly beyond anterior end, sculptured with concentric ridges breaking into nodules at base of prominent umbonal ridge; dorsal line bowed, post-ventral line with long gentle incurve; broad shallow valley in front of post-umbonal ridge; ventral margin bowed in scmicircular form; epidermis greenish to rusty brown or black or mingling of both green and black; rest lines furrowed giving an undulated effect; post-umbonal ridge prominent.

INTERNAL STRUCTURES:-Cardinals single and pyramidal in right, double and roughly socketed in left; laterals double in 
both valves; scars deeply impressed; beak cavity narrowly deep; nacre silvery white; male shell usually more compressed than that of female, but no true dimorphism shown.

\begin{tabular}{ccccccc} 
Length & Width & Diameter & Um. ra. & \multicolumn{2}{c}{ Locality. } \\
75 & $\mathrm{x}$ & 63 & $\mathrm{x}$ & $48 \mathrm{~mm}$ & 0.16 & (Miss. R., LaGrange, Mo.) \\
70 & $\mathrm{x}$ & 64 & $\mathrm{x}$ & $49 \mathrm{~mm}$ & 0.78 & ( ", ," , \\
55 & $\mathrm{x}$ & 43 & $\mathrm{x}$ & $39 \mathrm{~mm}$ & 0.17 & (Meramec, R., Fern Glen. Mo.) \\
60 & $\mathrm{x}$ & 55 & $\mathrm{x}$ & $46 \mathrm{~mm}$ & 0.17 & (Osage R., Linn Cr., Mo.)
\end{tabular}

Juvenile Shells are described as having a light yellowish brown epidermis with green rays most distinct on anterior slope, and finely ribbed lines running from beaks to ventral margin across center of disk.

MiscellaneOUS REMARKS:-This species was hidden in synonomy for many years until Mr. Bryant Walker (rgrob, p. 5) brought it to light through diligent study. It is found in most typical form in the Mississippi River and occasionally it may be found in the Meramec and Osage Rivers where it is to be distinguished from $F$. Alava by its swollen high beaks and darker epidermis. Then, too, this species is determined largely ecolngically, being an inhabitant of the large streams and deep water, for the most part. In most of the interior streams of the state, undata, however, is found chiefly in an intermediate, or intergraded, form with flava. In the whole southwest this species does not seem to be very near the type as found in the Ohio drainage or in the Upper Mississippi, especially in Wisconsin where Barnes secured his type lots. The Des Moines River, Clark Co., Mo., has produced rather good types, some shells of which have been sent to the National Museum by Mr. B. F. Bush and are now on exhibit there under the number 132,633 . However, none of these so-called undata types come up to those of the Upper Mississippi. Surber (1913, p. I13) finds F. undata in the larval state to be a gill parasite on the black crappie (Pomoxis sparoides) as an occasional host. Undata is a tachytictic form, but begins its breeding very early, bearing glochidia June, July and August and hence has an unusually long period for a summer breeder. The writer has observed that during the first part of the breeding season, when the ova are bright carmine color, that not only the marsupium but also the nutritive parts-especially the foot are also a brighter color - chiefly orange--than at the end of the season when most of the anatomy has a brownish or soiled white color. 
Before maturity the glochidia have been observed to be yeliowish brown and contained in pinkish sacs.

\title{
Fusconaia undata trigona (Lea).
}

\author{
("Little Pigtoe.") \\ Pl. xv. Figs. $3 I$ A and $B$.
}

19r3a-Fusconaia undata trigona (Lea) Ortmann, Pr. Am. Phil. Soc., LII, No. 210.

\section{ANIMAL, CHARACTERS.}

The nutritive and reproductive structures of this subspecies are, of course, identical with those of its species.

\section{SHELL CHARACTERS.}

Shell more quadrate than that of $F$. flava, post-umbonal ridge not so prominent, more solid anteriorly, higher fuller beaks, epidermis darker. Compared to its typical species it never matures to be as large, nor as heavy, is not quite so upright, nor as inflated, has lower beaks and more of a reddish epidermis. The internal shell structures are identical with those of its species. From the subspecies, trigonoides, it differs chiefly in being more upright, not so elongated, nor as large.

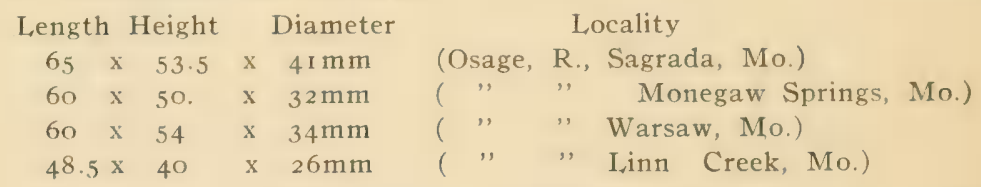

Miscellaneous REMARKS:--This sub-species is one of the decided intergrades for $F$. undata and flava and is the most common form in the interior streams of the state-especially in the Osage where the writer, in a 300 mile survey by boat, made a thorough study of them to find the interior of shell and soft parts to be identical with those of the species; however, none of these forms were found with reddish conglutinates, nor yellowish soft parts. Probably this whitish colorization was due to the advanced stage of gravidity in which they happened to be found when they were encountered between the upper and lower stretches of the river. at the latter part of July. This variety of undata may be ecologically determined as a dweller in medium sized rivers, or, if found in a large river, in medium stream conditions. This is found to be the case in the Osage, for the more the mouth is approached the more this form is supplanted by the heavier, more inflated 
and more typical shell of the main species. This subspecies, however, is more like the type than the trigonoids of Firicrson, the latter being more nearly the flava type and hence might be well named "F. undata flava (Raf.)"

Fusconaia undata trigonoides Frierson, MS.

("Big Pigtoe.")

Pl. XV-Figs. 30 A-D; Pl. IV, Figs. ga, and $g h$.

1913-Fusconaia undata trigonoides Frierson MS.-Personal Letter, February 22, 1913.

AnImal Character:- Soft parts indentical with species. Glochidium measures 0.180 x $0.165 \mathrm{~mm}$; conglutinates white in glochidial and late embroyonic stages, pink in earlier stages.

SHELI, CHARACTERS.

EXTERNAL STRUCTURES:- Shell elongate trigonal, thick, heavy, very large for the genus; disk without sculpturing except that rest-lines are somewhat furrowed giving an undulate appearance to growth lines; beaks comparatively low and not placed so much anteriorly, sculptured with concentric bars breaking into two or three nodules at base of post-umbonal ridge; post-dorsal part of shell, bowed, slightly biangulated behind; epidermis cloth-like, reddish brown to horse bay color, rayed in young.

INTERNAL STRUCTURES:- Identical with those of the species and other intergrading forms, except that it may vary from a white to pink nacre.

\begin{tabular}{|c|c|c|c|c|}
\hline Lengtl & & Nidth & Diameter & Location \\
\hline 9.3 & $\mathrm{x}$ & 66 & $\times \quad 42$ & (Platte R., Dixon Falls, Mo.) \\
\hline 70 & $\mathrm{x}$ & 50 & 38 & (Osage R., Schell City, Mo.) \\
\hline 50 & $\mathrm{x}$ & 40 & 24 & (Osage R., Warsaw, Mo.) \\
\hline 28 & $\mathrm{x}$ & 20 & 14 & (Platte R., Garretsburg, Mo.) \\
\hline
\end{tabular}

The juvenile indicated by the measurement under the last number was found lying on its side in the shallow water of a riffle. It is different from the mature shell in its dark yellow epidermis marked all over by green rays, also by more prominent umbonal ridge, more centrally placed and more distinctly sculptured beaks. The soft parts are all of a bright orange color except the bluish visceral mass.

This specimen and also the one under the first measurement of the above list were kindly indentified by Dr. Ortmann as $F$ 
undata rubiginosa (Lea) a name which this form might well bear because of its closer relation with $F$. flava (Raf.) $[=F$. rubiginosa (Lea)]. After a prolonged correspondence among Messrs. Simpion, Walker and Frierson this rather common and peculiar form wa: left to the latter for naming; hence the MS. name herein given.

MiscellaneOUS REMARKS:- This intergrade is very near the form, undata-trigona, and differs only in being more elongated, less upright, more rounded, post-dorsal margin, more reddish epidermis, lower beaks, and is a larger, heavier shell. Those of this variety that are found in the Mo. Platte of North Mo. have the most ponderous shell of any of the Fusconaia-some reaching a length of Ioomm while the average length of the species $(F$. undata) for the Mississippi only average $60 \mathrm{~mm}$. 'This variety seems to be more of a creek form of $F$. flava and the reason for this form being larger in the Platte R., a smaller stream, than in the Osage, the largest tributary of the Missouri in this State, may be traced as a mere local effect since the shells of other species in the Mo. Platte are found to be abnormally large. Like most of the Unioninae this form has a peculiar habit of aborting its conglutinates when taken from its natural bed. The author has been able to pick out for study the little pink club-shaped conglutinates from whole masses of other white leaf-shaped conglutinates of Onadrulae or Pleurobemae that would also be aborted after being collected from the river and placed in a tub or aquarium. The habits of this form are that of deep and rapid burrowers and inhabitants of deep water and coarse gravelly bottom. It is found to be gravid from May until September and sterile for the rest of the year. A proposed publication by Mr. Frierson on these puzzling southwestern forms of Fusconaia will, without doubt, clear up the situation.

Fusconaia flava (Rafinesque.)

(Pigtoe," "Red Shell," "Red Nose," "Wabash Pigtoe.")

Pl. XV. Figs. 32 A-D.

1820-Unio farus Rafinesque, Monog. Bio. Shells of R. Ohio.

1829-Unio rubiginosa Lea, Tr. Am. Phil. Soc., III, p. 427. P1. VIII, fig. 10 .

1 898-Quadrula rubiginosa Baker, Moll. Chicago. Pt. I. p. 77, Pl. XIX, fig. I; XX, fig. I

1912-Fusconaia rubiginosa Ortmann, An. Car. Mus., VIII, pp. 241 242, Text Fig. 4. 


\section{ANIMAL CHARACTERS.}

NUTRITIVE STRUCTURES:-Branchial opening with papillae on inner edge, anal with fine but distinct papillae; supra-anal long and large with very short connection of mantle edge; gills sharply pointed behind with wide space between the anterior attachment to mantle and base of the palpi, inner laminae of the inner gills entirely free from visceral mass; palpi rather large, subfalcate; color of soft parts variable, but usually orange yellow especially the distal end of foot, also mantle edge and adductors, while sterile gills are brownish.

Reproductive Structures:-Marsupia with crowded septa dividing the ovisacs parallel to the gill filaments; when charged, lumen of ovisacs somewhat cylindrical containing club-shaped conglutinates which are carmine red or pinkish to whitish in color; glochidia somewhat small, semicircular, spineless, hinge line nearly straight, about as long as high (O.I50 x 0.15.5mm).

\section{SHELL CHARACTERS.}

ExTERNAL Structures:--Shell trigonal-quadrate, rather thick, compressed, rather rounded post-dorsad, gently curved ventrad; disk somewhat undulated by growth lines; beaks not very high or full, sculptured by concentric ridges breaking into 2 or 3 nodules at base of posterior ridge; this post-umbonal ridge usually flattened; epidermis yellowish to dark horn color, rayed in well preserved and young shells, eradiate in old.

INTERNAL STRUCTURES:-Cardinals double in both valves; laterals long, serrated; scars well impressed; beak cavity narrowly deep; nacre mostly white, sometimes tinged with salmon in beak and antero-branchial cavities, irridescent.

Length Width Diameter
$\begin{array}{rllll}65 & \mathrm{x} & 45 & \mathrm{x} & 30 \mathrm{~mm} \\ 43 & \mathrm{x} & 35 & \mathrm{x} & 25 \mathrm{~mm} \\ 50 & \mathrm{x} & 40 & \mathrm{x} & 24 \mathrm{~mm} \\ 34 & \mathrm{x} & 27 & \mathrm{x} & 16 \mathrm{~mm}\end{array}$

Locality.

(St. Francis River, Greensville, Mo.)

(White River, Hollister, Mo.)

This latter measurement is that of a somewhat advanced adolescent shell. However, it shows the juvenile characters of a flattened post-umbonal ridge, a rounded post-dorsal line and the very distinct concentric sculpturing on the beaks much more evidently than in the adult. The most striking characters, that are absent in the mature shell, are the green rays. 
MISCELIANEOUS REMARKS:- This species is distinguisher mostly from $F$. undata and the intergrades by its more quadrate and compressed form of shell, by lower beaks, and less upright position. F. undata trigonoides is separated from it by possessing a heavier and more elongated shell with a more prominent postumbonal ridge and black epidermis. The White River shells, indicated in the above measurements, are rather intergrades for this species and hebetata and the St. Francis flava are too inflated to be very typical. Since this State proves to be such grounds for the inconstant occurence of types, and this species is so susceptible to intergradation, it is diffecult to find a typical flava, such as found in the Interior Basin east of the Mississippi. Perhaps its nearest form is in drainage for the south slope of the Ozarks in this state, althougl Simpson reports it as having a general distribution throughout the Mississippi drainage. This distribution doubtless included its many forms. Simpson further states that the St. Lawrence River system includes flava. Dr. Sterki (1 898, p. 30) considers this species as occasionally hermaphroditic by examination of its gonads. Surely this finding can be confirmed by the forms of Missouri, for it is rarcly that it is even locally a gounchorist. Flava is typically tachytictic being only found gravid from May until August.

\section{Fusconaia hebetata (Conrad).}

$$
\text { Pl. IV,-Figs. } 33 A \text { and } B \text {. }
$$

1854-Unio hebetatus Conrad., J1. Ac. N. Sci. Phila. II, p. 296, P1. XXVI, Fig. 5 ; I888-B. H. Wright, Check I,ist.

I goob-Quadrula hebetata Simpson, Proc. U. S. Nat. Mus., XXII, p. 787 .

Animal, Characters:- The soft parts of a form of $F$. licbetata, found in the Osage River, were discovered to be indentical with those of $F$. flava.

\section{SHELL, CHARACTERS.}

EXTERNAL STRUCTURES:- Shell rather orbiculate-quadrate, thick, moderatcly inflated, post-umbonal ridge prominent, disk smooth, beaks flat, and well back from the anterior end postdorsal ridge rounded, post-ventral margin gently undulate; epidermis black with a few faint imbricated rays toward (but not across) the disk in the middle of the umbonal region.

INTERNAL STRUCTURES:-Cardinals single in right, double 
in left, interdentum deeply gashed in right; laterals double in left with slight tendency to double in right; umbonal cavity narrowly deep, scars deep; nacre white to pale pink.

Length Height Diameter Locality. $58 \times 50 \times 26 \mathrm{~mm}$ (Osage River, Linn Creek, Mo.)

MiscelianeOUS REMARKS:--The above measurement is that of a moderately compressed shell resembling that of some typical hebetata shells which are sent to the writer from Alabama and considered as types by Messrs. Wright, Walker and Simpson. The latter student ( $1900 b$, p. 787 ) reports the Alabama hebetata as also found here in Missouri, but no specific locality is given. Since there seems to be so much confusion concerning this shell of Conrad with his own cerina or with I,ea's rubida it should be investigated. Probably it would be found (through longer suites of shells) that the broad compressed flava of the White River would either be a form of Conrad's hebetata or an unusual flava of Raflnesque, or perhaps an age-form of the latter. As matters now stand this species (if it be a good one anywhere) must be listed with some doubt for Missouri.

\section{Fusconaia ebena (Lea).}

\section{("Nigger Head.")}

I83 I-Unio ebena Lea, Trans. Am. Phil. Soc., V. p. 84, pl. IX, fig. I4. r goob-Quadrula ebenus, Simpson, Proc. U. S. Nat. Mus., XXII, p. 79.3. I 9 1 2b-Fusconaia ebena (Lea) Ortmann, An. Car. Mus., VIII, p. 245.

ANIMAL CHARACTERS.

NUTRITIVE STRUCTURES:- Branchial opening large with branched papillae; anal smooth or crenulated; supra-anal large briefly connected to anal by mantle edge; gills brown outer pointed anteriorly inner laminae of inner gills free from visceral mass; palpi moderately large and connected about half of their length antero-dorsad.

REPRODUCTIVE STRUCTURES:-All four gills marsupial; when charged scarlet, not distended; before gravidity ovaries carmine color; glochidium semicircular, spineless, medium size, hinge line straight but slightly oblique, length and height about equal (0.160 x 0. I5 mm), conglutinates subcylindrical, bright pink.

SHFLL C CHARACTERS.

FixTERnAl. STRUCTURES:- Shell thick, solid, subrotund, some- 
times shows a tendency to bianguation posteriorly; beaks incurved, projecting forward, sculptured with concentric lines but no sculpturing carried out on the disk; rest lines of growth concentric and furrowed; epidermis satiny horn color.

INTERNAL STRUCTURES:-Cardinals large and massive; laterals long and heavy; interdentum broad; beak cavities deeply creviced; scars deep; nacre pure white, stippled, irridescent.

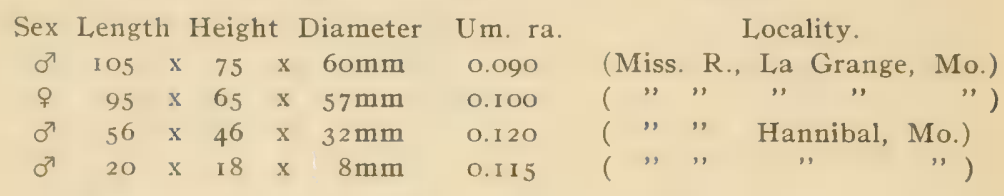

The shell of the juvenile of this last measurment is so round, and with beaks so drawn up to center of dorsal line that it resembles that of a Sphaerium. Umbonal sculpturing not very distinct even in this juvenile. It can always be identified in the early stages of its juvenility by white spots located post-dorsad on its shell.

MisCeILANEOUS REMARKS:-The writer, after some years of extensive collecting from the largest streams of the state, has failed to find ebena in the interior streams, neither have any Missouri collectors, nor old "clammers" reported it. This shell is known not only for its greatest commercial value and for its rarity in general geographical distribution but also for its great abundance locally. Of course its only home, known so far, is the Mississippi north of the Missouri River. It is not known why this species does not occur for this state in those Ozark rivers that bear it in great abundance in Arkansas not far from the Missouri-Arkansas line. Sometimes a black shelled Pleurobema pyramidatum or Fusconaia undata trigonoides may be taken for the "Nigger Head" (F. ebena), but, from the characteristic cornucopia-form of shell, together with its deep brown satiny epidermis and regular, concentric furrowed rest lines of growth, it should be easily identified. Frierson reports ebena as a rare shell in Louisiana and Isely (1914, pp. I-4) does not report it at all for the Arkansas and Red River drainages of eastern Oklahoma. Perhaps Call's account of it (I895, p. I6) as a common shell, not only for Arkansas, but for all the larger rivers west of the Mississippi, is more conjectured than real. Its breeding season has been found. by Wilson and Clark (1914, p. 42) to extend from May to the middle of July. Surber 
(I9I3, p. IU4) finds the host that is the specific distributor of this valuable shell to be a fish known as "skipjack" (Pomolobus chrysochloris).

\section{Genus Amblema Rafinesque.}

1820-Amblema Rafinesque, Monograph Biv. Shells of R. Ohio. I912b-Crenodonta (Schluter) Ortmann, An. Car. Mus., VIII, pp. $245^{-250 .}$

\section{(Type Unio plicata [Lesneur] Say).}

ANIMAL CHARACTERS:-Branchial opening long with few small arboreal papillae; anal large, very slightly crenulated; supra-anal separated from anal by very short mantle connection, sometimes no connection at all; gills large, inner wider and longer, outer connected high up to mantle antero-ventrad, inner laminae of inner gills free from visceral mass; palpi long, falcate united most of their length antero-dorsad; marsupia occupy all four gills, ovisacs of inner being wider, when gravid ovisacs expand transversely; conglutinates white, compressed, leaf-like shape, discharged through anal passage in rather broken or loose masses; glochidia small, spineless, subovate.

SHEll CHARACTERs:- Shell subquadrate to subtrapezoidal, thick, beaks more or less elevated, sculptured with concentric lines slightly angled at the base of the post-umbonal ridge and disappearing out upon the disk or continued there in a zigzag pattern of irregular broken pustules, nodules and oblique, indulated or plicated folds, the latter being disposed across the posterior half; hinge teeth heavy and well developed; beak cavities deep crevices under rather wide interdentum; vein markings on antero-pallial margin distinct; nacre usually white.

MISCELLANEOUS REMARKS:- It is recognized by students of Naiades that this genus needs a thorough revision especially as to its shell characters. I,ike the genus Fusconaiu, Amblema is a group of all sorts of inter-grading and puzzling forms. However, for this State it is not so much a question of facts regarding a predominance of these plicated forms for the different faunae as it is an application of these varieties to the present chaotic nomenclature for this genus. As nearly as the writer is able to determine, after a correspondence with students and a thorough study of literature and actual field conditions, the present status of affairs would group the species and other allied forms of Amblema 
for North Missouri under the so-called plicata (Say) types, for the most part; those of Central Missouri under both types of plicata and the better known undulata (Barnes), and those of Southern Missouri under undulata. These facts might be accounted for by the natural physiological adjustment to ecological conditions-that is to say, the quiet, sluggish, muddy streams of North Missouri tend to produce a heavy, inflated, rarely plicated shell, mostly represented by $A m b$. rariplicata of Deshayes; on the other hand, the swift, clear water streams of South Missouri have the tendency to shape up a compressed and multi-plicated shell best represented by $A m b$. perplicata quintardi of Cragin, while the intermediate or combined ecological conditions of Central Missouri give combinations of these two extremes. In the grouping of the members of this genus there has been much necessary elimination of local varieties and races and thus types have been adherred to as much as possible. The arrangement is only submitted as tentative due to the doubt of the present nomenclatural situation. This problem may be easily solved if it may be found that the morphology of shell characters may be traced, in most instances, to ecology. Probably this solution may be accomplished by studies of closely connected series from the glochidial to the mature shell. Our judgment, from studies of local conditions in this state, would be that the obliquely undulated and plicated folds, forming the chief shell character of this genus, are more developed in swifter current as a physical adaptation for survival by the way of more permanent anchorage, etc., just as we may account for the pustulate and nodulous characters of the shell instead of considering them as mere characteristic markings. However, when it has been found that the beak sculpture (the most constant shell character) of Amb. plicata (Say) and costata (Raf) [=undulatus (Barnes)] are really different and that there has been a differentiation from the adolescent shells to the mature ones we are compelled to recognize genetic distinctions in these two species. Yet it seems that it may be safely stated that two such well defined groups are connected in all manner of inter-grades through environmental causes such as seen in the different ecological provinces of Missouri. It is found that this genus has a short period breeding season, that the white, leaf-shaped conglutinates are discharged by the natural outlet of the anal opening and that these are delivered in broken, loose masses just as soon as the larvae are mature, or even ejected 
before maturity ("aborted") if disturbed. According to recent studies of Dr. Ortmann and Mr. Frierson Amblema Rafinesque should supplant all previous names for this genus because Amb. costata Raf. is without doubt Unio undulatus Barnes; hence the following nomenclature:

(i) - Amblema plicata (Say) $18 \mathrm{I} 7=U$. plicatus Say. $=U$. hippopea Lea = Quadrula plicata hippopaea Simpson.

(2) - Amblema plicata costata (Raf) $1820=U$. undulatus Barnes $1823=$ Quadrula undulata Simpson.

(3)-Amblema peruviana (Lamarck) is I $9=$ Quadrula plicata Simpson.

Note that because of the Law of Priority the local form (plicata Say) from Lake Erie must be considered unfortunately as the main species, although other than taxonomic reasons would not justify the recognition.

Amblema peruviana (Lamarck)

("Three Ridge," "Big Blue Point").

$$
\text { Pl. XVI,-Figs } 35 A \text { and B. }
$$

I8r9-Unio peruviana Lamarck, An. Sans. Vert., VI, p. 7I., Deshayes,

An. Sans. Vert., 2 d ed., VI, I 835, p. 533; 3d. ed., II, I 839, p. 667.

I goob-Quadrula plicuta (Say) Simpson, Pr. U. S. Nat. Mus., XII, p. 767 .

Animal Characters:- Since this species is simply an Amb. rariplicata (Des.) with very full, high beaks and with identical soft parts, except a small difference of form due to a more elongated shell with deeper umbonal cavities, we would refer our readers to the description of these characters for rariplicata. Gravid marsupia have the same structure. Glochidia of peruviana are found to be semicircular, spineless, medium size, about as long as high (0.200 x $0.210 \mathrm{~mm}$.)

\section{SHELL, CHARACTERS.}

EXTERNAL, STRUCTURES:- Shell elongate-quadrate with ventral edge rather straight, post-dorsal portion bowed, heavy and greatly inflated anteriorly, rather compressed posteriorly; beaks high, full, incurved, well placed forward, sculpture consisting of concentric lines forming two loops at base of post-umbonal ridge; undulations four to five, coarse, oblique from ventral margin to umbonal region across post-umbonal ridge; costae on slopes 
of post-dorsal ridge few, broad, shallow and faint; epidermis leathery red to black, rarely yellowish or greenish.

InTERnal Structures:- Cardinals double in both valves; laterals single in right, double in left valve; umbonal cavities narrowly deep; muscle scars well impressed; nacre marble white with blue and old rose tints posteriorly; deep vein mark on anteroextra pallial border.

Sex Length Height Diameter

\begin{tabular}{|c|c|c|c|c|}
\hline$O^{x}$ IOI & $\mathrm{x}$ & 64 & $\mathrm{x}$ & $54 \mathrm{~mm}$ \\
\hline I I 2 & $\mathrm{x}$ & 74 & $\mathrm{x}$ & $46^{\prime \prime}$ \\
\hline $4^{8}$ & $\mathrm{x}$ & 40 & $\mathrm{x}$ & 29 \\
\hline $0^{7} \quad 33$ & $\mathrm{x}$ & 28 & $\mathrm{x}$ & $20 "$ \\
\hline
\end{tabular}

Juveniles of latter measurement very globose; epidermis olivaceous with a reddish brown band in center parallel to growth lines; post umbonal ridge rather prominent; one heavy undulation at post base with two heavy furrows on either side. The very greatly inflated beaks of adult shell is doubtless due to the globular shell of the juveniles.

Misceldaneous Remarks:-Amblema peruviana (Lam) is the Quadrula plicata (Say) of authors according to the recent decision of Mr. Bryant Walker who is making a special study of original I.amarckian types. Mr. Walker states that Say's type of plicata came from Lake Erie and is the form that Lea describes as hippopaea and that peruviana is a form of the Ohio shell commonly called plicata but which is really the rariplicata Deshayes. 'This species should perhaps be reduced to the subspecies, "Amb. rariplicata peruviana (Lam); however, because of its difference irom rariplicata in the possession of full beak and more globular juvenile shell it is left in specific rank. It is found in typical form in the Mississippi north of the Missouri, is scarce but rather typical in the Osage, but is not found at all in the interior north of the Missouri, River.

Amblema rariplicata (Deshayes)

("Ohio Plicata," "Few Ridge," "Big Blue Point.") Pl. IX, -Fig. 20; Pl. NVI,-Figs. 36A-D.

1830-Unio rariplicala Deshayes, Enc. Meth; II, p. 578; An. Sans. Vert., 2 d. ed., VI, 1835, p. 533; 3 d. ed., II, 1839, p. 667.

ANIMAL CHARACTERS.

NUTRITIVE STRUCTURES:--Branchial opening very long with short yellowish papillae; anal slightly crenulate; supra-anal very 
closely-even decidously-connected to anal by mantle connection; inner gills longer and wider-much wider anteriorly, inner laminae free from the visceral mass; palpi large, connected for about one-third of their length antero-dorsad; except for its brownish gills and palpi the soft parts are a soiled white color.

ReProductive Structures:-All four gills marsupial, ovisacs of inner marsupia more extesded transversely, giving the white conglutinates a leaf-shape; ventral edges pointed; glochidia medium size, semi-circular, hinge line long and nearly straight, as long as high, $0.210 \mathrm{~mm}$; conglutinates lanceolate, leaf-like, discharged in broken masses, white in color.

\section{SHELL CHARACTERS}

ExTernal, Structures:- Shell subquadrate, thick, inflated, posterior end rather rounded; beaks flattened, sculptured concentrically with two or three nodulous structures at base of flattened post-umbonal ridge but disappearing upon the disk; disk with but few shallow undulations, sometimes entirely smooth and running obliquely to position of post umbonal ridge; slopes of post-dorsal ridge rarely costated; epidermis brown or very dark horn color.

InTERnal STRUCTURES:- Cardinals massive, scars deep, umbonal cavity deeply creviced; nacre white with blue, irridescent posterior surface.

Sex I,ength Height Diameter

o $120 \times 72 \times 52 \mathrm{~mm}-\mathrm{O} .169$

\% $130 \times 80 \times 62$ × 6.230

아 I $5 \times$ X $80 \times 5$ I $"-0.2$ I 5

$\sigma^{7} 22 \times 20 \quad x \quad \mathrm{I} 4$ " $\quad-0.220$
Locality

(Platte R., Dixon Falls,)

( " " Garretsburg, )

(Tarkio R., Craig,)

(Platte R., Agengy Ford,)

Juvenile shell indicated under last measurement is orbicular in outline, has medium inflation and comparatively high beaks; however, it does not possess the globose character of peruviana and its full beaks are soon lost the older it becomes as determined by a good suite.

MICCELLANEOUS REMARKS:--Amb. rariplicata, as already explained, is the Ohio shell many authors refer to as the plicatus of Say, or even as the perplicatus of Conrad. It is to be distinguished from the former since that is the Lake Erie form with full beaks; from the latter, however, rariplicata is not so easy to distinguish, as its beaks are similar, yet it differs from perplicata in being more inflated, with less and shallower plications and with 
no tendency toward posterior biangulation. Perplicata, being more of a southern form, is not found in this state north of the Missouri, while rariplicata, a more northern shell, is mostly confined to North Mo., where it is the predominant species of the Amblemae, yet it is found occasionally in Central Missouri. Mr. Bryant Walker, who has rescued raripliplicata from the synonomy of Simpson's Quadrula plicata, has recognized the North Missouri "plicata" as Deshayes' shell. 'The habitat of this species is that of muddy bottom with a substratum of limestone, of deep and quiet water and prefers muddy rivers to that of clear creeks. It is found in the Mo. Platte, Grand R., Big Tarkio and occasionally in their larger tributaries. It has never been found in any of the lakes. Its breeding season is very short, having been found gravid only in June.

\section{Amblema perplicata (Conrad)}

("Blue-Point," "Three-Ridge," "Round-Lake.”)

Pl. XVI. Figs. $37 . A$ and $B$.

I84 I-Unio perplicalus Conrad, Pr. Ac. N. Sci. Phila., I, p. I9.

I $900-$ Quadrula perplicata Simpson, Proc. U. S. Nat. Mus., XXII, p. 767 .

1912b-Credononta perplicata Ortmann, An. Car. Mus, VIII, p. 247-248.

SHELL CHARACTERS.

EXTERNAL STRUCTURES:- Shell ovate, or obliquely, quadrate, medium in size, moderately inflated, greatest inflation at center of disk; beaks low concentrically sculptured with two or three loops at foot of post-umbonal ridge; posterior end of shell biangulated, $5^{-6}$ coarse plications across post-half of shell parallel to antero-postero axis; costae on rounded, post-dorsal ridge few, broad; epidermis black.

INTERNAL STRUCTURES:- Cardinals double in both valves; interdentum long and broad; laterals single in right, double in left; muscle scars decply impressed; nacre white with posterior surface bluish to lavender, irridescent.

Sex Length Height Diameter

\begin{tabular}{|c|c|c|c|c|}
\hline 115 & $\mathrm{x}$ & 80 & $\mathrm{x}$ & $48 \mathrm{~mm}$ \\
\hline 90 & $x$ & 66 & $\mathrm{x}$ & $4^{6} "$ \\
\hline 83 & $\mathrm{x}$ & 67 & $\mathrm{x}$ & $48^{\prime \prime}$ \\
\hline 16 & $\mathrm{x}$ & 14 & $\mathrm{x}$ & $10^{\prime \prime}$ \\
\hline
\end{tabular}

Many juveniles taken in the Osage average as the above
Locality

(Osage R., Osceola, Mo.,)

(St. Francis R., Greenville, Mo.,)

(Osage R., Linn Creek, Mo.,)

( ", " Warsaw, Mo.) 
Warsav specimen. They are rotund, inflated, epidermis greenish and approach the spherical form of the juvenile peruviana. Beaks, even in these young shells, are too croded to make out the sculptural markings.

Miscellaneous Remarks:- Since $4 m b$. perplicata is a Southern species it is only found in this state in typical form in the south drainage of the Ozark Uplift. Personal collections made by the writer from the St. Francis are found to compare well with typical perplicata shells received from Mr. Firierson and taken from type localities. This species is also sparingly found in the Osage where its subspecies, quintardi of Cragin is the predominant form of Amblemae, and from which it is distinguished by the smaller, more compressed, and much plicated shell of the latter. Under the description of $4 m b$. rariplicata the distinguishing features between that species and perplicata have been mentioned. At first the inclination was to set this species down in the synonomy of rariplicata from general shell features, but the few specific differences in shell as well as that of geographic range are enough to make it distinct. This species is tachytictic, being found gravid by Wilson and Clark (19I4, p. 42) from May until July inclusive. The writer examined many throughout June and July to find none gravid; however, its subspecies (quintardi) was found gravid during these months and because of these fact some reason was given that this smaller, compressed form was only the female of the larger one, just as seen in case of Plagiola securis or Obovarià retusa.

\section{Amblema perplicata quintardi (Cragin)}

("Iittle Blue-Point," "Multiplicate.")

$$
\text { Pl. XVT. Figs. } 38 \text { A-D. }
$$

r887-Unio quintardii Cragin, Bull. Wahb. Coll., II, p. 6; Pilsbry, Pr. Ac. N. Sci. Phila., I892, p. I31, pl. VII, figs, I-3.

I 891 - Unio pilsbryi Marsh, Nautilus, V. pp. I and 2; Nautilus, VII, I 893 , pl. I, figs. 7 and 8 .

ANIMAL CHARACTERS.

Nutritive CHARACTERS:- Similar to those of the species, having its anal and supra-anal openings often unconnected by mantle edges, free laminar edges of inner gills, palpi mostly connected by their edges, and being colored a dirty white or tan; reproductive structures also rather identical in possessing marsupia 
occupying all four gills, swollen in the center, when gravid, white when filled with ova, rich brown when charged with glochidia; conglutinates leaf-like, not solid, easily broken; glochidia semicircular, medium in size, hinge line nearly straight, measuring $0.205 \times 0.215 \mathrm{~mm}$. Dr. Surber kindly indentifies:-- "Like plicata, but slighlty larger. Easily within the range of variation shown by this species from different localities."

\section{SHEI,L, CHARACTERS.}

External STRuctures:- Shell obliquely quadrate, small, moderately compressed, rounded before, usually biangulated behind; slightly alated; posterior half of disk profusely plicated, some plicated folds devaricated behind; slopes of post-dorsal ridge with several upcurved costae; beaks low well placed anteriorly, sculptured in concentric fashion with strong ridges upcurved posteriorly; epidermis dark reddish brown to black, without rays.

INTERNAL STRUCTURES:-Cardinals compressed, obliquely grooved, double in both valves, laterals long, slightly curved; beak cavities rather deep; nacre dull white.

\begin{tabular}{|c|c|c|c|c|c|}
\hline Sex & Lengt & & Heigh & t Diameter & Locality \\
\hline q & I I 5 & $\mathrm{x}$ & $80 \times$ & $48 \mathrm{~mm}$ & (Osage R., Proctor, Mo.) \\
\hline $0^{7}$ & 80 & $\mathrm{x}$ & 58 & $38^{\prime \prime}$ & (White R., Hollister Mo.) \\
\hline 웅 & 16 & $\mathrm{x}$ & 9 & $5 \cdot 5^{\prime \prime}$ & (Osage R., Monegaw Springs, Mo.) \\
\hline$\sigma^{7}$ & 5 & $\mathrm{x}$ & 4 & $3.5^{\prime \prime}$ & ( " " Taberville, Mo.) \\
\hline
\end{tabular}

'These last two measurements are among the smallest juvenile shells obtained from the Osage where quintardi is so abundant The writer has examined hundreds of them resulting in this general description:- Subovate, slightly longer than high, inflated (yet diameter never equal to height or length), rather bialated; beaks flat (dorsal line over umbonal region curved), sculptured quite well down on disk with three coarse irregular shaped ridges directed post-ventrad having comparatively deep valleys between these bars; epidermis brownish yellow; not byssiferous. Dr Howard kindly comments: "These juvenile are of the plicata group of the Osage the exact relationships of which seems to be undecided."

Miscellaneous Remarks:- Surely this subspelies is a decided intergrade of the perplicatus Conrad and costata Rafinesque (=U. undulatus Barnes). Mr. Walker has referred this abundant shell for South and Central Missouri to perplicata rariety quintardi 
Cragin while Mr. Frierson would assign it to undulata variety Pilsbry Marsh; however, comparisons of these two forms seem to indicate that they are so identical as to assign the latter, through rules of priority, to the synonomy of the former. Dr. Ortmann, who has examined the anatomy as well as the shell characters of this confusing form, considers it as more like Amblema costata (Raf.) and suggests the reason why the writer should only find this little "Blue Point" gravid during a six week's survey of the Osage River was that the larger Amblemae were probably males of the same species although such sex dimorphism has not been observed in this genus before. Prof. Clark would also assign this form more to the undulata (Barnes) than to the plicata (Say) group. It has also been considered as very near undulata varicty latecostata (I,ea). Dr. Surber would not refer it to either group. One thing is certain, that it is not the typical $4 m b$. plicata costata (Raf.) and is far from either Amb. rariplicata (Des.) or peruviana (Lam). Since there are few intergrades above or below quintardi and since it is also such an abundant shell for this state and Kansas it is hoped that its assignment here settles it fairly well in this genus. The identical form is common in the White, St. Francis, Black and other southern streams of the Ozarks as well as in the drainage basins of the Osage, Gasconade, Meramec and other streams of the north slope of the Ozark Uplift. However, this sub-species is not found in North Missouri. Hence its habitat is more that of the swift, clear-water streams. Its breeding season is found to be the same as that of its parent species.

Amblema (plicata) costata (Rafinesque)

("Wash-Board," "'Three-Ridge," "Blue-Point.")

"Flat-Plicate," "Fluter.")

Pl. XTI, Figs. 39 A-D.

$1820-$ Amblema costata Rafinesque, Monograph of Biv. Moll. of R. Ohio.

1823- Unio undulatus Barnes, Am. Jour. Sci. and Arts, Ist. ser., VI, p. 120 , fig. 2 .

I goob-Quadrula undulata Simpson, Proc. U. S. Nat. Mus., XXII, p. 769 .

i 9 I 2 b-Crendonta undulata Ortmann, An. Car. Mus., VIII, pp. 246-247.

ANIMAL CHARACTERS

Nutritive structures, as well as the reproductive, are identical with those of $A m b$. rariplicata in every respect. Even the glochidia 
are similar, except slightly larger $(0.2$ I $0 \mathrm{x} 0.220 \mathrm{~mm})$. Like other members of this genus there is no trace of brilliant colors of the soft parts such as red or orange as seen in the Fusconaia or Alasmidonta.

SHELL CHARACTERS.

ExTERnAl Structures:- -Shell elliptically subquadrate, compressed; rather thick and heavy umbones, not elevated, slighly inflated, sculptured by five, coarse concentric ridges most pronounced at base of post-umbonal ridge, slighlty alated anteriorly; dorsal ridge high, with four or five upcurved costae; posterior half of shell crossed with five or six oblique undulations with shallow valleys; epidermis reddish brown to yellowish.

INTERNAL STRUCTURE:- Cardinals very heavy, double in both valves; laterals heavy, serrated; interdentum broad, thick; beak cavities deep narrow, crevice-like; muscle scars well impressed, vein markings on extra-antero pallial border; nacre white, often rusty spotted, with blue irridescence at posterior end.

$\begin{array}{ccccccc}\text { Sex } & \text { Length } & \text { Height } & \text { Diameter } \\ \sigma^{7} & 112 & x & 73 & x & 36 \mathrm{~mm} \\ \text { } & 76 & \mathrm{x} & 55 & \mathrm{x} & 32 & \text { ", } \\ \sigma^{7} & 32 & \mathrm{x} & 25 & \mathrm{x} & 15\end{array}$

Locality

(Osage R., Schell City, Mo.)

(Gasconade R., Gascondy, Mo.)

(Chariton R., Kern, Mo.)

Juvenile shells have coarse concentric undulations upon the umbonal region-especially at base of the post-ridge where they are upcurved; a single broad undulation at the post-ventral position of shell, a slight alation just anterior to the lunule; color of epidermis olivaceous.

Miscellaneous Remarks:- Amblema costata Rafinesque is without question the Unio undulatus Barnes, but the trinomial name, Amb. plicata costata (Raf.), is used for taxonomic reasons as has already been explained under the remarks on this genus conceming the nomenclature incident to the revival of Rafinesque's "Amblema." This species is very seldom seen in typical form in North Missouri, (never in North-West Missouri) and for that matter, it is also scarce in Central or South Missouri-but its actual forms are most abundant of all the Naiad species in this State south of the Missouri River. Most of the students of Naiades have returned the results of their studies of the Missouri Amblemae indicating a greater prevalence of the "undulata" rather than the "plicata" form--especially for the swift clear-water mountain streams of the South. By actual surveys of some streams of 
Central Missouri, where ecological conditions are the most diverse for the State, the autho has been able to observe the same occurrence of the Amblemae as noted by Wilson and Clark in the Cumberland River (I9I4, p. 2I) in that the more plicated and less inflated (undulata) one will be found in upper courses, while the smoother and more inflated (plicata) one is confined to the lower portions of the rivers where there is more mud and a weaker current. On the basis of not only these state-wide observations but also on these as limited to a single river, we would account for the existence of these two opposing types of Amblema as due to ecological rather than to genetic causes. However, as juvenile shells of two forms are different their origin would also indicate difference and the matter of their occurrence under certain ecological relations might, after all, be simply one of survival. A careful study of $A m b$. costata shows it to be a summer breeder, beginning in May and closing the latter part of July. As this "undulata" group has been understood hetter taxonomically than the "plicata" the geographic distribution of costata has also been better determined. Simpson reports it (i. e., his 2. undulata (Barnes)) for the Mississippi basin generally; also for the drainage basins of the St. I awrence, the Red River of the North and the Alabama River. The varieties of this species, however, are reported by many for the area south and west of the Mississippi River known as the "South-West," the fauna of which is included in Central and South Missouri and bounded on the north by the great faunal barrier, the Missouri River.

Genus Megalonaias Utterback.

(New Genus.)

Type, Unio heros Say, I829.

ANIMAL, CHARACTERS.

NUTRITIVE STRUCTURES:-Branchial opening very large with short papillae; anal and supra-anal also large, almost smooth, separated by short but distinct mantle connection; inner laminae of inner gills partly free from visceral mass or sometimes almost entirely connected; palpi long, enormous; color of soft parts, tan colored, with gills brownish.

REPRODUCTIVE STRUCTURES:- Marsupia occupying all four gills, when gravid enormous, padlike, not so distended at ventral 
edge; conglutinates, sole-shaped, brown, rather solid; glochidia large, ventral margin obliquely rounded, hinge line long.

SHELL CHARACTERS.

Shell large, ponderous, broadly rhomboid, moderately inflated, post-dorsal ridge alated, sculptured with regular upcurved undulations; post-umbonal ridge broken with coarse plications running more or less parallel with it; beaks rather low, sculptured with coarse double looped-corrugations which extend out as nodules at base of post-ridge and as zigzag ridges all over umbonal region to upper part of disk; epidermis black; cardinals heavy; laterals long and straight; interdentum short; beak cavities narrowly deep; scars very deeply impressed - especially anterior retractor cicatrix; nacre white to pink.

Miscelianeous REMARKS:-Because of the peculiarities of heros (Say) as to its animal and shell characters, as well as to its uniqueness of breeding season it is thought by the author in conference with other students, that this species of Say, very well descries rank as the type of a now genus. Although the author has not examined the animal of boykiniana Lea, triumphans Wright, etc., yet, from shell characters, these allied forms would naturally fall under this new genus, Megalonaias. In all probability crassidens (Lamarck) [=trapesoides (Lea)], which has been grouped very near heros (Say), may also deserve a special compartment, according to the recent opinion of Mr. Frierson, who has made special study of this species abundant beds of which are very accessible to him; hence because of the difference of shell characters of crassidens from that of heros (or from any other Naiad shell in the possession of a "ventral scar" as pointed out by Mr. Frierson) this species of I amarck is not grouped there. Besides crassidens is not found in Missouri, neither is boykiniana, triumphans and other conchologically allied forms of $M$. heros and thus the new genus will safely stand out for this State with its type, (heros Say), as the lone representative. Bariosta (Raf.) might be the available name for our new genus, if crassidens could be found to be congeneric with heros, since Rafinesque erected his genus for this species which he termed ponderosus, but which Mr. Walker, through his close study of Lamarckan types, says is Lamarck's crassidens that ante-dates Lea's trapezoides as well as Rafinesque's type. From the fact that Crenodonta (Schlüter) falls into the synonomy 
of Amblema (Raf.) because of Simpson's and Ortmann's treatment, (preceded by that of Mörch in 1853) Schülter's name cannot be used. Thus it may be seen why an original name, "Megalonaias," (etymologically embodying a chief character) is herein submitted.

\section{Megalonaias heros (Say)}

$$
\text { ("Giant Heros," "Washboard.") }
$$

Pl. VII, Fig. I6; Pl. IXII, Figs. $18 \mathrm{~A}-F$.

1829-Unio heros Say, New Harm. Diss., II, No. 19, p. 29 I.

I83I-Unio multiplicatus Lea, Tr. Am. Phil. Soc., IV, p. 7o, P1. IV, fig. 2 .

I goob-Quadrula heros Simpson, Proc. U. S. Nat. Mus., XXII, p. 770. I 912 b-Crenodonia heros (Say) Ortmann, An. Car. Mus., VIII., p. 248.

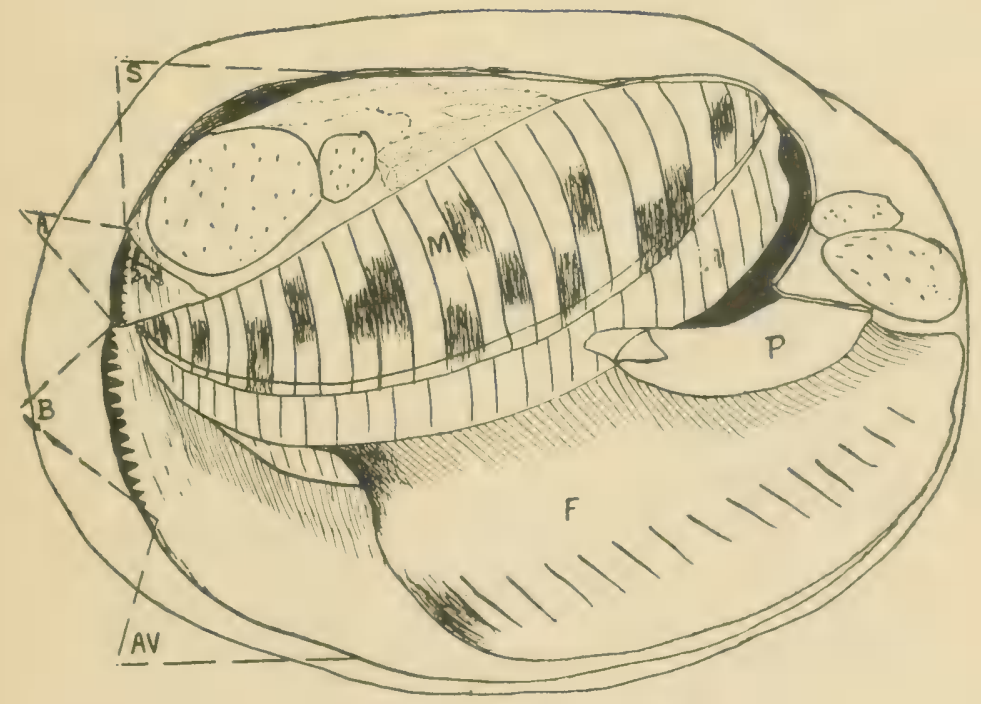

FiG. 2. Megalonaias heros (Say). \& Diagram of a gravid individual from Platte River, Garretsburg, showing animal characters in left valve. Coll. Jan. 25,1913 . (3/4 nat. size.)

\section{ANIMAL CHARACTERS.}

Nutritive STRUCTURES:- Branchial opening very large, with comparatively few and small papillae branched at their tips; anal large, very finely dentate on outer edge; supra-anal immense, slightly but distinctly separated from anal by mantle 
connection; anus tentacled: gills very long and large, inner much wider, inner lamina free from visceral mass for the posterior half or connected except for a slight slit at posterior end or even entirely connected; palpi enormous, connected about nine-tenths of their length antero-dorsad; soft parts mostly a fleshly-tan, brancisial edges brown with yellowish papillae in incurrent opening, patch in front of branchial opening chamois-like.

REPRODUCTIVE STRUCTURES:- Marsupia occupying all four gills; when gravid, enormous purplish pads, obtusely rounded at ventral edges; ovisacs simple, undivided, some filled with rustybrown mucus next to the laminae thus giving the marsupia a splotched appearance; conglutinates shape of an insole, rather solid, usually discharged whole, edges with brownish red pigment, rather thick with no thin transparent portions; glochidia large, post-ventral border obliquely rounded, hinge line long, nearly straight, no spines present, very vital, measures $0.280 \times 0.340 \mathrm{~mm} .^{\mathrm{I}}$
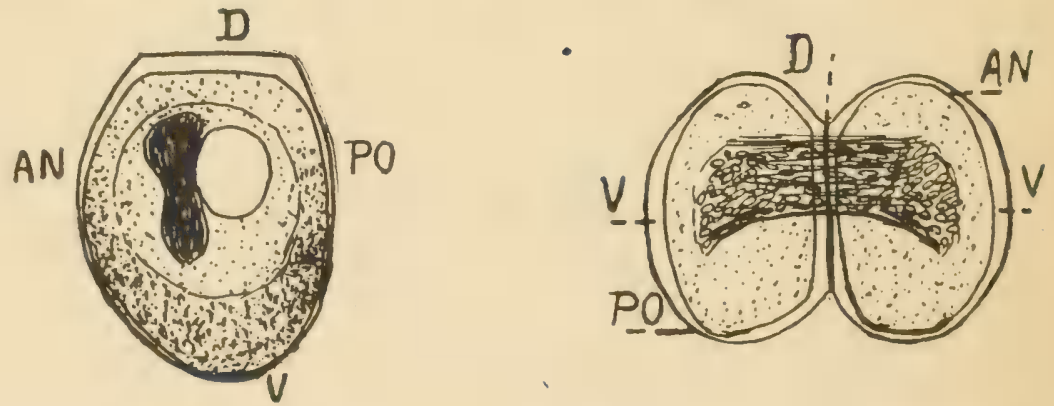

FIG. 3A. Mature glochidium of $M$. heros showing peculiar oblique post-ventral margin from lateral view. (x87-a camera lucida sketch. Left hand figure.)

FIG. 38 Ventral view of open glochidium of $M$. heros. (x87-a camera lucida sketch. Right hand figure.)

SHELL CHARACTERS.

External, Structures:- Shell massive, heavy, subrhomboid, post-dorsal ridge rather high slopes of which ribbed with coarse, upcurved, regular undulations originating from umbonal region; post umbonal ridge broken with heavy undulations more

I According to Dr. T. Surber, (U.S. B.F. Doc., No. 813, 1915) this glochidium has the greatest variation in size and moreover, he has also found it parasitic upon the gills of the "water dog" (Necturus maculosus). 
or less parallel to post-ridges; beaks rather low and full, sculptured with numerous corrugated or double-looped ridges extending out as prominent nodules on the post-umbonal-looped ridges and zigzag, or WM-shaped, ridges on the umbonal region and upper part of disk; epidermis black, more or less dull color.

INTERNAL STRUCTURES:-Cardinals moderately heavy, double in both valves; laterals very long, not much curved, interdentum short, narrow; beak and branchial cavities rather deep; muscle scar-expecially the progressive impression and that of anterior retractor-very deep; nacre white (often with rusty spots) varying to pink.

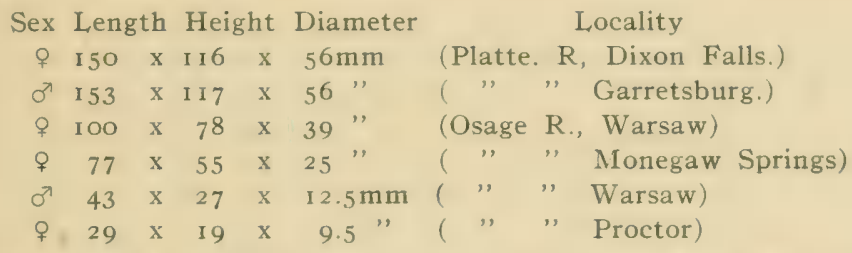

The young and juvenile shells of the last two respective measurements are very profusely sculptured-no part of the external surface being smooth-yet no undulations appear as seen in adult. Beaks low, corrugated; slopes of post-dorsal ridge finely costated; post-ridge with coarse, apiculated or spurred nodules; center and anterior of disk covered with irregularly placed V-shaped ridges and with scattered tubercles; valves extremely flat; nacre sky blue, irridescent. "Work up old shells from the young ones" is Mr. Walker's advice.

MiscellaAnEOUS REMARKS:-This most ponderous shell of the Naiades is typical in North Missouri and the Mississippi, but the typically massive shell is not found in Central Missouri, and, so far, it is not reported at all for the southern slope of the Ozarks in this state. As a rule, heros is only found in the large rivers; however, in this State the type is found in the Missouri Platte-a rather small river, while the medium sized one is found in the largest river of the interior-the Osage-where it assumes the small form perhaps approaching that of dombeyana Valenciennes. "Giant heros," as this species is often called, is most frequently found in the deepest depressions of mud bottom with a substratum of solid limestone. It hardly ever moves from these situations and perhaps because of this inactivity it accumulates its heavy shell. Because of the following peculiar characters the 
author sees fit to create a new genus for heros of Say:I.-An unusually heavy shell, with zigzag or V-shaped, sculpturing on upper part of disk and corrugate scupture on beaks.

2.-A tendency of the inner laminae of the inner gills to become more or less united with the visceral mass.

3.- The gravid marsupium an enormously distended pad, colored purplish, or slaty, with reddish splotches here and there parallel to the septa.

4.-Thick, sole-shaped, subsolid conglutinates with rustybrown margins discharged more or less whole with glochidialying all through the conglutinated mass.

5.-A large, vital glochidium with post-ventral margin obliquely rounded.

6.--Breeding season intermediate, or tachytictic with late season (i. e., bearing glochidia in late winter but being sterile during the summer.)

From Amblema this peculiar species must be removed on account of its beak sculpture which is more like that of Cuadrulaespecially of the "Lachrymosa" group, yet it is separated from the latter chiefly by its ponderous shell and rugose, V-shaped sculpturing on the umbonal region and upper part of disk. It has been grouped under Amblema more on account of the oblique folds on post-half of its shell; however, these plications are, after all, usually disposed differently with respect to the post-umbonal ridge and are not so constant and numerous, nor do they appear so early in the life history of the shell, as in the type for Amblema. The special reason that a new genus should be built for heros is on the basis of its unique character of soft parts. No other generic type of Unioninae (nor of any of the Naiades for that matter) possesses such peculiarities of form, color or size for its marsupium, conglutinate or glochidium; and as to its nutritive structures, none are so eccentric regarding the connection of the inner laminae to its inner gills. Its idiosyncrasy of breeding habits would not only give it a special station, aside from all other Naiades so far known, yet this physiological character may account for its oddity morphologically. 'The author has kept an accurate breeding record of heros throughout the year-especially for the winter months when other records have been incomplete-to find it gravid with ova of early embryos in fall and early winter. 
with late embryos and immature glochidia in midwinter, and with mature larvae in late winter but barren from April to August. Ovulation has been observed for the latter part of August and unfertilized ova have been found in the ovaries August igth. Sperm having been found within the visceral mass without being accompanied by ova for those individuals that possess gills without the crowded septa of the female proves the sexes distinct and separate and thus disproves the claim of hermaphroditism for this species. It is true that during the height of the breeding season that all individuals found seem to be females but this is the time when there is greater activity among females; hence, they may be more in evidence while the males remain inactive and burrowed from ready accessibility during this season. This fact may account for the so-called hermaphroditism among other species. By laboratory tests the writer has kept the glochidia of this species alive in cold, clear, fresh water exactly thirty days (five time longer than the life of any other mature glochidia submitted to this watch-glass test) after being taken from the mother. This unusual vitality of the larvae is an adaptation to its prolongation of breeding season into late winter when they are discharged into the ice-cold water and left to their fate, for it is the belief of the writer that they are discharged as soon as mature.

\section{Genus Quadrula Rafinesque.}

I 820 -Quadrula Rafinesque, Ann. Gen. Sci. Phys. Brux., p. 305.

I 852-Rotundaria Agassiz, Arch. fur, Naturg., p. 48.

(Type, Obliquaria (Quadrula) metanerra (Rafinesque).

AnImal Characters:-Branchial opening large with short arboreal papillae; anal smooth to finely dentate; supra-anal very large, briefly and loosely connected to anal by mantle edges; inner laminae of inner gills free from visceral mass; palpi large, somewhat sickle-shape; color of soft parts not bright, except for brownish gills and palpi, tannish or soiled white; marsupia occupying all four gills, when gravid ovisacs swell moderately in center, ventral edge obtusely pointed; conglutinates white, leaf-like, sometimes divided at distal ends; glochidia small to medium in size, subovate, spineless.

Sheld Characters:- Shell roundly quadrate, or subrhomboidal, occasionally elongate with moderately high beaks sculptured with $3^{-4}$ parallel ridges developed on post ridge to nodules; 
disks usually sculptured; epidermis generally dark colored, rayless or with greenish splotched paintings; cardinals heavy, double in both valves, ragged; laterals double in left, single in right; beak cavities deep, compressed or creviced; shells mostly not sexually dimorphic.

Miscellaneous REMARKS:-This genus naturally falls into three groups as follows:-

I. Pustulosa Group.

This group is mostly represented in this State by the northern and western form, Q. pustulosa schoocraftensis (Lea), and is charasterized by its greater inflation, smoother, larger and more elongated shell with beaks drawn back up more toward the center of the dorsal line; beak sculpture concentric. The actual typical pustulosa is rarely, if ever, found in Missouri.

II. "Lachrymosa" Group.

This is represented in Missouri by Q. quadrula (Raf.) (=lachrymosa Lea), nodulata (Raf.), fragosa (Conrad), aspera (Lea), verrucosa (Raf.), nobilis (Conrad) and their intergrades, and may be characterized briefly by a somewhat quadrate or trapezoidal shell, profusely sculptured disk with tubercles arranged in two radiating rows from the beaks to ventral margin divided by a more or less broad radial furrow; beak sculpture double-loop type.

\section{Metaneura Group.}

This third group is only represented in this state by $Q$. metanerra (Raf.) and cylindrica (Say) and is characterized especially by its height and coarsely sculptured umbonal ridge in front of which is a depression but no definite radial furrow and by its peculiarly triangular greenish splotches; beak sculpture doublelooped or zigzag type.

The genus Quadrula tends toward an unusual intergradation of forms among the above groups in this state and because of this fact the genus might be more properly treated under various sub-genera for this catalogue; however, this treatment may be made unnecessary by the elimination of all the intergrades except those that possess the nearest approach to types. As to soft parts, this genus is identical with Amblema but is especially separated from the latter by the negative shell characters of oblique folds across the disk. Simpson, who bases much upon deep beak cavities, as one of the special characters of this genus, 
includes more under this group, that is, the genera, Fusconaia, Amblema, Megalonaias, Rotundaria, Plethobasus and even some species of Pleurobema.

\section{Quadrula pustulosa (Lea) ${ }^{1}$}

("Warty-Back," "Warty Pigtoe," "Pimple Back.")

Pl. XVII. Figs. $4 I$ A and $B$.

I831-Unio pustulosus Lea, Tr. Am. Phil. Soc., IV, p. 76, pl. VII. fig. 7

1834-Unio nodulosus Say., Am. Conch., VI.

1898-Quadrula pustulosa Baker, Moll. Chicago, Pt. I., p. 86, pl $\mathrm{XXV}$.

\section{ANIMAL CHARACTERS.}

Nutritrve Structures:-- Branchial opening with yellowish plumed tentacles; anal smooth; sura-anal very closely connectec- even disconnected--by mantle edge; inner lamina of inner gills free from visceral mass; color of soft parts dingy white; palpi connected for about one-third of their length.

REPRODUCTIVE STRUCTURES:-All four gills entirely marsupial, septa crowded, ovisacs narrow; conglutinates white, leaflike, broken; glochidia large, semi-elliptical, spineless, hinge line short and evenly curved, measures $0.230 \times 0.300 \mathrm{~mm}$.

\section{SHELL, CHARACTERS.}

External Structures:- Shell ovate-quadrate, higher than long, post-umbonal ridge almost horizontal, posterior half pustulate to smooth, dorsal ridge with nodulous costae; beaks protruding anteriorly sculptured concentrically with upcurved ridges posteriorly; epidermis rusty brown with somethimes broad green banded rays diverging from beaks.

INTERNAL, STRUCTURES:-Cardinals heavy just under beaks; interdentum broad, upright; laterals straight, at right angles to interdentum; umbonal cavity compressed, deep; nacre white.

Sex Length Height Diameter

Locality

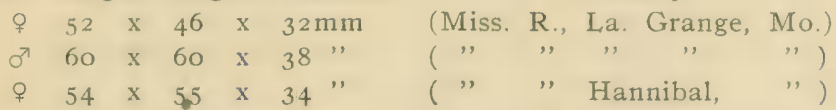

No juvenile shells have been obtained for descriptions; this species is so rare in its typical form for this State that adult shells have been secured with difficulty.

I The name of this species should read $Q$. bullata (Raf.) if we accept Rafinesque's evident description of it in his Monograph (1820, p. 4I). 
MISCELLANEOUS REMARKS:- Typically this species is a small shell, very upright with beaks protruding extremely anteriorly and with irregularly arranged pustules over its disk. In this latter character it is separated from $Q$. nodulata with which it is often confused; then too nodulata is not so rotund. Pustulosa is more typically a southern shell while its variety, schoolcraftensis, is more of a northern and western form. Its favorite home is clear water and rather swift streams and is associated with Q. sphaerica, refulgens, mortoni, etc.,-all of which are not found in Missouri; on the other hand its northern relative (schoolcraftensis) is more of a lover of mud bottom and sluggish current. It is strange that this species is not found in South Missouri where its ecological conditions are most favorable; however, it is not at all common anywhere in the great South-west. It is occasionally found in Central Missouri but mostly in varietal forms. The Mississippi River is the only locality for anything like its type. It should be a species of wide distribution since its host distributor is the common crappie ( $P$. annularis).

\section{Quadrula pustulosa schoolcraftensis (Lea).}

("Warty-Back," " Pimple-Back.")

$$
\text { Pl. XVII. Figs. } 42 \text { A-D. }
$$

I834-Unio schoolcraftensis Lea, Tr. Am. Phil. Soc., V., p. 37, pl. MI, fig. 9 .

ANIMAL CHARACTERS.

Nutritive Structures:-Branchial opening large, low, with short arboreal papillae; anal obscurely crenulated; supra-anal closely connected to anal but not deciduous; gills tilted at an abrupt angle, inner laminae of inner gills entirely free from visceral mass; palpi unusually long, somewhat curved; except brownish gills and palps the soft parts are dull whitish or tan.

REPRODUCTIVE STRUCTURES:- All four gills marsupial, septa crowded, ventral edges pointed and distended slightly in center when gravid; conglutinates white with thin, transparent spots arranged transversely in rows; glochidia same in form as the parent species, but a little larger $(0.235 \times 0.320)$.

SHELL, CHARACTERS.

FixternAL, STRUCTURES:- Shell large, subquadrate, ventral margin gently curved, moderately inflated, thick, heavy; posterior 
half profusely and irregularly pustulate to smooth; beaks rather high, moderately inflated sculptured concentrically but faintly; epidermis dark straw to chocolate brown in color.

INTERNAL STRUCTURES:-Cardinals heavy, irregular, double in each valve: inter-dentum broad, at right angles to laterals; laterals heavy, double in left, single in right; scars deeply impressed; umbonal cavities compressed by deep crevices; nacre usually white, irridescent especially posteriorly.

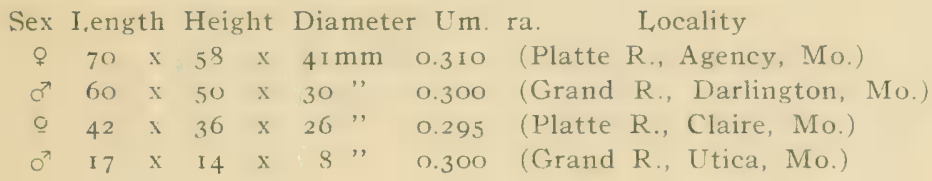

Since schoolcraftensis is one of the greatest occurrence in individuals for this state, the writer has been able to secure the largest collection of its adolescent shells than any of the Naiades in Missouri. The above latter measurement is that of the smallest one but it was without byssi. Its general outline is more elongated than the mature shell, resembling the adult Q. quadrula, postnmbonal ridge more prominent, beaks fuller, almost drawn back to the center of dorsal line, characteristically painted with a bright, broad, fan-shaped, green ray at base of post ridge within the original shell area; beak sculpture indistinct, concentric, broken anteriorly by a radiating furrow directed out on disk.

MISCELIAANEOUS REMARKS:- The differences of this variety from the species has already been mentioned under the description of the genus. This form was not admitted by Simpson as a race and is merely referred as "a nearly smooth, compressed form of pustulosa." The varieties of typical pustulosa, indeed, are greatespecially as to disposition of pustules, etc., but this larger more characteristically quadrate form is so abundant in the north and west, where pustulosa-types are rarely found, that it surely cleserves a separation into the subspecific, if not specific class. According to the figure and description that triangular variety found in the Ohio River, (that is, Lea's pernodosa,) might be a synonym of schoolcraftensis. Taking it all in all this subspecies is purely a geographical race, but may pass into normal form in a few places, even in the north and west, such as in the Mississippi River, Illinois and local points where clear water and swift streams are found. Schoolcraftensis is a lover of quiet, muddy situations, 
where it has developed a heavier, less pustulous shell as we note in the ecologic results for some shells of Amblemae. This form is reported also for the St. I.awrence basin as well as through all the northern part of the Mississippi Valley, even down into the South-west as far as Kansas and Oklahoma. The writer has been able to keep a good breeding record for this very acessible form for Missouri to find it only gravid through June and July.

\section{Quadrula pustulosa asperata (L,ea).}

Pl. XVII. Fig. $42 A$ and $B$.

I86I-Unio asperatus Lea, Pr. ac. Nat. Sci. Phila. V, p. 4I; Jl. Ac.

N. Sci. Phila., V., p. 68. Pl. VII. Fig. 218.

ANimal Characters:- Soft parts have been examined afield and found to be identical with those of the parent species. None were found gravid. All four gills of sterile females were marsupial in character through the test of finding more crowded septa.

SHELL CHARACTERS.

EXTTERnal, Structures:- Subtrigonal, very upright, higher than long, post-umbonal ridge moderately inflated, dorsal line rather straight, ventral margin abruptly curved, rounded posteriorly, subtruncated anteriorly; beaks well forward and eroded; tubercles few, disposed on upper part of disk; epidermis reddish brown to black.

INTERNAL STRUCTURES:-Identical with those of type, pustulosa except perhaps a broader, thinner and more upright interdentum.

\begin{tabular}{ccccccc} 
Sex & \multicolumn{4}{c}{ Length } & Height & Diameter \\
o $^{7}$ & 44 & $\mathrm{x}$ & 46 & $\mathrm{x}$ & $28 \mathrm{~mm}$ \\
9 & 50 & $\mathrm{x}$ & 48 & $\mathrm{x}$ & 32 \\
o $^{7}$ & 46 & $\mathrm{x}$ & 46 & $\mathrm{x}$ & $3 \mathrm{I}$ & "
\end{tabular}

Locality

(Osage R., Warsaw, Mo.)

( " " Osceola, Mo.)

( " " Bagnell, Mo.)

MiscellaneOus REMARKS:-The form of the above description is of rare occurrence in the Osage River, but still the other form for this state, schoolcraftensis, does not occur much oftener in this river. According to Mr. Bryant Walker this is "a western form of $Q$. pustulosa and if it came from the Coosa River, Alabama, it would surely be referred to Q. asperata (Lea)." Comparisons to the actual shell from Alabama (Coosa R., Cedar I luffi) shows it to be almost identical both as to external and iriternal features. 
Quadrula quadrula Rafinesque.

("Maple Leaf," "Monkey Face," "Tear Shell.") Pl. I.X., Fig. I0; Pl. XIIII., Fig.s 45 A-F.

1820-Quadrula quadrula Rafinesque, An. Gen. Sci. Phys. Brux. p. 305 .

I828-Unio lacrymosus Lea, Tr. Phil. Soc., III, p.:272, pl. VI, fig. 8. $183 \mathrm{I}$-Unio asperrimus Lea, Tr. Am. Phil. Soc., IV, p. 7 I, pl. V., fig. 3. 1834-Unio quadrulus Say, Am. Conch, VI.

r898-Quadrula lachrymosa Baker, Moll. Chicago, Pt. I, p. 83, pl. XXV., fig. I, XII, fig. 2 .

\section{ANIMAL, CHARACTERS.}

NUtritive Structurfs:- Branchial opening rather large with arboreal papillae; anal slightly crenulate; supra-anal very large closely connected to anal by mantle edges; palpi very long united about two thirds of their length antero-dorsad and heavily vein marked; inner laminae of inner gills free from visceral mass; color of most soft parts tanned flesh color.

REPRODUCTIVE STRUCTURES:-All four gills marsupial; ovisacs wide in middle transversely, ventral positions being divided, giving the white conglutinates a double or triple split appearance, septa thickened at intervals leaving thin transparent elongated spots arranged regularly and transversely in the conglutinates; glochidia not found by writer; Dr. Surber reports it as the smallest of the Quadrulae; color of charged marsupia brown; crenulated flap on post-dorsal part of foot; probably sexual in function as only noted in females.

\section{SHELL, CHARACTERS.}

EXTERNAL Structures:- Shell medium in size, subquadrate 10 subtrigonal, dorsal ridge more or less alated with costae on slopes undulated or sulcated post-umbonal ridge prominently anglerl set with coarse tubercles, a valley or radial furrow in front bounded anteriorly by a row of more or less irregularly placed tubercles on center of inflated disk, presenting the appearance of drops of melted wax; epidermis varies from olive green to chest nut brown or even black, in some instances faintly rayed antcriorly and with continuations of green paintings ventrad to some of the tubercles; beaks high, full, furrowed, post-obliquely, sculptured with corrugated, concentric ridges that break into great numbers of small tubercles out on the umbonal region. 
Internal. Structures:-Cardinals more or less double in both valves; laterals inclined to double also; umbonal cavities deep and rounded out; nacre white irridescent.

\begin{tabular}{|c|c|c|c|c|c|c|c|}
\hline Sex & Leng & & Heigl & & Diamete & r Um. ra. & I,ocality \\
\hline \& & 115 & $\mathrm{x}$ & 75 & $\mathrm{x}$ & $5 \mathrm{Imm}$ & 0.210 & (Lake Contrary, St. Joseph, Mo. \\
\hline $0^{x}$ & 90 & $\mathrm{x}$ & 65 & $\mathrm{x}$ & $48 "$ & 0.220 & (Platte R., Agency Ford) \\
\hline$\sigma^{7}$ & 86 & $\mathrm{x}$ & 70 & $\mathrm{x}$ & 38 & 0.350 & (Flat Creek, Sedalia, Mo.) \\
\hline ㅇ & 68 & $\mathrm{x}$ & 54 & $\mathrm{x}$ & $29 "$ & 0.325 & (Auxvasse R., Fulton, Mo.) \\
\hline$\sigma^{x}$ & 8 & $\mathrm{x}$ & 5 & $\mathrm{x}$ & $4^{\prime \prime}$ & 0.300 & (Grand R., Utica) \\
\hline
\end{tabular}

The above measurement is the smallest ever taken by the author. It was discovered stranded on a sandbar, where it was traced by its tiny furrowed track in the fine wet sand. Although it had been but few days since its escape from its parasitic life on the fish, yet it had no byssi. It would seem from this, and many other instances, that neither the Unioninae nor Anodontinae develop byssal threads. Three other juveniles found on this same bar (measuring I I, I 3 and 22 millimeters) were also devoid of byssi. It has been the author's experience to find juveniles in companies. The juvenile quadrula has the general appearance of a young fragosa, having a straw-colored epidermis, very pointed posterior end, deeply sulcated post-ventral position, full rather doubleapiculated beaks, with corrugated sculpturing and placed almost in the middle of the dorsal line; tubercles rather folded on anterior umbonal slopes ridged on post-umbonal slopes and finely ribbed on post-dorsal slopes.

Miscel.laneOUS REMARKS:- Q quadrula is represented by many forms in this state-especially in Central Missouri; however, the large, heavy form that ranges from Ohio to Nebraska is rather constant in the drainage basins north of the Missouri River. It is strange that there should be such a depauperization of any of these forms in South Mo. This species is found in Arkansas but rather in the aspera form, a small quadrula such as mostly seen in the Osage system. Mr. Walker thinks that the key for tracing out the relative ranges of forms might be found in some ancient drainage system, and varieties, such as found in Missouri. ought to help solve the question. The inflated, solid and comparatively smooth variety of $Q$. quarula of North Missouri may be referred to Pratt's Udio lunulatus (Proc. Dav. Ac. Nat. Sci., I. I 876, p. I67, Pl. XXXI, fig. I). However, this may simply be the lacustrine form of the type since the fluviatile forms of North 
Missouri approach more the typical quadrula in being more compressed and more tuberculated. Perhaps the most typical quadrula of Missouri is to be found in the geographic center of the state where the flatter, thinner and more "lachrymosed" shell occurs. As in many of the species of these related genera the intergrades are so numerous that we can consider only the most striking ones that may be traced to mere local conditions. The author has found this species to be the most sensitive to discharge its conglitinates immaturely when disturbed from its natural bed and then, too, since conglutinates, spawned in nature, have been examined to find them containing late embryos it is to be inferred that maturity may take place outside. Hence we may account for our difficulty in securing the mature glochidia from the ovisacs of the mother. The writer has examined hundreds of gravid quadrula in mid-and late summer only to find every stage of embryonic development except the glochidial. In this respect this species resembles Q. verrucosa and the fact that the ovisacs of each contain unusually large quantities of mucus may have some association with their eccentric breeding habits. The breeding season of Q. quadrula is from May to August and hence is tacytictic.

Special attention is given here to a deeply sulcated form of this species which occurs rather commonly in our North West Missouri lakes but which may only be a pathologic condition due perhaps, to parasitic attacks upon the mantle glands that build up the shell. Three type shells measure as follows:

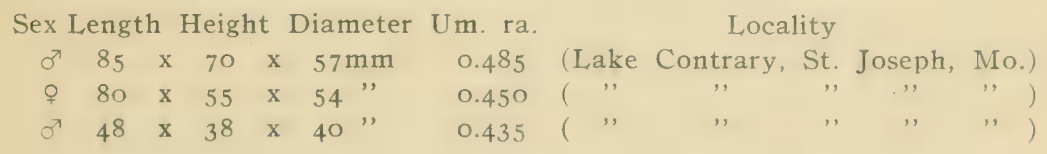

These measurements show an unusual inflation and extraordinary position of the umbones. If this should be a normal form it would deserve specific consideration because of the deep post-dorsal sulcation and also because of the wide, deep radial furrow in front of the prominently angled post-umbonal ridge. However, since Mr. Frierson concurs with the author in the belief that it may only be " a strange freak" after all it would be dismissed here with only the reference to its photograph (Pl. XVIII, Figs. $46 A$ and $B$.) 


\title{
Quadrula quadrula contraryensis Utterback.
}

\author{
(Round Maple Leaf.) \\ Pl. XTIII, Fig's $47 A$ and $B$. \\ ANIMAL CHARACTERS.
}

NUTRITIVE STRUCTURES:- Same as that of the parent species, except for an absence of a supra-anal opening, a difference in the greater posterior extension of foot and also a general difference of form of soft parts due to a more rounded shape of shell.

REPRODUCTIVE STRUCTURES:-Identical with that of the parent species except for shorter, wider marsupia.

\section{SHELL CHARACTERS.}

ExTERnAL STRUCTURES:- Shell medium in size, suborbiculate, abruptly curved before, broadly rounded behind with very slight incurvature post-ventrad; well inflated, inclined to globosity; beaks full, high up on dorsal line (as indicated by the large average umboidal ratio of 0.495$)$; tubercles few and small, mostly on umbonal area; post-umbonal ridge rounded, scarcely sculptured; sculpturing on beaks corrugated as on parent species; epidermis olivaceous.

INTERNAL, STRUCTURES:-Cardinals different from parent in being reduced to a single, jagged tooth in right valve; somewhat double in left; interdentım long, wide, not so deeply gasher in right valve for the reception of the post-right cardinal; umbonal cavity deep, basin-like; nacre an unblemished white.

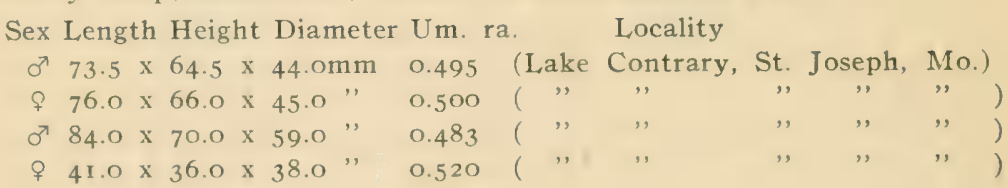

The young shell of the last measurement shows an approach to the parent shell. The comparatively deep sulcation at the post-ventral portion of the shell disappears as seen in a shell series of fairly close connection in ages.

MiscellanEOUS REMARKS:- The author of this sub-species is satisfied that he has a sufficient collection of this peculiar shell taken from different parts of Lake Contrary, St. Joseph, Missouri, to prove the validity of this form as a variety of that very common, 
heavy shell, that occurs in the Mississippi Valley, North of the Ohio and also of the Missouri Rivers. The differences in this upright, rounded shell from its parent are stated in the comparative description. Since students of Naiades have pronounced it a variety, if found in sufficient numbers, the author concurs by naming it for its type locality, Iake Contrary, St. Joseph, Mo. Wherever found in this lake, the bottom is a soft, marly mud, and the situations are in rather deep water sheltered from wave action. The author has discovered a short period breeding season for contraryensis.

\section{Quadrula nodulata Rafinesque.$$
\text { ("Pimple Back," "Warty Back.") }
$$$$
\text { Pl. XIII, Figs. } 44 A \text { and } B \text {. }
$$

1820-Obliquaria nodulata Rafinesque, Bivalves of River Ohio, Ann.

Gen. Sci. Phys. Brux.

I 834-Unio pustulatus Lea, Tr. Am. Phil. Soc., p. 79, PI. VII, fig. 9.

1834-Unio nodulatus Say, Am. Conch., VI.

Animal Characters:- Nutritive structures absolutely identical with those of Quad. pustulosa (Lea). The glochidial characters are the same, except a difference in size, the glochidium of nodulata being the larger $0.230 \times 0.290 \mathrm{~mm}$. However, small differences in size may not be considered good distinctions as it is the glochidial form that is to be taken into greater account.

\section{SHELL CHARACTERS.}

EXTERnal Structures:- Shell medium in size, solid, suborbicular, inflated, post-dorsal ridge projected; umbones very full, high, incurved bearing three or four small corrugated, concentric ridges; post-umbonal ridge and central part of disk ornamented with two radial rows of small, erect pustules sometimes terminating with half-tubercles at ventral margins; cpidermis light tan to dark horn.

INTERNAL STRUCTURES:--Identical with pustulosa.

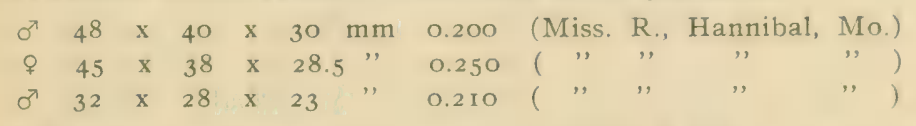

Shell of juvenile subglobose, post-umbonal ridge prominent, post-dorsal ridge short, high; tubercles few in two rows-one on post-ridge - no radial furrow between; beaks very full, sculptured 
by rather coarse, irregular ridges, extending as tubercles on the disk; epidermis yellowish green with alternate bands of brown and straw color. Interior of shell much like adult except not so broad, nor as upright, nor as long; nacre white with light blue irridescent sheen posteriorly.

MiscellaAneous REMARKS:- Q. nodulata seems to be only a globular-shaped Q. quadrula and is more typically a southern shell; however, it is occasionally met with in the Upper Mississippi, where it is most found in this State. Mr. B. F. Bush collected some miscellaneous shells from the interior of the state and donated them to the United States Museum where some were identified as this species. It is to be distinguished from $Q$. pustulosa especially by two regular radiating rows of widely separated tubercles obliquely arranged from the umbones to the ventral margin on the posterior half of the disk; then, too, it is more inflated, is not so upright, has greater umboidal ratio, has more of an alated dorsal ridge and belongs to the so-called "Lachrymosa" Group, whereas, pustulosa is a member of the first group of this Genus of which it is the type; hence, the latter is, after all, not even closely allied. However, there is not much difference between these two Quadrulae as to the form and size of their larvae, and as to form of adult shell, it lies nearer to the variety, contraryensis of $Q$. quadrula. Surber (I9I3, p. II3) finds this species to be a gill parasite upon the crappie (Pomoxis annularis) as an occasional host. As to its breeding habit, it is tachytictic.

\section{Quadrula fragosa (Conrad). \\ ("Hickory Nut Shell.") \\ Pl. XIIII, Figs. 48.4 and $B$.}

1836-Unio fragosus Conrad, Monog. of Fresh-water Shells, II, p. 12, Pl. VI., fig. 2 .

ANIMAL CHARACTERS.

Nutritive and Reproductive Structures:-Identical with Q. quadrula as far as can be determined, with the scanty supply of material at hand-none of which is in gravid condition. However, Wilson and Clark (19I4, pp. 59 and 6o) report it with all four gills marsupial, thick, pad-like. Glochidium unknown.

SHELL CHARACTERS.

EXTERnal Structures:- Shell most quadrate of the Quad- 
rulae, medium in size, greatly inflated, characteristically sulcated post-ventrad; dorsal ridge prominent, the slopes coarsely cos tated; post-umbonal ridge prominent and profusely tubercled; radial furrow deep and wide, in front of which another row of rather scattered tubercles extend from the beaks post-ventrad across the disk; epidermis dark yellowish.

INTERNAL STRUCTURES:- Identical with those of Q. quadrula.

\begin{tabular}{|c|c|c|c|}
\hline ex & Length & h Height & t Diamete \\
\hline$\sigma^{7}$ & 63 & x 59 & $\mathrm{x} \quad 35 \mathrm{~mm}$ \\
\hline \& & 44 & 39 & 18 \\
\hline$\sigma^{7}$ & 23 & I 6 & $\mathrm{x}$ \\
\hline$\sigma^{\pi}$ & $15.5=$ & 6.5 & 7 \\
\hline
\end{tabular}

Locality

(Miss., R. Hannibal, Mo.)

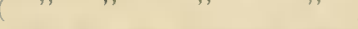

( Iо2 R., St. Joseph, Mo.)

(Osage R., Schell City, Mo.)

It may be that the juvenile shell measurement of the last two above is only that of $Q$. quadrula since all juveniles of the latter possess the characteristic sulcation at the post-ventral portion of the shell as well as the profuse costation on the slopes of the post-dorsal ridge; hence, the inferrence the author would draw in asserting that $Q$. fragosa may be an occasional instance of an overgrown shell of Q. quadrula.

MiscellaAnEOUS REMARKS:- This type of Conrad is of rare occurrence in this State, the Mississippi being the only place where anything like its type may be found with any degree of assurance. Abnormal forms of fragosa are seen occasionally in the headwaters of the Osage. Simpson is not certain about the distribution of fragosa outside of the Ohio and Tennessee-Cumberland systems. It is mainly distinguished from typical $Q$. quadrula by being more squarely quadrate, more inflated and the upcurved tubercular costae on the rounded post-dorsal ridge being more pronounced. It differs chiefly from aspera, (the small C. quadrula form of the Osage) in not being biangulated posteriorly. It has been found to belong to the short period breeders.

\author{
Quadrula aspera (Lea). \\ ("Little Rough Shell.") \\ Pl. XVIII, Figs. $49 A$ and $B$.
}

I83 I-Unio asper Lea, Tr. Am. Phil. Soc., IV, p. 85, pl. IX, fig. I5.

ANIMAL CHARACTERS.

NuTritive; STRUCTUREs:- Branchial opening finely papillose; anal smooth; supra-anal loosely, to deciduously, connected to anal by mantle edges; inner gills much wider (posteriorly), 
inner laminae of inner gills free from visceral mass; palpi long and broad; soft parts a light tan.

REPRODUCTIVE STRUCTURES:-Marsupia identical with those of $Q$. quadrula. No gravid forms found.

SHELL, CHARACTERS.

ExTERnAL STRuctures:- Shell small, subquadrate, biangulated behind, the biangulation pointed ventrad; post-dorsal ridge costated; post-umbonal ridge prominent, profusely tubercled; radial furrow rather wide and shallow, bounded in front by a rather scattered row of sharp tubercles; epidermis blackish.

INTERNAl. STRUCTURES:--Identical with those of Q. nobilis which are somewhat peculiar.

\begin{tabular}{|c|c|c|c|}
\hline Sex & Length & Height & Diameter \\
\hline क & $5^{2}$ & $46 x$ & $29 \mathrm{~mm}$ \\
\hline$\sigma^{7}$ & 44 & 39 & $27^{\prime \prime}$ \\
\hline 8 & 40 & 38 & $24^{\prime \prime}$ \\
\hline
\end{tabular}

Locality
$\left(\begin{array}{ccc}\text { (Osage R., Warsaw, Mo.) } \\ (\text { ", ", } & \text { ", } & \text { ", })\end{array}\right.$

Miscellaneous REMARKs.-Although this species has only been found in the Osage basin for this State, yet it is not to say, a very common shell there. So closely related is this small form of quadrula to $Q$. nobilis that a good series of shells may reveal it as the young of nobilis. Aspera has been considered the southern form of $Q$. quadrula and it may be the small multi-tuberculated representative of the South-west which is connected geographically by all forms of intergrades to that large, heavy, smoother representative of the North Mississippi Valley.

Quadrula nobilis (Conrad).

("Big Buck Horn," "Maple Leaf.")

Pl. XIX. Figs. $5 I$ A and B.

1854-Unio nobilis Conrad. J1. Acad. Nat. Sci. Phila., 11, p. 297, P1. XXVII, figs. 2 and 3 .

ANIMAL, CHARACTERS.

NUTRITIVE STRUCTURES:- Branchial opening large with feathered papillae, anal crenulated, supra-anal without mantleconnection to anal-hence both openings virtually one, gills long, rather narrow, inner laminae of inner free only one-half way, palpi enormous connected two-thirds of their length antero- 
dorsad, color of soft parts tan, for most part, mantle edges at siphonal openings black, gills and parts above darker tan tha parts below.

REPRODUCTIVE STRUCTURES:-Only sterile marsupia observed; all four gills, however, marsupial and same in structure as that of $Q$. verrucosa; glochidium not found.

SHELL CHARACTERS.

EXTERNAL STRUCTURES:- Shell roughly pentagonal in general outline, heavy, thick, solid, compressed posteriorly, inflated for one-half of the shell anteriorly, obtusely biangulated behind with truncation obliquely antero-ventrad, broad, shallow, radial furrow, post-umbonal ridge flattened and sculptured with few tubercles, area in front of radial furrow irregularly and coarsely tuberculated, slopes of post-dorsal ridge with low upcurved costae, epidermis dark brown, growth lines coarse.

INTERNAL STRUCTURES:- Cardinals and laterals both distinctly doubled in the two valves, interdentum short, wide, cut away in right valve for the post-left cardinal, anterior adductor muscle scars usually drawn to the front, nacre milky white.

\begin{tabular}{|c|c|c|c|c|}
\hline Sex & Length & Height & Diameter & Locality \\
\hline ᄋ & $120 \mathrm{x}$ & $88 \mathrm{x}$ & $57 \mathrm{~mm}$ & (Marais des Cygnes R., Rich Hill, ) \\
\hline$\sigma^{7}$ & $80 x$ & 56 & $30 "$ & (Osage R., Greenwell Ford) \\
\hline 우 & 56 & 46 & $27.5 \mathrm{~mm}$ & $\left(\begin{array}{llll}\prime \prime & \prime & \prime\end{array}\right)$ \\
\hline
\end{tabular}

No juveniles were obtained. The last measurement, is that of the smallest in the writer's collection, but shows no real juvenile characrters, and is more like $Q$. aspera except for its difference in posterior biangulation and also in its tuberculation.

MiscellaneOUs Remarks:- Simpson (rgoob, p. 776) puts Q. nobilis down in the synonomy of aspera, but later refers it to Q. verrucosa. However, from studies of its peculiar anatomy and internal shell structures it may come very near to verrucosa. This is a rather common species for the Osage where it reaches a larger, heavier growth of shell than is ever attained by verrucosa. It is also a broader, shorter shell with great solidity and inflation anteriorly and also greater compression posteriorly. Novilis is reported by Isely (19I4, p. 4) for the lower Neosho basin. It likewise appears occasionally in this same drainiage for Missouri and is also found in the Grand River of North Missouri. Like $R$. tuberculata (Raf.), nobilis may be said to have no true supra-anal opening due to its lack of mantle connection between the anal and 
supra-anal region. This lack of mantle connection is a constant character in this species, whereas this deciduity is inconstant among other Quadrulae. The fact of its partial union of the inner laminae of the inner gills with the visceral mass is also a departure from the general characters of this genus and a step toward the modern arrangement. In this latter character nobilis is somewhat like Megalonaias heros. From the fact that females were found sterile all through early and mid summer, it may be inferred that its breeding season is very short and begins early in spring, or like, heros begins late in the season. Later investigations may relate this species more closely to Megalonaias for the physiological reasons as well as for the morphological.

Quadrula verrucosa Rafinesque.

("Deer Horn," "Buck Horn.")

Pl. XIX, Figs. $5^{O} A-D$.

I820-Unio (Obliquaria) verrusoca Rafinesque, Ann. Gen. Phys. Brux. 1823-Unio tuberculata Barnes, Am. J1. Sci., VI, p. 125, Pl. VII, figs.. $8 \mathrm{a}, 8 \mathrm{~b}$.

1899-Tritogonia tuberculata Simpson, Pr. U. S. Nat. Mus., p. 608. I912a-Quadrula tuberculata Ortmann, Ann. Car., Mus., p. 254.

ANIMAL、CHARACTERS.

Nutritrve Structures:--Branchial opening densely set with arboreal papillae, anal crenulated, supra-anal smooth, very large, slightly (even deciduously) connected to anal by mantle edges; gills very long, comparatively narrow, inner broader, inner lamina of iuner gills connected to visceral mass except for a short distance anteriorly; palpi very long, connected anterodorsad for a little more than half their length; color of soft parts, mostly solid white, gills brown.

\section{SHELL CHARACTERS.}

EXTERnal Structures:- Shell rather large, elongate, roughly trapezoid; male shell shorter, more pointed posteriorly and angled dorsad; female shell much longer, biangulated post-ventrad; disk profusely tuberculated, the coarser tubercles located ventrad; post-umbonal ridge prominent and nodulated; slopes of postdorsal ridge faintly costated, beaks rather small, apiculated, sculptured with double-looped, zigzag markings that extend out on the disk; epidermis chestnut brown to dark horn color. 
INTERNAL STRUCTURES:- Cardinals heavy, ragged, double in left usually single in right; laterals long, rather straight and heavy; beak cavities deep; nacre marble white, occasionly pink, irridescent posteriorly

\begin{tabular}{cccccc} 
Sex & \multicolumn{4}{c}{ Length Width } & Diameter \\
o & 169 & $\mathrm{x}$ & 88 & $\mathrm{x}$ & 48 \\
$\sigma^{7}$ & 150 & $\mathrm{x}$ & 78 & $\mathrm{x}$ & 44 \\
$\sigma^{7}$ & I 10 & $\mathrm{x}$ & 50 & $\mathrm{x}$ & 30 \\
& 54 & $\mathrm{x}$ & 30 & $\mathrm{x}$ & 15
\end{tabular}

\author{
Locality \\ (Grand R., Darlington) \\ (Platte R., Agency Ford) \\ (Osage R., Warsaw) \\ (White R., Hollister)
}

No juveniles obtained. The last measurement is that of the youngest verrucosa obtanied. Its beak sculpture and disk are entirely sculptured with nodules and tubercules. The slope of the post-dorsal ridge are sculptured with three or four coarse, costated undulations and with numerous fine costae arranged dorsad; shell very greatly compressed; nacre bluish.

MiscellaneOUS REMARKS:- - Q verrucosa is the most peculiar species of its genus on account of the sexual dimorphism of its shell. For this reason especially, Simpson created a special genus (Tritogonia) for it. Some students are inclined to think that Tritogonia deserves sub-generic rank at any rate, because of its morphological departure form the typical Quadrula shell. Its soft parts, however, are so identical with those of the typical Quadrula that there is no reason for its groupings with any other genus. Even though the form of the shell may be differnt, yet its conchological parts correlate with those of other Quadrulae. Although Rafinesque's figure of this species is abomnable, yet an unbiased study of it, together with that of his good description, would give preference for the adoption of his verrucosa over that of Barnes' tuberculata. Like Q. quadrula, its breeding season is about as eccentric, in that the mature glochidia are not retained in the marsupia for any length of time; hence this accounts for the great difficulty of securing its larvae for study. Surber was fortunate in securing specimens with ripe glochidia June Ioth. The writer would judge from this record and that of his own (i. e., sterility for the Fall and Winter months) that this species is tachytictic. Vercucosa has the widest distribution for this State: however, it varies somewhat in size, inflation, disk sculpture, nacre-color for the different sections of the State; e. g., the pink-nacred ones are exclusively confined to the Southern Missouri streams. 
Quadrula metanevra (Rafinesque).

("Maple Leaf," "Monkey-face" "Stranger.")

Pl. XIX, Figs. $53 A$ and $B$.

I820-Obliquaria (Quadrula) metanevra Rafinesque, Ann. Cien. Sei.

Brux., V, p. 305. Pl. LXXXI, fig. 15 and 16.

1834-Unio metanevrus Say, Am. Conch., VI.

I goob-Quadrula metanevra (Raf.) Simpson, Proc. U. S. Nat. Mus,, XXII, p. 774 .

ANIMAL, CHARACTERS.

Nutritive Structures:- Branchial opening large with short feathered papillae; anal smooth to finely dentate; supra-anal very long, open, closely connected by mantle edges to anal; gills short and wide the anterior connection of outer to mantle far removed from base of palpi, inner laminae of inner gills free from visceral mass; palpi long, pointed, connected for one-third of their length; color of soft parts mostly a dingy white, the only different color being a straw-yellow of the mantle margin at branchial opening.

REPROductive: Structures:--All four gills marsupial, septa and water tubes (ovisacs) well developed, when gravid, marsupia moderately swollen, ventral margins sharpened; conglutinates white, broken, compressed, leak-like; glochidia average $0.180 \mathrm{x}$ o.19omm., semi-elliptical, ventral margin rounded, spineless, medium size, hinge line undulate.

\section{SHELL, CHARACTERS.}

EXTERNAL STRUCTURES:- Shell roughly pentagonal, alated, deeply furrowed between dorsal and post-umbonal ridges to emarginated post-dorsal portion; shallow radial furrow just in front of coarsely tuberculated and prominent post-umbonal ridge; disk with smaller, tear-like tubercles scattered all over; beaks rather apiculated, sculptured by coarse corrugations extending out on disk; epidermis brownish yellow, pointed by irregular, downward pointing, green, chevron-like splotches.

INTERNAL STRUCTURES:-Cardinals doubled in both valves; laterals also doubled, right faintly so; beak cavities deep, compressed; nacre pure white to pale pink. 


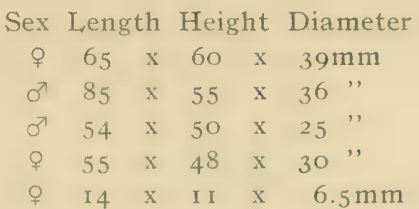

Locality

(Miss. R., Hannibal)

(Meramec R., Fern Glen )

(Osage R., Proctor)

( " " Greenwell Ford)

( " " Osceola)

Juvenile shell with three nodulous expansions on post-umbonal ridge, deep furrows between nodules; ligament bright pea green; epidermis straw-color; slopes of dorsal ridge slightly ribbed; beaks high upon dorsal line; posterior peculiarly roundly lipped for the branchial opening.

MiscellaneOUS REMARKS:-The shell characters of metanevra, typical of the whole genus, are highly emphasized. The enormous supra-anal opening and yellow mantle border at the siphonal opening are characteristic of its soft-parts. This species is well represented in Central Missouri and in the Des Moines and Mississippi, but is seldom found in North or South Missouri. The writer has only found it in the Grand River of North Missouri and while he himself has not found it in South Missouri, yet Mr. Walker has it in his collection from Black River, Popular Bluff, Missouri. Simpson (Igoob p. 774) reports it for general distribution throughout the Mississippi drainage area except its southern portion, extending to the Tennessee and Arkansas rivers. Its favorite habitat is sandy or gravelly shoals and, as its shell responds to its surroundings, the general form of shell may vary so much as to make it appear as a different species, or sub-species. Its breeding season is found to be tachytictic.

\title{
Quadrula metanevra wardii (Lea).
}

\author{
("Monkeyface.") \\ Not Figured.
}

I86I-Unio wardii Lea. Pr. Ac. N. Sci. Phila., V, p. 372; J1. A. C. N Sci. Phila., V., p. 187, Pl. XXIV, fig. 257

Animal Characters:- Identical with those of its parent species.

\section{SHELL CHARACTERS.}

EXTERAAL CHARACTERS:- Shell more elongated than its species, comparatively smooth, heavier, more solid, post-umbonal ridge with an expansion just before reaching basal line; otherwise 
its external and internal shell structures are identical with those of Q. metanevra.

Sex Length Height Diameter

우 $86 \times 70 \times 54 \mathrm{~mm}$
Locality

(Des Moines R., Dumas)

MISCELIANEOUS REMARKS:- Shells from the type lot, sent to the National Museum and now under the label of variety wardii of I,ea, and numbered I 34,639 , are now in the writer's collection through the kindness of the collector, B. F. Bush. However, it is the opinion of the writer that this form may not deserve a name since metanevra is subject to so many intergrades due to local conditions. The above comparative description shows its departure not far from type, besides the form is inconstant.

\section{Quadrula cylindrica (Say).}

("Razor Handle,"'“Cob Shell," "Rabbit's Foot," "Spectacle Case.")

$$
\text { Pl. XIX, Figs. } 52 A \text { and } B \text {. }
$$

I8 16-Unio cylindricus Say. Nich. Ency., II, P1. IV, fig. 3. I819-Unio naviformis Lamarck, An. Sans., Vert. VI, p. 75 . r goob-Quadrula cylindrica (Say) Simpson, Proc. U. S. Nat. Mus., XXI1, p. 773 .

\section{ANIMAL CHARACTERS.}

Nutritive, STRUCTUREs:-Branchial opening moderately large with brownish yellow tentacles; anal finely papillose; supraanal briefly connected to anal by mantle edge; gills very long and narrow, outer more narrow anteriorly, inner laminae free from visceral mass; palpi long, narrow connected one-third of their length antero-dorsad; color of soft parts peculiar, foot with orange back-ground striped in black, visceral mass uniorange, mantles with black pigment especially along the margins at siphonal openings.

REPRODUCTIVE STRUCTURES:-Only sterile marsupia found, these with normal structures of Quadrula. Glochidia unknown.

SHELL CHARACTERS.

EXTERNAl, StRUCTURES:--Shell rectangular-elongate, length three times the height, dorsal posterior ridge, long, high, slightly costated; wide behind, abruptly rounded before; post-umbonal ridge high, hummocky and pustulate; umbones low, somewhat sharp pointed, incurved, sculptured by corrugated ridges breaking into tubercles ont on disk; epidermis dark straw painted (as 
in metanevra) with green toothed splotches pointed ventrad.

INTERNAL, STRUCTURES:--Cardinals double in both valves, serrated and irregular; laterals slightly double and very long; interdentum unusually long; nacre white subject to stain.

Sex Length Height Diameter Um. ra. Locality.

\begin{tabular}{|c|c|c|c|c|c|c|c|}
\hline $3^{7}$ & I05 & $\mathrm{x}$ & $4^{\circ}$ & $\mathrm{x}$ & 34 & 0.190 & (White R., Hollister-) \\
\hline & IOS & y & 40 & $\boldsymbol{X}$ & 39 & o. 190 & (Center Cr., Webb City) \\
\hline & 75 & $\mathrm{x}$ & 30 & $\mathrm{x}$ & 28 & 0.200 & (St. Francis, Greenville) \\
\hline & 70 & $\mathrm{x}$ & 28 & $\mathrm{x}$ & 26 & 0.210 & (Black R., Williamsville) \\
\hline
\end{tabular}

MISCELLANEOUS REMARKS; - It is regretted that the description of this interesting species still remains incomplece, from the fact that no juveniles, nor mature individuals bearing ripe glochidia, are found yet. Cylindrica is distinctly a southern species and is not found in North or even Central Missouri and is never found in the Mississippi north of the mouth of the Missouri. It is a rather common shell for the White and St. Francis Rivers and from deposits of shells in Indian graves it has been found to be abundant in the streams of Southwest Missouri where it is now extinct. Perhaps the identity of cylindrica is one of the most evident because of its unique shell and yet it may well be described as an extremely elongated $Q$. metanevra. The breeding record kept by the writer is early embryos August I 4 and sterile maruspia August 29; Wilson and Clark (19ri, p. 42) record its gravidity for June 17 and July 27 but do not indicate the embryonic stages.

\section{Genus Rotundaria Rafinesque.}

(Type Obliquaria [Rotundaria] tuberculata Rafinesque.)

1820-Rotundaria Rafinesque, Monograph of Bivalve Shells of River Ohio, Ann. Gen. Sci. Phys. Brux.

I goob-Rotundaria (Raf.) Simpson, Proc. U. S. Nat. Mus., XXII, p. 794 (as subgenus)

ANIMAL CHARACTERS:- Siphonal openings peculiar in possessing no true supra-anal openings; gills short wide, inner much wider centrally, inner laminae free from visceral mass; palpi connected about two-thirds of their length antero-dorsad, acuminate postero-ventrad; only outer gills marsupial water tubes more crowded than in non-marsuplal gills when gravid marsupia not much distended length-wise throngh center, ventral edge pointed; conglutinates white, broken, rather narrowly leaf-like, or lanceloate; glochidia semi-elliptical, spineless, large, hinge line short and undulate. 
Shell Characters:- Shell rotund, disk sculptured for twothirds of posterior part with irregularly placed tubercles, slopes of post-dorsal ridge regularly costated, some costae somewhat parallel to umbonal ridge behind; beaks well placed anteriorly, sculptured profusely with concentrically zigzag lines across two obliquely posterior ridges being coarser in the valley between; nacre purple; cardinals heavy, double in left, more inclined to be single in right; beak cavities deep antero-postero, narrow diametrically, wide vertically.

Miscellaneous Remarks:-This genus is unique for its absence of supra-anal opening, for its limitation of marsupia to the outer gills and for its peculiar shell structure in the presence of a well developed sulcus at the post-dorsal part and in its remarable beak sculpture. The two species of this Genus are most typically represented in the Mississippi of this State, but are found to be more intermediate in form for Central and South Missouri. In the Gasconade and Osage basins these forms grade into those that may be referred to Plethobasus cooperianus as far as shell structure is concerned.

Rotundaria tuberculata (Rafinesque).

("Purple Warty Back," "Red Nigger Head."))

Pl. XIX, Figs. 54 A and B; Pl. I, Figs. I-4.

I820-Obliquaria (Rotundaria) tuberculata Rafinesque, Ann. Gen. Sc. Brux., V., p. 103

I 898-Quadrula verrucosa Baker, Moll, Chicago, Pt. I, p. 85, pl. XXIII. r goob-Quadrula tuberculata Simpson, Proc. U. S. Nat. Mus., XXII.

p. 795 .

1912b-Rotundaria tuberculata (Raf.) Ortmann, An. Car. Mus., VIII, pp. $258-259$.

ANIMAL CHARACTERS.

NUTRITIVE STRUCTURES:-Branchial opening very large with few short simple papillae; anal as large as branchial with still shorter papillae; rectum large, visible, anus slightly tentacled; gills wide, short, tilted at abrupt angle, inner much wider, inner laminae free from visceral mass; palpi connected over half of their length antero-dorsad, pointed postero-ventrad; soft parts dingy wihite, for most part, gills dark brown black posteriorly, foot dark tan.

REPRODUCTIVE STRUCTURFs:--Only outer gills marsupial, 
septa closely crowded, when charged distended very little even in median-longitudinal line, ventral edge not blunt, ovisacs rather narrow; conglutinates white, narrowly lanceolate, not solid; glochidia large, spineless, ventral margin rounded, hinge line short, straight, or nearly so, measures $0.267 \times 0.325 \mathrm{~mm}$., collected by author, Aug. I1, Ig 13, Osage River, Bagnell, Missouri.

SHELI, CHARACTERS.

EXTERNAL STRUCTURES:- Shell oval quadrate, medium in size, compressed, heavy, thick, rounded in front, usually emarginated post-dorsad with radial furrow from this sulcation to beaks, dorsal ridge rather high with upcurved costae; post-umbonal ridge rather rounded; posterior half of shell profusely sculptured with coarse pustules and fine tubercles; umbones low, pitched considerable anteriorly, sculptured with numerous, heavy, wavy or corrugated ridges which extend down on upper part of disk; epidermis brownish red to black.

INTERNAL STRUCTURES:--Cardinals double in left, rather tripartite in right valve; laterals double in both valves, lower right lateral rudimentary, scars deep; beak cavities very deep antero-postero, narrow diametrically, wide vertically, nacre rich purple, with part within the mantle line a lighter shade, sometimes whole nacreous surface faded to whitish with pinkish teeth.

Sex Length Height Diameter U. ra. Locality.

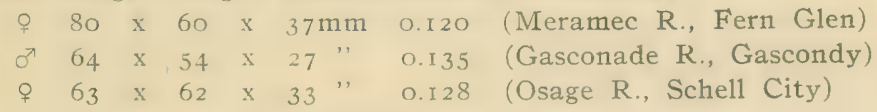

The last measurement is that of the smallest juvenile out of a collection of 156 collected in a space twenty-feet square in the White River. This place was a quiet retreat of shallow water with a thin coating of mud over a substratum of limestone.

MISCELLANEOUS REMARKS:-The peculiar shell characters of this species in being suborbicular, heavy, with low corrugated beaks and the nnique anatomical characters in possessing no supra-anal opening and only outer gills as marsupial are features especially to be noted. Its distribution in this state is peculiar in that it is not found at all in the interior northern drainage of the Mississippi River, and is confined in its typical form more in the drainage of the south slope of the Ozarks and in the Missouri portion of the Mississippi while it occurs by intergrades in the 
southern drainage of the Missouri River. Simpson reports it for the Mississippi drainage generally. A three hundred mile survey of the Osage River, beginning at the headwaters, reveals the shell of this species in all its external form and nacre-color extending to granifera and even including Pleth. cooperianus. Variation in nacrecolor for this species is remarkable; however, this deviation from the unipurple nacre of the type may be due to local reaction since it is most noticed in the Osage below the region of medicinal springs. Its favorable habitat is that of rocky shoals, but is occasionally found in deep, quiet water with mud bottom where it acquires a smoother, heavier and less inflated shell. The writer has had the good fortune to secure, for the first time, several individuals gravid with mature glochidia. The larva is found to be somewhat smaller than that of $R$. granifera and with hinge line shorter and straighter; as to form, and even as to size, it is hardly distinguishable from granifera when allowance is made for variation in a large series. This glochidium is figured and described hore for the first time (See Plate I, Fig. 4). It is observed by the writer to be gravid from June until the middle of August, bearing ripe glochidia mostly about the middle of July. It is decidedly a short period breeder.

Rotundaria granifera (Lea).

("Purple Warty Back," "Purple Pit.")

Pl. XIX, Figs. $55 A$ and $B$.

I838-Unio graniferus Lea, Tr. Am. Phil. Soc, Vi, p. 69, Pl. XIX, fig. 60. igoob-Quadrula granifera (Lea) Simpson, Proc. U. S. Nat. Mus., XXII, p. 795 .

ANIMAL CHARACTERS.

Nutritive Structures:- - Identical with those of $R$. tuberculata in all respects.

REPRODUCTIVE STRUCTURES:- Typical specimens from the Mississippi show the outer gills marsupial; conglutinates same color and form as those of $R$. tuberculata; glochidium measures $0.290 \times 0.350 \mathrm{~mm}$., being a little larger with more of an undulated hinge line, but with the same general form.

SHELL CHARACTERS

EXTERNAL STRUCTURES:- Like $R$. tuberculata except smaller rotund, upright, alated, inflated,-- especially fuller, higher, more antero-protruding beaks and with more of a rayed character of epidermis on anterior umbonal slope. Interior of shell identical 
except perhaps shorter laterals arranged at right angles to the interdentum.

\begin{tabular}{|c|c|c|c|c|c|c|c|c|}
\hline Sex & Leng & & Heig & & Diameter & & Lo & cality \\
\hline $0^{x}$ & 57 & $\mathrm{x}$ & 57 & $\mathrm{x}$ & $40 \mathrm{~mm}$ & (Miss. & R., & LaGrange) \\
\hline 우 & 56 & $\mathrm{x}$ & $5^{6}$ & $\mathrm{x}$ & 34 & ( " , & ," & ", \\
\hline $0^{7}$ & 46 & $\mathrm{x}$ & 46 & $\mathrm{x}$ & 30 & & ", & ," \\
\hline 우 & 23 & $\mathrm{x}$ & 21 & $\mathrm{x}$ & 10.5 & (White & " & Hollister) \\
\hline
\end{tabular}

The latter measurement is of a juveniles from a lot identified by Mr. Frierson as approaching granifera although would perhaps fall more under tuberculata. However, it meets the test of granifera in length and height being about equal and in prominent beaks. Its beak sculpture consists of numerous, fine concentric corrugations extending out on disk somewhat like $Q$. quadrula. In general shape of shell and dispositition of tubercules it is also like the latter in this adolescent stage.

MiscellaneOUS ReMARKS:-According to shell measurement, and with an allowance for eroded beaks, the Osage forms may be more classed under granifera. A divergence of equality for length and altitude may indicate and approach to the tuberculata, Lea's type, when diameter may be reduced to unity, it measures length and height the same. On this same basis so many of the Rotundariae of South Missouri would approach more nearly to the granifera type. Because of its full, projecting beaks, uprightness of shell and disk sculpture this species has sometimes been confused with $Q$. pustulosa and $P$. cooperianus. However, distinction can be easily made by comparing to the rich purple nacre of granifera-a color that is not possessed by either pustulosa or cooperianus. Its breeding season is found to be the same as that of tuberculata. Despite their identity of breeding habits, of reproductive and nutritive structures and of internal shell characters there may be sufficient evidence of difference in external shell structures to make granifera a good species and thus take it out of its class as a subspecies of inberculata, as Simpson had treated it, and elevate it as Mr. Walker considers.

\section{Genus Plethobasus Simpson.}

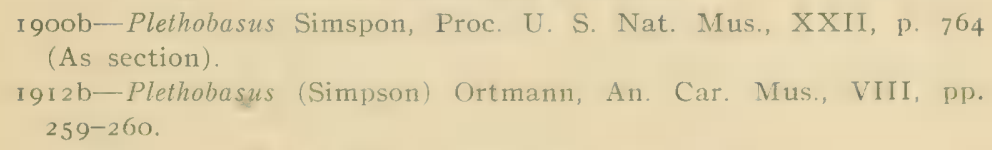

ANIMAL CHARACTERS:-Anal separated from supra-anal 
opening by short mantle connection; gills long, wide anteriorly, inner laminae of inner gills free from visceral mass; palpi short and wide; only outer gills marsupial, when gravid the ovisacs distend but little, giving the conglutinates a lanceolate shape; conglutinates white, discharged whole; glochidium small, spineless, subovate or slightly oblique; soft parts orange or sulphur color.

Shell Characters:--Shell elongated to ovate; beaks moderately high, sculptured by obscurely concentric ridges, not extending out on disk; epidermis brown to yellow, usually rayless; beak cavities moderately deep; hinge well formed; nacre white to pinkish.

As to shell characters this genus resembles both those of Quadrula-particularly those of the pustulosa group-and also the genus Rotundaria. Its marsupial characters show an advance over the genus immediately preceeding. The bright coloration of its nutritive soft parts and of its ova would suggest some affinity with the Fusconaia. Dr. Ortminn points out this genus as a connecting link between the more primitive Unioninae and those of the type of the genus Pleurobema and thus elevated Simpson's section, Plethobasus, to generic rank, since Simpson recognized special characters of the type, aesopus, in shallow beak cavities and outer gills only as marupial. This genus is represented in this state by aesopus, but doubtfully by cooperianus.

\section{Plethobasus cooperianus (Lea).}

\section{("Cumberland Pig-toe," "Warty Pig-toe.")}

Pl. XX, Figs. 57 A. and B.

1834-Unio cooperianus Lea, Tr. Am. Phil. Soc., V., p. 6I, pl. VIII, fig. 2 I.

\section{ANIMAL CHARACTERS.}

NUTRITIVE STRUCTURES:-Branchial opening densely papillose; anal and supra-anal separated by short (even deciduous) connection; gills rather short, inner gills wider, its laminae free from visceral mass; color of soft parts bright orange yellow, for most part.

REPRODUCTIVE STRUCTURES:-Marsupia only occupy outer gills; when gravid swell moderately in center leaving ventral edges sharpened; no glochidia found yet; its ova bright yellow, giving the marsupia a sulphur color. 
SHELI CHARACTERS.

ExTERnal Structures:-Shell orbicular, to egg-shape in general outline, disk tuberculated and transversely nodulous between beaks and ventral margin in front of post-umbonal ridge; latter flattened, dorsal ridge low, faintly costated; beaks low, well placed anteriorly; epidermis light-brown to yellowish, somewhat glossy.

INTERNAL STRUCTURES:-Cardinals tripartite in left valve, rather single in right; interdentum broad, rather doubly gashed in right valve; laterals double in left and single in right valve; mantle line high up from ventral margin; nacre whitish, pinkish (or even bluish) within the mantle line, usually lighter color on extra-mantle line border.

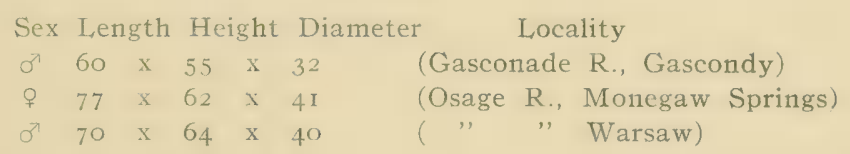

Miscellaneous Remarks:-As this state is out of geographic range of typical cooperianus it is natural that no real type may be found in Missouri. However, the writer upon finding a few shells of the tuberculata (Raf.) type with white and pink nacre submitted one of the latter to Mr. Walker for his consideration. His comments are:- "A very curious and interesting shell. It has the shape of Quadrula tuberculata (Raf.) but the nacre of cooperiana (Lea) and I should call it that, although out of range. I never heard of tuberculata except with purple nacre." A white nacred shell of the same form is considered by Prof. Clark as "rather plump, approaching granifera" but that the nacre "suggests cooperiana." Other Missouri collectors have commented upon this strange departure of $R$. tuberculata and granifera from type. However, if it may be proved that this difference of nacre-color is merely a "fading out" due to chemical reaction of mineral water there would be instead of a true cooperianus in this state a mere local form of a Rotundaria. The real home of this species is in the Tennessee-Cumberland system where Wilson and Clark (I9I4, pp. 44 and 6o) have found it as a summer breeder (a tachytictic species). 


\section{Plethobasus aesopus (Green). ${ }^{1}$}

("Bull Head," "Sheep's Nose," "Clear Profit.")

$$
\text { Pl. XX, Figs. } 56 \mathrm{~A} \text { and } B \text {. }
$$

I827-Unio aesopus Green, Cont. Mac. Lyceum, I, p. 46, fig. 3

1834-Unio cyphia Conrad, New F. W. Shells, p. 68.

I goob--Pleurobema aesopus Simpson, Proc. U. S. Nat. Mus., p. 764.

I912b-Plethobasus aesopus (Green) Ortmann, An. Car. Mus., VIII,

Pp. $260-261$

ANIMAL CHARACTERS.

Nutritrve Structures:--Branchial opening densely set with long and short papillae; anal smooth; supra-anal connected to anal by short mantle attachment; gills long and sharply pointed posteriorly, inner gills wider in front, inner laminae free from visceral mass; palpi short, wide; color of soft parts, peculiar, mostly orange, the foot, adductors and mantle margins being a brighter orange.

REPRODUCTIVE STRUCTURES:-Only outer gills marsupial; ovisacs, when gravid, swell moderately in the center leaving their unswollen distal ends pointed, thus giving their conglutinates narrow, lanceolate shape which are solid, red and discharged in unbroken form; glochidia semicircular, ventral margin obliquely rounded, hinge line long, medium in size, length slightly greater than height $(0.220 \times 0.200 \mathrm{~mm})$.

\section{SHELL CHARACTERS.}

EXTERNAL STRUCTURES:- Shell triangular, rounder before, pointed behind, rather heavy; post-umbonal ridge rounded; umbones high and full, tilted anteriorly, incurved, sculptured by a deep furrow just posterior to tip of each beak and by a few coarse concentric ridges and fine radiating lines; disk sculptured by a row of six or eight, coarse, elongated, undulated or hummocky tubercles extending from beaks to ventral margin with a broad, shallow trough between this tubercled row and the post-ridge; epidermis dark straw to glistening yellowish brown.

INTERNAL STRUCTURES:-Cardinals double in left, single in right; interdentum narrow; laterals double in left only faintly

I According to Rafinesque's evident description of Green's aesopus in his Monograph of 1820 (p. 39) under the name of Obliquaria cyphya ( $U$. cyphia) this species should really bear the name now of Plethobasus cyphius (Raf.) because of priority. 
double in right; umbonal cavity moderately deep; nacre pearly white, irridescent.

\begin{tabular}{|c|c|c|c|c|c|}
\hline Sex & Length & Height & Diameter & Um. ra. & Locality \\
\hline q & $87 x$ & $70 x$ & $47-$ & 0. 170 & (Miss. R., Hannibal) \\
\hline$\sigma^{2}$ & 63 & 45 & 34 & 0.230 & (Des Moines R., Dumas) \\
\hline 우 & 55 & 40 & 32 & 00.180 & (Little Blue, Courtney) \\
\hline & $\mathrm{x}$ & 22 & 20 & 0.210 & (Des Moines R., Dumas) \\
\hline
\end{tabular}

This last measurement of a young shell shows great inflation comparatively. (See Figs. $56 \mathrm{C}$ and D.)

MiscellaneOUS REMARKS:-This species has a general distribution over the Ohio-Cumberland system. It is not uncommon in the Mississippi and Des Moines Rivers, but has only been found in one interior stream, the Little Blue, Kansas City, where it was collected by Mr. Bush and donated to the U. S. National Museum under No. 134,642. Some have found all four gills of aesopus marsupial, but most observations seem to prove that only the outer are used as marsupia. The writer has only observed outer gills as marsupial-even in case of many individuals with sterile gills. He is able to verify Dr. Ortmann's observation of charged marsupia with the "lilac hue." Its accidental host has been found to be "sauger" (S. canadense).

\section{Genus Pleurobema Rafinesque.}

I 820-Pleurobema Rafinesque, Monograph of Bivalve Shells of River Ohio, Ann. Gen. Sci. Phys. Brux., p. 313. I goob-Pleurobema (Raf.) Simpson, Proc. U. S. Nat. Mus., XXII, p. 745 (amended).

\section{(Type, Unio clava Lamarck.)}

AnImal CHARACTERS:-Anal opening with short mantle connection to supra-anal; inner gills much longer, inner laminae free from visceral mass; palpi small very pointed; only outer gills marsupial; ovisacs distend but little when gravid; conglutinates white, narrowly leaf-like or lanceolate, not broken; glochidium small, spineless, subovate.

SHELl, CHARACTERS:- Shell subtrapezoidal, subquadrate, rounded or elongated, upright, or, when oblique, with beaks produced anteriorly; beaks usually rather full and high, sculptured obscurely with concentric ridges not extending out on the disk; disk without sculpture; epidermis olivaceous, reddish brown or even.black, rays more or less present in umbonal region; hinge 
teeth well developed; umbonal cavities moderately deep; nacre generally whitish or red.

MISCELLANEOUS REMARKS:- The above descriptions of the anatomy shows the genus to be identical to that of the genus Plethobasus; but in shell characters there is much difference. It may well be stated in general terms that Pleurobema resembles Quadrula as to its nutritive soft parts and Fusconaia as to external shell structures. However, the Pleurobema shell does not usually possess such a prominent, angular, and inflated umbonal ridge as that of the Fusconaia; neither does it possess the yellowish color of the nutritive anatomy as in the case of Fusconaia. However, the differences among the species of Pleurobema are well marked ecological, as well as morphological, ones; i. e., the heavier, more inflated forms being more as dwellers in the large rivers, and the smaller, more compressed shells being found in the creeks and medium sized rivers. From the two following genera Pleurobema may be easily distinguished by not possessing such an elongate and straight type of shell.

The author of this catalogue wishes to gratefully acknowledge the dedication of a new species of Pleurobema to him under the authorship of Mr. Frierson. The description and figures of this new species (Plen. Utterbackii $F$.) appear here for the first time, and, until more data can be secured, concerning its soft parts in gravid condition, it is placed here tentatively at the close of the list of Pleruobemae.

\section{Pleurobema obliquum (Lamarck).}

("Pig-toe," "White Pig-toe," "Ohio River Pig-toe.") Not figured.

I819-Unio obliqua Lamarck, An. Sans. Vert., VI, p. 72. I 900 - Quadrula obliqua Simpson, Proc. U. S. Nat. Mus., XXII, p. 788. r 9 rab-Pleurobema obliquum, (Lamarck) Ortmann, An. Car. Mus., VIII, p. 264.

ANIMAL Characters:- The soft part of typical obliquum not having been seen by the author, reference is made to the descriptions of the varieties of this species-the anatomy of which is, of course, identical. Wilson and Clark (I9I4, p. 6I) report this species as occasionally bearing ova in all four gills and that the conglutinates have the appearance of cucumber seeds.

SHell CharaCTERS:- Shell trigonal, medium in size, emargi- 
nated post-ventrad with radial furrow in front of flattened postumbonal ridge; beaks swollen, protruding anteriorly, sculptured by concentric ridges; epidermis reddish brown to black with rays originating in umbonal region; cardinals heavy, double in left single in right valve; laterals double in left, more or less double in right valve; nacre white.

MiscellaneOus Remarks:- The writer has been unable to find Pleu. obliquum in typical form anywhere in the state and claim is only made for it through its various forms and through Simpson's report, that it is found in the Mississippi above the mouth of the Missouri River. Surely there is much need of research chiefly with regard to the geographic facts relating to the distribution of this species. Most students of geographic distribution concur in the belief that no true obliquum is found west of the Mississippi and that it is rarely seen north of the Ohio. Its metropolis is that richest of all centers of mussel faunae, the Cumberland River, where Wilson and Clark report it as the most abundant of all the numerous species found there. Briefly stated, obliquum occurs in this state, but with its characteristic radial furrow obliterated and its intergrading forms are very numerous running into each other in every puzzling way.

\section{Pleurobema obliquum plenum (Lea). \\ Not figured.}

1840-Unio plenus Lea, Tr. Am. Phil. Soc., I, p. 286; Tr. Am. Phil.

Soc., VIII, 1843, p. 2 II, pl. XIV, fig. 26.

r $900 \mathrm{~b}-Q u a d r u l a$ plena Simpson, Proc. U. S. Nat. Mus., p. 790.

The writer has not found this species in this state and no description appears here, since neither soft parts nor shells have been seen. However, plenum is listed as a variety for Missouri through the kind report of Mr. Walker that he has it from the James River, near Springfield, and that it bears the same relation to obliquum as does also a variety of coccineum found in the same locality.

\section{Pleurobema obliquum pyramidatum (Lea).}

("Pig-toe," "Pyramid Pig-toe.")

$$
\text { Pl. XX, Figs. } 58 \mathrm{~A} \text { and } B \text {. }
$$

r834-Unio pryramidatus Lea, Tr. Am. Phil. Soc., IV, p. ro9, pl. XVI, fig. 39 .

r goob-Quadrula pyramidata Simpson, Proc. U. S. Nat. Mus., XXII, p. 790 . 
I9i2b-Pleurobema pyramidatum (Lea) Ortmann, An. Car. Mus., VIII, p. 264 .

\section{ANIMAL CHARACTERS.}

NUTRITIVE Structures.:- Branchial opening densely papillose; anal finely papillose; anal and supra-anal very closely connected by mantle edges - sometimes connection deciduous;inner gills broader, longer, inner laminae free from visceral mass; palpi long and thickened; most of soft parts dirty white, mantle edges at branchial openings black.

REPRODUCTIVE STRUCTURES:-Only outer gills marsupial; sterile marsupia with crowded septa, those of male gills very distinct and more separated; no gravid specimens found.

\section{SHELL, CHARACTERS.}

EXTERNAL STRUctures:- Shell obliquely pyramidal or trapezoidal, very solid and heavy anteriorly; disk smooth; beaks very full and projecting anteriorly; rather straight dorsad, greatly curved ventrad, epidermis black.

InTERnal STRUCTURES:- Cardinals single in right, double in left valve; laterals double in left, single in right; scars deeply impressed; beak cavities moderately deep; nacre white, tinged with blue posteriorly-sometimes pinkish.

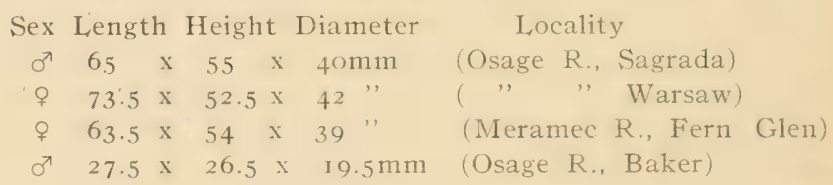

Juvenile shell thick, almost globular, very smooth; beaks full but not protruding anteriorly, sculptured with two or three ridges arranged rather concentrically and breaking into three coarse tubercles at base of post-umbonal ridge; epidermis reddish and leather-like with rays on the anterior half of shell; lateral teeth more inclined to double in right valve than in mature shell; beak cavities very shallow; nacre solid pink.

Miscellaneous Remarks:--This pyramidatum is the same as found in Arkansas and Oklahoma where it is also found unassociated with typical obliquum. The species, Pleu. pyramidatum (Lea) and obliquum (Lam.) are most typically represented in the Tennessee-Cumberland system and the fact of their forms turning up in the South West (i. e., in the region south of the Missouri and 
west of the Mississippi Rivers) is a question worthy of investigation. This heavy, oblique shell is very easy to identify and cannot be very well confused with other Pleurobemae. It has been defined as "an overgrown Pleu. clava."

\section{Pleurobema obliquum catillus (Conrad).}

("Round Pig-toe," "Pink Pig-toe," "Osage Nigger-Head.") Pl. XX, Figs. 62 A and B.

I836-Unio catillus Conrad, Monog. III, p. 30, pl. XIII, fig. 2. 1838-Unio solidus Lea, Tr. Am. Phil. Soc., VI, Pl. V, fig. I3.

ANIMAL, CHARACTERS.

NUTRITIVE STRUCTURES:- Brachial opening rather large, with many papillae; anal smooth, separated from supra-anal by very short mantle connection; gills short and wide, inner the wider, its inner laminae free from visceral mass; palpi short, wide pointed; color of soft parts mostly dingy white.

REPRODUCTIVE STRUCTURES:-Outer gills only maruspial, when gravid brownish, slightly swollen longi-centrad leaving ventral edges tapering somewhat obtusely; conglutinates white, formed like seeds of an immature cucumber; glochidium intermediate for calillus and obliquum as to general form, but larger than either, averaging 0.I $70 \times 0.180 \mathrm{~mm}$.

\section{SHEIL, CHARACTERS.}

External Structures:- Shell trapezoidal to subovate, subglobose, thick , heavy, medium in size, rounded before, obtusely rounded behind; disk smooth no radial furrow; beaks high, full, sculptured by obscure concentric lines; epidermis of red-leather color, rayed anteriorly.

INTERNAL STRUCTURES:-Cardinals single in right, roughly double in left; laterals single in right, double in left valve; scars deeply impressed; beak cavities rather deep; nacre solid pink, rarely white.

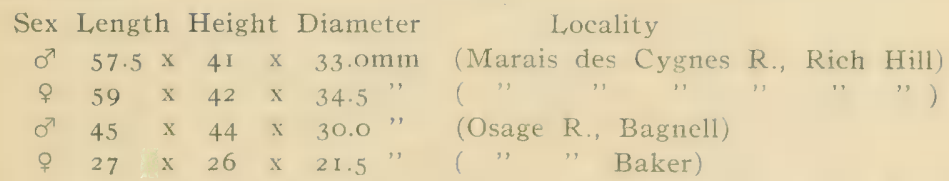

This last measurement shows this juvenile to be sub-globular. Its shell is unusually thick with very shallow beak and branchial 
cavities; hinge teeth usually flattened, very wide and heavy; nacre bright pink; epidermis leathery-red with rays on anterior part of shell ...

MISCELLANEOUS REMARKS:-This form of catillus is the most common of the Pleurobemae in the Osage-Gasconade system and is not found any where else in the state. This "solida" variety is characteristic for its small, solid, subglobular shell, with a more rounded posterior end and less compression for the posterior half than in typical caillus. The radial furrow of the type species (obliquum) is entirely lost. The only difference between this form in the two basins (that of the Osage and Gasconade) is in that of nacre-color - the Osage never varying from pink and the Gasconade shell always with white-nacre. The almost endless inter-gradations for obliquum and catillus seem to be the general rule rather than exception, but here in Central Missouri the variety herein described is predominant. Another form occasionally met with in the Osage and grading in between this subspecies and catillus is one that comes near to fulgidus of Lea, but it would not be listed on account of its rare occurence and doubt whether it should be really separated from this variety, oblicuum catillus. Hundreds of individuals of this form were examined daily throughout the entire month of July, when it was in the height of its breeding season, to find it only gravid (without exception) in its outer gills. It is found to be tachytictic. Perhaps the best idea can be otbained, concerning the difference of the Central Missouri catillus from that of South Missouri, by comparing two average measurements of mature shells given in the following:

$\begin{array}{cccccccc}\text { Sex } & \text { Length Height Diameter } & \text { Locality } \\ 0^{7} & 87 & x & 64 & x & 4 \mathrm{I} & \text { (White R., Hollister)-S. Mo. } \\ 0^{7} & 54 & \mathrm{x} & 44 & \mathrm{x} & 30 & \text { (Osage R., Warsaw)-Cen. Mo. }\end{array}$

In both the radial furrow of typical catillus is effaced. The measurement of the latter removes it so far from the type species that probably a good species might be made out of it.

\section{Pleurobema obliquum coccineum (Conrad).}

("Pink Pig-toe," "Round Pig-toe," "Flat Nigger Head.")

Pl. XX, Figs. 6I A, B, C and D.

1836-Unio coccineus Conrad, Monog. III, p. 29, Pl. XIII, fig. I.

I839-Pleurobema obliquum coccineum (Conrad) Ortmann, Pr. Am.

Am. Phil. Soc, LII, pp. 287-390. 


\section{ANIMAL CHARACTERS.}

NUTRITIVE CHARACTERS:- Branchial opening with two ranks of papillae; anal crowded with fine, short papillae; supra-anal moderately separated from anal; inner gills slightly wider than outer, inner laminae free from visceral mass; palpi thick and long; connected antero-dorsad over half of length; color of soft parts dingy white, for most part.

REPRODUCTIVE STRUCTURES:-Only outer gills marsupial; when gravid marsupia cream colored, somewhat padiform; conglutinates white, leaf-like, solid; glochidium medium, subovate spineless, measures O.I 50 x O. I $55 \mathrm{~mm}$.

\section{SHELI, CHARACTERS.}

ExTERnal, STRUCTUREs:- Shell roundly elliptical, thick and solid anteriorly, moderately thin and compressed for posterior half; post umbonal ridge flattened; beaks not prominent, nor protruding anteriorly, sculptured by concentric corrugations; epidermis reddish brown, rayed anteriorly.

INTERNAL STRUCTURES:- Cardinals double in both valves; laterals single in right, double in left valve; interdentum wide and thin; beak cavities shallow; nacre rose pink.

\begin{tabular}{|c|c|c|c|c|c|c|}
\hline ex & Length & Height & Diamete & & Local & lity \\
\hline$\sigma^{7}$ & $74 x$ & $62 x$ & 34 & (Osage & R., & Warsaw) \\
\hline of & 64 & 54 & $3 \mathrm{I}$ & & & \\
\hline $0^{\pi}$ & 40 & 37 & 22 & " & " & Baker) \\
\hline
\end{tabular}

MiscellaneOUs Remarks:- No juveniles of this form are at hand for description. The writer met with this variety in the Osage. It can be easily distinguished from the more typical coccineum of South Missouri in not possessing such compression for the posterior half of shell, in being more elliptical and heavier. The general outline is that of $O$. ellipsis. It can be separated from Pleu. obliquum catillus by this elliptical shape, but its greater compression (especially posteriorly) and by its thinner, less solid shell. The writer made an interesting discovery while examining a gravid individual of this form afield with a ( $\mathrm{X}_{\text {I2 }}$ ) lens to find its late embryos in rapid rotary motion around one axis. This phenomenon had been observed by the author in Lastena ohiensis. A breeding record of this form shows it to be a summer breeder 


\section{Pleurobema catillus (Conrad).}

("White Pigtoe,-" "Pink Pig-toe," "Solid Pig-toe.") Pl. XX, Figs. $59 A$ and $B$.

I 836-Unio catillus Conrad, Monog. III, p. 30, pl. XIII, fig. 2. I838-Unio solidus Lea, Pr. Am. Phil. Soc., VI; pl. V, fig. I3.

I845-Unio fulgidus Lea, Pr. Am. Phil. Soc., p. 164; Tr. Am. Phil.

Soc., X, I 848 , p. 73 , pl. IV, fig. Io.

I goob-Quadrula solida Simpson, Pr. U. S. Nat. Mus., XXII, P. 789.

ANIMAL CHARACTERS.

Nutritive STRUCTURES:- Branchial opening densely papillose; anal finely papillose; supra-anal closely connected to anal; gills rather long and wide, the inner being wider and longer, inner laminae free from visceral mass; palpi long and connected about two-thirds of their length antero-dorsad, soft parts tanned fleshcolor, yellowish in front of branchial opening, papillae blackish.

REPRODUCTIVE STRUCTURES:--Marsupia only occupying outer gills, ovisacs swollen more centro-lengthwise tapering obtusely at ventral edges; conglutinates leaf-like, compressed white; glochidia semicircular, medium in size, hinge line nearly straight; length and height equal (o.I60 x xo.r6omm.).

\section{SHELL CHARACTERS.}

ExTERnal, STRUCTURES:- Shell subtriangular with obtusely pointed posterior end, very solid and thick through cardinal hinge region, ventral line always more curved than dorsal; disk smooth, post-umbonal ridge flattened; radial furrow in front rather shallow and wide; beaks full, protruding but not beyond anterior end; epidermis reddish brown with decided streaks of green radiating ventrad from umbonal region.

INTERNAL STRUCTURES:- Cardinals heavy, double in both valves; laterals double in right, single in left valve; interdentum broad, short and thick; umbonal cavities shallow; nacre salmon to rosy pink.

\begin{tabular}{ccccccc} 
Sex & \multicolumn{8}{c}{ Length } & Height & Diameter \\
? & 82 & $\mathrm{x}$ & 65 & $\mathrm{x}$ & $4 \mathrm{I}$ \\
\% & 83 & $\mathrm{x}$ & 64 & $\mathrm{x}$ & 40 \\
\% & 80 & $\mathrm{x}$ & 63 & $\mathrm{x}$ & 40
\end{tabular}

Locality

(White R., Hollister)

(Black R., Williamsville)

(White R., Hollister)

Miscellaneous REMARKS:-Conrad's catillus (described as separate from coccineus by the author, but united by Simpson) is 
the solidus of Irea and (in the conventional sense) may be called Pleu. solidum. The latter being antedated, we must use the former name. This species is rather typically represented in the Mississippi for Missouri, the mountain streams of South Missouri and also in the Neosho basin of South West Missouri. No real types are ever found in Central Missouri and not even forms are found in North Missouri. This species is distinguished from Pleu. coccineum by always being rather swollen and having a radial furrow more or less expressed. In this latter character it never reaches the extreme, as seen in obliqunm, of the pinched radial groove terminating in sulcus at the post-ventral margin. Its breeding record shows it to be tachytictic.

\section{Pleurobema coccineum (Conrad).}

("Flat Nigger-Head," "Pink Pig-toe," "Round Pig-toe.") Pl. III, Fig. 6ob; Pl. XX, Fig. 6o $A$ and B.

1836-Unio coccineus Conrad, Monog., III, p. 29, pl. XIII, fig. I.

I goob-Quadrula coccinea Simpson, Proc. U. S. Nat. Mus., XXII, pp. $788-789$.

igizb-Pleurobema coccineum (Conrad) Ortmann, An. Car. Mus., VIII, p. 263 .

ANIMAL CHARACTERS.

NUTRITIVE: STRUCTURES:-Branchial opening densely set with papillae; anal with indistinct crenulations and papillae; mantle connection between anal and supra-anal very close; gills wide, the inner wider and longer, inner laminae free from visceral mass; palpi long, united two-thirds of their length; color of soft parts tannish, mantle edge at siphonal openings black.

REPRODUCTIVE STRUCTURES:-Only outer gills marsupial; when gravid marsupia swell moderately lengthwise in the center; conglutinates white, thin, leaf-shape, discharged whøle; glochidia, suboval, spineless, medium in size measure $0.150 \times 0.150 \mathrm{~mm}$.

\section{SHELL CHARACTERS}

EXTERNal, STRUCTURES:- Shell subelliptical to subquadrate varying with age, flat, very much compressed through post half, greatly inflated (comparatively) anteriorly, dorsal and ventral margins curved about the same; beaks rather full not very well placed to the front, sculptured by concentric lines with two or 
three knotty elevations behind; epidermis marked by darker bands parallel to the growth lines, rayed in young.

INTERNAL STRUCTURES:- Cardinals sharply doubled in both valves; interdentum cut away in the left valve to receive the posterior left cardinal; laterals curved, double in left single in right; umbonal cavity moderately deep; nacre salmon pink to white.

\begin{tabular}{|c|c|c|c|c|}
\hline $\operatorname{Sex}$ & Length & Height & Diameter & Locality \\
\hline 우 & $60 \times$ & to $\mathrm{x}$ & 24 & (White R., Hollister) \\
\hline 8 & 75 & 56 & $3 \mathrm{I}$ & Francis, Greenville) \\
\hline o & 47 & 40 & 22 & (White R., Hollister) \\
\hline
\end{tabular}

Note that the younger shell is more rounded and squarer, has more of an olivaceous epidermis with green rays; umbonal sculpture plainet with three bumps on base of post-ridge; nacre more pearl bluish.

Misceldaneous Remarks:-This species (Pleu. coccineum) is most typically represented in the South and South-west Missouri drainage systems and, while it is not found at all in North Missouri. it is only represented occasionally by mere forms in Central Missouri. It is usually restricted to the smaller streams or to the headwaters of large rivers. Normally, marsupial characters are limited to the outer gills only, although this fact has been denied by some. The writer on one occasion, found this species with all four gills gravid, but in all other cases the outer gills were only found functioning as marsupia. In this species and in some other Pleurobemae, there may be some variabilty in this respect. Coccincum has a short breeding season as determined by the writer's breeding record.

\section{Pleurobema missourense (Marsh). \\ ("Missouri Shell.") \\ Not figured.}

I90I-Pleurobema Missouriensis Marsh, Nautilus, XV, pp. 74-75.

ANIMAL CHARACTERS.

Not having seen the soft parts of this species the writer can offer no description. Although the author of missourense gave no such description, yet the establishment of this species within the genus Pleurobema must have been inferred from these characters. 
SHELL, CHARACTERS.

Through the kindness of Mr. L. S. Frierson the writer was loaned a shell of this rare species from the original lot, described by Mr. Marsh and collected by Mr. Elwood Pleas in the Black River, Popular Bluff, Butler County, Missouri. From the fact that the writer had but one shell before him, he quotes a more complete description from the author than can be given without a series at hand:- "Shell smooth, obliquely triangular, rounded behind, subbiangular behind, moderately thick, very much thicker anteriorly, sicles somewhat flattened, beaks wide, solid, incurved; ligament long, light brown; epidermis light brown, without rays, growth lines numerous, not raised; umbonal slope wide and rather flat; posterior slope wide, flattened with two dark inconspicuous lines running from beaks to posterior margin; beak sculpture unknown; cardinal teeth rather long and solid, depressed, disposed to be double in both valves, corrugate; lateral teeth straight, oblique, corrugate; anterior cicatrices distinct, deep, post cicatrices distinct and well impressed; shell cavity wide and deep; nacre white."

The above description was made from four specimens from young to adult. The young shells are much flatter. The measurement of one of these adult shells is:

Length Width Diameter $66 \times 54 \times 36 \mathrm{~mm}$
Locality

(Black R., Popular Bluff)

MISCELLANEOUS REMARIS:-The author of this species states that he knows of no described species which closely resembles it. From the single specimen in hand it seems to be rather intermediate for $P$. catillus and coccineum; however, it does not possess the radial furrow of the former nor the rounded and compressed posterior half of the latter. The shell of missourense compares well with that of Fusconaia subrotunda and if its soft parts could be obtained for study it might be found to be a form of the latter as, it is often difficult to separate the species of Fusconaia and Pleurobema solely on the basis of shell characters. Even from character of shell, Frierson would group this species under Fusconaia; however, Walker, who considers this a valid species, would class it near P. estabrookianum (Lea). ${ }^{x}$

1 More recently (April, 1915) Mr. Walker determines this species as a Quadrula of the subrotunda groupp (Nautilus XXVIII, P1. V., figs. I and 2). 
Pleurobema Utterbackii Frierson. ${ }^{2}$ New Species.

Pl. V., Figs. I2 $a$ and b; Pl. XX., Figs. $63 A-D$.

ANIMAL CHARACTERS.

“NUTRITIVE STRUCTURES:--Branchial opening with many short antennae; anal very finely crenulated; supra-anal with short but distinct mantle connection to anal; gills long, much pointed posteriorly, inner laminae of inner gills free from visceral mass; palpi wide, short connected about two-thirds of their length antero-dorsad; color of soft parts mostly a light tan, mantle edges at siphonal openings blackish, gills of male and sterile female a darker tan.

"REPRODUCTIVE Structures:- No gravid females found, but sterile ones only present outer gills as marsupial; sterile marsupia wider with more crowded septa than outer gills of male.

\section{SHELL CHARACTERS.}

"ExTERnal STructures:- Shell elliptical, somewhat rhomboidal; evenly truncate above posteriorly; beaks at one fourth of their length; epidermis rough, dark reddish brown, faintly rayed when young; post-slope somewhat biangular and low; beaks rather strongly corrugate.

"INTERNAL STRUCTURES:- Cardinals teeth roughish, inclined to be double in both valves; laterals long, medium size; interdentum narrow; muscle scars well marked and separate; cavity of shell irregular, that of the beaks of medium depth; nacre white, sometimes pinkish, irridescent behind.

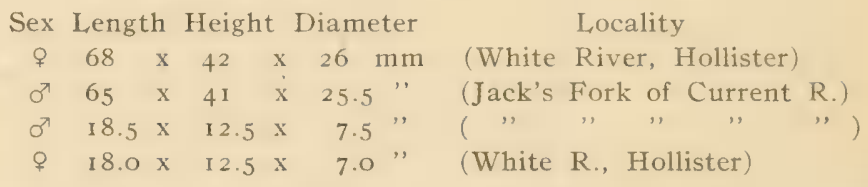

"Two juvenile shells are at hand measuring as above. Epidermis of latter olive-green, of the former, yellowish, both with fine rays; nacre of latter bluish, of the former pinkish; beak sculpture of both roughly corrugate, the three or four coarse ridges curved up posteriorly into hummocks and directing the apices

2 This description of Pleu. Utterbackii is quoted from the M. S. of Mr. L. S. Frierson and is kindly permitted to be published here. 
of the beaks anteriorly; post-ridge inflated but not so sharply angled as in juveniles of Fusconaia, nor so greatly rayed; beak sculpture also different in being more corrugated.

"Miscellaneous Remarks:--The type shell is from the White River, Hollister, Missouri, collected by Mr. Utterback of St. Joseph, Missouri, for whom the species is named. Other specimens are at hand from contiguous territory. This species might possibly be the Pleu. argentea--"pannosa" of C. T. Simpson (indicated, but hardly described, in Proc. Nat. Sci. Phil., r9oo, p. 82). It is to be differentiated from the Eastern Tennessee Pleurobema argenteum (Lea) with difficulty, having its beaks further in front, and higher than in argenteum. Specimens have been received under the heterogeneous names of $L$. ozarkensis (Call), ellipsiformis (Conrad), etc. But a series of about a dozen sent by Mr. Utterback from two or more localities proves the novelty of the form. The appearances of Truncilla and Pleurobema in the mountain streams of Arkansas and Missouri, together with an undescribed Lampsilis very close to biangulatus (Lea), is an interesting and remarkable fact illustrating the power of environmental factors in the family." $r$

Genus Elliptio Rafinesque.

1819-Elliptio Rafinesque, Jour. de Phys. Chim. et His. Nat.

rgoob-Elliptio Simpson, Proc. U. S. Nat. Mus., XXII, p. 700. (as section.)

I9I2b-Elliptio (Raf.) Ortmann, An. Car. Mus., VIII, pp. 265-272.

(Type, Unio [Elliptio] nigra Rafinesque).

Animal Characters:-Branchial and anal openings large with many small papillae; mantle connections between anal and supra-anal short, or moderately so; gills wide, very much round

Being more doubted by some students that $P$. Utterbackii may not be distinct from L. ozarkensis (Call), Mr. Frierson would make this additional description:-

"Our shell is much more tumid at the beaks, or umbones; it is not furrowed on the post slope by the siphonal ridges as in ozarkensis; it is thicker; the anterior muscle scars are distinct, while in ozarkensis they are remarkably confluent. Our shell is not dimorphic, while, if Call has not confused two species in one, his species is considerably so. Our shell differs especially from his figures $\mathrm{I}$ and 3 , less so from fig. 4. Our shell has its whole facies of a heavier sort than ozarkensis. Our cotypes of the latter, from Mr. Call, are more inclined towards a Lampsiline structure, as indeed it is placed by C. T. Simpson." 
ventrad, inner wider but not much longer, inner laminae almost entirely free from visceral mass; palpi medium size; color of soft parts whitish suffused with black; only outer gills marsupial; glochidia small, suboval, spineless.

Shell Characters:--Shell thick, heavy, subsolid, rhomboidovate, longitudinal axis straight, disk smooth, beaks rather low, not near anterior end, sculptured with a few fine concentric ridges angled at the base of the post-umbonal ridge; epidermis brown to black, faintly rayed or rayless; hinge teeth heavy; nacre varying from white to deep purple and violet.

MiscellaneOUS REMARKS:- This genus falls into two groups for this State. The first group is represented by E. nigra (Raf.) which possesses a heavy subquadrate of subtrapzoidal type of shell but with obscure beak sculpture; the second group is represented by E. dilatata (Raf.) which has more of an elongate, gibbosed shell with a beak sculpture of thick, heavy, ridges running parallel to the growth lines. The two other groups of this genus (that is, beadleiamus and complanatus groups) are not found in Missouri, the former being mostly a representative of some gulf states and the latter of the immediate Atlantic drainage. Dr. Ortmann used "Elliptio" as a generic name available for the "American Unio" and employs the original name, "Unio," in the sense of the "European Unio". The soft parts of this genus being practically indentical with those of the genera immediately preceding, the species are indicated entirely on the basis of peculiar shell characters.

\author{
Elliptio nigra Rafinesque. ${ }^{\mathrm{T}}$ \\ ("Elephant's Ear," "Pink.") \\ Pl. XXI, Figs. 64 and $65 \mathrm{~A}$ and $B$. \\ 1820-Unio (Elliptio) nigra Rafinesque, Ann. Gen. Sci. Brux., V, \\ p. 291, pl. LXXX, figs. I-4. \\ 1823-Unio cuneatus Barnes, Am. J1. Sci., VI, p. 263.
}

ANIMAL CHARACTERS.

Nutritrve Structures:-Branchial opening large, well set

I Simpson (I 900 b, p. 706) applied the name "Unio crassidens Lamarck" to E. nigra Raf., but as previously stated under the description of Megalonaias (IV, p. 124) that close student of Lamarckian types, Mr. Bryant Walker, has settled the question by pronouncing $U$. crassidens (I8I9) as the so-called $U$. trapezoides of Lea (1831). 
with numerous short papillae; anal opening with small, but very distinct, papillae; supra-anal briefly but well connected with anal by mantle edges; gills large, broad, pointed both anteriorly and posteriorly, inner broader, only slightly longer, than outer, inner laminae free from visceral mass; palpi moderately large, connected antero-dorsad, edges curved; color of soft parts dirty white with mantle edges at siphonal openings blackish and gills brownish.

REPRODUCTIVE STRUCTURES:-Only outer gills maruspial, when gravid marsupia moderately swollen; conglutinates rather well developed, leaf like, white; glochidia small, suboval, spineless, measures O.I $30 \mathrm{x}$ o. I 5 Omm.

\section{SHELI, CHARACTERS.}

EXTERnal STRUctures:- Shell solid, heavy, subinflated, triangular in outline, post-umbonal ridge prominent; beaks also prominent sculptured by a few rather obscure ridges subparallel to growth lines and swollen at the base of post-ridge; disk more or less smooth; epidermis reddish brown to black often faintly rayed.

INTERNAL STRUctures:-Cardinals double in both valves, heavy; laterals heavy; interdentum long; beak cavities large not very deep; nacre (for Mo. nigra) only a deep purple-not variable.

Sex Length Height Diameter

$\begin{array}{rrrrrrr}\text { O }^{7} & 126 & \mathrm{x} & 80 & \mathrm{x} & 5 \mathrm{Imm} \\ \text { o }^{7} & 91 & \mathrm{x} & 6 \mathrm{I} & \mathrm{x} & 37 & \text { ", } \\ \text { 9 } & \text { II5 } & \mathrm{x} & 66 & \mathrm{x} & 47 & \end{array}$

MISCELLANEOUS REMARKS:- No juveniles, nor young shells found. This is a rare species for the interior of the state being only in the Meramec, outside of the Mississippi River. In the latter, where it is not to say an uncommon shell, it is different from the one found in the Ohio by a variation in nacre-color. The shell may show some variation in size and form in the same river, as Wilson and Clark (1914, p. 42) observed in the Cumberland where it is short and chunky in the headwaters but is heavier and more elongate in the lower stretches. Although nigra is essentially a big river species, yet it is not found in the Osage-the largest Missouri River tributary. Its occurence in the Meramec carries it farther west than recorded before. Its breeding record, although incompletely kept by the writer, shows it to be a tachytictic Unio. 


\section{Elliptio dilatata (Rafinesque). \\ ("Lady Finger," "Spike," "Pistol Grip.") \\ Pl. XXI, Figs. 66 A and B.}

1820-Unio (Elliptio) dilatata Rafinesque Monog. of Bivalves of Ohio,

Ann. Gen. Sci. Phys. Brux.

I823-Unio gibbosus Barnes, Am. JI. Sci., VI, p. 262, pl. XI, fig. I2. I838-Unio arctior Lea, Tr. Am. Phil. Soc., VI, p. 10, pl. IV, fig. Io.

1912b-Elliptio gibbosus (Barnes) Ortmann, An. Car. Mus., VIII. p. 271

\section{ANIMAL, CHARACTERS.}

NUTRITIVE STRUCTURES:--Branchial opening small with many short, blackish papillae; anal with a single row of low papillae; supra-anal separated from anal by short mantle connection; gills long and narrow, inner laminae of inner gills free-in some instances connected about one-fourth of the way anteriorly; palpi short, wide, connected antero-dorsad about two-thirds of their length; color of soft parts soiled grayish with area in front of branchial opening yellowish, pericardianl region invariably reddish brown.

RéPRODUCTIVE STRUCtURES:-Only outer gills are marsupial, marsupia moderately swollen in center when gravid, dark tan; conglutinates narrowly lanceolate, always whitish; glochidia medium size, spineless, hinge line slightly depressed, measure $0.200 \times 0.220 \mathrm{~mm}$.

\section{SHELL CHARACT'TERS.}

External. Structures:- Shell elongate-ellipsoid, gibbose, thick heavy, post-umbonal ridge rounded, inflated; disk smooth; beaks flattened, coarsely sculptured with five or six wavy ridges more pronounced behind; epidermis dark brown to horn or yellowish.

INTERNAL STRuctures:--Cardinals rather low, double in both valves; laterals double in left and inclines to double in right valve; interdentum very long, cut away in right to receive left post-cardinal; umbonal cavities rather shallow; however, deeper in female shell; nacre mostly dark purple, varies from all shades of purple to salmon and white.

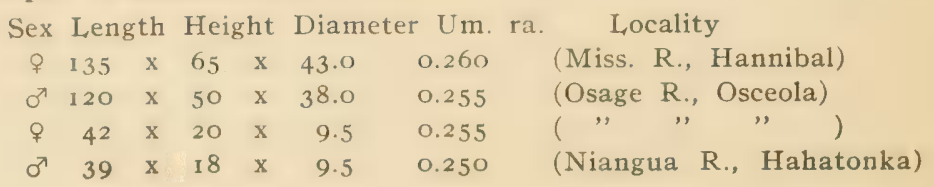


The last two measurements are those of the most adolescent shells at hand but are not young enough to present much additional information than can be obtained from the mature shell.

MISCELLANEOUS REMARKS:-This is one of the species of very wide geographic distribution in United States but is limited in this state for the interior to those streams south of the Missouri River where it is met with in a multitude of forms-especially of the small thin and compressed varieties found in the Ozarkan streams of South Missouri. In the Osage it is found most typically, aside from the Mississippi which produces the best types of all Naiad species. The depauperization of this species in size and form in the mountain streams is evidently due to a swifter current and hence these $d$ warfed forms may be merely a local ecologic race that may not deserve special names; however, two forms in this state occur often enough to require some little attention. Dilatata (Raf.) (=gibbosus (Bar.)) is more confused with Ellipsaria clintonensis (Simpson) than with any other shell. There is a difference, however, in the latter possessing capillary rays, and a broader interdentum, but the best distinction is in the marsupial structures of the latter that presents a folded appearance, when gravid. Simpson did not know the difference from shell structures until he found a gravid clintonensis. While this species is both lacustrine and fluviatile, yet it is never found in any lake or pond in this state. The typical dilatata with white nacre (E. arctior) is simply put down in the synonomy. A form like Conrad's $L$. arcus is sometimes found in the Osage but aside from its shortened dwarfed form of shell it does not even possess enough differentiating characters to give it a varietal place. The writer has found it to be gravid only from June to August; hence tachytictic.

Elliptio dilatata subgibbosa (Lea).

("Little Lady Finger," "Little Spike.") Pl. XXI., Figs. 68 A-D

1857-Unio subgibbosus Lea, Pr. Ac. N. Sci. Phila., IX, p. I69; I858,

J1. Ac. N. Sci. Phila., IV, p. 53, pl. VI, fig. 36.

I868-Unio lazarus Sowerby, Conch, Icon., XVI, pl. I,XVIII, fig. 348.

Animal Characters:-Absolutely identical with those of the parent. No real difference in glochidial characters even.

SHELl Characters:-Moderately small, short, rather inflated, somewhat heavy through the post-ridge, more elliptical, 
not so pointed posteriorly, older shells tending toward post-dorsal trunction, dorsal line arched, ventral rather straight, epidermis brownish; nacre white with pinkish umbonal cavity or solid color.

Sex Length Height Diameter Locality

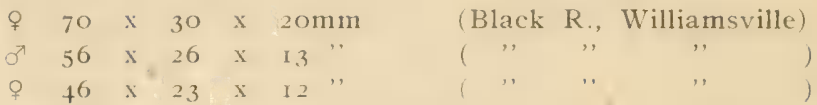

Miscellaneous Remarks:- Specimens collected from streams in Stone County have been sent to the Division of Mollusks in the National Museum where they were identified as subgibbosus. It has also been reported from the streams of Texas and Shannon Counties. It is different from the variety delicatus of Simpson by being somewhat larger, not so thin-shelled, more arched dorsad, more pointed both anteriorly and posteriorly, with rather prominent post-umbonal ridge. 'This variety is rather common in the Black and St. Francis drainage.

Elliptio dilatata delicata (Simpson).

("Little Lady Finger.")
Pl. X.Y., Figs. 68 A-D.

I goob-Unio gibbosus delicatus Simpson, Proc. U. S. Nat. Mus., XXII, p. 704 .

Animal Characters:- Although the anatomy of this variety is smaller than the parent, yet it is precisely identical. Only sterile individuals found; however, only outer gills marsupial.

Shell Characters:- Shell greatly compressed, very small, thin, outline evenly elliptical; epidermis brownish red to olivaceous; hinge teeth rather prominent, thin, nacre purple or copperyrarely white.

Sex Length Height Diameter
$\begin{array}{ccccccc}0^{7} & 55 & \mathrm{x} & 26 & \mathrm{x} & 13 & \text {," } \\ \text { 우 } & 48 & \mathrm{x} & 24 & \mathrm{x} & 1 \mathrm{I} & \text { ", } \\ \sigma^{7} & 43 & \mathrm{x} & 2 \mathrm{I} & \mathrm{x} & 10 & \text { 10 }\end{array}$

Locality

Miscellaneous Remarks:-The writer has in his collection a shell of this subspecies bearing the original label of Mr. Simpson, the author. The dilatata shells of the White River compare well to it. For the same ecologic reason we may account for this small form in the South Missouri drainage as well as for the occurrence of subgibbosa. These two forms are not found north of the Ozark divide, neither is the typical dilatata of Rafinesque found south of it in this State showing the ready response of the parent species to different environmental conditions. 


\section{Genus Uniomerus Conrad.}

1853-Uniomerus Conrad, Proc. Ac. Nat. Sci. Phila, VI, p. 268. (as genus).

r goob-Uniomerus (Conrad) Simpson, Proc. U. S. Nat. Mus., XXII, p. 739 (as section).

\section{(Type, Unio tetralasmus Say).}

Animal Characters:- Both branchial and anal openings papillose and crenulate; supra-anal closely and loosely connected to anal; inner laminae of inner gills free from the visceral mass almost their full length; papli short almost as wide as long; color of soft parts mostly a soiled white, gills brownish; gills only marsupial in outer ones, when gravid rather distended lengthwise in center, tapering at the ventral edge, ovisacs not divided; septa wavy; conglutinates white, sole-shaped; glochidia medium in size, semielliptical, higher than long, hinge line straight.

SHEll Characters: - Shell trapezoidal, rather obtusely pointed behind; disk smooth with the exception of roughened growth lines; beaks low, sculptured with several coarse concentric ridges which curve abruptly upward behind where they are crowded closely together; epidermis rayless, shiny, yellowish to black; cardinals compressed; laterals nearly straight; nacre whitish to bluish.

Miscellaneous Remarks:-Dr. Ortmann elevates Uniomerus from Simpson's treatment of it as section mostly because of the peculiar beak sculpture of its type since this character alone is a great departure from the Elliptio-shell (See Plate xxi, fig. 69). Then, too, the shell is thinner, has more of a rayless, vari-colored polished epidermis and is more elongated with less curved dorsal or ventral line.

\section{Uniomerus tetralasmus (Say) \\ ("Pond Horn Shell.") \\ Pl. XXI, Figs. $69 A$ and $B$.}

r830-Unio tetralasmus Say, Am. Conch., III, pl. XXIII.

I 836-Unio declivis Conrad, Monog., V, p. 45, pl. XXIII, fig. I.

I839-Unio sayi Ward, (in Tappan). Am. J1. Sci., XXXV, p. 268, pl. III, GE. I. 
1912b-Uniomerus tetralasmus (Say) Ortmann, An. Car. Mus., ViII, pp. 272 and 273 .

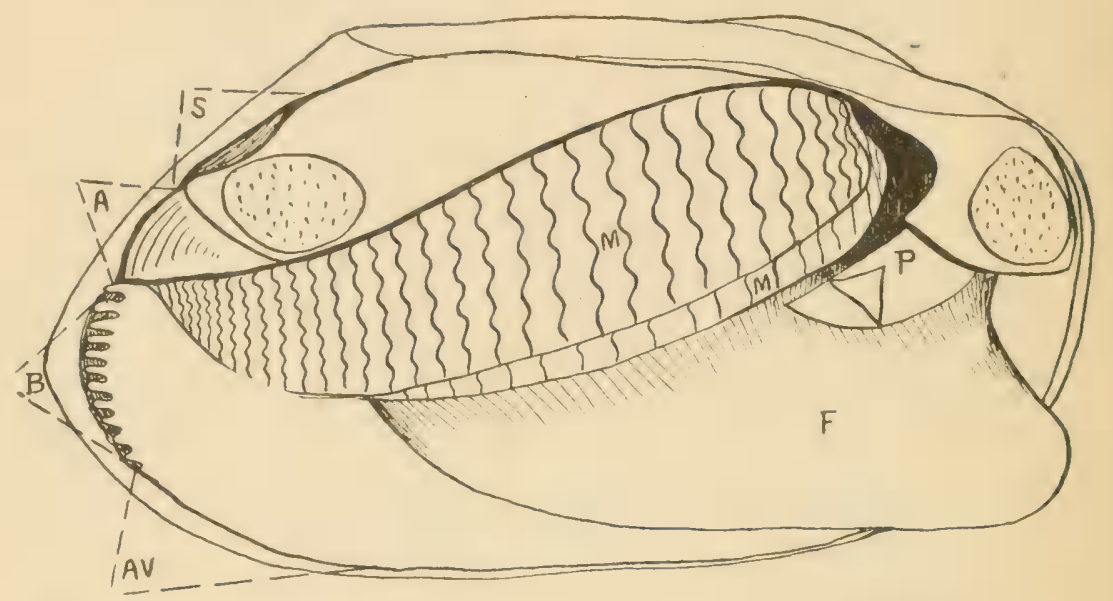

FIG. 4. Uniomerus tetralasma (Say) $\odot$. Diagram of a gravid individual from Lost Cr., Amity, showing animal characters in left valve. Coll. May 3, 19i3. (3/4 nat. size.)

ANIMAL CHARACTERS.

Nutritive Structures:- Branchial opening large, set with numerous papillae; anal finely crenulate on inner edge; supra-anal large extending to dorsal line, closed from anal by a moderate mantle connection; gills about the same width, inner onger, inner laminae free from visceral mass for whole length except for a short distance anteriorly; palpi short and broad, connected only for one-fourth of their length antero-dorsad; color of soft parts, for most parts, a dingy white with mantle edge at siphonal openings blackish, gills brown.

REPRODUCTIVE STRUCTURES:-Marsupia only occupying outer gills, when charged rather padiform, distended at center, but not near the ventral edges, ovisacs simple, undivided; conglutinates also undivided, white, sole-shaped, with regular thin transparent areas arranged cross-wise made by the thickening of the septa at regular intervals; glochidia spatulate, very regular in outline, hinge line short and straight, medium in size measuring $0.160 \times 0.210 \mathrm{~mm}$. 


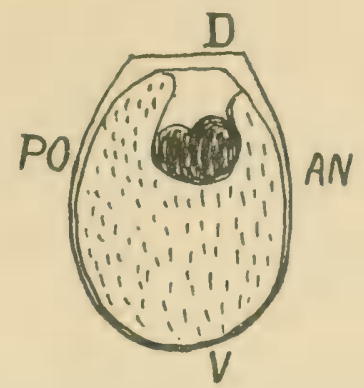

Hig. 5. Mature closed glochidium of $U$. tetralasma. $(\times 87)$

SHELL, CHARAC'TERS.

EXTERnal Structures:- Shell subtrapezoid; post-dorsal ridge rather high, usually obtusely pointed behind, evenly rounded in front; disk smooth; beaks low, drawn well back from anterior end, sculptured with many coarse, concentric, regular ridges curved up very abruptly behind at base of post-umbonal ridge where the ridges are drawn closely together; epidermis light yellow back ground with alternated brown bands running parallel with the growth lines, or nearly all colored in brown horn with polished appearance, almost rayless, sometimes faintly rayed in green on post-umbonal ridge.

INTERNAL STRUCTURES:-Cardinals compressed into rather blade-like processes; laterals delicate but rather prominent; interdentum long, thin; umbonal cavities rather shallow; scars well impressed, nacre light bluish to grayish.

Sex Length Height Diameter Um. ra.

Locality

$\sigma^{7} 95 \times 45 \times 3$ r mm 0.260 (Batterton Pond, Columbia)

q $88 \quad x \quad 44 \quad x \quad 32 \quad " \quad 0.265$ (Lost Creek, Amity)

ๆ $76 \times 42 \times 24.5$ " 0.260 (Mill Creek, Courtney)

q 23 X 12 X 8 " 0.270 (Lost Creek, Amity)

Miscellaneous Remarks:- - . tetralasma is peculiar ecologically, as well as morphologically, in that it can become more quickly established in artificial ponds and lakes than any species. It is naturally lacustrine, but for some unknown cause it is not found in any of our lakes prefering small ponds or quiet creeks where it is found accompanying Anodonta Danielsii, or Eurynia subrostrata. From the fact that the writer has not found any individuals of this species in North Missouri without marsupial characters he is led to believe that it is locally hermaphroditic at 
any rate. The writer, too, has had the good fortune to find its glochidium for the first time and is figured here in this catalogue for the first (See Text fig. 5). Many were taken from Lost Creek of the Grand River drainage, May 3d, and also August 5th, most of which were gravid with glochidia on both occasions. Although winter observations have not as yet been made, still we would judge from these two records that this species is not tachytictic as in most Unioninae. However, like most of the members of this Sub-Family their conglutinates are "aborted" when removed from their natural bed. Simpson speaks of this species as being very susceptible to variation; however, the writer has not noticed any great variability in this State, where its distribution is rather wide, and has not seen any varieties worth listing except comptodon, which has also been reported for Central Missouri by Dr. Britts.

\section{Uniomerus tetralasmus comptodon (Say).}

("Pond Horn Shell.")

Not figured.

1832-Unio comptodon Say, An. Conch., V, pl. XIII.

1832-Unio geometricus Lea, Tr. Am. Phil. Soc., V, p. 28, pl. IV, fig. 10.

Animal, CHaracters are the same as those of the species; so are also its shell characters except in its outline being more rhomboid, its epidermis being more of a dull drab-or uni-color in having more roughened growth lines and a more curved hinge line.

Sex Length Height Diameter

o $80 \times 40 \times 25 \mathrm{~mm}$

P $75 \times 40 \times 24$ "

$963 \times 33 \times 20$ "
Locality

(Grindstone Creek, Maysville)

(Lost Creek, Amity)

MiscellaneOUS REMARKS:- This variety is often found in the same bed with the species from which it is discriminated, as above indicated, by the character of its epidermis. On this superficial basis of epidermis color there are so many intergrades and for this reason it mar be doubted whether this and other recorded varieties are really worthy of theit names. Comptodon was collected by Dr. Britts in Clinton Co., and is now on exhibit in the Division of Mollusks of the U. S. National Museum under the number, I50402. According to Henderson (1907, p.87, pl. ii, figs. $7 \mathrm{a}$ and $7 \mathrm{~b})$ this variety predominates over the main species in Colorado. Dr. Scammon (I906, p. 337) reports it for Neosho County, Kansas. The writer has examined both sterile and gravid 
specimens of this form to find it with the same breeding season as its parent species.

\section{II-SUB-FAMIry Anodontinae Ortmann.}

rgra-Anodontinae Ortmann, An. Car. Mus., IV, p. 336; r9r2b, An. Car. Mus., ViII, pp. 278-300.

AnIMAL Characters:- Mantle edge, antero-ventrad to branchial opening smooth without specialized structures; supraanal antero-dorsad to anal opening usually widely separated; no tendency toward tubular siphonal openings; inner laminae of inner gill generally free from visceral mass; region just anterior to pericardium of watery composition; palpi very large; marsupia-occupyiug two entire outer gills, when gravid pad-like, enormous, tissue thickened at edge to permit transverse distention, two water tubes present on either side of an enclosed central undivided ovisac and facing outer and inner laminae, these laminae very thin and delicate rupturing at the slightest scratch; glochidia usually large, spadiform, generally longer than high, with a spine at each ventral tip; no well-defined conglutinates, but held together in unstable masses by brownish mucus and a tangle of larval threads.

SHELl CHARACTERS:- Shell thin for the most part; disk usually without sculpturing; beaks usually coarsely sculptured with concentric or double-looped ridges; hinge variable, teeth completely lacking, or, if present, rudimentary or peculiar; beak cavities not deep as a rule; sexual dimorphism rarely seen.

MISCELLANEOUS REMARKS:-The members of this group have a long period breeding season (bradytictic) due perhaps to their origin at a time, as Dr. A. E. Ortmann considers, when a possible shortening of the warm season induced them to retain their embryos in the marsupia and discharge the glochidia in the spring; hence, the constant and admirable adaptation of water-tubes for the aeriation of the embryos in the marsupia while being retained for that time. This adaptation elevates this group from the primitive one and places it more among the modern Unionidae. Even on the basis of shell structure, in that the sculpturing, seen on the disk of the shells of the Unioninae, is carried back up to the umbona region where it is almost exclusively confined, there is sufficient evidence for the more modern grouping. 'The inability of the Anodontinae to spread their vavles very wide may accuunt for 
the lack of papillae or other specialized structures (as related to the processes of reproduction) in the region of the branchial openings. Since the species of this group are mostly lacustrine we find them, of course, mostly distributed in the chain of lakes along the Missouri River or in the ponds and small sluggish streams of the interior of the state north of the Missouri River. Compared to the other sub-families, we do not find so many variations in this Sub-Family due to the more constant ecological conditions to which the Anodontine species are remarkably constant-especially as to reproductive structures, in which respect they differ from those of the Lampsilinae; however, the Anodontine species are like the Unionine in the possession of large palpi, whereas those of the Lampsiline species are small. In all probability the larger palpi are for reproductive as well as nutritive purposes. It is interesting to note the recapitulation of the evolution of the whole race of Naiades in some of the individual members of this Sub-Family in that the coarse sculpturing, noted on the disk of juvenile shells, is carried back up to the umbones in mature shells - a progression from the sculptured disk of the more primitive to the smooth disk of the more modern forms of the adult.

Genus, Symphynota Lea.

1829-Symphynota Lea, Tr. Am. Phil. Soc., III, p. 424

(Type, Symphynota compressa Lea)

ANIMAL STRUCTURES:-Branchial opening with short papillae; anal smooth, or finely crenulated; supra-anal larger or smaller than anal, separated by more or less long mantle connection; gills bowed ventrad, septa and water-tubes well developed, inner lamina of inner gills free from visceral mass; marsupium occupying outer gills, pad-like and with secondary water tubes, when charged; glochidia large, spadiform, spined, hinge line undulate; palpi sickle-like united for one-half of their length anterio-dorsad; color of soft parts usually yellowish.

SHELl CHARACTERS:- Shell elliptical to oval, compressed, smooth except for costae sometimes on posterior dorsal ridge; beak sculpture double looped, or sinuate-concentric; cardinals always present; laterals imperfect, or even absent; nacre white or bluish.

MISCELLANEOUS REMARKS:-The shell characters of Symphynota would relate it more closely to the more primitive group than 
any of the Anodontinae on account of its sculpturing on the posterior dorsal ridge, the costae there being somewhat similar to those on the shell of some Amblemae or Quadrulae. Simpson treated this genus under three sub-genera and while the shell characters may greatly differ, yet, the animal characters are so constant and the known species are so few to retain this subgeneric treatment. The type, S. compressa (Lea), is not found in this state-not even in the Mississippi River. Only two species of this genus, S. complanata (Barnes) and costata (Rafinesque), are found in Missouri and they are not widely distributed, the former being confined mostly to the north and the latter to the south part of the state.

\section{Symphynota complanata (Barnes).}

("Heel Spitter," "Hackle Back," "Hatchet Back," "Pan-cake.") Pl. XXII, Figs. $70 A$ and $B$.

1823-Alasmodonta complanata Barnes, Amer. Jour. Sci. and Arts, p. 278 , pl. XIII, fig. 21 .

rgoob-Symphynota complanata (Barnes) Simpson, Proc. U. S. Nat. Mus., XXII, pp. 665-666

ANIMAL CHARACTERS.

NUTRITIVE STRUCTURES:-Branchial opening thickly set with short papillae; anal finely dentate; anus of intestine fringed with three or four papillae; supra-anal large, mantle connection widely separating it from anal; inner gills, wider than outer, inner laminae free except briefly, anteriorly; marsupia occupy entire outer gills, truncated along ventral margin when charged, ovisacs not divided; glochidium very large, spined, hinge line undulate measures $0.310 \times 0.320 \mathrm{~mm}$; most of soft parts yellowish, gills rusty color when gravid.

SHELL CHARACTERS.

EXTERNAL STRUCTURES:-Usually rhomboidal, compressed; alae high, marked with a few upcurved costae; disk smooth; beaks low, sculptured with coarse double-looped ridges; epidermis of young shell reddish with brown rays; of old specimens, brown to black.

INTERNAL STRUCTURES:- Cardinals single in right, double in left valve; laterals faintly double in both valves; umbonal cavity shallow; nacre bluish to satiny white with marginal ribbon of 
lavender; sexual dimorphism not very distinct; the biangular character climed for posterior end of male shell not constant.

\begin{tabular}{|c|c|c|c|c|c|c|c|}
\hline Sex & Len & & $\mathrm{Hei}$ & & Diamete & Un. ra. & Locality \\
\hline q & 170 & $\mathrm{x}$ & 105 & $\mathrm{x}$ & $72 \mathrm{~mm}$ & 0.26 & (Big Mud Lake) \\
\hline$\sigma^{7}$ & 175 & $\mathrm{x}$ & 105 & $\mathrm{x}$ & $55^{\prime \prime}$ & 0.26 & (Platte R.) \\
\hline 우 & 100 & $\mathrm{x}$ & 65 & $\mathrm{x}$ & 29 & 0.20 & $\left(\begin{array}{ll}\prime, & ,\end{array}\right)$ \\
\hline 웅 & 88 & $\mathrm{x}$ & 55 & $\mathrm{x}$ & , & 0.20 & River) \\
\hline
\end{tabular}

The juvenile shell is very flat, a very beautiful wine-colored epidermis marked with bright brown rays: beaks are coarse, marked with the characteristic sculpturing of adult shell except the later bars are down on the upper part of the disk; nacre bluish.

MiscellaneOUS REMARKS:-This species is both fluviatile and lacustrine for this state. Observation of aquarium specimens discharging sperm proves this species a gonochorist-a character this is opposite to the congeneric species and type of this group, compressa Lca. The author has also observed this species to be gravid with glochidia from November to April and, in most instances, has noted early and late embryos mingled with the glochidia in the same individual at the same time. 'This species is very common in North Missouri where it grows very large in the lakes, but is uncommon and dwarfed in Central Missouri and is not found at all in the clear, swift water-streams of South Missouri. Complanata is so distinct from other alated forms that there should be no confusion. It differs from Proptera alata (Say) in that the latter is dimorphic more inflated and has a purple nacre. There is such difference between this species and the type ( $S$. compressa) that it may well deserve its subgeneric name, Pterosygna Raf. (I 8 I3), that Simpson applied.

\section{Symphynota costata (Rafinesque).}

("Fluted Shell," "Squaw Foot," "Sand Mussel.")

$$
\text { Pl. XXII, Figs. } 7 I A-F \text {. }
$$

I820-Alasmidonta costata Rafinesque, Ann. Gen Sci Brux., p. 3 I 8 ,

P1. IXXXII, fig. I5, I6

1823-Alasmidonta rugosa Barnes, Am. Jour. Sci. and Arts, p. 278, pl. XIII, fig. 2 I

I goob-Symphynota costata (Raf), Simpson, Proc. Nat. Mus., XXII, p. 665 .

ANIMAL, CHARACTERS.

NUTRITIVE STRUCTURES:-Anal opening slightly crenulated on inner margin; supra-anal moderately scparated from anal 
inner gills larger, much wider anteriorly, inner lamina free from visceral mass nearly whole length; palpi not large, triangular, united partly anterio-dorsad.

REPRODUCTIVE STRUCTURES:-Marsupium typically Anodontine; glochidium next to largest on record (0.380 x $0.390 \mathrm{~mm}$ ) wider than long, hinge line undulate; soft parts yellow; marsupium, however, rich brown when charged.

SHELL CHARACTERS.

EXTERNAL STRUCTURES:- Shell moderately large, thin to moderately thick, elongate, compressed (especially in male), posterior end bi-angulate, costae on slopes of post-dorsal ridge; disk without sculpturing; umbones peculiarly marked with four coarsely mingled concentric and double-looped bars; epidermis from light horn-color to dark chestnut in old specimens, greenish and rayed in young.

INTERNAL STRUCTURES:-Cardinals single in right, rather tripartite in left valve and interdentum deeply notched; laterals almost obliterated; nacre deep rich cream in umbonal cavity, while lavender and $\mathrm{b}$ ue on pallial border, often whole nacreous surface yellowish or ferruginous due to a distomid infection to which this species is so susceptible.

\section{SHELL, MEASUREMENTS.}

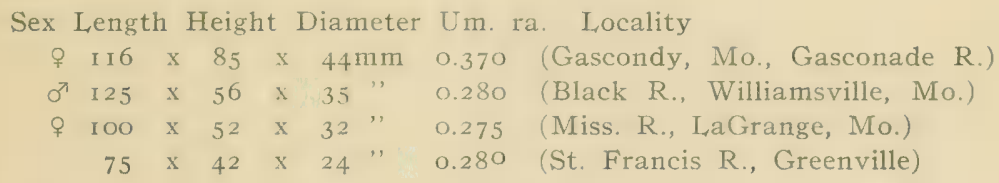

MiscellaneOUS REMARKS:- $S$. costata is found in sandy and muddy situations, is a deep burrower and very active. With this habitat and physiological characters it is strange that it should not be found at all in the sluggish muddy streams of North Missouri and very rarely in Central Missouri where the streams are intermediate for clearness and current. Perhaps this species has the most variegated nacre of any Naiad shell. It is a very common species in the clear and rapid streams of the Ozark Plateau and Center where its shell is duller epidermis than those of the Mississippi. (See Pl. xxii, Figs. 7I A-F.) This compression and plication are due, doubtless, to swifter current and more rocky bottom. 
Its general distribution is for the St. Lawrence drainage and in the Mississippi as far south as Texas. This species can be easily identified and distinguished from other shells by rugose or ribbed structure on the abrupt slopes of the post-dorsal ridge, by its peculiar deep socket just underneath the beak, by its comparatively unridged laterals, but, most of all, by its very characteristic compound beak sculpturing. Because of these very striking shell characters it may deserve the subgeneric treatment of Simpson (190ob p. 664) who gave this species the name Symphynota (Lasmigona) costata (Raf.) Dr. Ortmann and Mr. Frierson think this subgenus, Lasmigona, really deserves generic rank. The author has found the breeding season of costata to extend from August until May with eggs and early embryos for late summer and fall and glochidia for winter and spring.

\section{Genus Arcidens Simpson}

I goob-A Arcidens Simpson, Proc. U. S. Nat. Mus., XXII, p. 661.

(Type Alasmidonta confragosa Say).

ANIMAL CHARACTERS.

Branchial opening densely set with papillae; anal finely serrated; supra-anal long with short mantle connection to anal; inner gills wider in front than outer, inner laminae of inner gills free; palpi large, united two-thirds of their length antero-dorsad; marsupium Anodontine both in external and internal structures; glochidium spined, large, hinge line undulate.

\section{SHELL CHARACTERS.}

Shell somewhat rhomboidal, inflated with rather high full beaks; disk and beaks profusely sculptured, the latter coarsely double-looped, the spinuous tuberculed loopes extending in two diverging rows upon the disk; the former with oblique folds on the post-ventrad part with pustulated expansions along the postumbonal ridge; cardinals present but only traces of laterals are seen; nacre white.

This genus is represented in this state by few individuals and while the only species of this genus, known so far, is both fluviatile and lacustrine it is more often found in quiet creeks, head waters of rivers or in other lacustrine conditions of the rivers, such as the pond-like stretches, sloughs, bayous, etc. 


\section{Arcidens confragosus (Say).}

("Black Pocket-Book," “Black Pocket," "Rock Shell,”

"Rock Pocket-Book.")

Pl. XXII, Figs. $72 A$ and $B$.

1829-Alasmodonta confragosus Say, N. Harm. Dis., II, p. 339.

I888-Margaritana confragosa B. H. Wright, Check List.

1 goob-Arcidens confragosus (Say) Simpson, Proc. U. S. Nat. Mus.

XXII, p. 662 .

ANIMAL CHARACTERS.

NUtritive Structures:-Branchial opening large, with few papillae; anal with tiny papillae on inner edge; supra-anal very long, connected antero-dorsad two-thirds of length; inner gills somewhat wider, inner laminae free from visceral mass; color of gills and palpi brown, all other soft parts soiled white and chamois like.

REPRODUCTIVE STRUCTURES:-Marsupium occupying only outer gills, light brown when sterile, spotted and vertically striated when gravid with early embryos, padiform and dark brown when gravid with ripe glochidia; internal structure of gravid marsupium typically Anodontine; glochidium of specimen from Platte River, Missouri, ( $0.355 \times 0.350 \mathrm{~mm}$.) but possessing same shape, i. e., subtriangular, with undulate hinge line.

SHELI, CHARACTERS.

EXTERNAL STRUCTURES:- Shell subrhomboid, inflated, roughly sculptured with apiculated tubercles in umbonal region, ribbed tubercles on post-umbonal ridge, coarse undulations across postventrad part of disk, slopes of post-dorsal ridge sub-costated; beaks full, high, corrugated; epidermis brown to black in adult, greenish mingled with black in youth.

INTERNAL, STRUCTURES:-Cardinals single in right valve, double in left, the posterior one being long, serrated and placed just under the beak in place of the interdentum; laterals, faint in both vales; scars rather well impressed; umbonal cavity somewhat deep; nacre bluish to white with sky-blue border.

Sex Length Width Diameter Um. ra Locality

\begin{tabular}{|c|c|c|c|c|c|c|c|}
\hline o 103 & $\mathrm{x}$ & 67 & $x$ & 48 & $\mathrm{~mm}$ & 0.30 & (Platte R., Mo.) \\
\hline 102 & $\mathrm{x}$ & 65 & $\mathrm{x}$ & 48 & ", & 0.34 & (L. Contrary, Mo.) \\
\hline 115 & $\mathrm{x}$ & $74 \cdot 5$ & $\mathrm{x}$ & 51.5 & & $0.3 \mathrm{I}$ & (Osage R., Mo.) \\
\hline 4 & $\mathrm{x}$ & 33 & $\mathrm{x}$ & 22.5 & & 0.30 & ") \\
\hline
\end{tabular}


The latter measurement is that of a juvenile taken in a cutoff slough at Warsaw, Mo. Like that of other juveniles of this species, its supra-anal opening is found to be rudimentary - a mere furrow and the gills are specked with minute black pigmented spots. Its shell is more rhomboidal than older; also two rows (five in a row) of ribbed tubercles; more prominent, coarse undulations not so distinct, nor horozontal; more zigzag sculpturing on disk; epidermis more blue-greenish; alae more costated; nacre more irridescent and bluish in beak cavities and with a brighter lavender ribbon around the margins.

Miscellaneous Remarks:--Arc. confragosus is peculiar in its shell structure by its profuse subspiny sculpturing on disk and beaks, its coarse tubercles - especially on umbonal ridge being smooth dorsad and ribbed ventrad and by its postero-cardinal of left valve being long, coarsely serrate and in place of interdentum. In many characters this shell is like that of of Arkansia wheeleri $\mathrm{W}$. and $\mathrm{O}$., but differs in not having well developed laterals and in having more profuse and prominent sculpturing. Confragosus is fond of quiet water and muddy bottoms; thus it is more lacustrine and when fluviatile it is found in creeks or in the head waters and bayous of the large streams. It has a general distribution from western Indiana to Iowa. Simpson reports it as most abundant in Illinois and is also generally found in the Mississippi and in the states adjoining, although it is, by no means, a common shell anywhere. It is a rare species even for North and Central Missouri where there are more lacustrine conditions and is not found at all in South Missouri. The author has found it gravid with active glochidia the latter part of January and with late embryos in the middle of March and great numbers were examined daily during July and August to find it sterile; thus it is bradytictic.

\section{Genus, Lastena Rafinesque.}

1820-Lastena Rafinesque, Ann. Gen. Sci. Phys. Brux., p. 316. 1853-Leptodea (Raf.) Conrad, Pr. Ac. N. Sci. Phila., p. 262.

Animal Characters:-Branchial opening narrow, upcurved, papillose, anal smooth, supra-anal short, widely separated from anal; gills long, tapering posteriorly, outerand inner gills about the same size; inner laminae of inner gills free from visceral mass; palpi subfalcate; color of most exposed soft parts orange, rest of soft parts tan-colored and soiled white; marsupia, rusty color 
when charged, ventral edges distended, water canals present. no specialized structure of mantle edge antero-ventrad to branchial opening; glochidium large, broadly spadiform, spined, hinge line straight.

Shell Characters:- Shell thin, subalated, smooth on disk ; beaks flat, sculptured with four or five rather double-looped ridges; epidermis smooth, polished, rayed in green in the region of the post-umbonal ridge; hinge teeth absent; scars faint, confluent: nacre bluish.

In this state this genus is represented by the two species, Las. ohiensis (Raf.) and suborbiculala (Say) - the latter not having been completely described hitherto. The author has had convenient access to large beds of suborbiculata and has been fortunate in securing specimens gravid with embryos in all stages and with mature glochidia. Neither has the latter been figured nor described before. Because of the fact that the marsupium of suborbiculata is more like that of Arcidens and that of ohiensis closer to Anodonta we would group the latter as more modern; then, too, the hermaphroditism and longer breeding season of ohiensis would also indicate an advance in being able to perpetuate the race.

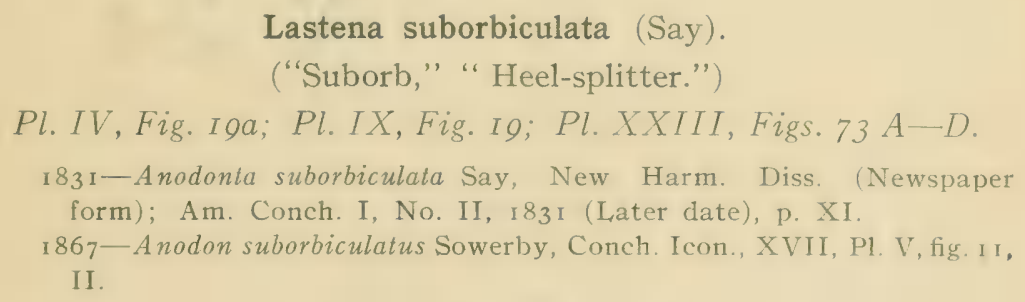

ANIMAL CHARACTERS.

NUTRITIVE STRUCTURES:-Branchial opening comparatively small, upward curved with many fine orange colored papillae; anal also directed upward, smooth with $\mathrm{X}$-shaped yellow markings: supra-anal long, far removed from anal by mantle connections; inner gills wider but very little longer than outer, inner laminae of inner gills not connected to visceral mass; palpi rather long, united antero-dorsad about one-third of their length; pericardinal region very large, watery, pinkish-brown in color; foot, long, thin, deep orange in color, adductors also orange, yellowish retractors and protractors visible through the watery, transparent 
soft parts; gills olivaceous; patch in front of branchial opening light tan or chamois-like; cerebral ganglia bright orange spots external and on top of foot antero-ventrad to palps.

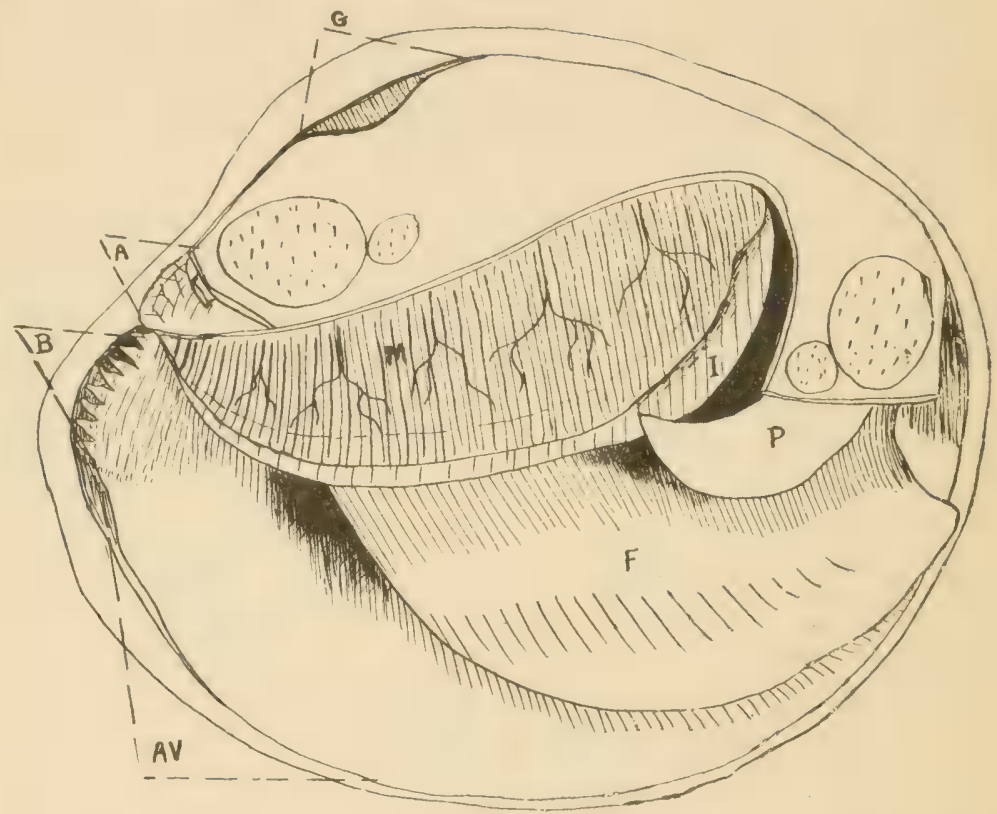

Fici. 6. Lastena suborbiculata (Say) $\subsetneq$. Diagram of a gravid individual from Lake Contrary, St. Joseph, showing animal characters in left valve. ( $3 / 4$ nat. size.)

REPRODUCTIVE STRUCTURES:-Marsupia when sterile, dark tan with crowded septa, tissue of ventral edge thickened, occupying outer gills only; when gravid, russet, with heavy septa more widely separated, distinct, veining enormously pad-like, greatly distended and faintly scalloped ventrad, longitudinal line, near and parallel to the ventral margin, indicating terminations of gill filaments; water canals next to thin laminae on either side of an undivided central ovisac which is closed at the base; no sexual specialization on margin of mantle antero-ventral to branchial opening (thickened edges here have nutritive function of siphonal contraction); glochidium spined, very large, broadly spadiform, hinge line straight, longer than high. $(0.325 \times 0.320 \mathrm{~mm}$.$) glochidial$ shell russet color, bluish spots for the adductors; no conglutinates 
but glochidia are held together in loose masses by brownish mucus and coiled larval threads.

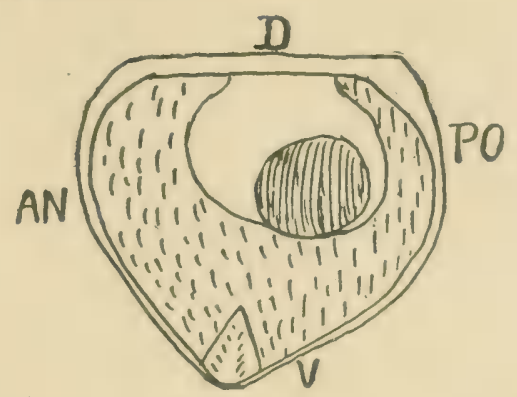

Fir. 7. Mature closed glochidium of L. suborbiculata. (x87.)

SHELL CHARACTERS.

EXTERNAL STRUCTURES:- Shell subround, or suborbicular, thin, compressed, rounded before, bowed ventrad, pointed behind, sulcated post-dorsad, alated, dorsal line from apex of wing to anterior end, straight and at an angle of 45 degrees; disk smooth; beaks flattened, sculptured with coarse wavy bars, intermediate ones bow-shaped and arched toward apex, latter double-apiculated 'with smaller tubercles just ventrad, later bars subundulate on upper disk and running more or less parallel with growth lines; epidermis polished, straw colored in young. light brown-horn in old; rayed all over with green capillary lines and one or two broad bluish-green bands from beak to extreme posterior point of shell; growth lines raised and undulated showing through on nacreous surface.

INTERNAL STRUCTURES:-Cardinals and laterals entirely lacking; anterior adductor muscle scars two comparatively deep elongated triangular areas, progressive impressions most distinct; other cicatrices very faint, confluent, mantle line broken by minute ridges; umbonal cavity shallow; nacre whitish, bluish or coppery, irridescent.

Sex Length With Diameter Um. ra. Locality

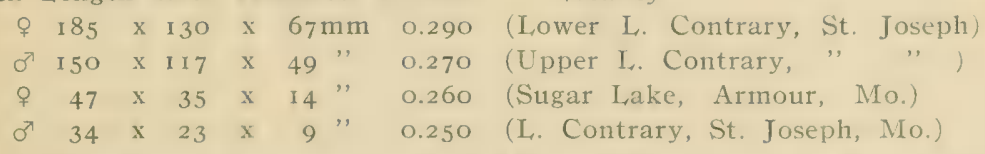

The latter measurement is that of the smallest juvenile of this species out of a collection of a little over a hundred of these delicate shells. This one was without byssi and doubt is expressed 
as to whether any of the lacustrine Anodontinae are byssiferous, since the quiet water of the lake would perhaps make these threads unnecessary. The specimen above measured has a very thin, papery shell, almost transparent; ground-glass-like inside view, yellow-horn color outside appearance, beautifully rayed in green especially on post-umbonal slope. In life the heart beat could be detected through the thin shell and the alimentary tract traced; the heart beat 28 times per minute, regular but feeble, while that of an adult was only twenty-two times per minute, irregular but strong.

Miscellaneous Remarks:- This species is especially characteristic for the shape of its shell being not variable, but somewhat like an ordinary dinner plate as to form and size; also the very distinct progressive impressions are somewhat characteristic. Its shell is the largest in outline of any of the Narades, although it is not heavy,--even with its soft parts. Its meat has been tested through Domestic Science to be of great food value. Except for greater inflation, in case of the female shell, no real sex dimorphism can be detected. The author has noted more of a greenish granular appearance for the outer gills of the male. The fact that the writer has discovered, from aquarium observations, individuals discharging sperm on two occasions disproves that it is hermaphroditic. For reference one of these males was killed and preserved in the act of discharging its sperm.

This discharge of sperm made the water milky and when examined by a high-power $\left(\mathrm{X}_{385}\right)$ lens it was observed to be the flagellated sperm in cysts rolling about through the water like the colonial Protozoa. Then, too, the simple test that not all individuals have the crowded septa of the outer gills disproves that all have marsupial characters of these gills. Thus hermaphroditism can not be applied to this genus Lastena, as a general character, if this species is to remain with it. This is the first description of the animal of this species that has been drawn up and the author has been the first to report its mature glochidium which in general shape is about like that of A. grandis having about the same shape with the same straight hinge line, but being smaller. The glochidium is very active, having been observed to snap fifteen times per minute. The habitat of suborbiculata is that of black sand and mud bottoms in deep quict water, is a rare shell in general distribution, but, when found, is abundant. Simpson reports it for Nebraska, Iowa, 
Illinois, and Louisiana. Dr. W. S. Strode reports it as very large typical and abundant in Illinois and the fact of its southern range to Louisiana (as reported by Mr. Frierson) is interesting. Although this mussel is very susceptible to the attacks of the parasite, Atax, its shell is hardly ever distorted for that reason; neither is the shell hardly ever eroded or injured by chemical reaction. An accurate breeding record, kept by the writer, shows it to be a long period breeder, but not so long or continuous as that of Las. ohiensis (=imbecillis.) It is found to be with early and late embryos from September to December, and mature and immature glochidia from December to March, but sterile for the remaining months.

Lastena ohiensis Rafinesque.

\author{
("Paper Pond Shell.") \\ Pl. XXIII, Figs. $74 A$ and B.
}

1820-Lastena ohiensis Rafinesque, Ann. Gen. Sci. Brux., V, p. 3 I6. I829-A nodonta imbecillis Say, N. Narm. Diss. II, p. 355.

ANIMAL CHARACTERS.

NuTritive STRUCTURES:--Branchial opening with yellowish tentacles pointed upward, anal narrow, smooth supra-anal small, far removed from anal; outer and inner gills about the same size, inner laminae free from visceral mass; palpi long, sickle-shaped, united antero-dorsad about two-thirds of its length; foot, adductors branchial opening region orange color, rest of soft parts tannish or dirty white.

REPRODUCTIVE STRUCTURES:-Marsupia rusty brown and pad-like with water-tubes and undivided ovisács when gravid; mantle edge antero-ventrad smooth without sexual specialization; glochidium golden russet, broadly spadiform, spined, hingle line straight, longer than high (0.310 x $0.290 \mathrm{~mm}$.); no conglutinates; glochidia enmeshed in a tangle of larval threads.

SHELL CHARACTERS.

EXTERnal Structures:- Shell subelliptical and subcylindrical, thin, inflated, slightly alated; disk smooth, shinning; beaks flush with dorsal line sculptured with coarse looped bars, later ones being finely tuberculated, apex doubly apiculated; epidermis grass green, to olive with post umbonal slope marked by two or three bluish parallel rays.

INTERNAL STRUCTURES:- Teeth entirely lacking; muscle 
scars faintly impressed, confluent; branchial cavities large; nacre pearl blue.

Sex Length Height Diameter Um.ra.

ㅇ $98 \times 40 \times 39 \mathrm{~mm} \times 0.320$ (Mud Lake, Kenmoor, Mo.)

$0^{7} 63 \times 34 \times 31$ " $\quad x \quad 0.340$ (Lower Lake, St. Joseph, Mo.)

우 $6 \mathrm{I} \quad \mathrm{x} \quad 28$ x 35 " $\mathrm{x} 0.360$ (Spring Lake, Monegaw Spgs. Mo.)

$0^{7} 25 \times 10 \times 2$ " 250.330 (Mud Lake, Halls, Mo.)

'The latter juveniles of the last measurement has the least diameter that the author has ever examined. It was discovered in very active locomotion in shallow water along the lake beach and wonder was expressed how such a compressed shell could contain enough musculature for such vitality. Its beak sculpture presents two apiculations at the apex of the umbone surrounded by rather wavy or looped bars extending low to the disk. So thin were the valves and soft parts that when studied with the lens the heart action could be observed through the shell when held up to the light. 'The characteristic green rays, extending parallel along the post umbonal ridge area, are more pronounced here than in the adult shell.

Miscellaneous REMARKS:- The vitality of ohiensis of the embryos in the active rotary motion is seldom seen in the Naiades. This motion was observed to take place around one axis from right to left in very rapid rotation. Mr. I. S. Frierson states that he has seen the glochidium taken from the mother and so sufficiently metamorphosed as to turn its shell up from a glass slide through an angle of 180 degrees. ${ }^{*}$ The fact, too, of this species being normally hermaphoroditic gives it a character possessed by few Naiades. 'The adult shell is also so peculiar that there is no need for confusion in making identification. The nearest to it in general form and color is Lasmonos leptodon, yet it can be easily distinguished from this distant relative by the beak sculpture and hinge. Its suppressed umbones flush with the dorsal line, making "beakless beaks," are perhaps its recognition marks. It is a lover of quiet, shallow water and muddy bottoms and for this reason is distinctly lacustrine. The author has found it in

* Dr. A. D. Howard has lately discovered Lastena ohiensis as also nonparasitic in its glochidial life and accounts for its distribution through the buoyancy of its juvenile shell as a compsensatory provision for the loss of the usual means of distribution by fishes. (Science, N. S., XL, pp. 353355. Sept. 4, 1914). 
the main body of rivers but in such cases there was always some slough, bayou, or lake near by from which its light shell may have been carried over in time of flood. This species has a general distribution over the Mississippi and St. Lawrence basins. In this state it is confined to the lake district of N. W. Missouri, and in the lacustrine conditions of Central and South West Missouri. Its breeding season seems to be continuous for the year, or at least there is a very short interim of sterility. The author examined it nearly every month of the year to find it gravid and that, for the most part, with mature (active) glochidia. The "eye spots," mentioned by Simpson, as characteristic marks on the mantle edge at the branchial opening, have not been observed by the writer. Because of its Anodonta-like marsupia, but more on account of its physiological characters, in being a hermaphrodite with an almost continuous breeding season, this species should be assigned to a little higher position in the genus than suborbiculata. The fact that Rafinesque used ohiensis as the type for his genus Lastena and also because of such departure in anatomical and conchological features from those of the genus Anodonta for ohiensis and its nearest ally, suborbiculata, this genus Lastena should now be employed for these two species of this State.

\section{Genus, Anodonta Lamarck.}

1799-Anodonta Lamarck, Prodrome Class. Coq., p. 87.

I 8 I 7 -Anodontes Cuvier, Regne. An., II, p. 472.

\section{(Type, Mytilus cygneus Linnaeus).}

Animal Characters:-Branchial opening with yellowish papillae, anal smooth to slightly crennulated; supra-anal generally small, removed from anal by long mantle connection; inner lamina of inner gills free from one-half to entire length; palpi usually long and large; only outer gills marsupial, when marsupia are gravid, ventral edge distends and secondary water-tubes appear, ovisacs simple, undivided, dark brown when gravid with mature glochidia no conglutinates formed; glochidia large, brownish, spined, spadiform.

Shell Characters:- Shell elliptical, inflated, thin, slightly alated; disk smooth; beaks full high, sculpturing distinct, doublelooped, angled upward centrally; epidermis polished, brightly colored; hinge teeth completely lacking.

No genus is so susceptible to so many mutations, yet it is 
really only represented in this state by $A$. grandis and Danielsii. However, the latter, even may only be a creek form of grandis. A few other species, reported for this state under this genus, have doubtless received their names without deserving them and hence will only receive passing notice. The members of this group being lacustrine, they are limited more to the lake distinct in Northwest Missouri, to that portion of Central Missouri where lakes, ponds and sloughs abound, and to the Mississippi Lowlands of Southeast Missouri. Very few Anodontae are reported for South Missouri where lacustrine conditions are rare.

Anodonta grandis Say.

("Floater.")

Pl. VII, Fig. 15; Pl. XYIII, Figs. $75 A$ and B.

I829-A nodonta grandis Say, N. Harm. Diss., II., p. 341 .

1852-Anodonta opaca Lea, Rr. Am. Phil. Soc., X, p. 285, pl. XXV, fig. 46 .

ANIMAL CHARACTERS.

NUTRITIVE STRUCTURES:--Branchial opening with rather long yellowish papillae; anal directed upward, smooth; supraanal separated from anal by long mantle connection, small, almost closed in some instances; inner gills wider and longer, inner laminae entirely free from visceral moss; palpi very large united anterodorsad about one-half of their length; anterior portion of pericardial region thick and watery; color of gills usually dark brown, mantle edge at siphonal openings blackish, palpi cream to purplish, remaining parts mostly tan or soiled white.

REPRODUCTIVE STRUCTURES:--Marsupium occupying outer gills only, when gravid pad-like, distended at ventral edge, seconary water canals present, undivided ovisacs in center, laminae very delicate rupturing at slight touch; sterile marsupia thickened at edges to allow for distention; glochidium largest on record, (o.400 x $0.395 \mathrm{~mm}$.), spadiform, spined, russet color, straight hinge line; no conglutinates, glochidia held in loose mosses by brownish mucus and tangles of crinkled larval threads.

SHELL CHARACTERS.

EXTERnAL Structures:- Shell subovate, large, greatly inflated especially in umbonal region, subalated, subsolid anteriorly, 
rounded before, pointed behind; disk unsculptured; beaks full, apices recurved, sculptured by several coarse irregular doublelooped ridges the loops being more or less nodulous; epidermis glossy, varied in color from brown-horn to green, growth lines rather undulated.

INTERNAL STRUCTURES:- Hinge teeth completely lacking; muscle scars not well impressed, progressive impressions most evident; umbonal cavities large and deep especially in female shell; nacre variable naturally from whitish, or bluish to coppery or even to salmon chocolate or brick-red, irridescent. Probably the latter colors are more pathologic than normal.

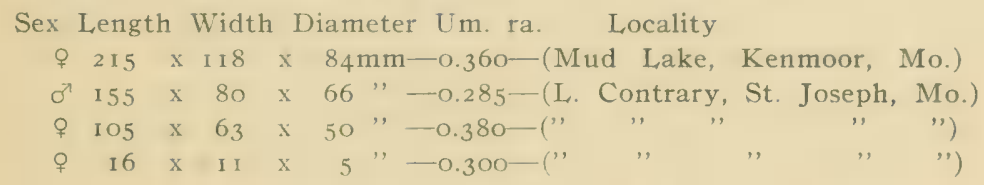

Several of these juvenile shells of $A$. grandis (the latter measurement being the smallest) were found in one spot on the west beach of Lake Contrary. These juvenile shells were indentified by Dr. A. D. Howard of the U. S. Fisheries, Biological Station, Fairport, Iowa, where experimental rearing of these species from the glochidium has been made and a series of shells have been obtained all the way from its larval to its independent and mature life. At the end of the fifth year it is identical with that of Lea's opaca. The juvenile of the above measurement is very thin and papery almost transparent, is coarsely sculptured even on its disk-the bars being decidedly double-looped with a re-entering angle between the nodulous loops terminating at the tip of the umbone in two minute conical tubercles. It is especially to be noted that single laterals are faintly seen in each valve of this juvenile shell; also double right and single left cardinals may be seen with a (x12) lens.

-Miscellaneous Remarks:--Perhaps no species of Naiades is so polymorphic as $A$. grandis. Probably these mutations are only zöogeographical expressions of its shell which seems to respond most readily to every change in ecological relations. Its pliable juvenile shell may be so shaped by its environment as to give rise to its many varietal forms. By choice grandis is lacustrine under which conditions its shell is typically inflated, shorter and thinner; if subjected even to the mild fluviatile action of a creek 
it becomes thicker and more compressed and more elongated. Its changes are so great at different ages that many names have given it for this reason; doubtless A. opaca, stewartiana, leonensis, etc., are mere synonyms for this reason. Because of parasitism, pounding of the surf, etc., this species is found in many pathologic forms in our lakes; a common one being that of a shell deeply sulcated at the post-ventral point and another with its shell extremely truncated post-dorsad. To the latter $A$. footiana and perhaps A.dakotana, may be referred. A. salmonia may also be assigned to a grandis-form that has a blistered salmon-colored nacre due to a distomid infection. A. grandis has a general distribution all over the Mississippi drainage, also in the St. Lawrence drainage and that of the Red River of the North. In this State it is found in most of its forms in the chain of lakes, "cutoffs," sloughs and bayous along the Missouri River and quiet, muddy creeks of the north and central portions. It has only been rarely reported for the Ozark Center or Plateau. The soft parts of the half-grown grandis (A. opaca) are found by Domestic Science tests to be very edible. A strict breeding record, kept by the author, shows this species to be gravid with glochidia from December until March and sterile from this month on to September; therefore it is a long period breeder and its larvae are the largest and most-active known, contracting from ten to fifteen times per minute. The species which follow in description under this genus are only believed to be as mere forms of grandis and only receive separate notice because of their original report for this state, under these names, - and are so grouped for sake of conformity to other writers.

Anodonta dakotana Frierson.

("Dakota Shell," "Short Nose.")

Pl. XXIV, Figs. $77 A$ and $B$.

1914-Anodonta dakota Frierson MS

Animar, Characters:-With the exception of shorter, wider gills, due to the shape of shell, the nutritive and reproductive structures of this species (if it be one) are identical with those of A. grandis. Its marsupium, in gravidity, is exactly the same; so are its glochidia in form and size $(0.400 \times 0.395 \mathrm{~mm}$.).

Shell Characters:- Shell subrhomboidal, short, obese, abruptly truncated behind and, with the exception of not being 
flat on the center of the disc, it may not be the typical dakota of Frierson. In other respects the shell structures are identical with those of $A$. grandis.

Sex Length Width Diameter

Locality

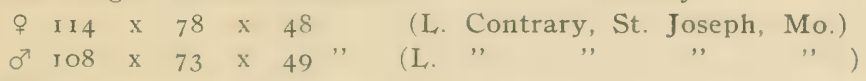

MiscellaneOUS REMARKS:-This truncated form may only be the result of a local reaction on grandis as it is not often found in very quiet water but in the more disturbed water near the shore, yet its occurrence in such a constant shell-form is so common in our Missouri lakes that it would be safe to assign it to the definite species herein referred, or at least its subspecies. Dr. Ortmann thinks this form may bear the same relation to our western lakes as A. benedictis (a form of grandis-footiana) does to Lake Erie where it is grown close to the shore in the surf.

Anodonta corpulenta Cooper.

("Big Floater," "Slop Bucket.")

Not figured.

I834-Anodonta corpulenta Cooper, App. to Narrative, Exp. Miss. R to St. L., p. 154.-B. W. Wright Check List, 1888.

Animal Characters:- The nutritive and reproductive structures are identical with those of A. grandis; however, its glochidium is different in shape and size, having an irregular, undulate, hinge line with length and depth equal (0.350 x $0.350 \mathrm{~mm}$.).

Sheil Characters:- With the exception of a shorter, wider, more inflated shell and also of more recurved beaks the shell is the same as that of $A$. grandis.

Miscellaneous Remarks:- Some students of Naiades are inclined to call corpulenta an "overgrown grandis." However, its smaller, but most of all, its differently formed glochidium would separate it from grandis since nothing is so constant as glochidial characters. This form is reported as rather common in the sloughs and lakes along the Mississippi in this state; yet it is not found in the lakes of North-west Missouri. Simpson reports it for the Missouri river (rgoob, p. 646) but is not specific about the locality and states that it has a general distribution for the upper Mississippi River east to Indiana and south to Texas where it may be replaced by $A$. stewartiana. Dr. Surber (1913, p. 106, P1. XXIX, fig. I) has found this species to be an occasional fin-parasite upon 
the same host as that for Fusconaia ebena. Its breeding season is the same as that of $A$. grandis.

\author{
Anodonta Danielsii Lea. \\ ("Daniel's Shell.") \\ Pl. XXIV, Figs. $76 \mathrm{~A}$ and $B$.
}

1858-Anodonta danielsii Lea, Proc. Ac. N. Sci. Phila., III, p. 113;

J1. Ac. N. Sci. Phila., I860, IV, p. 365, P1. LXIII, fig. I90.

I859-Anodonta texasensis Lea, Proc. Ac. N. Sci. Phila; p. II3; Jl.

Ac. N. Sci. Phila. 1860 , p. 366, Pl. LXIII, fig. I9r.

Animal Characters:-Branchial opening wide, densely papillose, anal smooth, supra-anal small, far removed from anal by mantle connection; palpi large, united two-third of their length antero-dorsad; inner laminae of inner gills free from visceral sac.

REPRODUCTIVE CHARACTERS:-Marsupia occupying outer gills, when charged pad-like, ventral edge blunt, greenish posteriorly, rest rusty brown; glochidia not found so far.

SHELL CHARACTERS.

External Structures:- Shell subelliptical, moderately large, subsolid; disk smooth; beaks rather low, sculptured with coarse double loops radiating from the beaks; epidermis dark horn with areas of green between the dark lines of growth.

INTERNAL STRUCTURES:-No teeth; scars faint; umbonal cavity shallow; nacre pearly-blue to light salmon with bluish border.

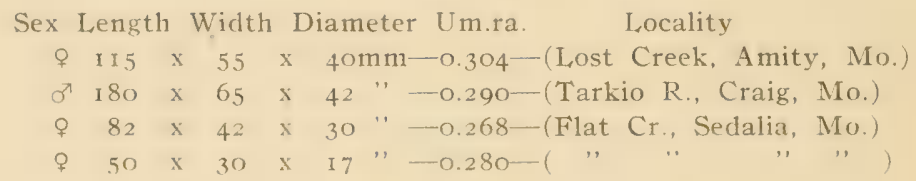

The last measurement is that of the smallest and youngest Danielsii that has been obtained. It is a beautiful grass-green shell with a single brown band running parallel with the growth lines. Its beak sculpture is the most distinct of any in the writer's collection and is typically Anodontine. Its soft parts are tannish and the outer gills are plainly marsupial.

MiscellanEOUS REMARKS:-This species is a rather common creek form of grandis. It is especially characterized by a more elongated, compressed and smaller shell. As a rule its shell is also thicker and its epidermis takes on more of a greenish color 
with alternate brownish bands. It is striking to note such a close likeness of its shell to that of Uniomerus tetralasma with which it often accompanied in our muddy, sluggish creeks of North Missouri. Of course it can be distinguished from the latter by its very different umbonal sculpturing and by the absence of teeth. Mr. Bryant Walker very kindly identified this species and stated that the shells were more compressed than those from Oklahoma and Kansas and that he had practically the same shells in his collection from South-west Missouri under the names of Anodonta texasensis Lea, but, being a doubtful species, it may equal to Danielsii, or at any rate the latter has priority. Hence, we are placing A.texasensis in the synonomy of this species. Simpson treats texasensis as very near Danielsii and, although he had only a young, broken shell from Lea's collection for study, yet he is very doubtful about the validity of it as a species and thinks it may only be a mere variety of grandis after all.

\section{Anodonta Bealei Lea. \\ ("Beale's Shell.") \\ Not figured.}

I863-Anodonta bealei Lea, Pr. Ac. N. Sci. Phila., VII, p. I94; J1. Ac. N. Sci. Phila., VI, I866, p. 26, Pl. IX, fig. 25.

The writer, not having seen this species, would infer from Lea's figure that it is the same as A. Danielsii, or near. Through the kindness of Dr. Dall, curator of the Divison of Mollusks for the U. S. National Museum, report was made that Dr. John H. Britts, (deceased), a well-known conchologist of this state, collected shells of A. Bealei from the Grand River, Henry County, Missouri and sent them to the National Museum where they are now deposited under the numbers, I50,392 and I50,391. Simpson states the geographic distribution of this species from Texas to Kansas.

\section{Genus, Anodontoides Simpson.}

1898a-Anodontopsis Simpson (in Baker), Tr. St. Louis Ac. Sci., VIII, p. 76 .

1898b-Anodontoides Simpson (in Baker), Moll. Chicago, p. 72

ANIMAL CHARACTERS.

An mal with marsupium occupying the outer and sometimes the fcur leaves of the branchiae, ovules more numerous in the 
outer, the whole pad-like; gills large, inner semi-circular, free from the abdominal sac or united with it; branchial opening large with many small, papillae; anal with well developed papillae." (Simpson.

\section{SHELL, CHARACTERS.}

EXTERnal, Structures:- Shell sub-elliptical inflated, thin; disk smooth; beaks somewhat full with distinct beak sculpture consisting of concentric ridges upcurved behind; epidermis dark brown, polished, sometimes rayed; hinge-teeth lacking, or merest rudiments, scars shallow; nacre bluish white.

Dr. Ortmann considers this genus pratically an Anodon with concentric beak sculpture and as a good connecting link for Anodonta and Alasmidonta. The only species of this genus, ferussacianus, is only represented along the Mississippi of this state where it is a rare shell. Unfortunately the soft parts, have not been secured for description. The glochidia of the species and subspecies (subcylindricus) of this genus have the same shape and measure 0.32 and $0.33 \mathrm{~mm}$. respectively - height and length being equal.

Anodontoides ferussacianus (Lea).

("Ferussac's Shell.")

Pl. III, Figs, $7 a-8 a$.

1834-Anodonta ferussaciana Lea, Tr. Am. Phil. Soc. V, p. 45, pl. VI, fig. 15 .

1898-Anodontoides ferussacianus (Lea) Baker, Moll. Chicago,

Pt. I, p. 72, pl. III, fig. 6; V, fig. 2

ANIMAL CHARACTERS.

According to Dr. Ortmann (1912b, p. 294) the anatomy of this species is essentially that of Anodonta and differs only in the shorter mantle connection between the anal and supra-anal and in the anal being distinctly papillose. The glochidia (Ortmann I $8 \mathrm{IIb}$, pl. 89, fig. I2) are described as rather small (0.320 $\times 0.320$ $\mathrm{mm}$.) for the subfamily, subtriangular and spined.

SHELL CHARACTERS.

ExTERnal Structures:- Shell subelliptical, thin, inflated, medium in size, post-umbonal ridge rather faint; compressed with distinct, regular, concentric ridges bent up behind and apiculated at the apices; epidermis brownish to bluish-green, some- 
times rayed; hinge teeth rudimentray, usually lacking; muscle scars faint, confluent; nacre whitish or pearl blue.

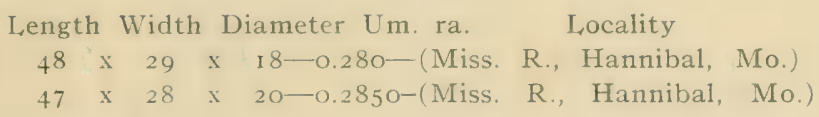

MIScellaAneous Remarks:-Probably this species can be best characterized by its medium sized, sub-elliptical shell with its concentric, umbonal sculpturing, polished olive-green or brownish epidermis and slightly incurved hinge in front of beaks. A. ferussacianus is only known to occur for a certainty in the Mississippi of this state. Old, eroded shells from the Niangua River, Camden, Co., and from Casteel Creek, Clinton Co., have structures of this species more than anything else, but the identification is too doubtful for much consideration. The shell of this species is like that of Strophitus, but differs in beak sculpture; it also differs from some similar shells of Anodonta by the incurved anterior hinge to the beaks and by a compressed post-dorsal portion of shell back of a slight posterior ridge. Ortmann (I92 r b, pp. 293-294) denies that all four of its gills are marsupial, and Simpson, who claims to have found embryos in all four gills does not class this species under his Tetragenae (i. e., those that have all four gills marsupial) because its characters of shell and nutritive soft parts seem to agree better with his Homogenae (Unios with only outer gills marsupial.) This species is generally distributed throughout the Mississippi drainage, the St. Lawrence system and that of the Red River of the North. The subspecies only occur in the St. Lawrence drainage.

\section{Genus Alasmidonta Say.}

I 8 I 8-Alasmidonta Say, J1. Ac. N. Sci. Phila., I., p. 459 I840-Uniopsis Swainson, Tr. on Mal., p. 382.

\section{ANIMAL CHARACTERS.}

Mantle connection between anal and supra-anal openings moderately long; inner laminae of inner gills free from visceral mass, or, more or less connected to it; outer gills only marsupial; when charged, distended at ventral edges, water canals facing laminae present, central ovisacs undivided; no conglutinates, embryos held in mucus masses; glochidium large, spined, subtriangular, hinge line straight, or nearly so. 
SHELL CHARACTERS.

Shell subquadrate to subtrapezoidal, thin, inflated; disk smooth; beaks heavily sculptured with irregular concentric barsthe later ones being more or less undulate; epidermis olivaceous to burnt orange with broken rays; cardinals present, laterals reduced; beak and branchial cavities deep; nacre white to pearl blue.

The characters of the shell of this genus especially in its coarse concentric beak-sculpture-shows that it is somewhat primitive, yet the tendency of the union of the inner laminae of the inner gills with the visceral mass in an indication of progress in structure. The two species that represent Alasmidonta for this State are not found in the interior north of the Missouri River.

\section{Alasmidonta calceolus (I,ea).}

("Slipper Shell.")

$$
\text { Pl. XXIV, Figs. } 79 \text { A-D. }
$$

I 830-Unio calceola Lea, Tr. Am. Phil. Soc., III, p. 265, pl. III. Fig. I I898-Alasmodonta deltoidea Baker, Moll. Chicago, Pb. I., p. 63 , Pl. VI, fig. 2; VII, fig. +. rgoob-Alasmidonta calceola (Lea) Simpson, U. S. Proc. Nat. Mus. XXII, p. 668.

\section{ANIMAL CHARACTERS.}

NuTRITIVE STRUCTURES:- Siphonal openings large, mantle edges with regular blocks of black; gills of medium size, inner laminae partly united with visceral mass; palpi rather long, tongue shaped; most of soft parts light yellowish.

REPRODUCTIVE STRUCTURES:- Marsupium pad-like and brownish when charged, water-canal present; glochidium large, spined, spadiform, longer than high, hinge line straight.

SHELL CHARACTERS.

EXTERNAL STRUCTUREs:- Shell small, slipper-shaped or subtrapezoidal, obtusely angular behind, post-umboidal ridge rounded; disk smooth:- beaks high, pointed, with coarse concentric sculpturing consisting of four or five bars sharply bent in behind; epidermis yellowish or olivaceous with wayy double rays on and parallel to the post umbonal ridge.

INTERNAL STRUCTURES:-Cardinals single and conical in right valve, double in left with post tooth saddle-shaped; laterals mere thickened hinge line; nacre white. 


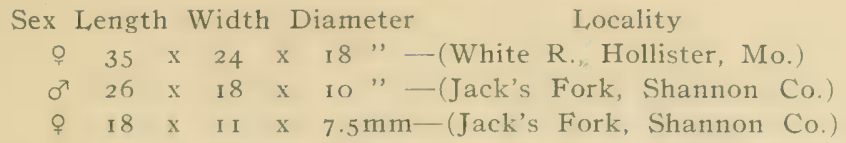

The latter is a juvenile, tawny in color, with beak sculpture extending well out upon the disk in undulated bars, showing here, as in so many of the Anodontinae, that in the adolescent shell there is more of tendency toward disk sculpture in the individual, just as seen in the primitive shell of the whole race of Naiades.

Miscellaneous REMARKS:--This species is easily identified by its small shell (being never much more than an inch and onehalf long), by its slipper-shape and by its coarse concentric sculpturing. It is a great burrower and, although it may be abundant, it may escape notice because of this habit. For this state calceolus is only found in the streams of the south slope of the Ozarks where it is found in company with its nearest relative Alas. marginata, and is found in greatest numbers in Jack's Fork of the Current River, Shannon County. It is found rather common in the streams of Arkansas, and has a general distribution in the Ohio, Tennessee and Cumberland Rivers; also the Lower and Middle St. Lawrence systems. Being found with mature glochidia in late Fall it can be classed as bradytictic.

\author{
Alasmidonta marginata Say. \\ ("Nigger Toe," “Elk Toe.") \\ Pl. XXIV, Figs. $78 \mathrm{~A}$ and $B$.
}

1819-Alasmidonta marginata Say, Nich. Inc., No. I.

1843-Alasmidonta corrugata DeKay, Zool. of N. Y., Pt. 5, p. 19t

P1. XXIV; fig. 259.

ANIMAL CHARACTERS.

NUTRITIVE STTRUCTURES:-Branchial opening densely papillose; anal with fine papillae; supra-anal moderately separated from anal, mantle-edges marked with squarish black blocks at regular intervals; outer gills wider than inner; inner lamina of inner gills connected with visceral mass; palpi very long and united for one-half of their length antero-dorsad; foot very long and powerful, orange colored; other parts tannish colored.

REPRODUCTIVE CHARACTERS:--Marsupium with wavy crowded septa when sterile; greatly distended when gravid, bluish with 
late embryos, brown with glochidia, ventral edge trucated, water canals on either side of undivided ovisacs; glochidia large, spined, spadiform, hinge line undulate, height greater than length (o.35o $\mathrm{x} 0.300 \mathrm{~mm}$.).

\section{SHELL, CHARAC'TERS.}

EXTERIOR STRUCTURES:- Shell subrhomboidal, inflatedextremely so along the sharply angled, post-umbonal ridge; post dorsal ridge low with broad gentle slopes finely costated; disk smooth; beaks long full, sculptured with heavy concentric bars, the later ones undulated low almost to disk; epidermis smooth, polished, with spotted, greenish rays from anterior portion of shell to posterior ridge.

INTERIOR STRUCTURES:-Cardinals single in each valve, interdentum displaced by saddle-shaped tooth in left valve; laterals reduced to rounded edges; muscle cicatrices faint; shell cavity deep; nacre whitish to pearl blue and pinkish.

Sex Length Width Diameter Locality

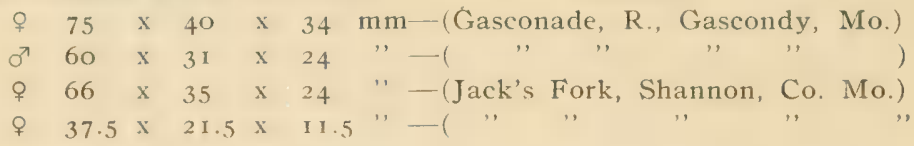

The juvenile of this last measurement presents the same sculpturing as in the juvenile calceolus except that the bars are somewhat more elongated in marginata and are really lower and coarser extending down well on the disk.

MiscellaneOUS REMARKS:- It has been well known by Pilsbry and Fox that this western shell is not the Alasmidonta truncata Wright, mentioned by Simpson. This species is easily recognized by its post inflated shell making the post - dorsal portion almost truncated and also by its extremely coarse beak sculpture. Its very long narrow foot extension is a notable physiological character. It delights in sandy, pebbly situations. The muddy waters of North Missouri is not conducive to its distribution there and is very rare in the Osage basin; however, it is rather a common shell in the Gasconade where it reaches its greatest perfection and is commonly distributed throughout the mountain streams of the south. Occasionally marginata is found in the Mississippi north of the Missouri River. The author has records of 
its breeding season for August through to December, a sufficient record to know that it is a long period breeder (bradytictic.)

Genus, Strophitus Rafinesque.

I 820 - Strophitus Rafinesque, Ann. Gen. Sci. Phys. Brux., p. 3 I 6 1852-Uniopsis Agassiz, Arch. fur Naturg., p. 49.

(Type, Anodonta undulata Say).

Animal Characters:--Branchial opening densely papillose; anal papillose or crenulate; mantle connection between anal and supra-anal not long and bordered by square, black spots; inner gills larger, inner laminae free from, or united to, the visceral mass; palpi united antero-dorsal for most of their length; color of soft parts variable but with the tendency to have certain parts (such as foot, adductors, mantle edge at branchial opening) orange in color; marsupium peculiar, consisting of ovisacs divided into many compartments at right angles to the laminae; conglutinates short, solid cords, (termed placentulae by Ortmann.)

Shell Characters:- Shell, subrhomboid to subelliptical, subsolid, inflated, with low post-umbonal ridge; disk smooth; beaks rather full, sculptured with rather heavy concentric bars upcurved behind; epidermis rayed or rayless, polished; hinge teeth mere rudiments, sometimes entirely absent.

Because of the great specialization in marsupial structure, the tendency of the inner lamina of the inner gill to become connected to the visceral mass and also because of a more developed hinge, this genus is the highest of the Anodontinae. It is represented in this State only by $S$. edentulus.

\section{Strophitus edentulus (Say.) \\ ("Squaw-Foot," "Creeper.") Pl. XXIV, Figs. 80 A-D.}

182.0-Alasmodonta edentula Say, New Harm Diss., II, No. 22, p. 340. 1888 - Anodonta shafferiana B. W. Wright, Check List. 19oob-Strophitus edentulus (Say) Simpson, U. S. Proc. Nat. Mus., XXII, pp. 6I6-6I8.

ANIMAL CHARACTERS.

NUTRITIVE STRUCTURES:- Branchial opening doubly papillose; anal with inner edge crenulated, supra-anal moderately 
connected to anal, mantle edge here blocked in black at regular intervals; inner gills much wider and longer than outer, inner laminae connected about one-half way; palpi united almost to their tips antero-dorsad; color of foot, palpi and adductors orange, variable with age.

REPRODUCTIVE STRUCTURES:-Marsupia occupying outer gills with secondary water tubes, ventral edges distended when gravid, ovisacs occupied by several other smaller sacs arranged crosswise facing the outer and inner laminae in which small, solid white cords (placentulae), containing the ova or two to ten larvae, are situated; glochidia large, spined, spadiform, hinge line straight, length greater than height, $(0.35 \times 0.285 \mathrm{~min})$.

SHELL, CHARACTERS.

EXTERNAL. STRUCtURES:- Elongate-ovate, moderately solid, inflated, post-umbonal ridge usually rounded; female shell more obtusely (or biangulated) posteriorly than male; umbones rather full sculptured by two or three very coarse, wavy concentric ridges abruptly bent up behind; disk not sculptured; epidermis usually a glossy brown, sometimes marked by bright green rays, especially in young shells.

InTERnAl STRUCTURES:- Cardinals almost obliterated, more pronounced in left valve, where it is rounded and placed just under the beaks; laterals and interdentum lacking; umbonal cavities deeper in female shell; nacre variable from solid salmon or white, to cream or pearl-blue color.

Sex Length Width Diameter Um. ra. Locality

q $95 \times 55 \times 38-\mathrm{mm}-0.360-$ (Marais des Cygnes R., Rich Hill, Mo.,)

o $77.5 \times 45.5 \times 27-\mathrm{mm}-0.430 \quad$ (Osage R., Linn Cr.,)

\% $34 \times 20 \times 14-\mathrm{mm}^{-}-0.330 \quad$ ( 102 R., Wyeth, Mo.,

$\sigma^{7} 41 \quad x \quad 24 \times 13.5-m m-0.335$ (Grand R., Darlington.)

The last two measurements are those of the only shells of edentulus jound in the interior north of the Missouri River and these are juveniles. Unlike most adolescent shells of this species, both shells are uni-colored except for a single brownish band parallel with the growth lines near the ventral margin on a back-ground of yellowish-green; hinge teeth and beak sculpture typically stro. phitus; nacre of both about the same; shell thin and transluscent.

Miscellaneous Remarks:- $S$. edentulus is rather easily recognized even through casual observation by its somewhat 
inflated elliptical shape with the beak sculpture or coarse concentric bars bent up behind, but, most of all, by its very peculiar marsupial characters which are an adaption to its eccentric habit of independent metamorphosis. This and Lastena ohiensis are the only species on record so far that do not normally possess a fish host for the metamorphosis of its larva. This species is not so particular about its habitat and hence it has one of the widest distributions of any species in the United States. It is strange that it should not have a wide distribution throughout the State. It is almost unknown for the interior of North and Northwest Missouri, and is perhaps best represented in numbers and typical form in the Osage basin. Its sub-species, pavonius Lea (which, at best, is perhaps only a color-variant) is not found in this State. The shell of this species is exceedingly variable, for this State, as to its shape, size and thickness, but these variations are only individual characteristics or deviations due to special local conditions. The author has found the breeding season of edentulus to be about as long and over-lapping as that of Lasmonos fragilis; however, there was a short interim noted in most individuals about the middle of July when there was more or less sterility. Because of the great vitality and nonparastic life of the larvae and also because of its constancy in breeding season, we might conclude the reasons for its prolificacy and wide geographic distribution; we might conclude, too, that its distribution may be due also to a dependent life as well upon fishes of those larvae that have been observed to escape from the extruded placentula, and, as some students have advanced, the buoyancy of the placcntula, bearing the juveniles, may be the greatest cause for the wide distribution.

\section{Sub-family Lampsilinae Ortmann.}

191 Ia-Lampsilinae Ortmann, An. Car. Mus., IV, pp. 337-338; 1912b, An. Car. Mus., VIII, pp. 300-360.

Animal Characters:- Mantle edge antero-ventrad to branchial opening of the female with special structures, such as papillae, flaps, etc., siphonal openings with tendency to become tubular; supra-anal separated from anal by a mantle connection of medium length; inner laminae of inner gills generally connected with the visceral mass throughout; palpi medium to small; marsupium occupying only the outer gills, or parts of the latter, situated in their posterior portion as a rule; when sterile an extra thickness 
of tissue on the ventral border to permit a bulging out; when gravid ovisacs are undivided internally, and distal ends are extended beyond the original edge externally; glochidia of both Propter ("ax-head") and Lampsilis ("apron-form") types, varying mucl in shape an size; conglutinates white, undivided at their distal ends, discharged more or less broken through the thin ventral edges of the ovasacs; color of soft parts modest, never so bright with tinges of yellow or red as seen in the other sub-families, Unioninae and Anodontinae.

Shel, Characters:- Shell rounded, sub-elliptical or elongated; beak sculpture generally obscure, when present usually the double looped type, rarely concentric; epidermis rarely dull, usually with bright color markings; hinge teeth rarely reduced, generally complete with well developed teeth; sex dimorphism of shell in most cases well expressed by a truncated or blunted posterior end, by an expanded post-ventral portion, etc.

MiscellaneOUS REMARKS:- With regard to marsupial structure the Missouri Lampsilinae naturally fall into three groups. All these agree, however, in the extension of the membranes beyond the ventral edge of the marsupium when gravid; hence this distention tends to make the membranes thinner so that osmosis may be facilitated. To aid further in this osmotic action, there is a tendency in the three following types to draw the marsupium back toward the branchial opening where there is the greatest amount of aëration due to the action of papillae, caruncles, flaps, etc.

I. Ellipsaria-Group. Marsupium most primitive in that the whole outer gill is occupied; yet advantage is secured for the aëration of the embryos in rendering the ventral edges thin by distention and in throwing the marsupia into folds, thus increasing the surface for greater exposure to the water currents. The only representative in this state is $E$. clintonensis (Simpson).

2. Obliquaria-Cyprogenia-croup. Number of ovisacs reduced, but each greatly enlarged and elongated and placed at the greatest vantage point for oxygenation of the embryos. This group is represented in Missouri by only two species, Obliquaria reflexa (Raf.) and Cyprogenia Aberti (Conrad). The former has its few large ovisacs drawn back beyond the middle of the gill, while the latter has its orisacs slightly in front of the middle of the gill, but extremely elongated into upward coiled spirals. 
3. Proptera-Lampsilis-Group. In this division the best adaptation for the proper respiration of the embryos is secured by situating the numerous, dilated ovisacs in a more or less kidneyshaped marsupium near to the branchial opening where the postero-ventral margin of the mantle is set with papillae, flaps, etc. The first members of this group have this mantle edge only slightly crenulate and lamellate, while beyond the genus, Protera, is the culmination of the modern structure in the arrangement of the inner edge with papillae or flaps close to, or remote from, the outer edge. This group is represented by about thirty species in this State.

It may be added that the Lampsilinae are dissimilar to the Unioninae in their breeding season in that practically-all the species are long period breeders (bradytictic), but that the glochidia of these two sub-families are similar in form and in being spineless. It is especially to be noted that the members of these two sub-families have developed perfect hinges in the adult shell, whereas those of Anodontinae possessing glochidia with spines have defective hinges. We should also note that the Lampsilinae are able to spread their valves far apart-a habit which may have some relation to the differentiation of their mantle margins in admitting greater incurrents of water-while the Unioninae and Anodontinae show a primitive character in being unable to force their valves far apart and accordingly in not developing stronger papillae and more extended mantle edges at their siphonal openings - a defect that may be somewhat counterbalanced by the delvelopment of larger palpi than is very often seen in the Lampsilinae. It may be stated further that there is not such intergradation of forms in this sub-family as seen among the Unioninae, or even as noticed among the Anodontinae as there seems to be more distinctness and fixity of characters among the several genera, especially as seen in the marsupial structures upon which a good key is built.

\section{Genus Ellipsaria Rafinesque.}

1820-Ellipsaria Rafinesque, Monog. Biv. Shells of R. Ohio., Ann. Gen. Sci. Phys. I goob-Ptychobranchus Simpson, Proc. Ac. N. Sci. Phila., p. 79.

'Type, Ellipsaria fasciolaris Rafinesque $1820=$ phaseolus Hildreth, I 828). 
Animal, Characters:- Branchial opening with papillae; anal separated from supra-anal by short mantle connection but never lacking; inner laminae of inner gills, more or less free from visceral mass; palpi very small, connected about one-fourth of their length; color of soft parts mostly whitish with mantle edg, black along the siphonal openings; marsupium occupying whole outer gill with a number of folds; ventral edge, when gravid, presenting a beaded appearance; glochidia medium in size, subovate; conglutinates white, solid, subcylindrical.

SHELl CHARACTERS:- Shell subelliptic rather elongate, arched dorsad, disk smooth; beaks low, sculpturing indistinct, finely concentric, later bars, however, somewhat double-looped; epidermis yellowish to olivaceous, painted with capillary-like rays forming interrupted squarish spots; hinge teeth well formed, branchial impression of female shell very distinct, nacre white to pearl blue.

Miscellaneous REMARKS:- This most primitive genus of Lampsilinae, like those of Anodontinae and some genera of Unioninae, uses the whole outer gill as a marsupium but shows modern character in the special structure of folding. Ellipsaria is only represented in this State (and perhaps only for the whole Southwest) by $E$. clintonensis Simpson. Since the shell of this species is about the same form as that of dilatata (Raf.) it is often confused with this species of Elliptio from which is widely separated by a sub-family. 'The real test of distinction between these two species is concerning the marsupial characters; hence we see here an instance of shell characters as a poor guide for discrimination even for species of very distant relation.

\section{Ellipsaria clintonensis (Simpson.)}

("Kidney Shell.")

\section{Pl. XXV, Figs. 8I A and B.}

1900a-Ptychobranchus clintonensis Simpson, Pr. Acad. Nat. Sci. Phila., Pt. I, p. 79, pl. V., fig. 3; rgoob, Proc. U. S. Nat. Mus., XXII, p. 6 I 3

1906-Ptychobranchus clintonense (Simpson) Scammon, Sci. Bull, Univ. Kans., III, p. 319.

AnImal CHARACTERS:--Identical with those of the type for this genus as to its nutritive structures and also as to the repro- 
ductive as far as able to determine from sterile material that is only at hand. Glochidia not known.

SHELL CHARACTERS.

ExTERnAl STRUCTURES:- Shell elongate-elliptical moderately inflated, obtusely rounded before, pointed behind, dorsal line acurate, ventral with a slight long upward curve; disk smooth: post-umbonal ridge rounded; beaks low, faintly sculptured con centrically across two radiating ridges; epidermis olive green or yellowish rayed with capillary lines, some arranged in bundles.

INTERNAL STRUCTURES:- Cardinals double in both valves, post-cardinal of right valve rudimentary; interdentum long, rather narrow, notched; scars well impressed; beak cavity shallow branchial, however, large with deep impression in female shell; nacre white to pearl blue.

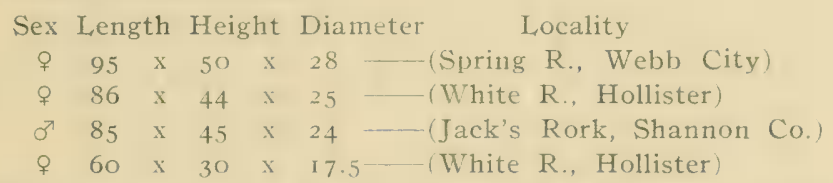

This last specimen being young and well preserved shows the fine characteristic rays more distinctly and while the beak sculpture would show more distinctly than in older shells yet it is even obscure here and does not add anything to the above description of the external shell structures.

Miscellanelus Remarks:-Before Simpson had studied the soft parts of this species he had considered it as $E$. dilatata ( $=U$. gibbosus $)$; however, its peculiar marsupial characters would not only discriminate, but also its different beak sculpture and dissimilar hinge. The beak sculpture of dilatata is one of the most emphatic among the Naiades while that of this species is one of the most obscure; besides the interdentum of the former is broader and thicker while the branchial impression of clintonensis distinguishes it from all other species outside of its genus. 'This species lies very close to its fellow, facsiolaris, and it is considered by some as merely a variety of it, but perhaps it is a good species on account the lack of the splotched rays and larger, heavier, thicker shell of the type for Ellipisaria. ${ }^{1}$ Clintonensis is abundant

${ }^{r}$ Recent studies by Dr. Ortmann and Mr. Frierson have resulted in the positive conclusion that the Unio occidentalis Conrad (Monog., VII, 
locally in the White, Black, and Neosho River basins. Simpson reports it for the Red River, Arkansas; Prof. Isely and Rev. Wheeler also report it for Arkansas and Oklahoma. Thus it seems to have supplanted fasciolarsis (=phaseolus) of the Tennessee drainage for the Southwest.

Genus Obliquaria Rafinesque.

1830-Obliquaria Rafinesque, Ann. Gen. Sci. Phys. Brux., p. 301. 1900b, Simpson, p. 610.

\section{('Type Obliquaria reflexa Rafinesque.)}

Animal Characters:--Branchial opening large with papillae; anal crenulated; supra-anal high with moderately short mantle connection to anal; inner laminae of inner gills free from the visceral mass except for a short distance anteriorly; palpi short and small; soft parts grayish; marsupium occupying only outer gills and consisting of $5^{-7}$ ovisacs placed posterior to the center of the gill and when gravid extending far beyond the edge of sterile marsupium; glochidia medium in size, semicircular, hinge-line with a slight up-curve in centre; conglutinates large, white, club-shaped, glochidia scattered all through the conglutinated mass.

SHell CHARACTERS:- Shell medium in size, thick roundly trigonal, inflated; disk of one valve with row of large knob-like nodules running from beaks centrally ventrad and alternating with the knobs on the other valve; beaks sculptured with two or three concentric bars which, although heavy, are not well defined; epidermis greenish-yellow to brown with paintings of numerous interrupted rays; cardinals prominent and ragged; laterals short nearly straight; beak and branchial cavities not very deep; nacre white; female shell smaller and slightly inflated post-ventrad.

Miscelianeous Remarks:- $O$. reflexa is the type and only member of this genus known thus far and is one of the most easily identifiable of all the Lampsilinae not only in its most unique marsupium, but also in the knobbed sculpture of its disk. The sex dimorphism of the shell for this type is rather peculiar as

1836, pl. XXXVI, fig. 23) is the Pty. clintonense Simpson (1900-a and b) and hence this species, whose type locality is the Current River, Missouri, should be:-Ellipsaria occidentalis (Conrad). 
described above and is not often seen among the Naiades. In that there are not such advantages for the aëration of the embryos and also a greater reduction in the number of ovisacs as seen in most other genera of this sub-family, this genus is given a primitive grouping here. However, in the reduction of the number of ovisacs a compensation is made in the enlargement and elongation. This genus has a rather wide distribution over the northern and central parts of the state, but is entirely absent from the drainage of the south slope of the Ozarks.

Obliquaria reflexa Rafinesque.

("Horny-Back," "Three-Horned Warty-Back.")

$$
\text { Pl. IXV, Figs. } 82 A-F \text {. }
$$

I820-Obliquaria (Quadrula) reflexa Rafinesque, Ann. Gen. Sci. Phys.,

p. 306; Chenu. Bib. Conch., rst ser., III, I845, p. 19.

I823-Unio cornutus Barnes, Am. Jl. Sci., VI, p. I 22, pl. IV, fig. 5.

I goob-Obliquaria reflexa (Raf.) Simpson, Proc. U. S. Nat. Mus.,

XXII, p. 6ri; Ortmann 19r2b-An. Car. Mus., VIII, pp. 310-312.

\section{ANIMAL CHARACTERS.}

Nutritive Structures:- - Branchial opening large with light colored papillae on a black back-ground; anal crenulated; supraanal rather large and briefly connected to anal; inner laminae of inner gills free except for a short distance anteriorly; palpi small, wide, short, connected for one-half of their length antero-dorsad; color of soft parts grayish or dirty white, mantle edges at branchial opening black, branchial papillae and inner margin of anal opening yellowish, gills of male and sterile female tan-color.

REPRODUCTIVE STRUCTURES:-Only outer gills marsupial, when sterile, the ovisacs not extending below edge of gill, when gravid larger and greatly elongated beyond the original edge, ovisacs $5^{-7}$ in number, large, club-shaped, curved post-ventrad, glochidia scattered throughout the conglutinated mass; conglutinates club-shaped, solid, white, discharged whole; glochidia semi-circular, medium in size, hinge line slightly curved upward in middle, measures $0.225 \times 0.235 \mathrm{~mm}$.

SHELL CHARACTERS.

External, Structures:- Shell sub-trigonal, heavy and thick anteriorly, post-dorsal line rounded; slightly incurved post- 
ventrad in male, slightly swollen in female; whole shell medium in size, small but more inflated; disk from beaks to central-ventral edge sculptured with a row of a few large knobbed tubercles, those of one valve alternating with the knobs of the other; postumbonal ridge with corrugations; epidermis yellowish-green to dark brown.

INTERNAL STRUCTURES:- Cardinals upright, jagged; laterals short, nearly straight at right angles to a rather broad interdentum beak and branchial cavities moderately deep; nacre a pure, stippled white.

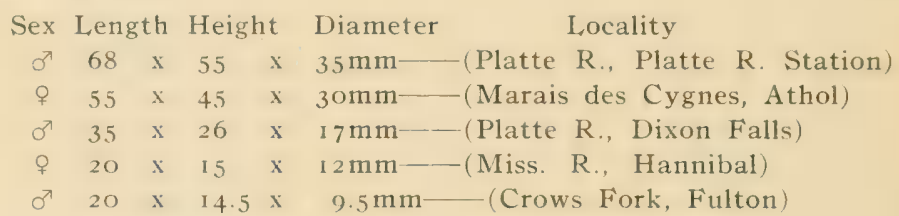

The last two are measurements of juveniles of widely different locality under far different ecological conditions, although the shell characters are not very much different. The former shows more of a rayed olivaceous epidermis and the latter a plain straw color. The Mississippi juvenile, being more typical as in case of most shells, is described here:--Shell sub-trigonal, valves inequilateral with two knobs on one side and one on the other, darker green epidermis below the knobs, rayed with interrupted $\mathrm{V}$ markings, beak sculpture irregular concentric undulations extending out on disk; nacre white, slightly tinged with pink.

Miscellaneous Remarks:-Both as to structure of shell and nutritive soft parts O. reflexa is rather primitive, but as to marsupial characters it naturally falls under the lower groups of the Lampsilinae. In North Missouri reflexa reaches a very large growth while in Central Missouri it averages only about one-half the size; for the two faunae this variation applies to many other species. Since Drs. Lefevre and Curtis (1912, pp. 137 and 138) have called attention to the eccentric breeding habits and glochidial behavior of reflexa the writer has followed up the breeding period rather closely to find that it is gravid with early and late embryos, also with glochidia, during June, July and August, but is sterile for late Fall and mid-Winter, thus showing that this species has a short period of gravidity, - a different reproductive habit from 
that of most Lampsilinae. The fact that the mature glochidia will not leave the conglutinated form after being extrued by the mother and because of the fact, too, that artificial infection of fish cannot be induced with its glochidia would lead to believe that its metamophosis may take place without parasitism.

\section{Genus Cyprogenia Agassiz.}

I 852-Cyprogenia Agassiz, Arch. fur Naturg., p. 47; rgoob, Simpson, p. 609 .

\section{(Type, Unio irroratus Lea.)}

Animal CHARACTERs:-Branchial opening with short papillae; anal finely crenulate; supra-anal closely connected to anal; mantle edge antero-ventrad to branchial opening with fine crenulations for a short distance; inner laminae of inner gills free from visceral mass except at anterior end; palpi very small, pointed, very wide gap between them and anterior attachment of outer gills; marsupium consisting of $5^{-7}$ ovisacs anterior to center of outer gills, when gravid ovisacs immensely elongated and coiled post-dorsad; conglutinates white, very long and solid, subcylindrical; glochidia semicircular, medium in size, ventral margin obliquely rounded, hinge line long and slightly upcurved.

SHell CHARACTERS:- Shell roundly triangular, subinflated; disk with peculiar nodulat structure; beaks more or less prominent, sculpture obscure; epidermis olive, painted with mottled rays; hinge complete; beak cavities rather deep.

MiscellaneOUS ReMARKS:-The type of Cyprogenia, irrorata ${ }^{\mathrm{I}}$ (Lea), is not found in Missouri being entirely displaced by $C$. Aberti (Conrad). The variety of irrorata pusilla of Simpson, is so doubtfully reported for the St. Francis River that it is not listed here. Simpson is of the opinion that all $C$. irrurata, reported for the localities west of the Mississippi, are really $C$. Aberti. As to soft parts there is a similarity to those of Obliquaria; however, the slight differentiation of the mantle border antero-ventrad to branchial opening and also its uniquely coiled and extremely elongated ovisacs would rank it above.

'From Rafinesque's evident description and figures (Ann. Gen. Sci. Brux., V, 1820 , p. 312 , pl. LXXXII, figs. 4,5 ) we should make C. irrorata (Lea) a synonym for C. stegaria (Raf.) 


\section{Cyprogenia Aberti (Conrad.)}

("Young Fan-'Tail.")

Pl. XXV, Figs. $83 A$ and B'.

$1850-$ Unio aberti Conrad, Pr. Ac. Nat. Sci. Phila., V, p. In; I8.54,

J1. Ac. Nat. Sci. Phila., p. 295, pl. XXV, fig. I

r885-Unio popenoi Call, Bull, Washh. Col., I, p. 49, pl. II.

1900b-Cyprogenia aberti (Conrad)' Simpson, Proc. U. S. Nat. Mus.,

XXII, p. 6 IO.

ANIMAL CHARACTERS.

NUtritive Structures:--Branchial opening with many short papillae; anal with finely crenulated inner edge; supraanal separated from anal by short mantle connection; mantle edge antero-ventrad to branchial opening slightly crenulate; gills short, wide, inner wider than outer, inner laminae free from visceral mass, except for a short distance anteriorly; palpi very small, connected about one-half of their distance antero-dorsad; color of soft parts dirty white, except for the black, squarish mottlings of the mantle edges around the supra-anal opening.

REPRODUCTIVE StRUCTURES:--Marsupium formed by five to seven ovisacs originating from the edge of the outer gills anteroventrad and extremely elongated posteriorily into a coil; conglutinates white, very long, solid, club-shaped; glochidia unkown.

SHELL CHARACTERS.

EXTERNAL STRUCTURES:- Shell sub-triangular, compressed; beaks rather pointed, sculpturing obscure; post umbonal ridge prominent with a hummocky expansion middle-ways for the female shell, not so sculptured in male; radial furrow rounded moderately wide; dorsal ridge faintly ribbed; disk entirely rugose; epidermis brownish yellow with numerous banded rays marked with mosaics of green mottlings of various patterns of geometric designs.

InTERnal Structurfs:- Cardinals double in each valve: laterals double in left, single in right; interdentum long; beak cavities deep; nacre bluish, irridescent.

\begin{tabular}{|c|c|c|c|c|}
\hline Sex & Length & Height & Diameter & Locality \\
\hline$\sigma^{7}$ & $4^{2} \quad x$ & $32 \times$ & 16.5 & I'rancis R., Greenville \\
\hline ㅇ & 40 & 32 & 16.0 & (White R.. Hollister) \\
\hline$\sigma^{7}$ & 37 & 30 & 14.5 & $\left(\begin{array}{llll}\prime \prime & * & . & \end{array}\right.$ \\
\hline q & 30 & 22 & I 1.0 & \\
\hline
\end{tabular}


Although the shell of the last measurement is young and well preserved, yet the beak sculpture does not even present anything very distinct. The beaks are pointed, incurved and two-ridged,one ridge radiating off to the posterior and the other to the anterior umbonal slope. The shell in this stage resembles that of young $P$. securis from a dorsal view. The soft parts of this specimen show that its marsupial characters consist of seven sterile ovisacs originating just in front of the middle part of outer gill curved backward toward the branchial opening.

Miscellaneous Remarks:- $C$. Aberti is a rather common little shell in the White, Black and Neosho basins of this State. It is distinguished from C. irrorata by not being so rounded, nor so solid, rugose and ridged parallel to growth lines. It is not to say a variable shell, yet the writer has noted some with such a truncated posterior end as to suggest an approach to irrorata, or is probably the C. Aberti lamarckiana (Lea) reported for the Black River, Missouri. Specimens taken from Indian mounds in Southwest Missouri show great preservation although deposited some centuries ago. As they were placed in these graves for "food" to the departed spirit" (as was the burial custom of the aborigines) in greater quantities than other mussel shells it is evident that this species was prized above all others for its food qualities. It can be determined that the live mussels were deposited since dried muscular tissue is still adhering to the muscle scars.

\section{Cyprogenia Aberti lamarckiana (Lea).}

(Not figured, nor described.)

1852-Unio lamarckianus Lea ,Tr. Am. Phil. Soc., X, p. 266, pl. XVII, fig. 20 .

This sub-species is simply listed for this State through a report of it by Mr. Elwood Pleas to the U. S. National Museum, where it is now on exhibit under the number, 124,630 - and also through a recent report of it for the Black River, Popular Bluff, Missouri, by $\mathrm{Mr}$. Walker who has received it in this same collection of $\mathrm{Mr}$. Pleas, a part of which lot was sent to the Washington Museum. No data is at hand for illustration or description. 
Genus Obovaria Rafinesque.

I8r9-Obovaria Rafinesque, J. de Phys. Chim. Hist. Nat., 1. 426

('Type, ('nio retusa Lamarck.)

Animal Characters:- Branchial and anal opening both papillose; supra-anal large, crenulated; mantle margin anteroventrad to branchial opening slightly specialized with lamellae or crenulations; inner gills twice the width of outer, inner laminae entirely connected to visceral mass; palpi small, far removed from anterior end of outer gills; color of soft parts soiled white; marsupium consisting of many ovisacs originating from posterior half of outer gills and extending far below the ventral edge; conglutinates poorly developed, embryos being held in rather loose masses; glochidia somewhat large, semielliptical, spineless, hinge line undulate.

Shell Characters:- Shell rounded or ovate, inflated, height, greater than length; post-umbonal ridge not distinct, disk smooth; beaks prominent, sculptured with a few indistinct, concentric, sinuate bars; epidermis brown with faint rays.

Miscelianeous Remarks:- Although this genus is another one of the primitive types of Lampsilinae, yet the differentiation of the mantle border antero-ventrad to the branchial opening and the tendency of the marsupium to assume the reniform shape and to acquire a position near the opening of the incoming currents all show and approach to the more modern groups. According to Dr. Ortmann the sub-genera of this genus, as fixed by Simpson, are well deflned enough to be retained.

Thus we have the following grouping:-

I.-Sub-Genus Obovaria (sens. strict.)

Shell upright, oval, rather solid; beaks drawn up more toward the middle of the dorsal line; cardinals mostly normal.

'Type, O. retusa (Lamarck.)

2.- Sub-Genus Pseudoön Simpson (190ob, p. 601).

Shell oblique, elliptical, solid, thick; beaks protruding anteriorly; cardinals subparalle] to laterals.

Type, O. ellipsis (Lea)

From the above diagnoses it may seem that division is made on the shell characters, the soft parts being identical,- even in marsupial and glochidial characters. However, this Genus is 
only represented in this State by ellipsis and that in a limited distribution both in the geographical and individualistic sense.

Obovaria (Pseudoön) ellipsis (Lea).

("Missouri Nigger-Head," "Egg Shell," "Hickory Nut.")

$$
\text { Pl. XXV, Figs. } 84 A \text { and } B \text {. }
$$

1828-Unio ellipsis Lea, Tr. Am. Phil. Soc., III, p. 268, pl. IV, fig. 4. r $900 b-O b o v a r i a$ ellipsis (Lea) Simpson, Proc. U. S. Nat. Mus.; I9I2b, Ortmann, Car. Mus., VIII, pp. 323-324.

\section{ANIMAL, CHARACTERS.}

NUTRITIVE STRUCTURES:-Branchial opening small with two-ranked papillae; anal finely papillose; supra-anal crenulated (a rare character) not well connected to anal; mantle border just antero-ventrad to branchial opening with crowded papillae or crenulations extending one-third of the way towards center of ventral margin; gills very wide, both blunt and pointed posteriorly, inner laminae of inner gills entirely connected to visceral mass; palpi rather small, connected about one-half of their length antero-dorsad; foot pinkish, mantle edge dark in region of siphonal openings, rest of soft parts dirty white.

REPRODUCTIVE STRUCTURES:--Marsupium occupying posterior portion of outer gills, rather kidney-shaped, consisting of several ovisacs, twenty-five or thirty which, when gravid, extend far below the original edge, pigmented purplish ventrad; conglutinates white, not well formed, ova and glochidia discharged in rather loose masses; glochidium medium in size, semi-elliptic, rather short and straight, measures $0.210 \times 0.265 \mathrm{~mm}$.

\section{SHELL, STRUCTURES.}

EXTERNAL STRUCTURES:- Shell sub-elliptical, rather oblique, very solid, thick, heavy; ventral margin more rounded than dorsal; disk smooth; no post-umbonal ridge; rest lines of growth very distinct; beaks projecting anteriorly, rather prominent, sculpturing indistinct; epidermis yellowish-horn color with green rays in young shell.

INTERNAL STRUCTURES:-Cardinals very heavy, nearly parallel to laterals with right post-cardinal converged dorsad and rounded up from a broad V-shaped gutter; interdentum broad, thick, right deeply gashed; beak cavities not very deep; nacre white. 


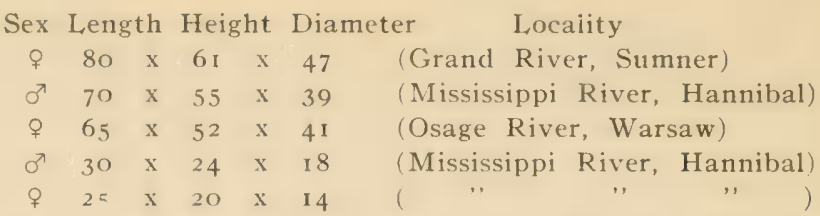

Beaks of these specimens of the last two measurements very full, rounded, poorly sculptured although not eroded; more inflated (comparatively) than adult shell; epidermis olive with profuse paintings of green rays so as to give the appearance of olive green; post-ventral edge of shell more obliquely rounded than in adult; nacre pearl blue.

MiscellaneOus REMARKS:-From shell characters there is no real sex dimorphism except a little greater inflation in the female, but not only a less crowded arrangement of septa is seen in gills of the male but there is a more intense black pigmentation in the region of the branchial opening. The crenulated supra-anal opening is surely a unique character and may indicate a conversion of this opening into the anal. The bare connection between the two openings would also indicate this merging. Although of rare occurrence ellipsis reaches its greatest perfection for the interior in the Grand River of North Missouri. It is found occasionally in the Osage Basin, but never develops a shell as large, heavy or bright as found in the Grand or in the Mississippi. This fact of difference in size, color and solidity for the shells of these different mussel faunae applies to most other species as well. Scammon (1906, p. 306) reports this species as very active with strong musculature and that he has traced this species for fifty yards by its furrow in the Kansas River. This species is bradytictic.

Genus Nephronaias Crosse and Fischer.

1893-Nephronaias Crosse and Fischer, Miss. Sci., Pt. 7. II, p. 556; I goob, Simpson, Proc. U. S. Nat. Mus., XXII, p. 591.

(Type, Unio plicatulus Charpentier.)

AnImal Characters:- - Identical with those of Obovariaeven in glochidial characters.

Shell Characters:- Shell rounded to sub-elliptic and elongate, usually compressed; posterior ridge rather indistinct, beaks not near the anterior end, sculpture poorly developed,consists of a few faint double-looped bars; epidermis greenish 
to yellowish, generally with very distinct green rays; sex dimorphism of shell not well shown.

MiscellaneOUS REMARKS:-This genus is set aside solely on shell characters. The sub-genus, Pseudoön, serves as a good connecting link between Obovaria and Nephronaias. Chiefly because of the lack of much specialization of the mantle border antero-ventrad to the branchial opening Unio ligamentina (Lam.) is taken out of Simpson's grouping of it as a Lampsilis. In this State this genus is best represented by $N$. ligamentina and ellipsiformis (Lea).

Nephronaias ligamentina (Lamarck).

$$
\text { Pl. XXV, Figs. } 85 \mathrm{~A} \text { and } \mathrm{B} \text {. }
$$

18 I9-Unio ligamentina Lamarck, An. San. Vert., VI, p. 72.

1900-Lampsilis ligamentina Simpson, Proc. U. S. Nat. Mus., XXII, p. 539 .

rgrab-Nephronaias ligamentina (Lam.) Ortmann, An. Car. Mus., VIII, p. 325 .

\section{ANIMAL CHARACTERS.}

NUTRITIVE CHARACTERS:- Branchial opening large with strong papillae; anal distinctly crenulated; supra-anal rather small, well separated from anal by thick mantle connection; gills very large, inner laminae of inner gills entirely connected to visceral mass; palpi very large, wide and pointed; color of soft parts dingy white for most part, however, post-mantle edge brownish.

REPRODUCTIVE STRUCTURES:-Marsupia occupying most of outer gills, consisting of about sixty ovisacs well separated by thick septa, when gravid extending far below original edge of sterile marsupium, making a longitudinal line; mantle edge antero-ventrad to branchial opening with twenty-five or thirty low denticulations; conglutinates white, broad, leaf-like, solid when ova are present, cohesion lost when mature glochidia are developed; glochidia semi-elliptical, spineless, large, hinge line undulate, measures $0.220 \times 0.260 \mathrm{~mm}$.

\section{SHELL CHARACTERS.}

EXTERNAL STRUCTURES:- Shell rather evenly eliptical, solid, moderately inflated, beaks rather low, sculpture consisting of several fine, wavy, concentric lines most pronounced at foot of posterior and anterior slopes; disk smooth; epidermis brown or yellowish with broad, dark-green rays. 
INTERNAL STRUCTURES:- Cardinals rather stumpy and stout; interdentum rather short and cut away; laterals very strong; nacre white with stippled effect-a very valuable shell commercially for this reason.

Sex Length Height Diameter

f $110 \times 68 \times 44.5 \mathrm{~mm}$

7) $110 \times 65 \times 43.5 \mathrm{~mm}$

아 $90 \times 59 \times 32.0 \mathrm{~mm}$

o $35 \times 21 \times 10.0 \mathrm{~mm}$

$15.5 \times 8 \times 4.0 \mathrm{~mm}$

$8.5 \times 5 \times 3.0 \mathrm{~mm}$

Locality

(Marais des Cygnes, Rich Hill)

(Meramec R., Meramec Highlands)

(Osage R., Osceola)

(Gasconade R., Gascondy)

(St. Francis R., Greenville)

(St. Francis R., Greenvile).

These last two measurements are those of two byssiferous juveniles identified by Dr. Howard and Prof. Clark. At first the writer was inclined to call them L. luteola chiefly on the grounds that both were found clinging by their byssi to a costata shell in a bed where luteola predominated; however, this identification was excluded on the basis of the presence of anterior rays and a difference of umbonal sculpture being less prominent with the ridges more broken in case of juvenile ligamentina as shown in these two specimens. The byssus is attached to the upper posterior part of the foot although it extends out antero-ventrad between the valves. In the smaller juveniles the bysuss is about $120 \mathrm{~mm}$ long, in the larger $135 \mathrm{~mm}$. Both bear dense papillae on both branchial and anal openings. Anterior end of outer gills lifted up very high above the palpi, gills dark tan-color; branchial papillae rusty red; epidermis yellowish with bright broad green rays-mostly placed anteriorly.

Miscellaneous Remarks:- While $N$. ligamentina may have the widest general distribution of the North American Naiades, yet it is not found anywhere in the interior of this State north of the Missouri River. However, it is the most common of species in the Mississippi, the Des Moines and in all the interior drainage south of the Missouri. It is not inclined to vary much from the typical ligamentina of Lamarck; however, the Osage River contains some forms that are somewhat puzzling due to ecological conditions that erode the epidermis and distort the shell of this species (and of other characteristically rayed species, for that matter), but these are of rare occurrence in the Osage from the center of its course to its mouth. As mentioned elsewhere this local effect may be traced to the chemical reaction of the mineral water of the springs' region. There are no species it may be confused with 
except $N$. ellipsi formis when the former is young. However, the more elliptic shell with broader, straighter rays would serve as the main distinguishing features. Surber (1913, p. 109) has found that its glochidium is a gill parasite upon the white bass $(R$. chrysops) as a natural host. Breeding records have been carefully kept for this species, especially for commercial reasons, to find that it is typically bradytictic.

\section{Nephronaias ligamentina gibba (Simpson).}

rgoob-Lampsilis ligamentinus gibbus Simpson, Proc. U. S. Nat. Mus XXII,p. 540 .

\section{("Southern Mucket," "Yellow Mucket.")}

Animal Characters:--Identical with those of the parent species, except, of course, in short gills and other modified parts due to a shorter shell. The glochidia are the same.

SHELl Characters:- Shell "peculiarly short, humped form" (Simpson); thicker, heavier more inflated with more roughened growth lines and more of a yellowish epidermis than the parent shell.

\begin{tabular}{|c|c|c|c|c|}
\hline Sex & Length & Height & Diameter & Locality \\
\hline $0^{x}$ & $85 \mathrm{x}$ & $60 x$ & $40 \mathrm{~mm}$ & (Osage R., Monegaw Springs) \\
\hline$q$ & 80 & 64 & $40 \mathrm{~mm}$ & "' Linn Creek) \\
\hline q & 89 & 70 & $38 \mathrm{~mm}$ & " Bagnell) \\
\hline
\end{tabular}

Miscellaneous Remarks:- Gibba seems to be a rather common variety throughout the southern range of the species and is expecially characterized by the short, stout, "humped" form of shell. Perhaps it bears the same relation to its species as dakotana Frierson does to grandis Say. The writer's experience in the study of the form of ligamentina while on a 300 -mile float down the Osage was that it was difficult to ascertain the point of separation between the species and the variety, gibba, so imperceptibly do they grade into each other. This form is met with in drainage of the Ozark Center as well-especially in the Black River.

\section{Nephronaias ellipsiformis (Conrad).}

("Ellipse.")

$$
\text { Pl. XXV, Figs. } 86 \text { A-D. }
$$

I836-Unio ellipsiformis Conrad, Monog. VIII, p. 60, pl. XXXIT, fig. I.

1845-Unio spatulatus Lea, Proc. Am. Phil. Soc., IV, p. I64.

I898-Lampsilis spatulatus Baker, Moll. Chicago, Pt. I, D. Io6, D] X, fig. 5 ; pl. XIII, fig. 2 . 
r goob-Lampsilis ellipsiformis Simpson, Proc. U. S. Nat. Mus., XXII, p. 557 .

ANIMAL CHARACTERS.

NUTRITIVE STRUCTURES:-Branchial opening with numerous yellowish papillae; anal very finely papillose; supra-anal small, high, closely but distinctly connected to anal; gills large, pointed even in the marsupial ones; inner laminae of inner gills connected entirely to visceral mass; palpi sickle-shaped; color of soft parts the usual dirty white with posterior mantle edges blackened.

REPRODUCTIVE STRUCTURES:-Marsupium occupying posterior half of outer gills, consisting of about twenty ovisacs separated by thick septa, when gravid extending below the original edge of sterile marsupium, tips pigmented with bluish, beaded spots; mantle edge antero-ventrad to branchial opening with papillae terminating in rather fine crenulations centrad-ventrad; conglutinates and glochidia unknown.

EXTERnAL STRuctures:- Shell small, elliptical, dorsal and ventral lines about the same curviture; post-umbonal ridge rather rounded; beaks very low, usually eroded, even in the youngest shells, thus sculpture not seen; epidermis brownish-yellow with bright waved rays all over disk; no sculpturing on disk; shells somewhat sexually dimorphic, the female being rather swollen post-ventrad.

INTERNAL STRUCTURES.-Cardinals strong, upright; interdentum large and thick; laterals short, stout, very slightly curved; beak cavities shallow; nacre white, sometimes with slight pinkish tinge and teeth rusty-red.

\begin{tabular}{cccccc} 
Sex & \multicolumn{6}{c}{ Length } & Height & Diameter \\
o & 56 & $\mathrm{x}$ & 33 & $\mathrm{x}$ & $22.5 \mathrm{~mm}$ \\
o & 43 & $\mathrm{x}$ & 28 & $\mathrm{x}$ & $2 \mathrm{I} .5 \mathrm{~mm}$ \\
ㅇ & 41 & $\mathrm{x}$ & 25 & $\mathrm{x}$ & $17.5 \mathrm{~mm}$ \\
ㅇ & 35 & $\mathrm{x}$ & 22 & $\mathrm{x}$ & $7.5 \mathrm{~mm}$
\end{tabular}

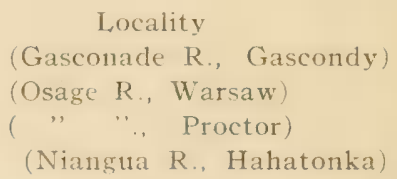

MISCELLANEOUS REMARKS:- This little striped shell is common throughout Central Missouri, but is never found anywhere in the interior north of the Missouri River and is rare in the southern drainage. Its shell may sometimes be taken for young $N$. liga mentina; however, the adult shells of these species are nothing alike. The anatomy of both are very similar; however, the inner mantle edge antero-ventrad to branchial opening is more specialized and indicates a step in advance. Hundreds of females were examined 
daily throughout July and the first two weeks of August to find them sterile in every case. Since Wilson and Clark (I9I2, p. 48) report it gravid for an earlier date this incomplete breeding would indicate that it is bradytictic.

Nephronaias ellipsiformis venusta (Lea).

Not figured.

I838-Unio venustus Lea, Tr. Am. Phil. Soc., VI, pl. II, fig. 4

I $900 \mathrm{~b}-$ Lampsilis venustus Simpson, Proc. U. S. Nat. Mus., XXII, p. 543 .

Animal Characters:- Entirely identical with those of the species both as to nutritive and reproductive structures. No glochidia have been found.

Shell Characters:- Also identical with the typical ellipsiformis-shell except for a small guttered furrow just antero-parallel to post umbonal-ridge of shell. The male shell of this sub-species is also more pointed posteriorly than the male type species.

Sex Length Height Diameter Locality

$\sigma^{7} 60 \times 37 \times 22 \mathrm{~mm}$ (Niangua R., Hahatonka)

ㅇ $55 \times 3 \mathrm{I} \quad \mathrm{x} 22 \mathrm{~mm}$ ( " " " " )

Miscellaneous Remarks:-The writer heartily agrees with Mr. Walker that venusta is very closely related to ellipsiformis and also with Mr. Frierson's opinion, that it is only a form of ellipsiformis. The type locality for $U$. venustus of Lea is Potosi, Washington County, Missouri, and belongs to the Meramec River basin. Simpson (190ob, p. 543) only reports it for that locality. Since then Rev. Wheeler has reported it for Arkansas; so has Wilson and Meek (I9I2. p. I9.). The writer has only found it in the Niangua River. Having such limited distribution and such lack of discriminating features from $N$. ellipsiformis there should be no hesitancy in naming venusta as a variety. From $\mathrm{N}$. pleasii this subspecies differs by a ticker, heavier, more coarsely rayed and more of a tawny clolored shell.

\section{Nephronaias Pleasii (Marsh).}

("Bleeding Tooth," "Pleas' Shell.") Pl. XXV, Figs. $A-D$.

I89I-Unio pleasii Marsh, "The Observer" (a newspaper), II, May; Nautilus, V. p. 2 .

r goob-Lampsilis pleasii Simpson Pr. U. S. Nat. Mus., XXII, p. 557.

Animal Characters:- No females have been secured by the 
writer; however, the nutritive structures of the males are identical with those of $N$. ligamentina and ellipsiformis.

SHELL CHARACTERS.

External Structures:- Shell sub-elliptical, rather thin, smooth, somewhat compressed, rounded before, obtusely angular behind; beaks rather low, sculptured by three or four fine shaped undulations; epidermis brown polished horn, with numerous green capillary rays, disposed mostly posteriorly and showing through the thin shell on the inside.

INTERNAL STRUCTURES:--Cardinals small, single in right, double in left valve, erect and parallel with laterals; left interdentum cut away for post-cardinal tooth; beak cavities rather shallow; nacre bluish, coppery or salmon in umbonal cavity.

\begin{tabular}{|c|c|c|c|c|}
\hline Sex & Lengti & Height & $\mathrm{t}$ Diameter & Locality \\
\hline $0^{7}$ & 55 & $2 \mathrm{I}$ & $\mathrm{x}$ i $3 \mathrm{~mm}$ & (White R., Hollister) \\
\hline $0^{7}$ & $35 \cdot 5$ & 21.5 & $13.5 \mathrm{~mm}$ & ", \\
\hline $0^{\pi}$ & 30 & 18 & I $2 \mathrm{~mm}$ & (James R., Galena) \\
\hline
\end{tabular}

Miscellaneous Remarks:-According to Mr. Marsh this shell bears some resemblance to Unio spatulatus Lea (i. e., $U$ ellipsiformis Conrad), but differs chiefly in being thinner, smaller and more compressed. It is like venusta in that the female shell is deeply emarginate or constricted in front of post-umbonal ridge as the writer determines from the author's description (189r, p. 2). This species was dedicated to Mr. Elwood Pleas of Indiana who collected this Species, together with many other rare Species, from South Missouri. It was also collected by Mr. S. M. Godbey at Morrisville, Polk Co., Missouri, who sent it to the National Museum where it is now recorded under the number, 132634. The writer found pleasii as a rather common shell in the White River, this State.

\section{Nephronaias ozarkensis (Call).}

("The Ozark Shell.")

\section{(Not figured.)}

I887-Unio ozarkensis Call, Pr. U. S. Nat. Mus., X, p. 498, pl. XXVII 1895, Tr. Ac. Sci. St. Louis, VII, p1). 33-34, P1. XVIII.

I $900 \mathrm{~b}-L a m p$ silis ozarkensis Simpson, Pr. U. S. Nat. Mus., XXII, p. 557

Animal Characters:- - Reference to rough field notes show 
that the soft parts are those of Nephronaias. The shell was identified later as ozarkensis of Call.

SHELL CHARACTERS.

EXTERnAL Structures:- Shell sub-elliptical, smooth, rather compressed; post-umbonal slope somewhat biangulate by siphonal ridges; beaks not prominent, sculptured by three fine undulations; epidermis brownish-yellow or olive with numerous fine green rays over central portion of disk; sexually dimophic.

INTERNAL STRUCTURES:- Cardinals tend to double in both valves, laterals rather short, slightly curved; nacre usual'y white, sometimes salmon or pink, irridescent; muscle scars confluent.

\begin{tabular}{ccccc} 
Sex & Length Height Diameter & \multicolumn{2}{c}{ Locality } \\
o & $55.0 \times$ & $35.0 \times$ & $2 \mathrm{I} .0$ & (Jack's Fork, Current R.) \\
$\sigma^{7}$ & $54.5 \times$ & $32.7 \times$ & 15.2 & (Jack's Fork, Current R.)
\end{tabular}

MiscELLANEOUS REMARKS:- The latter measurement is that of Call's taken for a shell from the same locality (which is one of the type localities of ozarkensis) as for the shell of the first measurement which is now in the hands of the writer through the kindness of Mr. B. F. Bush, but which is now too much damaged through shipment for figuring. Its shell is very much like that of $N$. pleasin as to general outline, but is a little thicker and has a different nacre and epidermis. Forms of this Species reported by Meek and Clark (1912, p. I8) for the White River drainage ard described as like "a very elongated Quadrula coccinea" and also identified by Mr. Walker as "Pleurobemae rather than species of Lampsilis" are doubtless only Pleurobemae utterbackii of Frierson. Definite assignment to the latter may be made for shells received from the White River, Hollister, Missouri, under the name of ozarkensis with the note:- "although not having Lampsiline beak sculpture." The reader is invited to compare descriptions and illustrations of Neph. ozarkensis and Pleu. utterbackii and note that the shell of the former does not possess such tumid beaks, nor such a furrowed post-slope, nor such distinct muscle scars, and its shell has its whole facies of a thinner, lighter character, thus being more inclined to a Lampsiline structure.

Genus Amygdalonaias Crosse and Fischer.

r893-Amygdalonaias Crosse and Fischer, Jour de Conch., pp. 31-32; I $900 \mathrm{~b},-$ Simpson, Proc. U. S. Nat. Mus., XXII, p. 604 (as subgenus for Plagiola). 


\section{(Type, Unio cognatus Lea.)}

Animal Characters:- Anal opening crenulated; supraanal widely separated from anal; inner laminae of inner gills connected to visceral mass except for a small posterior slit; palpi small; marsupia consisting of several ovisacs at posterior half of outer gill that acutely tapers; conglutinates white, undivided; glochidia smallest of all Naiades.

Shell Characters:- Shell among the smallest, roundly triangular, inflated, flattened on post-dorsal slopes; post-umbonal ridge sharply angular; disk smooth; beak rather full, sculptured with a few ridges, the latter ones being rather definitely double looped; epidermis greenish to yellowish with characteristic paintings of green arrow-marked rays; female shell slightly more inflated post-ventrad; hinge teeth delicate; nacre usually white.

Miscellaneous REMARKS:- Although this genus stands very close to Obovaria and Nephronaias, having essentially identical structures of soft parts, yet it deserves this compartment on account of its unique form, size and color markings of shell and especially upon its glochidial characters, being the smallest on record. The only two members of this genus are represented in this State by A. donaciformis (Lea) in North Missouri and by truncata (Raf.) in Central Missouri. The latter is never found north of the Missouri River and the former is rarely ever found in Central Missouri; neither have been found by the writer in South Missouri. The Osage River bears many intergrades for these two species.

Amygdalonaias donaciformis (Lea).

("Fawn's Foot," “Deer-Toe,” “'Zigzag.”)

$$
\text { Pl. XXV, Figs. } 89 A-D \text {. }
$$

I828-Unio donaciformis Lea, Tr. Am. Phil. Soc., 111, p. 267, pl. IV, Fig. 3 .

1820-Unio zigzag Lea, Tr. Am. Phil. Soc., III, p. 440, p. XII, fig. 19.

r898-Plagiola donaciformis Baker, Moll. Chicago, Pt. I, p. 92, pl. XIII, fig, 4; I $900 b$, Simpson, Proc. U. S. Nat. Mus., XXII, p. 605.

\section{ANIMAL CHARACTERS.}

NUTRITIVE STRUCTURES:-Branchial opening small with numerous papillae; anal indistinctly crenulated; supra-anal separated by a long and thick mantle connection to anal; inner laminae connected to visceral mass except for a narrow slit 
anteriorly; palpi small, connected one-half of their length anterodorsad; color of soft parts dirty white except for blackish mantle edge at siphonal openings.

REPRODUCTIVE STRUCTURES:-Marsupia rather low on postventral portion of outer gills; when gravid the numerous distinct ovisacs extend below the original edge of gill; glochidia smallest on record, measuring $0.600 \times 0.063$ min., semicircular, spineless, hinge line short, very slightly undulated; conglutinates white, loosely connected when glochidia mature.

SHELL CHARAC'TERS.

EXTERNAL STRUCTURES:- Shell very small, compressed, rounded before, pointed high behind; post-umbonal ridge rather prominent; disk smooth; beaks rather full sculptured by five upward angled bars extending out as finer concentric lines in later bars; epidermis green or olivaceous, painted with radiating green rays of zigzag or arrow-marks; female shell inflated post-ventrad.

INTERNAL STRUCTURES:-Cardinals double in left, single in right valve, compressed, high and ragged; interdentum narrow; laterals single in right, faintly double in left; nacre pearl blue or white. rarely pink.

\begin{tabular}{|c|c|c|c|c|c|c|c|c|}
\hline Sex & Leng & & Heigh & at & Diameter & & Loc & cality \\
\hline$\sigma^{7}$ & 54 & $\mathrm{x}$ & 30 & $x$ & $22 \mathrm{~mm}$ & (Grand & R., & Gallatin) \\
\hline @ & 35 & $\mathrm{x}$ & 22 & $\mathrm{x}$ & $15 \mathrm{~mm}$ & (Platte & R.. & Dixon Falls) \\
\hline 우 & 33 & $x$ & 20 & $\mathrm{x}$ & $\mathrm{I} 4 \mathrm{~mm}$ & & , , & Agency Ford \\
\hline$\sigma^{x}$ & I 4 & $\mathrm{x}$ & 8.5 & $\mathrm{x}$ & $9.5 \mathrm{~mm}$ & (Grand & R., & Darlington) \\
\hline q & I I & $\mathrm{x}$ & 7.0 & $\mathrm{x}$ & $4.5 \mathrm{~mm}$ & & , & Chillicothe) \\
\hline
\end{tabular}

The last two are among the smallest juveniles in the writer's collection. The smallest meets with the following description:Post-umbonal ridge sharply angled; beaks prominent, well up toward middle of dorsal line, sculptured by five early bars bowed upward in the center, the latter ones being rather fine, concentric: epidermis green with costa-like paintings on the post-dorsal ridge; disk with two rows of zigzag paintings parallel to the growth lines. Four juveniles of this species were found in the Osage clinging to one byssal thread, but unfortunately they were lost.

MisceldaneOUS REMARKS:-Typical donaciformis may be easily distinguished from Amyg. truncata in possessing a smaller shell, more painted, thinner, less inflated, more dorsally ridged, and is more of an inhabitant of quiet water with mud-sand bottom. Donaciformis is more supplanted in Central Missouri by truncata 
(Raf.), but, as stated before, it takes the place of the latter wholly in North Missouri. The North Missouri Grand River bears donaciformis in its most typical form. The writer finds this species most colonial in their habits, and has been able to find many of them nearly every month of the year, but has not found any gravid during the winter. The earliest date for the bearing of glochidia is June Igth. No previous public record has ever been made of this unique glochidium. From the above data it may be inferred that it is not bradytictic as is mostly the breeding habit of the Lampsilinae. 'This little mussel is also eccentric in that while in the parasitic stage it develops an adult shell five times the size of the glochidial one. Surber (1913, p. 109) finds that its specific distributor is "Sheep's Head" (A. grunniens).

Amygdalonaias truncata (Rafinesque).

("Deer-Foot," or "Deer-Toe.") $X X V$, Fig. $88 A$ and $B$.

I820-Unio truncata Rafinesque, Ann. Gen. Sci. Phys. Brux.

$183 \mathrm{I}$ - Unio elegans Lea, Am. Phil. Soc., IV, p. 83., pl. fig. I 3.

1898-Plagiola elegans Baker, Moll. Chicago, Pr. I, p. 91, pl. XXI, fig. I; I 900 b, Simpson, Pr. U. S. Nat. Mus., XXII, p. 604.

I 9 I 2b-Amygdalonaias elegans (Lea) Ortmann, An. Car. Mus., XXII, p. 328

\section{ANIMAL CHARACTERS.}

Nutritive Structures:- Identical with those of donaciformis.

REPRODUCTIVE STRUCTURES:-Branchial mantle margin a little more thickened with slight crenulations than in donaciformis; glochidia a little larger, measuring $0.060 \times 0.070 \mathrm{~mm}$-otherwise these structures are identical with those of donaciformis.

\section{SHELL STRUCTURES.}

EXTERNAL, STRUCTURES:--Shell short, roundly triangular, inflated; post-umbonal ridge sharply angulated from beaks to posterior point of shell; disk smooth; beaks rather prominent, sculptured with a few fine ridges more or less double-looped or sinuated; epidermis yellowish, brownish or even grreenish with beautiful paintings of green broken by arrow-marked rays; no sex dimorphism of shell, both sexes being rather swollen postventrad.

INTERNAL STRUCTURES:- With the exception of a deeper and 
more rounded out branchial cavity and somewhat coarser cardinals these structures are identical with those of donaciformis.

Sex Length Height Diameter

$\begin{array}{lllllll}0 & 50 & \times & 36 & \times & 25 & \mathrm{~mm}\end{array}$

ㅇ $43 \times 34 \times 23 \quad \mathrm{~mm}$

\& $38 \times 30 \times 17 \mathrm{~mm}$

o $37 \times 27 \times 16.5 \mathrm{~mm}$
Locality

(Osage R., Linn Creek)

(Gasconade R., Gascondy)

(Osage R., Schell City)

(" ", " Proctor)

MiscellaneOUS REMARKS:- As pointed out under the description of donaciformis, truncata is as distinct when typical as its only con-generic ally-especially in its broadly truncated shell post-dorsad. Neither is truncata so sexually dimorphic; however, the male shell is unusually more elongated and pointed posteriorly and has less inflation. Both sexes have their shells rather expanded post-ventrad. This species is rarely found in South Missouri, (the writer not having made personal collections of it there at all) although it is really more of a southern species than donaciformis. It is not to say very typical in the Osage or Gasconade basins where there are many intergrades for it and its ally, but reaches its greatest perfection in the Mississippi. The breeding habits of this species is the same as that of donaciformis as far as records show.

\section{Genus Plagiola Rafinesque.}

r819-Plagiola Rafinesque, J. de Phys. Chim. Hist. Nat., p. 426; 1852, Agassiz, Arch, Fur Nat., p. 48, (redefined); I goob, Simpson, Pr. U. S. Nat. Mus., XXII, p. 603.

\section{(Type, Unio securis Lea.)}

Animal Characters:- Anal opening smooth, connected to supra-anal by close mantle attachment; inner laminae of inner gills free or partly connected to visceral mass; gills brownishall other soft parts tannish; marsupium rather reniform consisting of 40-50 well defined ovisacs; conglutinates lanceolate, not very solid; glochidium spatulate, very much higher than long, spineless, very large.

SHELl. Characters:- Shell sub-triangular, solid, not greatly inflated, with square cornered post-umbonal ridge and flat postdorsad; disk smooth; beaks pointed, rather high, sculptured with faint double-looped ridges; epidermis yellow with broken rays; cardinals low and jagged; laterals rather stout, straight or slightly curved; nacre white.

Miscellaneous Remarks:- The chief characteristic of this 
genus is in its peculiar shell and glochidial characters. As to its animal characters it is essentially that of Obovaria and Amygdalonaias. Because of its spatulate and higher-than-long glocidia there is "a transition," as Dr. Ortmann aptly puts it, "toward the glochidia of the Proptera-type," which has essentially the same hinge line and rounded ventral margin, but with different postterior and anterior ends.

\section{Plagiola securis (Lea).}

(Butterfly.")

Pl. II, Figs. $5 a-6 b$.

I829-Unio securis Lea, Tr. Am. Phil. Soc., III, p. 437, pl. XI, fig. 17. 1834 -Unio lineolata Say, ${ }^{\mathrm{I}} \mathrm{Am}$. Conch., VI

I 900 -Plagiola securis (Lea) Simpson, Proc. U. S. Nat. Mus., XXII p. 603 .

ANIMAL, CHARAC'TERS.

Nutritive Characters:- Branchial opening rather small with numerous papillae; anal crenulated; supra-anal very large closely, but definitely connected by mantle edges to anal; anus tentacled; inner laminae of inner gills free about three-fourths of their length from the visceral mass; palpi large, connected one-third of their length antero-dorsad; color of soft parts tan, or cream color with gills brownish and papillae yellowish.

REPRODUCTIVE STRUCTURES:-- Marsupium composed of about twenty-five ovisacs placed in the posterior half of outer gill; mantle border antero-ventrad to branchial opening with about fifteen very low, irregularly placed papillae; marsupium when charged with ripe glochidia color of brown sugar, somewhat kidney shaped; conglutinates not very solid; glochidia subelliptic or spatulate hinge line very short, ventral margin round, spineless, much higher than long $(0.230 \mathrm{x} .330 \mathrm{~mm})$.

SHELL CHARACTERS.

ExTERnal STRUctures:- Shell sub-triangular, not very much inflated, compressed in umbonal region, truncated narrowly postdorsad; disk more or less smooth; beaks somewhat pointed and directed anteriorly, sculptured with a few fine concentric

${ }^{1}$ This name, as employed by Say, was really preoccupied by Rafinesque in his Monograph of 1820 and hence through priority this species should bear the name Plagiola lineolata (Raf.) in spite of the fact that Simpson considered this as one of the many "indeterminates" of Rafinesque. 
and indistinctly double-looped ridges; post-umbonal ridge square cornered from beaks to post-extreme; epidermis yellowish or light brown painted with rays broken into square or lunate blotches; female shell smaller, thicker, shorter and more inflated than male.

INTERNAL STRUCTURES:-Cardinals rather low, ragged the the right one having four vertical subparallel ridges; interdentum broad; laterals stout, rather long and sharply inclined; beak cavities, moderately deep; nacre silvery white, irridescent.

\begin{tabular}{cccccccl} 
Sex & Length & Height & Diameter & \multicolumn{3}{c}{ Locality } \\
$0^{7}$ & 96 & $\mathrm{x}$ & 79 & $\mathrm{x}$ & $33 \mathrm{~mm}$ & (Merame R., Meramec Highlands) \\
क & 70 & $\mathrm{x}$ & 56 & $\mathrm{x}$ & $37 \mathrm{~mm}$ & (Marais des Cygnes, Athol) \\
क & 67 & $\mathrm{x}$ & 53 & $\mathrm{x}$ & $30 \mathrm{~mm}$ & (Miss. R., Hannibal) \\
$0^{7}$ & 48 & $\mathrm{x}$ & 36 & $\mathrm{x}$ & $\mathrm{I} 6 \mathrm{~mm}$ & (", "NaGrange)
\end{tabular}

Miscellaneous Remarks:- $P$. securis being more of a marine type of shell than fresh water renders it worthy of the creation of a genus. The young shell is like that of an "exquisite shell from the sea-shore," so narrowly flattened is it post-dorsal portion of shell, so delicately painted with broken lunate rays and so arched forward are its compressed and pointed umbones. This species is not found at all in the interior north of the Missouri River; neither is it found in Southwest Missouri. It is rather common in the Osage, Gasconade and Meramec though not very typical as a rule. The most perfect securis is the Mississippi. The writer found this species from the Mississippi bearing ripe glochidia June $22 \mathrm{nd}$; Wilson and Clark (1914, p. 52) found the Cumberland securis in the same gravidity June 3-16. Dr. Ortmann finding it gravid in late fall again fixes its breeding season as normally bradytictic.

\section{Genus Lasmonos Rafinesque.}

I820-Lasmonos Rafinesque, Monograph, Ann. Gen. Sci. Phys. Brux. 1911b-Paraptera Ortmann, Mem. Car, Mus., IV pp. 331, 334, 338.

\section{(Type, Lasmonos fragilis Rafinesque.)}

Animal Characters:- Siphonal openings large inclined to be tubular; supra-anal high, well separated from anal; inner laminae of inner gills entirely connected to visceral mass; palpi free their whole length post-dorsad, color of soft parts grayish with yellowish papillae on blackened mantle edge or branchial opening; marsupium kidney-shaped, consisting of several ovisacs occupying posterior part of outer gills; conglutinates white, leaf-like, not 
very solid; glochidia very small, sub-ovate; spineless, hingt line short, slightly curved.

Shell Characters:- Shell thin, sub-elliptical, alated, compressed; post-umbonal ridge lacking; disk smooth; unbones low marked with fine concentric lines followed by later doublelooped bars; epidermis glistening tawny, rayed; sex-dimorphism shown in wider more blunt vertically at posterior end of female shell; hinge teeth reduced to rudiments.

MiscellaneOUS REMARKS:-This genus is also constructed on the basis of characters relating to shell and glochidia rather than to anatomical structures. On basis of glochidial characters alone it classes with Amygdalonaias; however its shell characters throw it near to the genus Proptera. Lasmonos is represented in this State by its type (which is the commonest shell in North Missouri) and by simpsoni Feriss. The latter is grouped here tentatively until its soft parts are studied as its shell characters more closely relate it to the type of this genus than to any other. The species, Leptodea leptodon Rafinesque, is perhaps congeneric here and much depends upon its marsupial and glochidial characters, which are as yet unknown; however, the writer has not been fortunate enough to secure live specimens of this species (not even dead shells) in this State, but, because of the use Rafinesque made of it, we are concerned here for nomenclatural reasons, for should it be found to be really congeneric with fragilis, aside from its several shell characters, the generic name, Leptodea, would take preference to the one herein used.

Lasmonos fragilis Rafinesque.

("Paper Shell," "Razor Back.")

Pl. IX, Fig. I9; Pl. XXVI, Figs. go A-D.

$1820-$ Lasmonos fragilis Rafinesque, Mono. Biv. of Ohio

1823 - Unio gracilis Barnes, Am. J1. Sci., VI, p. 274

1861 - Unio dolosus Lea, J1. Phil. Ac., V, p. 75

1 goob-Lampsilis gracilis Simpson, Pr. U. S. Nat. Mus., XXII, p. 573

$1912 \mathrm{~b}$-Paraptera gracilis Ortmann, An. Car. Mus., VIII, p. 331.

ANIMAL CHARACTERS.

NUTRITIVE STRUCTURES:- Branchial opening round, with spreading, yellowish tentacles; anal slightly crenulated, with thickened edges and normal diaphragm: supra-anal long, extending to dorsal ala, usually closed; mantles parallel at edges, dark colored 
and thickened on edges of siphonal openings, white patch at base of branchial papillae, crenulated along border in front of branchial opening, post-ventral region of mantle darker than that of female; palpi united only at base, very long in old specimens; foot large, powerful, very extensile; gills dark tan, pointed posteriorly, inner gills longer and broader than outer, inner laminae of inner gills entirely connected to visceral mass.

REPRODUctive Structures:- Marsupia occupying posterior part of outer gill, reniform, consisting of about forty, leaf-like ovisacs and, when gravid, extending beyond original edge of gills, the extreme thickness of tissue here allowing the bulging out until glochidia escape through the ruptured edge; conglutinates white, elongate, leaf-shape, not very solid, usually surrounded with brick-red matter; glochidia among the very smallest $(0.085 \mathrm{~mm}$. by $0.075 \mathrm{~mm}$.) belonging to the Lampsilis type (i. e., semi-elliptical, ventral margin rounded, gaping, hookless, short hinge line which is slightly undulate.)

SHELL CHARACTERS.

External Structures:- Shell medium in size, thin, alate, posterior end of female shell blunt; beaks compressed, marked with three or four wrinkles arranged in a double loop ending with two or three rather nodulous elevations at the base of the postumbonal slope; epidermis straw color with bright green rays in young and well preserved specimens.

INTERNAL STRUCTURE:- - Cardinal teeth very weak, single in each valve; lateral teeth more solid, long, lamellar, elevated, no interdentum; muscle scars faint, retractor large and peculiarly placed; beak cavity shallow; nacre pearl-blue with the usual characteristic pink on the posterior portion.

\begin{tabular}{|c|c|c|c|c|c|c|}
\hline 2 & Lengtl & & Yidtl & Diamet & $\mathrm{L} \mathrm{m}$. & Locality \\
\hline q & 80 & $\mathrm{x}$ & 40 & 23 & 0.250 & (Perche Cr., Columbia) \\
\hline$\sigma^{7}$ & I 40 & $\mathrm{x}$ & 70 & 47 & 0.210 & (Grande R., \\
\hline 우 & 74 & $\mathrm{x}$ & 38 & 26 & 0.275 & (Platte R., Agency Ford) \\
\hline$\varsubsetneqq$ & 70 & $\mathrm{x}$ & 37 & 25 & 0.283 & ( $\mathrm{IO}_{2}$ R., St. Joseph) \\
\hline & 21.5 & $\mathrm{x}$ & II & 5.5 & 0.260 & Colley's Ford, \\
\hline
\end{tabular}

BySSIFEROUS JUVENILE:--The latter measurement is taken from a jurenile collected in the Osage River, Colley's Ford Mo.. July 15, I9r3. It possessed a bysuss I 6omm. long and was attached 
to a plicate shell. This byssal thread was so strong that it pulled off with some difficulty and was split in three strands near its base, each being marked by a muscilaginous substance. The umbonal markings of this flat straw-colored juvenile shell consists of four broadly inverted $\mathrm{V}$-shaped ridges the rear line being finer, longer and closer together, extending down the posterior umbonal ridge.

Miscellaneous REMARKS:- $L$. fragilis is distinctly a river form for this State, although we would naturally think that this alated and thin-shelled species would be established in the lakes and other quiet waters of Northwest Missouri, especially where it predominates the streams. Breeding records for this species show that it may bear glochidia every month of the year except for a few weeks in mid-summer; hence, a very long period breeder. It was found in August distending its ovisacs with water preparatory to ovulation. Only two other species possess smaller glochidiathose of Amygdalonayas donaciformis (Lea) and A. elegans (Lea) with which fragilis is closely related; however, external characters of shell alone-especially as to size and form-show no close connection. Fragilis may be distinguished from other similar alated forms by its peculiar yellow surface, marked by brown horn-colored restlines, depressed umbones, green rays in young and broadly elliptical outline in old specimens, if their alae are lost as is often the case. Through special cooking tests the writer has found out that nearly all the soft parts of this species is very edible. It is also economically important in producing pearls, since it is easily parasitized. No mussel is more active and as it anchors itself so firmly it is often extracted from its bed with great difficulty. The straw-colored and green rayed juveniles are easily located, not so much by color as by their "tracks" since they are the most active crawlers. This species is the most abundant in the One-Hundred-and-Two, Platte, Grand, Tarkio, Osage - in fact all the streams of Northwest and Central Missouri as determined by personal collections. It is poorly developed in the Osage and is not found at all further South in the clear-water streams of the Ozarks. Simpson reports it for the Missouri River, but I think he means only for the tributaries of the Missouri as no mussel life is actually reported in the main stream of this River throughout the State. Its general distribution is for the entire Mississippi River drainage; 
St. Lawrence system; Red River of the North; Eastern Texas and Cumberland River.

\section{Lasmonos simpsoni (Ferriss).}

(Simpson's Shell.)

$$
\text { Pl. XXVI, Figs. } 9 I A \text { and } B \text {. }
$$

r $900-L a m p s i l i s$ simpsoni Ferriss, Nautilus, xiv, p. 38.

Animal Characters unknown to writer.

SHELL CHARACTERS.

External Structures:- Shell subovate, elongated, subsolid, narrowly rounded in front, broadly rounded behind, somewhat alated; disk smooth; beaks low, sculptured by ridges somewhat corrugated and nodulous; epidermis tawny with green rays with rather roughened growth lines; hinge line evenly curved.

INTERNAL STRUCTURES:--Cardinals reduced to mere stumpy rudiments; laterals single in right, very faintly double in left valve; anterior scars rather deep, posterior shallow; nacre bluish shaded with violet, copper or pink.

\begin{tabular}{ccccccc} 
Sex Length Height Diameter & \multicolumn{3}{c}{ Locality } \\
$\sigma^{7}$ & 78 & $\mathrm{x}$ & 46 & $\mathrm{x}$ & $28 \mathrm{~mm}$. \\
& (White R., Hollister)
\end{tabular}

MiscellaneOUS ReMarks:-No juveniles, nor young shells, have been obtained by the writer in this State. However, Mr. Ferriss, the author, has obtained a good suite from Spring River, Hardy, Arkansas, and has described the young shells as possessing an epidermis with green rays and "coppery beaks," a well marked post-umbonal ridge and low but distinct beaks with coarse corrugations. The author of this species, groups it between Lasmonos fragilis and leptodon. From the former it may be distinguished by a thicker more elongated shell, by more reduced hinge teeth and less varigated nacre and from the latter by being more inflated, wider, thicker, not so pointed posteriorly and with fewer rays. Hence its place can be fairly well determined conchcologically. Future studies of its marsupial and glochidial characters of this species, as well as that of leptodon ( $=S$. teniussimus Lea), may classify it far differently, since shell characters are too liable for parallelism and convergence as true bases of classification. 


\section{Lasmonos leptodon? (Rafinesque).}

Not Figured.

1820-Unio (Leplodea) leptodon Rafinesque, Ann. Gen. Sci. Phys. Brux., p. 295, Pl. LAXXX.

1829-Symphynota tenuissimu Lea, Tr. Am. Phil. Soc., III, p. 435, Pl. XI, Fig. $2 \mathrm{I}$.

This species is listed here on the strength of reports of its occurrence in the Mississippi and Neosho Rivers of this State. From a shell, (measuring $58 \times_{3} \mathrm{IXI}_{4} \mathrm{~mm}$.), received from Michigan through exchange, the author is able to make comparisons and thus concur with the general assumption that it should group under Lasmonos. However, superficial observations would group it near Lastena ohiensis, but presence of hinge teeth, although not well developed, and also different beak sculpture would sufficiently separate it. Surely the "clear water streams" of South Missouri may also yield specimens of this species since the same rivers that reach up into Missouri are reported to bear it in Arkansas. Scammon (1906, pp. 304 and 305) reports it for Kansas and Simpson describes its general range for the upper Mississippi drainage south to the Tennessee River and for Southern Michigan. ${ }^{1}$

\section{Genis Proptera Rafinesque.}

I819-Proptera Rafinesque, Monog. An. Gen. Sci. Phys. Brux.;-19oob, Simpson, Pr. U.S. Nat. Mus., XXII, p. 566, (as sub genus); 1912 b, Ortmann, An. Car. Mus., VIII, p. 332.

\section{(Type, Unio alatus Say)}

Animal CHARACTERS:- Branchial opening with dense papillae; anal crenulated; supra-anal small, moderately closely connected to anal; inner laminae entirely connected to visceral mass; palpi only slightly antero-dorsad; marsupia reniform occupying posterior part of outer gills, consisting of several ovisacs; conglutinates not solid, broken; glochidium ax-head or celt-shape, usually armed with two spines at each corner of ventral edge of each valve; mantle border antero-ventrad to branchial opening slightly lamellar with crenulations only.

Shell Characters:- Shell subelliptic or subovate, solid to thin, strongly alated post-dorsad; disk smooth; hinge fairly well

I The presence of L. leptodon in Missouri need not be so questionable now because of A. A. Hinkley's recent report of it in the James River at Galena this State. (Dec. 23, I915. Pr. U. S. Nàt. Mus., Vol. 49. p. 588 ) 
d : veloped; beaks low, sculptured by the early bars of fine concutric arrangement and later one of double-lonped type--sometimes rather nodulous at base of post ridge; sexually dimorphic, the female shell being wider posteriorly by the expansion of the post-ventrad edge of shell.

MiscelLANEOUS REMARKS:- With the exception of unique glochidium and more developed hinge this genus stands with Lasmonos. Proptera is represented in this state by the four species: alata, which is found mostly in Central Mo., purpurata which only occurs in South Mo., laevissima which is mostly restricted to North Mo., and capax which is entirely confined to the Mississippi River. The last named species has not been definitely settled within any genus before on account of a lack of an exact determination concerning the morphology of its animal. The extreme inflation of the capax shell, as compared to the compressedtype of the other members of this genus, would seem to shut it out, but glochidial and marsupial characters (besides its similar beak sculpture) are by far more reliable affinities. All the members of this most sharply defined genus are long period breeders.

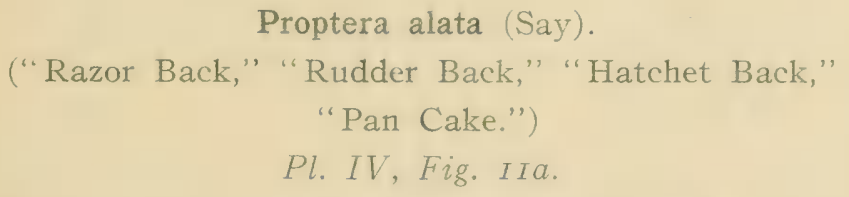

I 8 I6-Unio alatus Say, Nich, Encyc., II, pl. IV, fig. 2.

I898-Lampsilis alatus Baker, Moll. Chicago, Pt. I, p. 97, pl. XVIII.

rg1 2b-Proptera alata (Say) Ortmann, An. Car. Mus., VIII, p. 333.

ANIMAL CHARACTERS.

NUTRITIVE STRUCTURES:- - Branchial and anal openings inclined to tubular structure, branchial upcurved, small with numerous papillae; anal smooth thick edges; supra-anal large thick and close mantle connection to anal; inner laminae of inner gills entirely connected to visceral mass; palpi about as wide as long, connected about one-half of their length antero-dorsad; color of soft part tan-flesh color with dark mantle edges and orange colored cerebral ganglion.

REPRODUCTIVE StRUCTURES:-Marsupia large, occupying posterior half of outer gills, consisting of large ovisacs sulcated ventrad mantle edge antero-ventrad to branchial opening lamelar with 


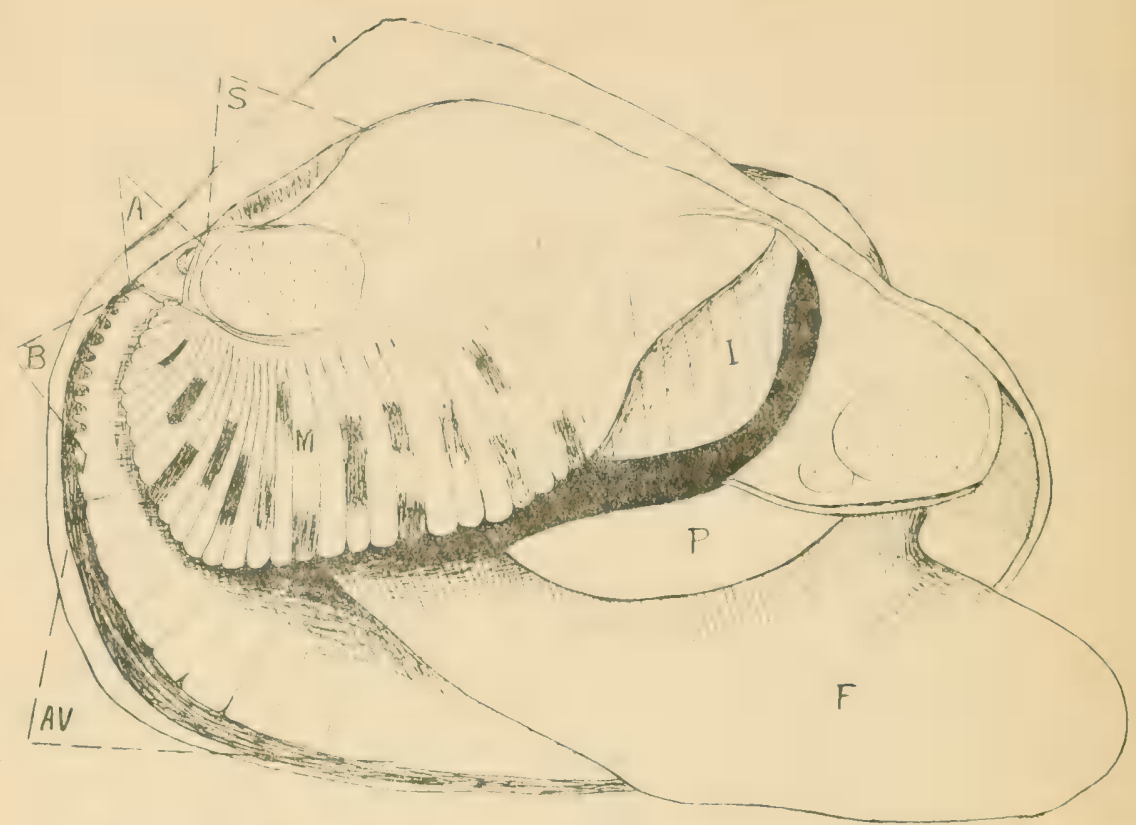

FIG. 8. Proptera alata (Say) ?. Diagram of a gravid individual from Platte River, Agency Ford, showing animal characters in left valve. Coll. June 7,1913 . ( $3 / 4$ Nat. size.)

crenulations; conglutinates large, broken with ova or glochidia all through the mass; glochidia large, ax-head shape, with spine at each ventral corner of shell $(0.220 \times 0.380 \mathrm{~mm}$.).

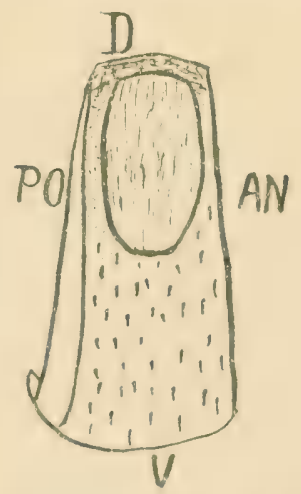

FIG. 9a. Lateral view of mature glochidium of $P$. alata. $(\times 87$.)

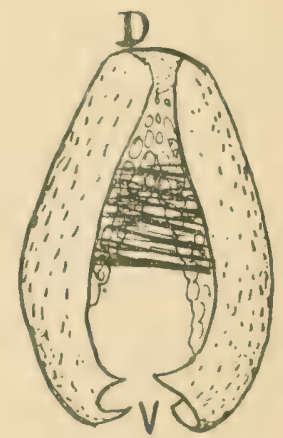

FIG. 9 b. Anterior view of open glochidium of $P$, alata. ( $(\times 87$. 


\section{SHELL CHARACTERS.}

ExTERnal STRUctures:- Shell large broadly elliptical, solid alated post-dorsad; somewhat inflated at middle of disk, beaks low sculptured concentrically and also double-looped; disk not sculptured; epidermis usually black-reddish with broad rays in young specimens; female shells blunt, or even truncate, vertically for its posterior end.

INTERNAL STRUCTURES:- Cardinals erect-double in both valves; laterals also double placed at an upward angle; beak cavities moderately deep; nacre usually purple.

\begin{tabular}{|c|c|c|c|c|c|c|}
\hline Sex & Lengt & & Heigl & & Diameter & Locality \\
\hline † & 156 & $\mathrm{x}$ & II 7 & $\mathrm{x}$ & 56.5 & (Platte, R., Dixon Falls \\
\hline$\sigma^{7}$ & 150 & $\mathrm{x}$ & I I 4 & $\mathrm{x}$ & 5.3 .0 & Platte City) \\
\hline \% & II 5 & $\mathrm{x}$ & 55 & $\mathrm{x}$ & 33.0 & (Osage R., Warsaw) \\
\hline q & 82 & $\mathrm{x}$ & 54 & $\mathrm{x}$ & 26.0 & (Grand R., Utica) \\
\hline
\end{tabular}

Miscellaneous Remarks:- This species is most typical in North Missouri; the shell is thinner, smaller and rather dwarfed in Central Missouri and is wholly lacking in South Missouri drainage. The writer has only found alata lacustrine on one occasion, but that may have been due to accidental translocation. Breeding records show it to be bradytictic. The writer has observed that most marsupia of this species, when gravid with ripe glochidia, have purplish blotched marsupia; this character, however, is rather inconstant. Alata has a general distribution throughout the Mississippi and St. Lawrence River basins.

Proptera purpurata (Lamarck).

("Purple Shell," "Purply," "Buttermilk Shell," Red Shell.") Pl. XXVI, Figs. 92 A-D.

I819-Unio purpurata Lamack, An. Sans, Vert., VI, p. $7 \mathrm{r}$.

190ob-Lampsilis purpuratus Smpson, Pr. U. S. Nat. Mus., XXII, p. 568 .

I 9 I2b-Proptera purpurata (Lam.) Ortmann, An. Car. Mus., VIII, 1). 234 .

\section{ANIMAL CHARACTERS.}

NUTRITIVE Characters:- Identical with those of alata.

REPRODUCTIVE STRUCTURES:-Marsupium consists of twenty ovisacs placed in posterior half of outer gills; glochidia (according to Lea) ax-head shape-no measurement given.

SHELL CHARACTERS.

EXTERnal STRUCTURES:- Shell large, rather elongate-ellip- 
tical, inflated; disk smooth; beaks high and full; post dorsal ridge somewhat alated; post umbonal ridge biangilated; epidermis slossy black.

INTERNAL STRUCTURES:- Cardinals double in both valve; laterals prominent, blade-like: umbonal and branchial cavities deep and rounded out; nacre rich purple.

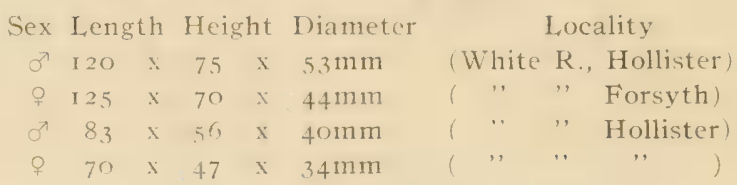

MiscellanEOUS REMARKS:-The young shells of $P$. purpurata are thin and fragile but later become thick and solid; resembling alaia in form and nacre but is more so alated not compressed. This shell only appears in the White and Neosho River basins and is one of the few not found in the Mississippi. Its favorite habitat is deep water and mud bottoms. It is hoped its glochidium may be verified and more proportionate measurements given than Lea was able to record.

\section{Proptera laevissima (Lea).}

\section{("Paper Shell," "Double Wing.")}

Pl. IX, Figs. Io and 20; Pl. XXVI, Figs. 94 A-D.

r830-Symphynota laevissima Lea, Tr. Am Phil Soc., III, p. 444, pl. XIII, fig. 23 .

I $900 \mathrm{~b}-$ Lampsilis laevissima Simpson, Pr. U. S. Nat. Mus., XXII, 1). 574

rara-Proptera laevissima (Lea) Ortmann, An. Car. Mus., VIII, p. 334

\section{ANIMAL CHARACTERS}

NUTRITIVE STRUCTURES:- Branchial and anal openings very tubular, directed away from each other; anal smooth; supra-anal high, well separated from anal by mantle connection; inner laminae of inner gills entirely connected to visceral mass; palpi broader than long, connected about one-half of the length anterodorsad; color of soft parts a modest tan, except for mantle edges at siphonal openings and the area over nephridium.

ReProductive STRUCTURES:-Marsupium large, kidneyshaped occupying over half of posterior part of outer gills and consisting 50-60 narrow ovisacs somewhat distended transversely 
and very much so ventrad from original edge of sterile marsupium, ventral tips of ovisacs teat-like, not colored; conglutinates white, discharged in broken disintegrated masses; glochidium ax-head shape or celtiform, small with spine-like structures measuring o. 100 x 0.I55mm; branchial mantle edge thickened, lamellar, but without palpilae.

\section{SHEI,L CHARACTERS.}

EXTERNAL STRUCTURES:- Shell elliptical compressed, thin, bialated, post-ala being drawn near to the beaks in definite lobes of growth, sometimes curved laterally; disk without any sculpture post-umbonal ridge absent, female shell swollen post-ventrad epidermis brown-glistening horn-color with faint rays and areas of indigo blue especially on post wing; beaks low, suppressed sculptured with a few fine concentric lines and a row of three small tubercles on line with a post-ridge.

INTERNAL STRUCTURES:- Cardinals thin, erect, double in right, single in left valve, laterals rather reduced; scars somewhat faintly impressed; beak and branchial cavities rather shallow; nacre solid purple.

\begin{tabular}{|c|c|c|c|c|c|}
\hline Sex & Lens & & $\mathrm{Hel}$ & ht & Diameter \\
\hline का & 150 & $\mathrm{x}$ & 105 & $\mathrm{x}$ & $42 \mathrm{~mm}$ \\
\hline$\sigma^{\pi}$ & 14.5 & $\mathrm{x}$ & 90 & $x$ & $39 \mathrm{~mm}$ \\
\hline O & I 37 & $\mathrm{x}$ & 89 & $\mathrm{x}$ & $37 \mathrm{~mm}$ \\
\hline 우 & +1 & $\mathrm{x}$ & 23 & $\mathrm{x}$ & $12 \mathrm{~mm}$ \\
\hline
\end{tabular}

Locality
(102 R., St. Joseph)
(Mud Lake, Kenmoor)
(Platte, R., Agency Ford)
(Lake Contrary, St. Joseph)

The last measurement of a juvenile-the youngest and smallest Naiad shell ever found gravid by the writer. Its glochidia were normal. Many of these juveniles are in the writer's cabinet. having been collected in "nests" from L. Contrary for the most part. The shells are like those of ground glass in color and transluscent both externally and internally. Beaks are rather apiculated and marked by rather coarse concentric ridges with three teat-like tubercles arranged in a row on line with post-ridge, resembling juvenile beak sculpture of Lasmonos.

MiscelLANEOUS REMARKS:- This species may represent the critical transition period from the primitive to the actual modern forms. Its glochidium is not a true Proptera form in not possessing typical spines at the ventral corners of its valves. Coker and Surber (I9II, pp. I79-182) have pointed out its metamorphosis in the parasitic life as eccentric in that the glochidium remains 
intact as a saddle over the beginning of its adult shell. No species, perhaps, has such tubular development of mantle edges for the branchial and anal openings. In this state its distribution is peculiar, being almost exclusively found in North Missouri and never in South Missouri. It is often found in company with alata from which it can be separated on account of thick shell and coarser epidermis of the latter. It may be mentioned here that laevissima shows the highest modern development of the siphonal openings, i. e., into the actual tubular form. (See Plate IX). This Species is distinctly bradytictic.

\section{Proptera capax (Green).}

("Pocket Book," "Swell Shell.")

$$
\text { Pl. XXVI, Figs. } 93 \mathrm{~A} \text { and } B \text {. }
$$

I832-Unio capax Green, Cab. Nat. Hist., II, p. 290.

1899-Lampsilis capax Smith, Bull U. S. Fish Com., p. 291, pl. LXXIV.

ANIMAL CHARACTERS.

NUTRITIVE STRUCTURES:- Branchial opening with rusty red papillae arranged in two ranks; anal finely crenulated; supra-anal large with two large tentacular siructures on each mantle edge; inner laminae of inner gills entirely connected; palpi rounded anteroventrad, connected antero-dorsad two-thirds of their length; color of soft parts tanish, mantle edge antero-ventrad, reddishbrown.

REPRODUCTIVE STRUCTURES:-Marsupium occupying the greater posterior part of the outer gill, consisting of about fifty small ovisacs distended transversely when gravid, and being also distended at the distal ends the ovisacs presenting teat-like appearance; no mantle flap antero-ventrad to branchial opening, nor any specialization except for a thickening of the mantle edge; conglutinates not solid, white; glochidium ax-head or hatchetshape in form, spined, rather small, 0.105 $\mathrm{x}$ 0.1 $85 \mathrm{~mm}$.

SHELL, CHARACTERS.

ExTERNAL Structures:- Shell rather globose, extremely inflated; disk smooth; beaks extremely full, round, high, sculptured with single tubercles on incurved tips surrounded by fine concentric ridges looped into two or three small tubercular markings at very base of post ridge; epidermis smooth, polished, 
brown horn-color, sometimes with yellowish narrow bands parallel to growth lines, rayless.

INTERNAL STRUCTURES:-Cardinals double in right, slightly so in left valve and arranged parallel with laterals; interdentum short; laterals single in right, double posteriorly in left valve; beak and branchial cavities very deep and large, basin-like; nacre white with light rosy pink in branchial cavities, border light bluish.

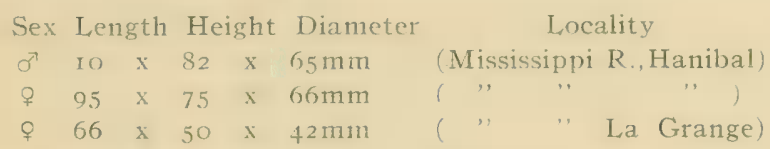

Miscellaneous Remarks:- Capax has the most inflated shell of the Naiades, yet because of the fact that it is rayless and has no sex dimorphism, nor furrowed beak sculpture, nor pure white nacre of $L$. ventricosa it must be removed far from the latter although its immensely inflated shell would superficially class it near ventricosa. Its great inflation is not any greater, however, than that of the relative inflation of the laevissima shell in the last stage of its parasitic life. Most of all, anatomical material kept by the writer, shows no mantle flap $(P l . X X V I, f i g .93 B)$ as seen in $L$. ventricosa, nor as to be noted in any Lampsilis, and the mantle edge antero-ventrad to the branchial opening is not even as much specialized as in laevissima, or alata; hence its place perhaps should precede lacvissima, at least, but is placed last in the grouping under this genus on account of its most peculiarly inflated shell which may show an advance over the other species that show the other extreme in possessing a compressed shell in their adult life. Capax is very rare shell for this State. It has a rather limited geographical distribution over the whole country; however, Simpson reports it as abundant locally, yet the writer's experience in collecting it for in the Mississippi is that it is rare even there and it was considered a stroke of good fortune to secure glochidially gravid material showing proptera characters.

\section{Genus Carunculina Simpson. \\ (Type, Unio parvus Barnes.)}

1898-Carunculina Simpson (in Baker, p. 109, as section). Igoob--Carunculina Simpson. Proc. U. S. Nat. Mus., XXII, p. 563. (as subgenus); I912b, Ortmann, Car. Mus., VIII, p. 337 (as subgenus).

AnImal CHARACTERS:--Branchial opening small with rather 
large papillae; anal smooth, supra-anal large, closely connected to anal; inner laminae of inner gills free, more or less, from the visceral mass; palpi small, connected half of their length anterodorsad; marsupia formed by a few large ovisacs occupying posterior part of outer gills, reniform; branchial edge with a papillose caruncle; conglutinates solid, white, club-shaped, glochidia medium in size, semi-elliptic.

SHell CHARACTERS:- Shell very small, elliptic, rounded before, rather thick, disk smooth; beaks low, coarsely sculptured by regular concentric bars upcurved behind; epidermis dark cloth-like.

MiscellaneOUS REMARKS:- This is a good genus as now considered by Dr. Ortmann who treated it at first ( I912, p. 337) as a subgenus for Enrynia, but even then he was inclined to consider it as merely conventional whether we use it generically or subgenerically. Carunculina is remarkable for its smallest sized shells, for its unique beak sculpture and for its peculiarly specialized mantle edge antero-ventrad to the branchial opening. It is well represented in this State by the typè, parza, and although the writer has not personally collected tecxasensis and glans yet these two have been reported in such manner that they can be definitely listed.

\section{Carunculina parva (Barnes).}

("Liliput Shell.")

$$
\text { Pl. III, Fig. 8c; Pl. XXVII, Figs. } 95 A-D \text {. }
$$

1823-Unio parius Barnes, Am. J1. Sci., VI, pl. XIII, fig. I 8 (outline). 1 $900 \mathrm{~b}-$ Lampsilis parvus Simpson, Pr. U. S. Nat. Mus., XXII, p. 564. I9rab-Eyrynia (Carunculina) parva Ortmann, An. Car. Mus., VIII p. 338 .

\section{ANIMAL CHARACTERS.}

Nutritive Structures:- Branchial small, directed upward, with few but large papillae; anal also pointed upward, smooth, supra-anal present, closely but definitely connected by mantle edge; inner laminac of inner gills usually free from visceral mass about one-half of their length; palpi comparatively large, connected antero-dorsad about two-thirds of their length; color of soft parts tan-color except for a blackish or reddish border to mantle at branchial opening.

REPRODUCTIVE STRUCTURES:-Marsupia kidney-shaped, con- 
sisting of twenty ovisacs, well marked, occupying posterior half of outer gills, somewhat distended transversely and also at distal ends below the original line of sterile marsupium; border of mantle antero-ventrad to branchial opening greatly specialized into a double row of red papillae terminating in a knobbed caruncle, which, under $\left(x_{87}\right)$ lens, is cellular -each cell being hexagonal in shape; conglutinates white, discharged whole, club-shaped, glochidia medium in size, sub-elliptical, hinge line straight, spineless, measures $0.175 \times 0.100$.

\section{SHELL, CHARACTERS.}

EXTERNAL STRUCTURES:- Shell very small, rather thick, elliptical, rounded before, disk without sculpture; beaks low with six coarse regular, parallel bars evenly curved up at foot of postridge region; epidermis brownish to reddish or olivaceous, clothlike female shells broader posterior ends made by more swollen post ventral portion, males with pointed shells.

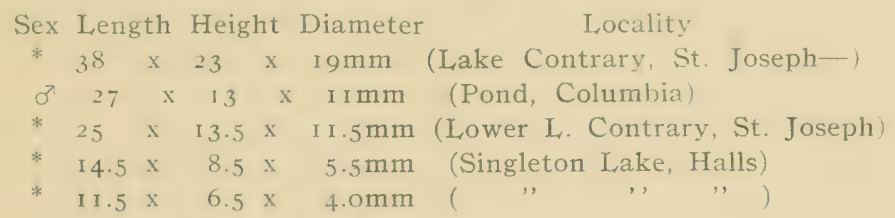

The writer obtained about forty juveniles, within the range of the last two measurements, in shallow clear water along the northwest shore of Singleton Lake. They were confined to a small space and were traced here and there among a maze of tiny tracks. These juvenile shells differ from the adult by a thinner shell, more pointed posteriorly, a more greenish epidermis, more compressed, and by a coarser beak sculpture which, although arranged the same in its concentric bars curved up posteriorly, yet they extend down well on the center of the disk. (See Pl. III, fig. 8c).

MISCELLANEOUS REMARKS:- The writer is able to bear out the statements of Drs. Sterki and Ormann that parva is locally hermaphroditic. In the past three years, hundreds have been collected in nearly all the Northwest Missouri lakes and streams, but not a single one has been found without the marsupial character of gills and the sexually dimorphic female shell. However, the male and female shells appear in Central Missouri. In all specimens

\footnotetext{
* This symbol (*) would indicate hermaphroditism here.
} 
for this State the writer finds the supra-anal opening present. Its presence has been doubted by some other writers. This pygmied mussel has great vitality. The writer records thirty-eight heart beats per minute-among the most rapid of the Naiades. It is one of the most active in its locomotion. Its breeding season show it to be bradytictic. The writer has been fortunate to secure parva's glochidium and make more of a definite study than has been recorded since Lea left his studies. (Obs. XIII, I874, pl. XXI, fig. 2.)

\section{Carunculina texasensis (Lea).}

("Texas Shell.")

Not figured.

1857-Unio texasensis Lea, Pr. Ac. Nat. Sci. Phila,, p. 84; Jl. Ac. N. Sci., IV, I 860, p. 359 , pl. XLI, fig. I 84

1862-Unio bealei Lea, J1. Ac. N. Sci., V., p. 204, pl. XXX, fig. 273.

19rab-Eurynia (Carunculina) texasensis Ortmann, An. Car. Mus., VIII, p. 339.

AnImal CHARACTERS:- The writer not having seen the soft parts of this species quotes Simpson's description:- "Animal with marsupium consisting of a few large ovisacs ( 8 to I3); inner gills wholly, or in part, free from the abdominal sac; female often having a well developed caruncle on the mantle below the branchial opening."

SHELL CHARACTERS.

EXTERNAL STRUCTURFS:- -Shell small, rather thick, subinflated, smooth, rounded before, pointed post-dorsad; postumbonal ridge rather prominent, especially in the female shell, which is shorter, more inflated and not so pointed posteriorly; epidermis a dark slaty color with one or two whitish rest lines; beaks low with coarse concentric bars upcurved at base of postridge.

INTERNAL STRUCTURES:- Cardinals double in right, faintly so in left valve; laterals single in both; interdentum lacking; beak and branchial cavities rather shallow and irridescent posteriorly.

\begin{tabular}{cccccccc} 
Sex & Length & Height & Diameter & \multicolumn{2}{c}{ Locality } \\
$0^{7}$ & 45 & $x$ & 24 & $x$ & $17.5 . \mathrm{mm}$ & (Lost Creek, Amity) \\
\& & 37 & $\mathrm{x}$ & 20 & $\mathrm{x}$ & $\mathbf{1} 2.0 \mathrm{~mm}$ & (Lost Creek, Amity)
\end{tabular}

Miscellaneous ReMARKS:-Comparison to some types of texasensis from Wimberly Lake, Texas, assures the writer that 
the specimens of the above measurements are a near approach, at least, to this species. However, this species is listed for Mo. more on the strength of Mr. Simpson's report of it for Harrison County, Missouri. where the famous author of the "Synopsis of the Naiades" used to reside. He states that texasensis ranges north into northern Missouri, southern Illinois and Indiana. This species is a good one and should be shut out of the synonomy of parva especially because its posterior end of shell is never evenly rounded, nor is its epidermis as cloth-like and nacre awhite as that of parva. The sex dimorphism, too, is different, as determined by the above description of shell.

\section{Carunculina glans (Lea). \\ ("Little Purple.") (Not figured.)}

1834-Unio glans Lea, Tr. Am. Phil. Soc., p. 82, Pl. VIII, fig. 12. Obs. X, I 863 p. 402 .

I goob-Lampsilis glans Simpson, Pr. U. S. Nat. Mus. XXII, p. 56.5.

I9r2b-Eurynia (Curunculina) glans Ortmann, An. Car. Mus., VIII, p. 339 .

Animal and SHell Characters:- Since the writer has not secured any actual shells or soft parts for this species the descriptions of these parts do not appear here.

MiscellaneOUS REMARKS:-The writer would also lay claim to this species for Missouri from Simpson's report of it for the White River, and also from a few scattered reports of it through some local collectors for the Elk River and other Southern Missouri streams. From Lea's description (Obs. X., I 863, pp. 402 and 405) and also from Wilson and Clark's ( I9 I2, p. 48) this species falls under this genus. From shells received by the writer in exchange it would seem to be more nearly like a young $P$. purpurata. It is distinguished from $C$. paria in being a wider, shorter, thicker, heavier and more polished shell and also in possessing a prominent post-umbonal ridge and a coppery and purple nacre.

\section{Genus Eurynia Rafinesque.}

(Type, Unio recta, Lamarck.)

I8120-Eurynia Rafinesque Monog., Ann. Gen. Sci Phys. Brux.; I $900 \mathrm{~b}$, Simpson, Pr. U. S. Nat. Mus., XXII, p. 534 (as section); I 912 b, Ortmann An. Car. Mus., VIII, p. 336 (as genus). 
ANImAL Characters:- Siphonal openings well formed: inner laminae of inner gills usually entirely connected to the visceral mass; in male no specialization, but in female the inner edge of mantle antero-ventrad to branchial opening always with well developed papillae, or short tentacles which often extend to the central of ventral edge; marsupium reniform, swollen, consisting of many ovisacs occupying posterior part of outer gill and ventral edges beaded in white or black pigment when gravid; conglutinates white, not very solid; glochidia-large or medium in size, semi-elliptical.

MiscellaneOUS REMARKS:- The special structures on the mantle antero-ventrad to the branchial opening would group this genus among the highest of the Lampsilinae from the fact that the aerration of the embryos is well secured through such specialization. Especially because of the number, form and arrangement of the papillae two sub-genera may be marked out. In the following description when the specialized mantle edge is discussed the female is considered.

\section{Siub-genus Micromya Agassiz.}

$$
\text { (Type, Unio fabalis Lea.) }
$$

I852-Micromya Agassiz, Arch. für Nat., p. 57; rgi2b, Ortmann, An. Car. Mus., VIII, p. 337.

AnIMAL Characters:- Mantle edge antero-ventrad to branchial opening specialized by papillae, both regular and irregular, arranged rather widely separated in a single row but never extending to the middle of the ventral margin; inner laminae of inner gills entirely connected, or more or less free.

SHELl ChARACTERS:- Shell sub-elliptical, small or medium in size; beak sculpture rather double looped-or distinctly sinuate with the posterior sinuation rather open.

MISCEII.ANEOUS REMARKS:-This sub-genus is represented in this state by three species all found only in the Ozarks. 'The type fabalis of Lea of Micromya is not found anywhere in Missouri. The essential distinction between the two sub-genera, Micromya and Eurynia (sens. strict.) is in the less extensive and less crowded arrangement of the papillae on the inner edge of the mantle antero-ventrad to branchial opening in the former. 


\title{
Eurynia (Micromya) lienosa (Conral.)
}

\author{
("Little Spectacle Case.") \\ Pl. XXVII, Figs. go A-D.
}

1834-Unio lienosus Conrad, An. J1. Sci., XXV, p. 339, pl. I, fig. 4.

I goob-Lampsilis lienosus Simpson, Pr. U. S. Nat. Mus., XXII, p. 547

I912b-Eurynia (Micromya) lienosa (Conrad) Ortmann, An. Car. Mus., VIII, pp. 340 and 34I.

ANIMAL CHARACTERS.

NUtritive STRUCTURES:-Branchial opening with two-ranks of papillae; anal crenulated; supra-anal high, small, closely connected by mantle edges to anal; inner laminae of inner gills more or less free from the visceral mass; palpi subfalcate connected antero-dorsad about one-half of their length; color of soft parts soiled white except mantle edge of siphonal area blackish, gills brownish.

REPRODUCTIVE Structures:- Marsupium kidney-shaped, restricted to posterior half of outer gill, consisting of twenty-five distinct ovisacs, which, when gravid, distend transversely in middle and ventrad as white beadlike bodies; inner mantle edge of females antero-ventrad to branchial opening with eight to ten conical tentacles rather wide apart and reaching a little over half way centrad-ventrad; conglutinates large, club-shaped; glochidia large, subovate, measuring $0.220 \times 0.270 \mathrm{~mm}$.

\section{SHELL CHARACTERS.}

EXTERnal, Structures:- Shell small, elliptical, moderately inflated, thick; post-umbonal ridge rounded; disk smooth; umbones low sculptured with inverted V-shapes; epidermis reddish brown with dark banded rays; female shell expanded post-ventrad, male rather biangulated behind.

INTERNAL STRUCTURES:-Cardinals double in left, single in right valve; laterals also double in left, single in right; interdentum lacking; beak cavities moderately deep; nacre purplish with old gold and copper-color in branchial cavity.

$\begin{array}{ccccccc}\text { Sex } & \text { Length } & \text { Height } & \text { Diameter } \\ \text { \% } & 53 & x & 30 & x & 21.5 \mathrm{~mm} \\ \sigma^{7} & 50 & \mathrm{x} & 30 & \mathrm{x} & 20.0 \mathrm{~mm} \\ 0^{7} & 42 & \mathrm{x} & 26 & \mathrm{x} & 17.0 \mathrm{~mm} \\ \text { \% } & 29 & \mathrm{x} & 18 & \mathrm{x} & 1 \mathrm{I} . \mathrm{omm}\end{array}$

Locality

(Black R., Williamsville

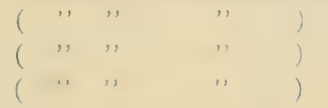


Miscellaneous Remaris:- In the young shell of the last measurement the beaks were sculptured with inverted $\mathrm{V}$-shaped ridges similar to that of subrostrata. This species is only found in the Black River for this State. Rev. Wheeler considers lienosa as intergrading with nigerrima and while the two are usually found in the same locality yet nigerrima is more likely to occur as a creek form. The writer obtained some gravid August 29 with late embryos. The young one of the above measurement was gravid and, as preserved, shows many characters like that of subrostrata but can be separated on account of an insufficient development of mantle edge antero-ventrad to branchial opening.

\section{Eurynia (Micromya) iris (Lea.) \\ ("Rainbow Shell.") \\ Pl. XXVII, Figs. $97 A$ and $B$.}

1830-Unia iris Lea, Tr. Am. Phil. Soc., III, p. 439, pl. IX, fig. I 8.

I898-Lampsilis iris Baker, Moll. Chicago, Pt. I., p. I05, pl. XIII, fig. I; pl. XIV, fig. 2

Iglab-Eurynia (Micromya) iris (Lea) Ortmann, An. Car. Mus., VIII, p. p. $34 \mathrm{I}$ and 342

\section{ANIMAL CHARACTERS.}

NUTRITIVE STRUCTURES:-Branchial opening densely papillose; anal crenulated; supra-anal large, closely connected to visceral mass; palpi small, one-half connected antero-dorsad; color of soft parts dark tan with posterior part of gills and mantle blackish.

REPRODUCTIVE STRUCTURES:-Marsupia composed of twenty closely crowded ovisacs occupying post-half of outer gills; inner mantle edge fringed with eight or ten papillae, the most anterior ones reaching well toward the center of ventral edge where they are larger, postero-curved and terminating in small low papillae near the branchial opening-all rather wide apart; glochidia rather large, subovate measuring $0.240 \times 0.300 \mathrm{~mm}$.

SHELL CHARACTERS.

EXTERnAL STRUCTURES:--Shell small, elongate-elliptic, thin, dorsal line slightly curved, ventral straight; compressed anteriorly inflated in center of post-umbonal ridge; beaks pointed but low, sculptured by seven or eight double-looped ridges; epidermis 
smooth reddish-brown with bright green rays arranged all over its shell.

INTERNAL, STRUCTURES:- Cardinals double in both valves, laterals double in left, single in right; beak cavities rather shallow; nacre white or light bluish.

\begin{tabular}{|c|c|c|c|c|c|}
\hline$\sigma^{7}$ & 45 & $x$ & 22 & $\mathrm{x}$ & I $5 \mathrm{~mm}$ \\
\hline q & 35 & $\mathrm{x}$ & 18 & $\mathrm{x}$ & I Omm \\
\hline 우 & 34 & $\mathrm{x}$ & 16 & $\mathrm{x}$ & I I $\mathrm{m} ! \mathrm{m}$ \\
\hline$\sigma^{7}$ & 22 & $\mathrm{x}$ & 12 & $\mathrm{x}$ & $7 \mathrm{~mm}$ \\
\hline
\end{tabular}

\section{Locality}

(Jack's Fork of Current R.)

(White R., Hollister)

(Black R., Williamsville)

(Jack's Fork of Current R.)

The last measurement is that of a young shell that shows a beak sculpture of a profusely double-looped or corrugated ridges the latest one being the strongest and running down quite low on the disk.

MiscelianeOUS Remarks:-For this State iris is strictly a southern shell, being only found in the White and Black River basins. Perhaps this pretty little shell is much more common than supposed, since it is so liable to escape observation due to its minuteness of size yet its bright green rays of uneroded shells make it rather conscpiuous in clear shallow water. It has been found to be bradytictic.

\section{Eurynia (Micromya) brevicula (Call).}

("Broken Rays," "Soul-of-Wit.")

$$
\text { Pl. XXVII; Figs. } 98 \mathrm{~A}-D \text {. }
$$

I887- - inio breviculus Call, Pr. U. S. Nat. Mus., X, p. 499, pl. XXVIII;

Tr. Ac. Sci. St. Louis, VII, (I895) p. 6, pl. XVI.

I goob-Lampsilis breviculus Simpson, Pr. U. S. Nat. Mus., XXII, p. 533 .

\section{ANIMAL, CHARACTERS.}

NUtRITIVE: Characters:- Branchial opening densely papillose; anal crenulated; supra-anal large, high, well separated from anal with thick, spotted mantle edges; inner laminae of inner gills not free from visceral mass; palpi rather large, connected by their edges one fourth of their length antero-dorsad.

REPRODUCTIVE STRUCTURES:- Marsupium rather kidneyshaped consisting of ten or fifteen ovisacs well separated, with bluish ventral border and each ovisac presenting a beaded appearance of black pigmented spots; in female mantle border anteroventrad to branchial opening with a flap-like structure bearing eight 
or ten papillae terminiating toward the center of ventral border with longer finger-like tentacles; glochidium unknown, but is identical doubtless with that of its sub-species, Brittsi.

SHEI, CHARACTERS.

ExTERnAL STRUctures:- Shell elliptical, medium in size, usually rather thin, evenly rounded before; post-umbonal ridge not present; beaks large but low sculptured by six inverted Vshaped ridges with their apices pointing toward the tips of the beaks and with the posterior ridges extending out as longer and more oblique rows at the base of the post-ridge region; epidermis smooth, shiny, straw-color with coarse broken rays most pronounced posteriorly.

INTERNAL STRUCTURES:- Cardinals erect, double in left, single in right valve; interdentum narrow; laterals double in left, single in right, blade-like; beak cavities rather deep and baselike; nacre bluish or whitish with tinge of pink in umbonal cavities.

\begin{tabular}{|c|c|c|c|c|c|c|c|c|}
\hline Sex & Len: & & Heiq & ht & Diameter & & \multicolumn{2}{|c|}{ Locality } \\
\hline$\sigma^{7}$ & 64 & $\mathrm{x}$ & 40 & $\mathrm{x}$ & $27 \mathrm{~mm}-1$ & White & R., & Hollister) \\
\hline 우 & 55 & $\mathrm{x}$ & 47 & $\mathrm{x}$ & $22.5 \mathrm{~mm}-($ & ", & " & ", \\
\hline 우 & 51 & $\mathrm{x}$ & 40 & $\mathrm{x}$ & $23 \mathrm{~mm}-($ & ,' & ", & ," \\
\hline$\sigma^{\pi}$ & 40 & $\mathrm{x}$ & 25 & $\mathrm{x}$ & $\mathrm{mm}-($ & , , & , & ," \\
\hline
\end{tabular}

MiscellaneOUS Remarks:- This species is strictly a S. Mo. shell and its sub-species is only found in Central Missouri. Some of the South Missouri streams bear brevicula that almost approach Brittsi; however, brevicula is a rather common shell in the streams of the south slope of the Ozarks, where it is typical. Young shells of this species are very thin, while the adult shells become very thick comparatively. Perhaps this species exhibits sexual dimorphism more than any of this genus. The female had a much broader, shorter more inflated shell than the male; the latter being more or less biangulated behind. The slightly long incurved post-ventral portion of the female shell is very characteristic. Gravid females are unknown. Brevicula is the largest, most emphatic member of the Micromya group.

\section{Eurynia (Micromya) brevicula Brittsi (Simpson).}

("Britts' Shell.")

$$
\text { Pl. XXVII; Figs. } 99 A \text { and } B \text {. }
$$

I $900 a-L a m p s i l i s$ brittsi Simpson, Pr. Ac. Nat. Sci. Phila., p. 76, pl. V., fig. I and 2; I goo b, U. S. Nat. Mus. Pr., XXII, p. 533 


\section{ANIMAL CHARACTERS.}

Nutritive Structures:-Branchial opening large with large yellowish papillae; anal crenulated; supra-anal moderately separated from anal by distinct mantle connection; gills wide, the inner slightly longer and wider, the inner laminae connected with the visceral mass their entire length; palpi wide and large, united one fourth of their length antero-dorsad; color of soft parts tancolor except foot which is more yellowish and mantle edge which is black for the siphonal openings.

REPRODUCTIVE STRUCTURES:-Marsupia wide, more or less reniform, consisting of about a dozen large distinct ovisacs, distended, when gravid, transversely in center and along the ventral edge into black pigmented beads at the distal ends; conglutinates white, rather club-shaped; glochidia moderately large, semi-elliptical, hinge line slightly oblique and undulate measuring $0.250 \times 0.305 \mathrm{~mm}$., mantle edge antero-ventrad to branchial opening with a flap extending toward the center of ventral margin with about ten papillae beginning rather low at edge of branchial opening and ending with tentacular processes at end.

\section{SHELL CHARACTERS.}

EXTERNAL, STRUCTURES:- Shell medium in size, thick to thin, subelliptical; post-umbonal ridge lacking; beaks large but lowsculptured by six inverted $\mathrm{V}$-shaped ridges the posterior ones being longer and thrown more or less obliquely across post-umbonal slope; disk without sculpture; male shell rounded before, rounded and more or less biangulated behind; female shell very deeply and widely sulcated at the post-ventral margin of shell and is less elliptic in general outline, also thicker and more inflated than male shell; epidermis yellow to olivaceous with broad, widely separated rays of interrupted lunate or $\mathrm{V}$-shaped splotches-all covering the whole shell.

INTERNAL STRUCTURES:-Cardinals stout, double in left, single in right valve; interdentum long, narrow; laterals short somewhat curved reaching far back; beak and branchial cavities rather deep and basin-like; scars well impressed; nacre white, pinkish and irridescent posteriorly.

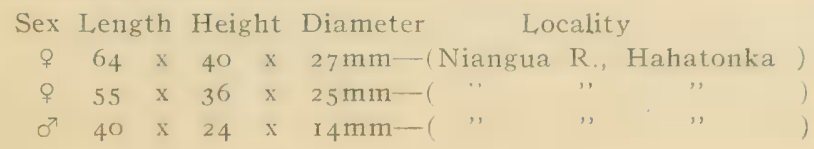


The peculiarity of the shell of this sub-species (as well as that of the species) is that the younger the shell the very much thinner. It is also more brilliantly tawny and green rayed.

MISCELLANEOUS REMARKS:- Surely this form of brevicula, found by the writer in its type locality, Niangua River, has enough peculiar characters to entitle it to a good species, as Simpson had first considered it. Its special characteristic is the very wide, deep emargination in the female shell at its post-ventral margin. However, it is almost identical with its parent species as to its soft parts. Its tentacled lamellar-like flap on the mantle edge antero-rentrad to the branchial opening is somewhat like that of ventricosa and hence might be grouped under the Lamp. luteola group; however, the smaller papillae along the posterior end of the flap (or rather thickened mantle edge) would class it more as an Eurynia. Brittsi is to be distinguished from its parent by the greater post-ventral sulcus (Fig. 99), which extends in as a rather deep radial furrow for a short distance forming the greatest inflation of the shell in front of this. It also differs in shell characters from the female species (brevicula) in not being so broad posteriorly and not as rounded post-dorsad. Dr. Britts collected the originals from Niangua River and sent them to Simpson for naming; hence the consequent name of this species. Cotypes (now in the hands of the writer and illustrated herewith) collected from almost the same point in the Niangua show a decided difference from cotypes of Call's brevicula many of which are now in the writer's collection, through the kindness of Mr. B. F. Bush, one of the most active students and collectors of Naiad shells now living in this State. This sub-species is bradytictic as inferred from the writer's brief breeding record. He has had the good fortune to collect the glochidia of this form for the first time. In all probability this glochidium is the same as that of Call's brevicula. However, its breeding season secms to be a little different as the writer collected many of the species only a day or two later to find them all sterile.

Sub-Genus Eurynia (Sens. Strict.) Rafinesque. I912b-Eurynia (as sub-genus), Ortmann, An. Car. Mus., VIII, p. 338. (Type, Unio recta Lamarck.)

Animal Characters:-Differs from those of Micromya in the structure of its rough mantle edge antero-ventrad to branchial opening being more differentiated into a greater number and longer 
row of papillae on the inner edge extending down quite to the central part of the ventral edge. These papillae are often quite tentacular and are rather regular and uniform in shape and size and are never widely separated as in case of the Micromya mantle edge of this anterior branchial border. Its inner laminae of the inner gills are usually entirely connected with the visceral mass; however, a small hole is sometimes left at the posterior end postdorsad to foot.

Shell Characters:- In shell characters there are no great distinctions to be considered as a group since the chief distinguishing characteristic is in the post-mantle edge as above discussed. Its beak sculpturing is identical with that of the Micromya shell being sinuated or double-looped, the posterior loops being more or less broken behind.

This group of Eurynia is represented in this State by E. $(E)$ subrostrata and recta, both having rather wide distribution.

Eurynia (Eurynia) subrostrata (Say).

("Common Pond-Mussel," "Lilliputian.")

Pl. XXVII; Figs. InI A-D.

1831 - Unio subrostratus Say, New Harm. Diss.

1850-Unio mississippiensis Conrad, J1. Ac. N. Sci. Phila., r, p. 277,

pl. XXXVIII, fig. I I

I868-Unio topekensis Lea, Pr. Acad. Nat. Sci. Phila., XII, p. I 44. 1900 -Lampsilis subrostratus Simpson, Pr. U. S. Nat. Mus., XXII, p. 546 .

19 12b-Eurynia (Eurynia) subrostrata (Say), Ortmann, An. Car. Mus., VIII, p. 344 .

ANIMAL CHARACTERS.

NUTRITIVE Structures:-Branchial opening narrowly papillose; anal finely papillose supra-anal separated from anal by a rather short mantle connection; inner laminae of inner gills connected to visceral mass; palpi rather small and connected anterodorsad about one-fourth of its length; color of soft parts grayish with mantle edge along siphonal region blackish.

REPRODUCTIVE STRUCTURES:-Marsupia kidney (or rather) fan-shaped, consisting of twenty large, well defined ovisacs, distended, when gravid, at ventral edge thus giving the conglutinates a club-like shape; ventral tips of ovisacs beaded bcaring bluish pigment with glochidia scattered throughout the sacs: 
gJochidia rather large, semi-elliptical, spineless, regularly rounded ventrad, hinge-line straight, measures $0.270 \times 0.330 \mathrm{~mm}$.; mantle edge antero-ventrad to branchial opening in female with numerous regular papillae extending quite down to the central part of ventral border.

\section{SHELL CHARACTERS.}

EXTERnAl STRUCTURES:- Shell small to medium in size, rather elongate-elliptic, thin, compressed; post-umbonal ridge rounded; female shell very wide and blunt posteriorly, male pointed and narrow; umbones low, sculptured by eight or ten coarse, regular, inverted $V$-shaped ridges with the apices pointed toward tips of beaks, the posterior ridges longer and more disposed obliquely across base of post-ridge; disk without sculpturing; epidermis brown to black with many rays disposed posteriorly and showing through on the nacreous surface.

INTERNAL STRUCTURES:-Cardinals double in both valves, rather thin and erect; laterals thin, double in both valves; scars rather well impressed; beak and branchial cavities rather deep and hollowed out; nacre white to light bluish irridescent posteriorly.

\begin{tabular}{|c|c|c|c|c|c|}
\hline $2 y$ & Len: & th & Hei & & Diameter \\
\hline $0^{2}$ & 62 & $\mathrm{x}$ & 27 & $x$ & $21.5 \mathrm{~mm}$-(Flat Creek, Sedalia). \\
\hline o & 65 & $\mathrm{x}$ & 36 & $\mathrm{x}$ & 25.5 mm-(Hinkston Creek, Columbia) \\
\hline 0 & 50 & $\mathrm{x}$ & 28 & $\mathrm{x}$ & I $5.5 \mathrm{~mm}$-(Lost Creek, Amity) \\
\hline 0 & 36 & $\mathrm{x}$ & 18 & $\mathrm{x}$ & I3.5 mm-(Flat Creek, Sedalia) \\
\hline
\end{tabular}

This last measurement is for one that has preserved soft parts and although it is very young and small yet it is gravid with normal glochidia. Its beak sculpture is very distinct as shown above in the description of shell character.

MiscellaneOUS REMARKS:-Subrostrata is a creek and pond shell, but in spite of this lacustrine disposition it is never found in any of the North West Missouri lakes. Like $U$. tetralasma it adjusts itself easily and quickly to artificial ponds and channels. It is never found in large rivers nor swift streams. It has a general distribution over the State, especially in the ponds and quiet creeks of Central part. Simpson gives it a general distribution over the entire Mississippi drainage north of about latitude $4 \mathrm{I}^{\circ}$. The breeding season of subrostrata is a long one. Its glochidia scem to be very constant in size for wiclely separated localities. Comparisons have been made of glochidia from mussels of Central Missouri 
sculptured by fine concentric ridges disposed somewhat like that of with those from the Mississippi to find them precisely identical in every respect.

\title{
Eurynia (Eurynia) recta (Lamarck). \\ ("Spectacle-Case," "Black Sand Shell.") \\ Pl. XXVII; Figs, I00 A-D.
}

\author{
I819-Unio recta Lamarck, An. Sans. Vert., VI, p. 74. \\ 1823-Unio praelongus Barnes, Am. J1. Sci., Ist ser., VII, p. 26I, fig. I I. \\ r goob-Lampsilis rectus Simpson, Pr. U. S. Nat. Mus., XXII, pp. \\ $544-545$. \\ 19r2b-Eurynia (Eurynia) recta (Lam.) Ortmann, An. Car. Mus., \\ VIII, p. 344 .
}

\section{ANIMAL CHARACTERS.}

NUTRITIVE STRUCTURES:-Branchial opening with numerous papillae; anal finely crenulate; supra-anal separated from anal by moderate mantle connection; inner laminae of inner gills connected to visceral mass; palpi small, almost entirely free along their antero-posterior edges; color of soft parts grayish with its posterior mantle border blackish or reddish brown.

REPRODUCTIVE STRUCTURES: - Marsupium rather kidneyshaped consisting of fifty large ovisacs extending below the original ventral line into thickened, cream-colored, cone-shaped beads when gravid; ova lying in irregular masses within the sacs; mantle edge antero-ventrad to branchial opening specialized with very great number of large, densely crowded papillae extending entirely to the center of the ventral edge; conglutinates white, glochidia rather medium in size, semi-elliptical, spineless, rounded ventral edge, hinge line undulated, measure $0.220 \times 0.280 \mathrm{~mm}$.

\section{SHELL CHARACTERS}

EiXTERnal STRUCTURES:-Elongate-elliptic, heavy, rather thick, large; female shell broader and more blunt posteriorly than male; no post-umbonal ridge; disk smooth; beaks large, low sculptured by fine concentric ridges disposed somewhat like that of

I This Species is the most generally distributed of the Lampsilinae. (See accompanying Map (Plate XXIX) for three other generally distributed Species; viz., Cumberlandia monodonta $(S a y)$ as representative of Margaritanidae, Quadrula verrucosa (Raf.) of Unioninae and Strophitus edentulus (Say) of Anodontinae. 
subrostrata; epidermis black, glossy, rayed with broad reddish stripes.

INTERNAL STRUCTURES:--Cardinals very long and stout, double in both valves; laterals long, somewhat pointed in male, more or less horizontal in female; nacre usually rich purple but is variable to white, or the two colors may be present for the same individual.

\begin{tabular}{|c|c|c|c|c|}
\hline S & Leng & & Height & Diameter \\
\hline$\sigma^{7}$ & 125 & $\mathrm{x}$ & $53 \mathrm{x}$ & 3 I mm-(Black R., Williamsville) \\
\hline 우 & 109 & $\mathrm{x}$ & 48 & 3omm-(Osage R., Osceola) \\
\hline$\sigma^{7}$ & 96 & $\mathrm{x}$ & 40 & $25 \mathrm{~mm}$ - (Gasconade, Gascondy) \\
\hline ㅇ & 78 & $\mathrm{x}$ & 30 & I $8 \mathrm{~mm}$-(White R., Hollister) \\
\hline
\end{tabular}

Miscellaneous Remarks:- No juvenile shells are at hand. Adolescent shells of recta are even difficult to obtain. Recta is not a variable shell for this state; even in nacre-color it is rather constant-being more purple in Central Missouri and white in South and Southwest Missouri streams. This species has one of the widest distributions in the state; however, it is seldom found in the North Missouri streams. It is strictly fluviatile. According to Simpson it has a very general distribution over the United States, although it is not very "common in its individual occurrence anywhere. The predominance of one sex over another in this species for the same stream is more noticed than in any other. Probably this occurrence is due more to breeding season than to any other cause. The writer notes from his own record, and that of others, that this species is bradytictic.

Surber (I913, p. I09) finds that the occasional host for recta to be the sunfish ( $L$. pallidus).

\section{Genus Lampsilis Rafinesque.}

1820-Lampsilis Rafinesque, Monog., Ann. Gen. Sci. Phys.

Brux. p. 298; I90ob, Simpson, Pr. U. S. Nat. Mus., XXII, p. 526. ('Type, Unio ovatus Say.)

Antmal Characters:- Branchial and anal opening papillose; supra-anal not very large, separated from the anal by a moderate connection; inner laminae of inner gills connected to the visceral mass, sometimes a small hole is left post-dorsad of foot; marsupium usually kidney-shaped, distended, consisting of many ovisacs which are distinct, extended below original edge of sterile marsu- 
pium when gravid into blunt, pigmeted beads; mantle edge double posteriorly, the inner one antero-ventrad to branchial opening developed into a ribboned flap usually produced into a tentacled lobe at its end located about the lowest post-ventral point; conglutinate not solid; glochidia rather large, subelliptic.

Shelr Characters:- - Shell elliptical to ovate; disk smooth; beaks sculptured by the sinuate or double-looped type, sometimes with a tendency of the posterior loop to become broken; epidermis usually smooth, thin and shiny often brilliantly rayed. Hinge with two cardinals and two laterals in left and two cardinals and one lateral in the right valve; f.emale shell with an inflation at the post-ventral region of shell just over the marsupia.

MiscelianeOUS REMARKS:- The differentiation of the mantle antero-ventrad to branchial opening into a flap marks this genus as among the highest of the Lampsilinae. This flap is so developed with tentacles and papillae that it is often extended externally and waved to and fro so as to produce almost the best possible aeration for the embyros. This genus is represented in this State by five species which have a good general distribution.

\section{Lampsilis anodontoides (Lea). ${ }^{\mathrm{I}}$}

("Yellow Sand Shell," "Lady's Finger.") Pl. VIII, Figs. I7 A and B; Pl. XXVIII, Figs. IO2 A-D.

I834-Unio anodontoides Lea, Tr. Am. Phil. Soc., IV, p. 81, pl. VIII, fig. 11 .

1834-Unio teres Say, Am. Conch,. VI; I820, Rafinesque, Monog. r898-Lampsilis anodontoides Baker, Moll Chicago, Pt. I, p. Ioo, pl. X, fig. I.

ANIMAL CHARACTERS.

NUTRITIVE STRUCTURES:--Branchial opening rather small directed upward; anal crenulated; supra-anal high well separated by mantle edges from anal; inner laminae of inner gills connected to visceral mass; palpi long, falcate, connected for one-half of their length antero-dorsad; color of soft parts grayish except brownish red mantle border at branchial opening.

I From Rafinesque's evident description of this Species in the Suppliment to his Monograph of 1820 under Unio teres (Elliptio teres) Lea's name, as given here by Simpson, (I 900 b, p. 543,) should stand as a synonym for Lampsilis teres (Raf.). 
REPRODUCTIVE STRUCTURES:-Marsupium rather reniform occupying over posterior half of outer gills and consisting of sixtyfive ovisacs well separated, when gravid extending below original ventral edge of sterile marsupia; inner mantle edge antero-ventrad to branchial opening a specialized flap reaching down to lowest point of the post-ventral part of shell where it is developed into a tentacular lobe; conglutinates white, sole-shaped, not very solid, glochidia medium in size, sub-elliptical, spineless, hinge line rather short, evenly curved, measuring $0.185 \times 0.210 \mathrm{~mm}$.

\section{SHELL CHARACTERS.}

EXTERnal, STRUCTURES:- Shell elongate-elliptic, medium in size, subsolid, disk smooth; umbones large, but not full, sculpture by five or six double looped or sickle-shaped ridges most pronounced and opened at base of post-umbonal slope; epidermis straw-color (usually without much display of rays) smooth, polished; female shell much produced at the post-ventral edge of shell and continued upward as a marsupiual inflation for a short distance; male shell pointed posteriorly.

INTERNAL StRuctures:- Cardinals prominent, serrate, double in right valve, single in left; beak and branchial cavities rather deep and basin-like; nacre satin-white, irridescent posteriorly.

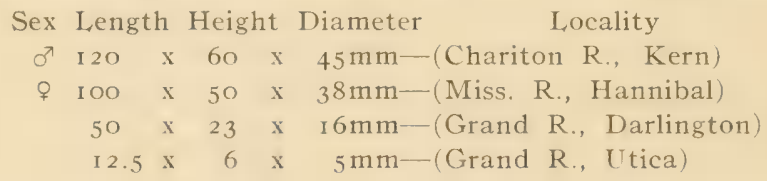

The last measurement was that of one of the smallest juveniles obtained by the writer. It has a black border to its shell and a short byssus extending from between the valves at ventral portion of shell.

Micellaneous Remarks:- Even in the juvenile anodontoides there is some difference from that of the fallaciosa shell in that there are not as evident. The main distinction between the adult shells of these two species is that of fallaciosa is brilliantly rayed, is smaller, has more reddish beaks and is a dweller in muddy creeks, sloughs and lakes while anodontoides loves sandy situations of swifter water and develops a large, thick shell, rayless, unicolored epidermis and is a most active mussel. When perfect (as it is found in the Chariton and Mississippi Rivers) it is one of 
the most beautiful shells. It is strange that it shoud not be found anywhere in the Ozarks as it seems to be a mussell that rather prefers swift current. Yet as that is an unglaciated region without much sand, to which it is partial, we may account for its absence there in part. It is entirely supplanted in the Osage by fallaciosa. From the writer's breeding record for this species it is bradytictic.

\section{Lampsilis fallaciosa Smith. ("Slough Sand Shell," "Creeper.)" Pl. VII, Figs. I8 A and B.}

1899-Lampsilis fallaciosa Smith, Bull. U. S. Fish., p. 291, pl. LXXIX; I gooa, Simpson, Pr. Ac. N. Sci. Phila., p. 74, pl. II, fig. 5.

Animal Characters:- Identical with L. anodontoides in every respect, except perhaps in glochidial characters.

Shell Characters:-Differs from anodontoides in possessing a smaller, lighter, thinner shell; a more prominent post-umbonal ridge; more pronounced beak sculpture; pinkish nacre in umbonal cavity; bright yellowish, or olivaceous epidermis with bright green rays all over shell-especially on the posterior slope; rusty red color often for umbonal region; a sulcus often seen just anterior to the post-ventral edge and extending a short distance up on the shell as a radial furrow.

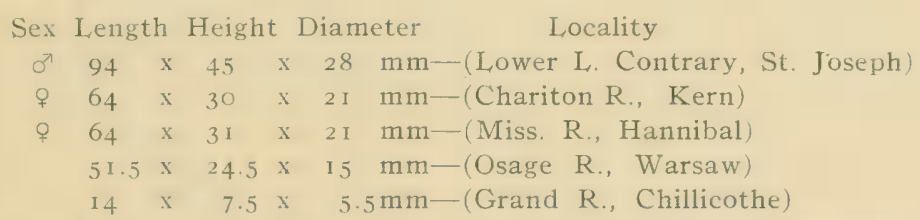

The last measurement is that of a juvenile identified by Dr. Howard. Its beaks are sculptured by two or three subparallel ridges at the base of the post umbonal slope and a few very faint tubercles at the base of the anterior umbonal slope. Anterior end of the shell is greatly produced as noted in most juvenile shells of any species. Note the very small inflation in the above measurement. It is strange that this shell at this stage of its life should be practically rayless while the rayed character of the adult shell is its chief feature.

Miscellaneous Remarks:-Fallaciosa may have developed from anodontoides for ecological reasons. This little striped shell 
is a dweller along the edges of muddy streams or in ponded stretches of the rivers and prefers lacustrine situations. For that reason it is commonly known as "Slough Sand Shell," and "Creeper." Mr. Walker makes the assertion that typically these two species are very distinct, but that it is frequently difficult to name individual specimens so given are they to intergrading. The fact, too, that both forms are found in the same stream (as in the Chariton R., for instance) and apparently entircly distinct would go to show that they are specifically distinct. Besides Surber (1912, p. 5) states a difference in size of glochidia, those of fallaciosa being larger $(0.200 \times 0.240 \mathrm{~mm}$.) than those of anodontoides $(0.185 \mathrm{x}$ $0.210 \mathrm{~mm}$.).

Surber (1913 p. 107) also reports that this species (fallaciosa) has for its fish host the crappie ( $P$. platorhynchus) its glochidium being a gill parasite.

\title{
Lampsilis Higginsii (Lea).
}

\author{
("Higgin's Shell.") \\ Pl. XXVIII, Figs. I05 $A$ and $B$.
}

1857-Unio higginsii Lea, Pr. Ac. N. Sci. Phila., IX, p. 84

$1900 \mathrm{~b}-L a m p s i l i s$ higginsii Simpson, Pr. U. S. Nat. Mus., XXII, p. 540.

AnImal, Characteres:-As only dead shells of this species have been secured by the writer no description of the soft parts can appear here. Surber (1912 p. 9) reports its glochidium as subelliptic, spineless, with hinge line short and measures 0.2 I0 $\mathrm{x}$ $0.260 \mathrm{~mm}$.

\section{SHELI, CHARAC'TERS.}

ExTERnal, Structures:- Shell very thick; male sub-elliptic; female subrhomboid with posterior end vertically truncate; beaks very large, rounded, full, sculpture unknown; epidermis brownishred with rays.

INTERNAL STRUCTURES:-Cardinals large, erect; laterals straight in female; slightly curved in male shell; interdentum wide, thick; beak cavities deep; scars deep; nacre rosy pink to salmon.

\begin{tabular}{|c|c|c|c|c|c|}
\hline ex & I.ength & Height & Diameter & & Locality \\
\hline$\sigma^{7}$ & $86 \mathrm{x}$ & $63 x$ & $45 \mathrm{~mm}-($ & Mississippi & R., Hannibal) \\
\hline & 68 & 50 & $38 \mathrm{~mm}-($ & ", & ," \\
\hline o & 85 & 48 & $48 \mathrm{~mm}-($ & ," & " Louisiana) \\
\hline
\end{tabular}


Miscellaneous REMARKS:-According to Simpson this is a puzzling species that closely resembles $O$. ellipsis in outline and its great posterior truncation and post-ventral inflation of the female shell would seem to be characteristic enough to make it a good species. Male shells obtained from the Mississippi River of this State, in the hands of the writer, look more like N. ligamentina than anything else, yet its cardinals are more stumpy, is a thicker heavier shell and has a rosy nacre. This State is within its range, as its distribution is from Iowa to Kansas. Surber reports "Sauger" (S. canadense) as its fish host.

\section{Lampsilis Powellii (Lea).}

("Powell's Shell.")

Not figured.

1852-Unio powellii Lea, Pr. Am. Phil. Soc., V., p. 252; Tr. Am. Phil. Soc., X, p. 270 , pl. XIX, fig. 25.

This species is listed for Missouri through a report by Mr. Frierson from a collection made by F. A. Sampson for the Elk River, McDonald Co., this State. Since no specimens are at hand the writer can give no description except that for the shell quoted from Scammon (r go6, pp. 288 and 289).

\section{SHELL CHARACTERS.}

EXTERnAL STRUCTURES:- "Shell large, rather thin, elliptical in outline, neither inflated nor compressed. Anterior margin almost circularly rounded; ventral margin gently and evenly bowed; posterior margin rounded, biangulated; dorsal margin rather long and straight. Umboidal ratio in specimens examined, 0.20 , umbones rather flattened. Anterior and lateral slopes flattened and rounded; posterior slope very slightly excavated and marked with two radial lines. Epidermis smooth and generally shining, olive-brown. Ligament long and rather thick.

INTERNAL STRUCTURES:- "Pseudo cardinals small, serrate, rather bluntly pointed, single in right valve and double in left. Laterals long, slightly curved, lamellar. Interdentum long, narrow, rounded. Anterior adductor cicatrix well impressed, large, much longer than wide; posterior scars large, very slighly impressed, confluent. Dorsal cicatrices on the lower surface of the interdentum. Pallial line well impressed in its one-half and crenulate. Cavity 
of beaks deep, of the shell moderately deep. Nacre white, decidedly irridescent posteriorly."

Dr. Scammon reports Powellii as a very rare shell for Kansas, being found in only one locality, Spring River, Baxter Springs, and further states that this species may be distinguished from L. Iuteola, its nearest ally in local waters, by the smaller and less pointed cardinals and the thinner, squarer and less inflated shell. Simpson states that Powellii is also found in Salina and Clinton, Arkansas, and in Guadaloupe River, Texas. The fact that Mr. Simpson found this rare shell in the Neosho basin of this State its range is more determined.

\section{Lampsilis luteola (Lamarck). \\ ("Fat Mucket.") \\ Pl. XXVIII, Figs. IO3 A-F.}

1819-Unio luteola Lamarck, His. Sans. Vert., VI, p. 79.

I898-Lampsilis luteola Baker, Mol. Chicago, Pt. I, p. Io3, pl. XI, fig. $12 ;$ pl. XXXVII, fig. I 2 .

\section{ANIMAL CHARACTERS.}

NUTRITIVE STRUCTURES:- Branchial opening large with numerous papillae; anal slightly crenulated; supra-anal well separated by thick mantle connection; inner laminae of inner gills connected to visceral mass; palpi short, wide; color of soft parts dingy white, mantle border blackened posteriorly.

REPRODUCTIVE STRUCTURES:-Mantle edge antero-ventrad to branchial opening with long spotted flap at the end of which are two or three finger like tentacles and about midway an eye spot appears; marsupium large, kidney-shape, consisting of numerous distinct ovisacs that lang down toward the mantle flap in beaded rows; conglutinates white, large, subsolid; glochidium rather large (uniformly smaller for lacustrine luteola), subelliptic, spineless, measuring $0.250 \times 0.290 \mathrm{~mm}$.

SHELL CHARACTERS.

EXTERNAL STRUCTURES:- Shell broadly elliptic, narrowly rounded before, broadly rounded behind; female shell greatly inflated, rather truncated posteriorly expanded post-ventrad, male shell pointed posteriorly; disk smooth; umbones large but low, 
sculpture faint consisting of fine broad, inverted $V$-shaped lines with the apices pointing toward tips of beaks; epidermis yellowish or olivaceous with widely separated and interrupted rays.

INTERNAL, STRUCTURES:- Cardinals double in left, single in right; laterals doubled the same; nacre white.

\begin{tabular}{|c|c|c|c|}
\hline Sex & Length & Height & Diameter \\
\hline ᄋ & I $10 x$ & $65 x$ & $48 \mathrm{~mm}$ - (Flat Creek, Sedalia) \\
\hline $0^{7}$ & 130 & 68 & $48 \mathrm{~mm}-(\quad " \quad " \quad, ")$ \\
\hline 우 & 82 & 46 & $30 \mathrm{~mm}-($ Black \\
\hline $0^{\pi}$ & 54 & 30 & I $7 \mathrm{~mm}-$ - White R., Hollister) \\
\hline
\end{tabular}

Miscelitanemous REMARKS:- Although L. luteola is considered as having the greatest geographical distribution over all United States yet (strange to say!) it has limited distribution in Missouri. It is not found at all in North Missouri, occurs very sparingly for Central Missouri, (especially in the Osage basin) and is not at all typical for South Missouri. The best types are found in Crow's Fork, Fulton, and in Flat Creek, Sedalia, where the female shells attain enormous size and thickness-the typical "Fat Mucket," as it is known on the market. Surber finds that the glochidia of luteola attain a larger size in the fluviatile forms (1912, p. 4) and thinks that the larger size of the river form may be correlated with the larva. Luteola is bradytictic.

Lampsilis luteola rosacea (DeKay).

(“Rosy Mucket.")

Pl. XXVIII, Figs. $104 A$ and $B$.

1843-Unio rosaceus DeKay, Zool. of New York, V., p. 192, pl. XXXIV, figs. 355 and 356 .

I goob-Lampsilis luteolus rosaceus (DeKay) Simpson, Pr. U. S. Nat. Mus., XXII, p. 535 .

Animal Characters:- No soft parts have been seen but in all probability identical with those of the parent.

SHELL CHARActers:- Identical in all respects with the parent species except in its solid pink nacre.

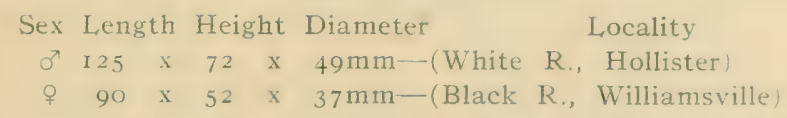

Miscellaneous REMARKS:-A cotype from a lot of pinknacred shells collected by the writer in the White and Black 
Rivers was pronounced by Mr. Frierson as rosacea DeKay but not exactly the author's shell from the St. Lawrence. Mr. Walker comments:- "I do not remember of ever having seen a red-nacred luteola from the southwest. The Great Lakes form, rosacea DeKay, is typically red or rather pink."

\section{Lampsilis reeviana (Lea).}

("Reeve's Shell.")

Not figured nor described.

1852-Unio reevianus Lea, Tr. Am. Phil. Soc., X, p. 272, pl. XX, fig. 28.

This species is catalogued through a report of it for Clinton, Missouri. The writer has not found it; hence no figure nor description appears here. Simpson reports this throughout the Southwest and hence the locality of this State, from which Mr. Walker reports as having received his reeviana shell, is within the range.

\section{Lampsilis ventricosa (Barnes). ${ }^{\mathrm{T}}$ \\ ("Pocket Book.") Pl. XXVIII, Figs. 106 A-D.}

1823-Unio ventricosus Barnes, Am. J1. Sci., VI, p. 267, pl. XIII, fig. If. (in outline).

rgoob-Lampsilis ventricosus Simpson, Pr. U. S. Nat. Mus., XXII, p. $35 \mathrm{I}$.

ANIMAL CHARACTERS.

Nutritive Structures:- Branchial and anal opening papillose; supra-anal large, closely connected to anal; inner laminae of inner gills connected to visceral mass; palpi connected about two-thirds of their length antero-dorsad, color of soft parts whitish except foot which is pinkish and gills of male and sterile female which are light brown, gravid nnarsupium darker brown, edged in blue and black.

ReProductive Structures:--Marsupium kidney-shaped con-

${ }^{1}$ According to Vanatta, 1. c., (1915, p. 55I), Lampsilis ventricosus Bar. (1823) of Simpson's Synopsis, p. 526, should read Lampsilis cardium Raf. since this Species is unquestionably the Lampsilis cardium (Unio cardium) of Rafinesque's Monograph (1820), p. 298, No. 14, Pl. 80, Figs. I6, 17, 18 and 19 , as now identified from Types in the A. N. S. P. Coll., No. 20, 210 . 
sisting of thirty large ovisaes distended, when gravid, at their distal ends into bulging beads drawn down near to mantle flap which is a long, wide, ragged ribbon that bears eye spots and extends to bend of the post-ventral curve of the shell; conglutinates white, discharged in unbroken masses; glochidia medium in size, semi-elliptic, with rather straight hinge line; measuring $0.205 \times 0.255 \mathrm{~mm}$.

\section{SHELL CHARAC'TERS.}

EXTERNAL STRUCTURES:- Shell of female sub-rhomboidal greatly inflated, swollen post-ventrad, male sub-elliptic not so inflated; narrowly rounded before, disk smooth, without sculpture; beaks very full, very much inflated, sculptured by four coarse sub-parallel bars with rounded furrows between; epidermis thin, smooth, polished, yellowish, bluish olivaceous or even terracotta, with broad brilliant green, or blue-green rays all over shell; post-umbonal ridge prominent but not angled.

INTERNAL STRUCTURES:-Cardinals prominent, serrate, rather curved; laterals erect blade-like; beak cavities very deep and basin-like; nacre pure marble white, sometimes inclined to pink.

\begin{tabular}{|c|c|c|c|c|}
\hline Sex & Leng & & Heigh & Diameter \\
\hline q & 100 & $\mathrm{x}$ & $65 \times$ & $45 \mathrm{~mm}$ - (Gasconade R., Gascondy \\
\hline б & 90 & $\mathrm{x}$ & 65 & $42 \mathrm{~mm}$ - (Black R., Williamsville) \\
\hline$\sigma^{7}$ & IIO & $\mathrm{x}$ & 39 & $26 \mathrm{~mm}$-(Osage R., Osceola) \\
\hline 운 & 55 & $x$ & 39 & $26 \mathrm{~mm}-($ Miss., R., La Grange) \\
\hline
\end{tabular}

The young shells are very bright colored. The specimen of the last measurement has a blue epidermis with bright bluegreen stripes. Its beak sculpture is very plain and eroded in curved beaks showing as above described. No juveniles obtained.

MiscellaneOus REMARKS:- Young shells look much like multiradiata but can be distinguished from the latter by the presence of post-umbonal ridge and by not possessing so many finer rays. The adult shell is told from that of ovata by not possessing the sharp cornered post-ridge, larger shell and more peculiar rays. Aside from these two related shells ventricosa is unique. Multiradrata and ovata are not found in Missouri. Ventricosa is also very peculiar in the structure of its soft parts-especially in the great development of the mantle flap that characterizes the genus Lampsilis. The writer has observed these flaps extended and in action both in the aquarium and in nature. Three have been seen 
spawning, at which time the mother buries her shell in the sand up to the siphonal openings, the flaps are waved to and fro exposing the ventral edges of the ovisacs through the branchial opening while ever now and then sole-shaped conglutinates emerge from the anal opening by convulsive jerks. With the eye spots showing at the base and the fringed flaps rhythmatically waving one is fascinated. Ventricosa is found to be typically bradytictic. The geographic distribution for Missouri is wide; however, it is of rare occurrence in the streams of North Missouri-never found in Northwest Missouri. South of the Missouri it is one of the commonest of shells.

\section{Lampsilis ventricosa satura (Lea). \\ ("Plain Pocket Book.") \\ Pl. XXVIII, Figs. I07 $A-B$.}

1852-Unio satur Lea, Pr. Am. Phil. Soc., V., p. 252; Tr. Am. Phil.

Soc., X. 1852 , p. 205, pl. XXVII, fig. 19.

I goob-Lampsilis ventricosus satur (Lea) Simpson, Pr. U. S. Nat. Mus.

XXII, p. 527 .

ANIMAL Characters:- Identical in every way to the parent species.

Shell Characters:--Also identical to the species except in its uni-coloration of epidermis which is rather a dark-brownish. All shells collected by the writer for this State are also smaller when mature.

\begin{tabular}{|c|c|c|c|c|}
\hline & Length & Height & Diameter & Locality \\
\hline & $88 \mathrm{x}$ & $55 \mathrm{x}$ & m- Black & Williamsville) \\
\hline $0^{2}$ & 75 & $54 \mathrm{x}$ & $42 \mathrm{~mm}$ - White & R., Hollister) \\
\hline
\end{tabular}

Miscellaneous Remarks:-This subspecies is only found in the Southwest. For this State it is definitely reported by Mr. Walker for the Black River., Popular Bluft. The writer collected some of these forms of ventricosa from the same stream a few miles north. The Black is a metropolis for ventricosa where it is found in all forms, since this species is liable to intergrading-satura being one of these intergradations. Yet its rayless character (like that of capax) would make it worthy of a name. 
Genus Truncilla Rafinesque.

(Type, Truncilla triqueter Rafinesque).

1819- Truncilla Rafinesque, Jl. de Phys. Chim. et Hist. Nat. pp. 427.

Anrmal Characters:-Branchial opening densely set with papillae; anal crenulated; supra-anal well separated from the anal by a definite mantle connection; inner laminae of inner gills entirely connected with the visceral mass; outer gills greatly tapering anteriorly; palpi very small, post-dorsal margins entirely free; color of soft parts grayish, posterior margins of mantle black. Marsupia kidney-shaped, distended transversely as well as ventrad when gravid; formed by many ovisacs that occupy the posterior section of outer gill and extend down from the ventral edge of the nriginal sterile gill in blunt, beaded unpigmented structures in state of gravidity; conglutinates not solid; glochidium medium in size, semicircular, hinge line very long, length about the same as height; post-ventral edge of marsupium doubled, the inner edge remote from outer forming a peculiar compartment as the highest specialization for the respiration of the embryos.

Shell. Characters:--Female shell very distinct from that of male, with a strong inflation or projection (marsupial expansion) in the post-ventral region which so changes its position and form that it assumes very many strange shapes; male shell not so modified post-ventrad, however, nodulous expansions do appear in some species; shell of either sex small, usually narrowly rounded in front much thicker anteriorly; beaks rather full, comparatively large, sculptured by double-looped ridges, usually obscure; epidermis yellowish or brownish, rayed with numerous fine green lines; cardinals and laterals usually single (or faintly double) in right valve, double in left; branchial cavity deep, basin-like: nacre white or bluish.

MISCELIANEOUS RFMARKS:- This remarkable genus is the most modern due to the best possible adaptation to reproduction both as to the morphology of shell and soft parts. This correlation of the physiology to the morphology is best seen in the greatest specialization of the reproductive structures of the animal. Recognizing that the most recent classification of the Unionidae is based primarily upon the modification of the marsupium and that the genus Truncilla has carried out this sexual differention to the 
greatest extent, Walker (I9Ioc pp. 75-8I) gives us the following systematic arrangement of Truncillae on the basis of reproduction:

I.--Perplexa-Group.--Marsupial expansion occupies the whole post-ventral area of shell.

2.-Triquetra-Group.-Marsupial expansion formed by the inflation of the post-umbonal ridge.

3.-Foliata-Group.-Marsupial expansion anterior to postumbonal ridge and more or less separated from it.

These groups may in turn be subdivided because of the different forms and shifting position of the sexual expansion. The first and third groups are represented in this State by two new species, discovered by the writer in South Missouri streams, and their novelty acknowledged by Mr. Frierson of Frierson, Louisiana.

Truncilla Curtisii Frierson and Utterback. New Species. ("Curtis' Shell.")

Pl. VI, Figs. I $4 a-d ;$ Pl. XXVIII, Figs. Iog A-D.

ANIMAL CHARACTERS.

NutRitive StRUCTUTES:-Branchial opening densely bordered with papillae; anal crenulated; supra-anal high, rather small, separated from anal by moderately short mantle connection, mantle border here spotted; inner laminae of inner gills entirely connected to visceral mass; palpi very small connected only by their anterior base which is remote from the anterior attachment of pointed outer gill; color of soft parts grayish except the blackish mantle edge at siphonal openings.

REPRODUCTIVE STRUCTURES:-- Marsupium very broad, rounded ventrad, kidney-shaped, ovisacs several, distinct nccupying posterior half of outer gills and distended into beaded, unpigmented structures along ventral edge when gravid; conglutinates broken masses; glochidia unknown as only specimens gravid with early embryos have been obtained; inner mantle edge of female antero-ventrad to branchial opening drawn in toward the interior of shell forming a chamber.

Shell Characters of Female:-Obvate, lacks flattened area of the disc, slightly emarginated just below post dorsal line; epidermis cloth-like, brownish-yellow, finely and obscurely radiate 
all over; nacre white; the antero-extra pallial layer remarkably thickened; anterior muscle scars deep, the posterior lightly impressed and confluent; the pallial line reflected upward and inward in the post-half; cardinals double in each valve, small, high, accuminate, sulcate; sexual expansion thin, swollen, slightly radiately and concentrically ridged, denticulate on edge.

Shell Characters of MALE:- Shell much the smaller of the two (so far as noticed); rounded before, sinuous below, widely biangular behind, flattened over the umbones and to the postbase; post ridge widely double.

Beaks of both sexes remarkably heavily ridged, inclined to be doubly looped, but obsately so in front, ridges heavy behind running downwards and backwards to the umbonal ridge. The earlier growth of the shell when looked at through a lens resembles in a striking way a diminutive Amblema plicata (Say.)

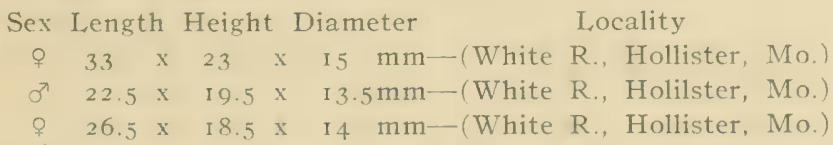

MISCELLANEOUS REMARKS:-The position of this interesting, species is exactly between capsaeformis Lea and biemargiatus Lea. From capsaeformis our species differs in the sexual enlargement being of the same general body color and in being more expanded or swollen in the middle and therefore not so regularly fan-shaped as in capsaeformis and our shell is not so regularly rounded behind. From biemarginata our species may be differentiated by its lack of pronounced angles and ridges of the former and by our species being much smaller and thinner and from its general almost solid piece color. Our species differs most remarkably in the heavy heak sculpture. From deviatus Anthony our shell similarly differs in color; and the sexual swelling is not so far protruded behind. A specimen of deviatus, recently procured, shows this species to have heaks nearly as heavily corrugate as our species and not, as Anthony supposed, nearly smooth as in capsaeformis. The presence of a form so intimately resembling those of the Fast Tennessee mountain streams in Missouri is of great interest.

The shell was taken by the co-author, W. I. Utterback, in the White River, Hollister, Mo., Aug. 26, r913, and is named in honor of Dr. W. C. Curtis of the Department of Zoology, Univer- 
sity of Missouri. The type shells, which are line-drawn and also photographed herewith, are now in the possession of $\mathrm{Mr}$. Utterback.

\title{
Truncilla Lefevrei ' Utterback. New Species.
}

\author{
("Lefevre's Shell.") \\ Pl. VI., Figs. 13 a-d; Pl. XXVIII., Figs. Io8 A-D.
}

ANIMAL CHARACTERS.

Nutritive Structures:-Branchial opening thickly papillose; anal crenulated; supra-anal moderately connected to anal; outer gills shorter and only half as wide as inner gill, inner laminae entirely connected to visceral mass; outer gills drawn up high and pointed anteriorly forming wide gap between palpi and anterior attachment; palpi small, free their whole dorsal length; color of soft parts dingy white with squarish, blotched mantle edge around anal and supra-anal openings and solid blackish border at branchial opening.

REPRODUCTIVE STRUCTURES:-Marsupium formed by several ovisacs arranged in a kidney-shape, which, when gravid, extend down to the edge of inner gills forming a plain beaded border on the ventral edge; inner mantle edge anterior-ventrad to branchial opening drawn over into the interior of shell forming a compartment evidently as a water reservoir; no conglutinates nor glochidia observed.

\section{SHELL CHARACTERS.}

EXTERnAl, Structures:- Shell small, narrowly rounded hefore, solid anteriorly, thin posteriorly; general shape of both sexes ovate-trigonal; epidermis brownish-yellow, smooth, with fine, continuous rays; beaks rather large, full, too eroded to make

${ }^{\mathrm{I}} \mathrm{As}$ may have been noted, the author has departed from the accepted Code of Nomenclature on Naiades in so far as to employ the initial capital for all names of those Species and Sub-Species derived from the names of persons when used substantively in both their respective binomial and trinomial forms. Although this action may seem somewhat presumptuous, yet the departure is surely justifiable on the grounds of efforts to be more consistent with clearness as to the nominal derivation and especially with the Latin and Greek etymology or diction. In this regard the suggestion of the Editor has been followed and reference would be made to his comments on "Proper Publication" (Am. Mid. Nat., Vol. IV., No. 3, pp. 95 and 96). 
out sculpture. Female shell broader posteriorly, marsupial expansion formed post-ventrad, above basal line just anterior to postumbonal ridge and bounded ventrad by a furrowed rest line. Male shell more trigonal in shape with post-umbonal ridge rather biangulated and with a very slight radial furrow in front; dorsal ridge rather prominent.

Internal structure of both sexes about the same except a higher mantle line in the female shell; cardinals double in both valves; laterals single in right, double in left; branchial cavities deeply basin-like; nacre blue with a tinge of yellow in the branchial cavity, irridescent posteriorly.

\begin{tabular}{|c|c|c|c|c|c|}
\hline ex & Length & Height & Diameter & Loce & lity \\
\hline & $32 x$ & $21 \mathrm{x}$ & -(Black & River, & Williamsville) \\
\hline & 26.5 & 18 & $4 \mathrm{~mm}-$ - Black & River, & Willi \\
\hline
\end{tabular}

MISCELLANEOUS REMARKS:- Although this rare Species has been found only in one locality yet a sufflcient suite of shells was secured to establish its novelty. One specimen was obtained gravid with ova, yet it was sufficiently, although briefly, described afield before it was lost as often results in a rush of field work. At first the author was inclined to call this Species $T$. triquetra, but comparisons to actual shells of typical triquetra show that it is placed in the third group of Truncilla which is characterized by the marsupial expansion formed by the inflation just anterior to the post-umbonal ridge not extending below the basal line and in which group triquetra is not classed. Lefevrei differs from the arcaeformis of Lea in not possessing a radial depression in front of the post-dorsal ridge and in not having such a prominently curved post-umbonal ridge and also in not possessing such coarse hinge teeth. This new and most modern Species is dedicated to Dr. George Lefevre of the Department of Zoology in the University of Missouri. The discovery of this new Species from the Black River, Williamsville, Missouri, and also of the new Truncilla, Curtisii Frierson and Utterback, from the White River, Hollister, this State, and, being the only completely described Truncillae west of the Mississippi, it seems fitting that these should bear the names of the two associate authors and instructors who have contributed so much to the science of the Naiades in their monumental work, "Studies on the Reproduction and Artificial Propagation of Fresh-Water Mussels."

(THE END) 


\section{BIBLIOGRAPHY.}

I898b-Baker, F. C.-The Mollusca of Chicago Area. The Pelecypoda. (Nat. Hist. Survey of the Chicago Acad. of Sci., Bull. No. 3, Pt. I. I 890-Brooks, W. K.- Handbook of Invertebrate Zoology for Laboratories and Seaside Work. (Boston, Mass., Pub. Co.).

I 885 - Call, R. E-A Geographic Catalogue of the UnionidaE of the Mississippi Valley. (Bull. Des. Moines Acad. Sci.; I, pp. 5-57.)

I 895-Call, R. E.-A Study of the UnIOnidaE of Arkansas with Incidental Reference to their Distribution in the Mississippi Valley. ( $T r$. St. Louis Acad. Sci., VII, No. I, pp. I-65, 2 I plates).

I 9 1 2-Coker, Robt. E.--Mussel Resources of the Holston and Clinch Rivers of Eastern Tennessee. (From Notes of Investigation Taken by J. F. Boepple). U. S. B. F., Doc. No. 765.

1914-Coker, Robt. E.-Protection of the Fresh-water Mussels. (U. S. B. F., Doc. No. 793, pp. I-23 with plates I and II).

I892-Dall, W. H.-Instructions for Collecting and Other Useful Hints, for the Conchologist. (Pt. G. Bull. U. S. Mus., No. 39).

I899-Frierson, L. S.-The UnIonidae of DeSoto Parish, Louisiana. (Reprint from Gulf Fauna and Flora., Bull., I, No. I.)

I9oi-Frierson, L. S.-A New Unio from Texas. (Naut., 15, pp. 75-76).

1904 -Frierson, L. S.-Observations on the Genus QUADRULA (Naut. I 7 , pp. II I and I I 2 ).

I9I I-Frierson, L. S.-A Comparison of the UnionidaE of the Sabine Rivers (Naut., XXIV, pp. 134-136).

I 914 -Frierson, L. S.-Remarks on Classification of Unionidae. (Naut., XXVIII, pp. 6-8.)

1900-Ferriss, J. H.-A New Arkansas Species (Lampsilis Simpsoni) (Naut. XIV, p. 38).

19r2-Hannibal, Harold-A Synopsis of the Recent and Tertiary Freshwater Mollusca of the California Province. (Proc. Mala. Soc. Lon., X, pp. I I2-I66, Pt. II; pp. I67-2II, Pt. III).

1907-Henderson, Junius-Mollusca of Colorado. (Pt. I I, pp. 77-96, Plates I and II, Univer. Sci. Ser.).

1915-Hinkley, A. A.,-New Fresh-water Shells from the Ozark Mountains.

(Proc. U. S. Nat. Mus., XLIX, pp. 587-589.)

I 912 - Howard, A. D.- The Catfish as a Host for Fresh-water Mussels. (Reprint Tr. Am. Fish. Soc.).

I 9 I I-Isely, F. B.--Preliminary Note on the Ecology of the Early Juvenile Life of the Unionidae. (Biol. Bull., XX, pp. 79-80).

1914-Isely, F. B.-Mussel Streams of Eastern Oklahoma. (U. S. B. F., Ec. Cir., No. 9).

1913-Israel, Von W.-Biologie der Europaischen Susswasser-muscheln (Herausgeben vom Thuringer Lehrerverein fur Naturjkunde).

1815-1843-Lamarck, J. B. de-Histore Naturelle des Animeaux sans Vertebres. (7 vols. Paris, 1815-1822; 2nd ed., Io vols., Paris, 1835-1 843 ). 
I 83 I-Lea, Isaac-Observations on the NaIAdes. (Tr. Am. Phil. Soc, pp. 63-121; I 834, pp. 23-1 19).

I 838 -Lea, Isaac-Description of New Fresh-water and Land Shells. (Tr. Am. Phil. Soc., pp. I-I54; I842, pp. I63-252).

I 852 - Lea, Isaac-Description of New Species of the Family UNIONIDAE. (Tr. Am. Phil. Soc., pp. 252-294).

I 862 - Lea, Isaac-Description of Ten UNIONIDAE of United States.

(Pr. Acad. Nat. Sci. Phila,, pp. 168 and I69).

$1912-$ Lefevre, Geo, and Curtis, W. C.- Studies on the Reproduction and Artificial Propagation of Fresh-water Mussels. (U. S. B. F., XXX, Doc., No. 756).

1906-Lindahl, Josua-Orthography of the Names of the NAIAdEs. (Jl. Cinn. N. Hist. Soc. XX, No. 5, pp. 235-243).

1891 -Marsh, W. A.-A Description of Two Species of Unio From Arkansas (U. Pilsbry and Pleasii) (Naut., V, pp. I-2; I 892 , VI, pp. I-2: I 893 , VII, p. I. pl. I.

I9oI-Marsh, W. A.-Description of a New Unio from Missouri. (P. missourensis, n. sp.) (Naut., XV, pp. 74-75).

I9I 2-Meek, S. E., and H. Walton Clark-The Mussels of the Big Buffalo Fork of White River, Arkansas. (U. S. B. F., Doc. No. 759).

I 909 -Ortmann, A. E.-The Breeding Season of UnionidaE in Pennsyl vania. (Naut., XXII, pp. 99-103).

I9ira-Ortmann, A. E.-The Anatomical Structure of Certain Exotic NaIAdes Compared with that of the North American Forms. (Naut., XXIV, pp. I03-Io8, I I 4-I20, I 27-I3I).

I 91 ib-Ortmann, A. E.-A Monography of the NaIAdes of Pennsylvania. (Mem. Car. Mus., IV, pp. 279-339).

I9i2b-Ortmann, A. E- - Notes upon the Families and Genera of the NaIAdes. (Reprint An. Car. Mus., VIII, pp. 222-365).

I 89 I b-Pilsbry, H. A.-Critical Notes on Eastern Texas UnionidaE. (Naut., V, pp. 74-77).

1901-Pilsbry and Fox. On Alasmidonta marginata. (Naut. I5, pp. i6 and 47).

I 906-Pilsbry and Ferriss-Mollusca of Ozarkian Fauna. (Pr. Acad. Nat. Sci. Phil., pp. 529-567).

I 878 - Pratt, W. H.-The Shell Beds of the Vicinity of Davenport, Iowa. (Pr. Dav. Acad., pp. I $56-162$ ).

I820-1831-Rafinesque, C. S.-Monographie des Coquilles Bivalves Fluviatiles de la Riverie Ohio. (Ann. Gen. Sci. Phys. Brux., V, pp. 287-322).

I829-Say, Thomas-Description of Some New Terrestrial and Fluviatile Shells of North America. (New Harm. Diss., II, pp. 229; $t$ t seq. ad interim, $1829-1831$ ).

1830-Say, Thomas-American Conchology; or Description of the Shells of North America. (New Harmony, Ind.)

1906-Scammon, R. E.-The UnionidaE of Kansas. Part I. (Kan. Univer. Sci. Bull., III, pp. 279-373.). 
1913-Shira, A. F.-The Mussel Fisheries of Caddo Lake and the Cypress and Sulphur Rivers of Texas and Louisiana. (U. S. B. F. Econ. Cir., No. 6).

I 895 - Simpson, C. T. - The Classification and Geographic Distribution of the Pearly Fresh-water Mussels. (Pr. U. S. Nat. Mus., XVIII, pp. 295-344).

rgooa-Simpson, C. T.-New and Unfigured Unionidae. (Pr. Acad. N. N. Sci. Phil., Vol. 52, pp. 74-86).

I goob-Simpson, C. T.-Synopsis of the NAIADEs or Pearly Fresh-water Mussels. (Pr. U. S. Nat. Mus., XXII, pp. 50i-1044).

rgo I-Simpson, C. T.-On the Classification of the UnionidaE. (Naut., $\mathrm{XV}, \mathrm{pp}, 72-82$ ).

I 898-Smith, H. M.-The Mussel Fishery and Pearl Button Industry of the Mississippi River. (Bull. U. S. Fish Com., pp. 289-3I 4, 3 I plates).

$189 \mathrm{I}$ - Sterki, V.-A Byssus in Unio. (Naut., V, pp. 73-74).

I 898 - Sterki, V.-Some Observations on the Genital Organs of UnionidaE with Reference to their Classification, (Naut., 12, pp. 18-32).

1903-Sterki, V.- Notes on the UNIONIDAE and their Classification. (Am. Natural., 37, pp. 103-113).

1907-Sterki, V.-A Preliminaty Catalogue of the Land and Fresh-water Mollusca of Ohio. (Pr. Ohio Acad. Sci., IV, Pt. 8).

19ro-Sterki, V.-Common or Vernacular Names for Mussels. (Naut., XXIV, pp. I6 and I6).

I89ı - Strode, W. S.-Mollusks of Thompson Lake, Illinois. (Naut., IV, pp. I33-134).

$189 \mathrm{Ib}$-Strode, W. S.-Mollusks of Spoon River, Illinois. (Naut., V., pp. $6 \mathrm{I}-64)$.

1896 - Strode, W. S.-The Size of Mussels. (Naut., IX, pp. 115 and 116 ). 1912-Surber, T.--Identification of the Glochidia of Fresh-water Mussels. (U. S. B. F., Doc. No. $77 \mathrm{I}$ ).

I9r3-Surber, T.-Notes on the Natural Hosts of Fresh-water Mussels. (U. S. B. F. Bull., XXXII, No. 778).

I 9 I 4-Utterback, W. I--Mussel Resources of Missouri. (U. S. B. F., Econ. Cir., No. 10, pp. 1-6).

I916a-Utterback, W. I.,-Breeding Record of Missouri Mussels. (Naut., XXX, No. 2, pp. I 3-2 т.)

r9io--Vanatta, E. G-- Unionidae of Southeastern Arkansas and North. eastern Louisiana. (Naut., XXIII, Jan., pp. IO2-104).

1916-Vanatta, E. G.,, Rafinesque's Types of Unio. (Proc. Acad. Nat. Sci. Phila., pp. 549-559.)

I 898 - Walker, Bryant-The Distribution of the UNIONIDAE in Michigan. (Mich. Ac. Sci., March).

1910 - Walker, Bryant-The Distribution of Margaritanidae margaritifera in North America. (Pr. Mala. Soc. of Lon., Vol. 9)

I goob-Walker, Bryant-On the Validity of Unio undalus Barnes. (Naut., pp. 6-10, 16-24). 
rgrob-Walker, Bryant-Notes on Truncilla, with Key to the Species. (Naut., 24, pp. 75-8I).

rgra -Wilson, Charles B. and H. Walton Clark-The Mussel Fauna of the Kankakee Basin. (U. S. B. F. Bull., No. 758).

I9 12 b-Wilson, C. B. and H. Walton Clark-The Mussel Fauna of the Maumee River. (U. S. B. F. Bull., No. 757).

I 9 I 2-Wilson, C. B. and E. Danglade - The Mussels of Central and Northern Minnesota. (U. S. B. F. Econ. Cir., No. 3).

1914-Wilson, C. B. and H. Walton Clark-The Mussels of the Cumberland River and its Tributaries. (U. S. B. F., Doc. No. 78I).

I883-Witter, F. M.-The Mollusks of Muscatine County (Iowa) and Vicinity. (Muscatine Pub. Co.).

I 888-Wright, B. H.-Check List of North America and other Fresh-water Bivalves. (Dore and Cook Pubs., Portland, Ore.).

1898-Wright, B. H.-New Varieties of Unionidae. (Naut., XI, pp. I $23-124)$.

I902-Wright, B. H. and Bryant Walker-Check List of the North American NaIAdes. (Detroit Pub. Co.).

\section{ERRATA.}

(For Reprints of Utterback on The Naiades of Missouri.)

Some errors have been due partly to improper and insufficient corrections of the MS. which originally followed Lindahl's "Orthography of the Names of Naiades," - an article that adheres strictly to the International Code. The following immediate errata for page 3 applies to all other like mistakes made in using capitals for the Greek and Roman names of Species and Sub-Species when used adjectively. On the other hand, through oversight in some instances, small initials have crept in for the substantive form when capitals were intended despite "Canon VIII" as adopted in the generally accepted Code of Nomenclature. (See foot-note for Truncilla Leferrei, page 192). Most of the other errors are the typographical mistakes that usually escape even the most careful proof-reading.

Page 3, line 23, for "Lamarckiana" read "lamarckiana"; line 24, for "Reeviana" read "reeviana."

Page 7, line 19, for "marsupial" read "marsupia"; line 40, for "Magnonaias" read "Megalonaias"; line 4, for "Schoolcraftensis" read "schoolcraftensis."

Page 8, line 16 , for "Cooperianus" read "cooperianus."

Page 9, line 7, for "Genus XII" read "Genus XIII"; line 19, for "Ferussacianus" read "ferussacianus"; line 29, for "Genus VXII" read "Genus XVII".

Page 10, line 39, for "texensis" read "texasensis." 
Page I I, line I2, for "Curtisi" read "Curtisii" (This latter inflection really should occur for all Latinized substantives derived from names of persons terminated by a consonant).

Page 19, line 25, insert "inner" before "usually."

Page 20, line II, for "Unionae" read "Unionidas"; line 18, for "The connection" read "the usual disconnection."

Page 2I, line 32, for " $F$. trigona" read " $F$. undata trigona".

Page 22, line 4, omit comma after "hermaphroditic"; line 12 , for "Plates I and I" read "Plates I and IP".

Page 29, line $2 \mathrm{I}$, insert next line below this reference:- "P1. XV., Figs. $34 \mathrm{~A}$ and B".

Page 33 , line 19 , insert comma after "p. 71 "

Page 36 , line 6 , for "raripliplicata" read "rariplicata"

Page 37 , line 24, for "these fact" read "this fact"; line 27 , for "quintardi" read "Quintardii (All other errors regarding Quintardii read as corrected here).

Page 44, for Text-Fig. 3 A transpose "AN" and "PO". .

Page 45, line 9, for "expecially" read "especially"; line 20, between "very" and "profusely" insert "compressed and".

Page 46, line 3, for "scupture" read "sculpture"; line I3, separate "glochidia" and "lying"; insert next line below:- "7,-No undulations in juvenile and adolescent shell as in Amblemae".

Page 48, line Io, for "charasterized" read "characterized".

Page 49, line 4, for all statements of "Quadrula pustulosa (Lea)" read "Quardrula bullata (Raf.)" as mentioned in the Foot-note for this page.

Page 54, line 38, for "Udio" read "Unio".

Page 55, line 22, for "tacytictic" read "tachytictic".

Page 61, line 2, for "tha" read "than".

Page 65, line 28, for "wardii" read "Wardii" (All other errors regarding the capitalization of "Wardii" read as corrected here).

Page 67, line 35, insert comma after "marsupial".

Page 68, line 37, for "wiite" read "white".

Page 73, line 17 , for "state" read "State" (All other errors in the use of this word when its antedecedent is geographic, e. g., "Missouri," correct as read here).

Page 76, line 25, for "Pleruobemae" read "Pleurobemae".

Page 80, line 39, omit "Am."

Page 81, line 30, between "catillus" and "by" insert "not only" and between "but" and "its" insert "also by"; line 35 , between "had" and "been" insert "also".

Page 84 , line $\mathbf{I} 8$, for period use a comma after "North Missouri".

Page 85, line 2, of Foot-note for "groupp" read "group".

Page 88, line 13, for the first word, "of" read "or"; line $2 \mathrm{I}$, for "used" read use".

Page 93, line io, for "papli" read "palpi"

Page 94, in Text-Fig. 4, for "M" on inner gill read " $I$ ".

Page 97, line 36, for "umbona" read "umbonal"; line 39, for "vavles" read "valves". 
Page 100, line 2, for "climed" read "claimed"; line 27, for "Pterosygna" read "Pterosyna".

Page I I, line 19, for "bue" read "blue".

Page I03, line 27, for the adverb. "ventrad" read as adjective, "ventral".

Page 104, line 33, insert next line below:-“(Type, Lastena ohiensis Raf.);" line 36 , separate "outer" and "and".

Page 105, line 26, for "p." read "Pl."; line 36, for "pericardinal" read "pericardial".

Page ro6, line ro, omit comma after "distinct" and supply after "veining".

Page 107 , in Text-Fig. 7, transpose "AN" and "PO".

Page II , line 3.3, for "brownsih" read "brownish-yellow".

Page I I2, line 22, for "moss" read "mass"; line 33, for "mosses" read "masses".

Page Ir 7, line 35, insert next line below:- "(Type, Anodonta ferussaciana Lea)"

Page I 8, line 6, omit "External Structuses"; line I8, add "about" after "being". Say)".

Page I I9, line 30, insert next line below:- "(Alasmidonta undulata

Page 122, line 26, for "known" read "shown".

Page I 24 , line 10, before "containing" insert "each" and for comma use semi-colon after "larvae" and also omit "are"; line II, omit "situated"; line 12, for "min" read "mm"; line 16 , for "obtusely" read "obtuse".

Page 129, line 34, for "facsiolaris" read "fasciolaris"; as indicated in Foot-note for this page, for all statements of "Ellipsaric clintonensis (Simpson)" read "Ellipsaria occidentalis (Conrad)".

Page 130 , line 7 , for period after "p. 301" use semi-colon.

Page 132, line 8, use semi-colon after "interdentum".

Page 133 , line 22, for "nodulat" read "nodulated".

Page 136, line 2, for "J" read "Jl."; line $\mathrm{I} 6$, omit comma after "height".

Page 143, line 30, for "pleasii" read "Peasii"; (do. page 144, line

29 ; do. page 145 , line 20); line 32 , for "clolored" read "colored".

Page 145 , line 26, for "utterbackii" read "Utterbackii"; (do. line 3 I).

Page 148 , line 18 , insert "IX" after "pl".

Page 152, line 15, for "simpsoni" read "Simpsoni"; (do. page 155, line 3).

Page 153, line 38, for "bysuss" read "byssus".

Page 155 , line 34, for "teniussimus" read "tcnuissimus".

Page I59, line 28, for "Lamack" read "Lamarck".

Page 160 , line 14 , for "more" read "not" and for "not" read "nor".

Page 163 , line 34 , for "propteru" read "Propt'ra".

Page 164 , line 20, for "tecvasensis" read "texasensis"

Page I68, line 6, for "central" read "center"; after line ro supply the following deletion from text:- 
Sheld Characters:- Shell elliptical, small or medium, beak sculpture rather double-looped or distinctly sinuate with posterior sinuation somewhat open.

\section{ERRATA.}

\section{(Plates I-XXVIII.)}

Pl. I, Fig. 2, for "vavel" read "valve".

Pl. II, Fig. 5a, Supply label 4, i. e., "Extreme dorsal point."

Pl. V, Fig. I 2 b, for "Utterbacki" read "Utterbackii"; do. Pl. XX, Figs. $63 \mathrm{~A}-\mathrm{D}$.

Pl. VI, Figs. I 4 a-d, for "Curtisi" read "Curtisii"; do. PI. XXVIII, Figs. $109 \mathrm{~A}-\mathrm{D}$.

Pl. IX, Fig. 19, After "feeding" supply comma and "respiring".

P1. XIII, Fig. 26, Supply "-Hundred" after "One;" do. PI. XXVI. Fig. 90.

Pl. XVI, Figs. 38 A-D, for "Quintardi" read "Quintardii".

Pl. XIX, Fig 52, for "cylindirca" read "cylindrica".

Pl. XXV, Fig. 8I, for "clintonesnsis" read "clintonensis".

Pl. XXVIII, Fig. I07, for "ventricoas" read "ventricosa" 


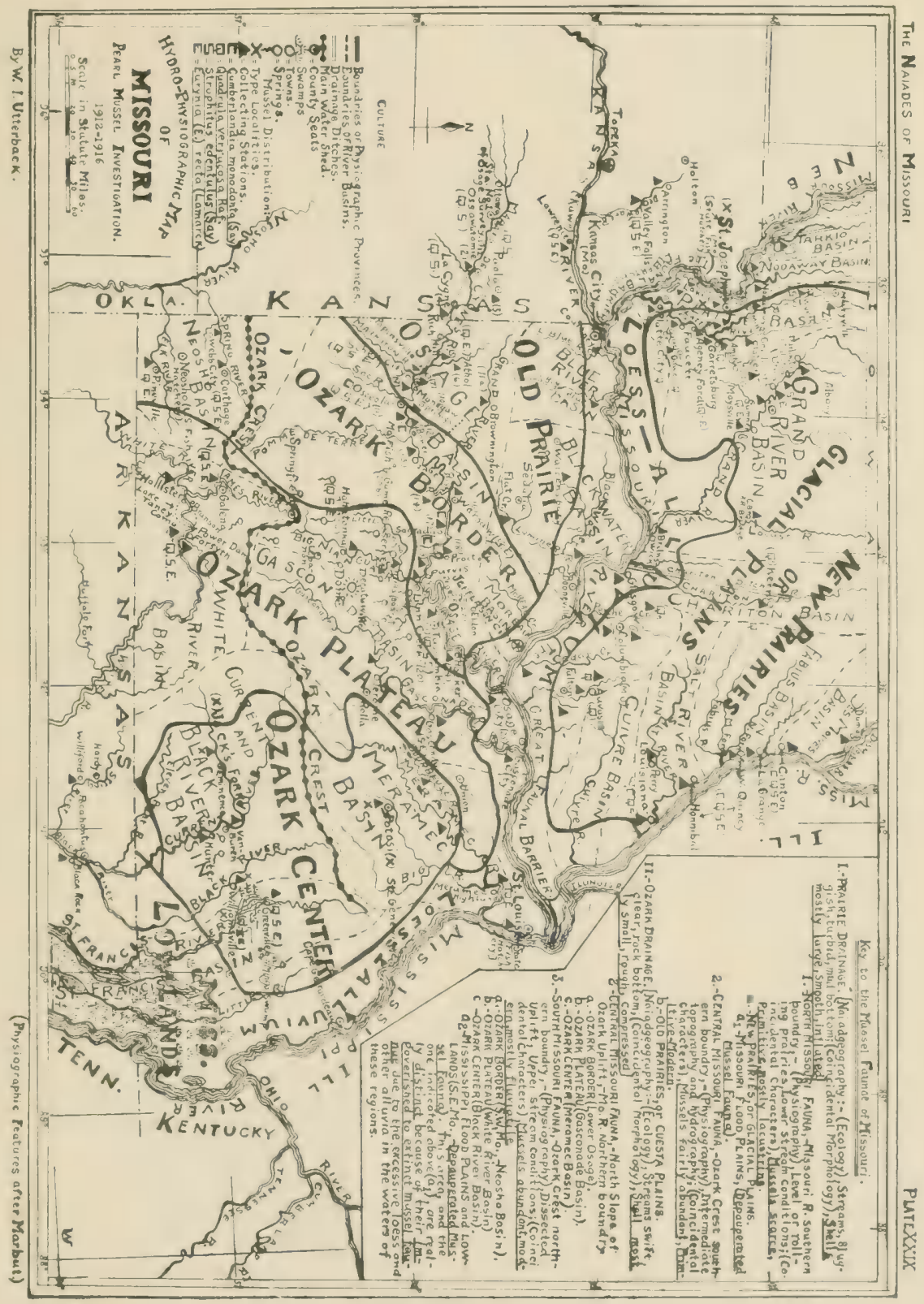



Sub=Family III LAMPSILINAE:-

Marsupium differentiated with special ovisacs mostly arranged posteriorily near the post-ventral mantle margin specialized with crenulations, papillae, etc.; only outer gills marsupial: glochidium Lampilis Type: hradytictic.

\section{Sub=Family II ANODONTINAE:}

Marsupium differentiated with lateral water tubes when gravid; postventral mantle margin undifferentiated: all four gills marsupial: glochidium Anodon!a Type: hradytictic.
Proptera Type (Intermediate to modern form of glochidium: Axehead shape, spin-

ed-spineless.

The Spineless glochidia are followed in the adult life by perfect and complete hinge teeth.

Lampsilis type, (ModernForm) of glochidium -Subovalsubelliptic, spineless.

This reversion of the modern form of glochidium to that of the primitive very strikingly shows that atavism characteristic of the principles of evolution.
Anodontu Type (Intermediate Form) of glochidium: Subtriangular. spined, followed in adult by incom plete hinge teeth. a.

Sub = Family I UNIONINAE :-

Undifferentiated marsupium an $\mathrm{d}$ post-ventral mantle margin: all four (or outer gills marsupial: tachytictic species: glochidia Lampsilis Type.

Family I MARGARITANIDAE:

Marsupium more primitive than that of Family II: post-ventral mantle margin undifferentiated: all four gills marsupial: glochidium Lumpsilis Type; tuchytictic 


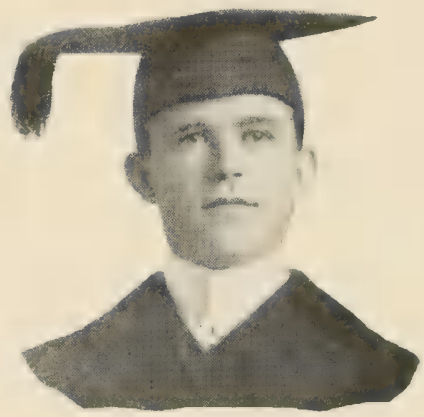

WILI.IAM IRVIN UTTERBACK, B. S., A. M.

Bachelor of Science, (B. S.), Wabash College, Crawfordsville. Indiana; Class 1901

Master of Arts, (A. M.), University of Missouri. Colum-

bia. Mo.: Class 1915. The author submits this catalogue ("The Naiades of Missouri",

to Missouri University as a

Master's Thesis 


\section{EXPLANATION OF PLATES.}

Plates I-IV, VII and VIII are intended to be a further elucidation of the text, especially as to shell structures. Plates III and IV are comparative representations of the beak sculpture and marsupial characters of the three Sub-Families. Plates V and VI are careful drawings of new species described and figured for the first time. Plate IX shows physiological relations while Plates $\mathrm{X}$ - XIV show the ecologic. Plates XV-XXVIII are photographs of shells representing about one-half natural size, arranged in progressive order of classification, and, in most cases, the shell structures of the exterior are shown by the left valve and of the interior by the right. 


\section{EXPLANATION OF PLATE I.}

Fig. I.-External structure of left valve of Rotundaria tuberculata Rafinesque, $q$ (Nat. size).

I.-Anterior end.

2.- Posterior end.

3.-Ventral side.

4.-Dorsal side.

5.- Antero-ventral side.

6. - Antero-dorsal side.

7.--Post-dorsal section.

8.-Post-ventral section.

9.-Nodule.

I o.- Tubercle.- U mbonal region.

11.-Center of disk.

I 2.- Lunule.

I 3.-Beak, or umbone.

14.- Ala, or dorsal ridge.

I5.- Costae.-Dorsal slope.

16.- Post-umbonal ridge.

17.- Rest lines of growth.

18.-Minor lines of growth.

Fig. 2.- Internal structure of right vavel of $R$. tuberculata (Raf.) क (Nat. size.)

I.-Epidermis.

2.--Outer nacreous zone.

9.-Branchial cavity.

3.-Middle nacreous zone.

Io.--Lunular hinge.

I1.-Cardinal tooth.

4.-Inner nacreous zone.

12.- Hinge tooth.

5.-Vein marks.

6.-Retractor muscle scar.

13.-Interdentum.

7.-Post, add. mus. scar.

14 - - Hinge ligament.

15. - Beak cavitiy.

8.-Anterior adductor muscle scar. 16.-Ala, or wing.

17.-Beak showing sculpture.

Fig. 3a.-Lateral view of juvenile $R$. tuberculata showing sculpturing of beak extending out on disk. (Nat. size).

Fig. 3b.-Dorsal view of juvenile $R$. tuberculata showing beak sculpture (Nat. size.)

Fig. 4--Right side of closed glochidium (X87) of $R$. tuberculata (nov. glochidium) showing:-

1.-Anterior end

2.- Posterior end.

3.-Dorsal, or hinge line.

4.-Ventral margin.
5.- Center of disk

6.-Adductor muscle.

7.- Posterior adductor.

8.-Pericardial area. 


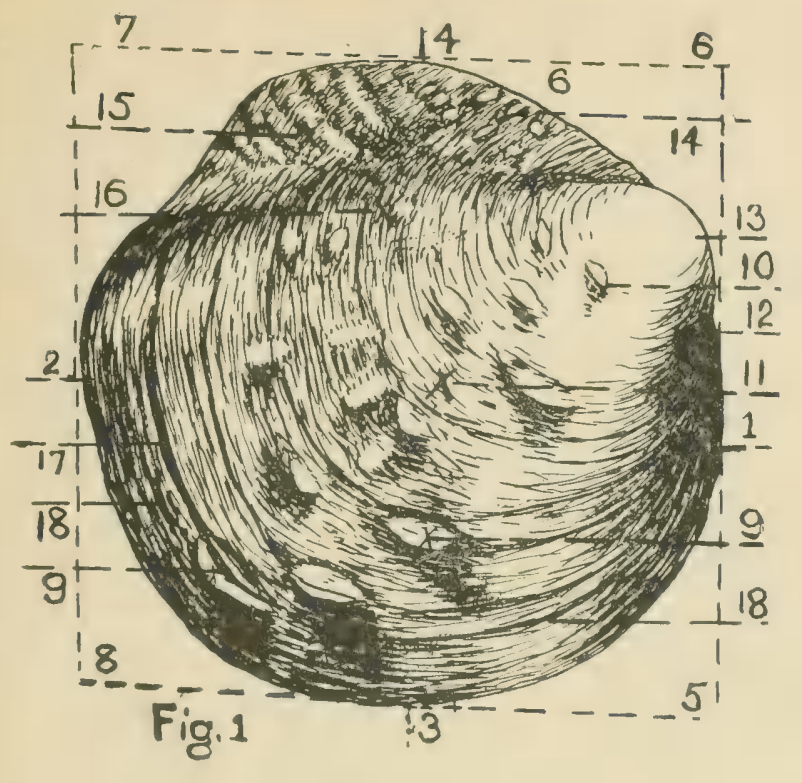

Fig. $3 a$

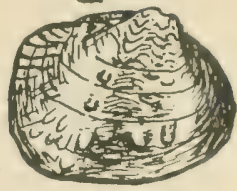

Fig. $3 b$
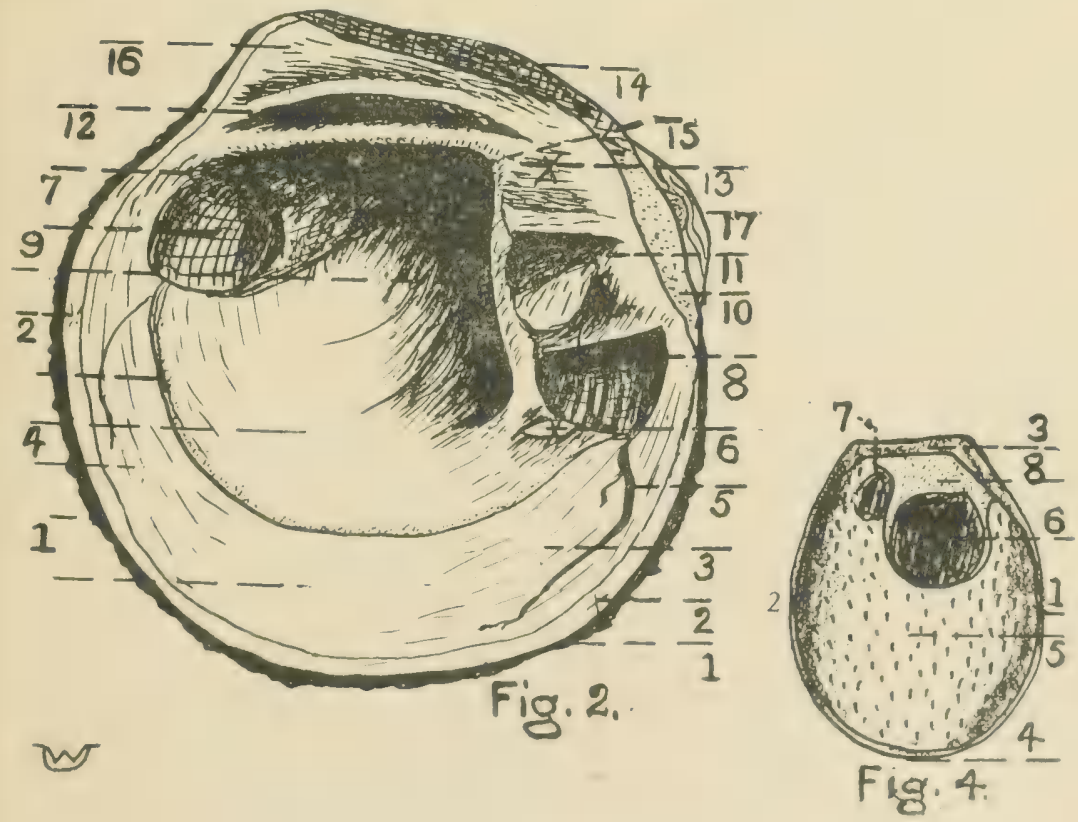

PLATE I 


\section{EXPLANATION OF PLATE II.}

Fig. 5a.-Fxternal structures of left valve of Plagiola securis (Lea)Male shell reduced one-fourth from natural adult size.

I.-Fxtreme ventral point.

2.-Extreme anterior point.

3.-Extreme posterior point. 1-2.-Antero-ventral section.

I-3.-Post-ventral section.

2-4.-Antero-dorsal section.
$3-$ +- Post-dorsal section.

5.- Minor lines of growth.

6.--Rest lines of growth.

7.-Lunule.

8.- Beak or umbone.

9.- Post-dorsal truncation.

Io.- - Broken rays.

Fig. 5b.-Internal view of right valve of $P$. securis. $\sigma^{7}$ Same reduction as in Fig. 5 a.

Fig. 6a.-External view of left valve of $P$. securis. Female shell reduced one-fourth from natural adult size. Same age as adult. Comparison to male shell of Fig. 5a. denoted by dotted outline.

Fig. 6b.- Internal structures of right valve of P. securis. $q$. Same reduction as in Fig. 6a.

I.-Ventral margin.

2.-Epidermis.

3.- Mantle line.

4.-Vein marks.

5.-Ant. retractor mus. scar

6. Ant adductor mus. sear

7.-Cardinal tooth.
8.-Beak cavity.

9.-Interdentum.

Io.-Beak

11.- - Hinge ligament

I 2.- - Hinge tooth.

13.-Protractor mus. scar.

14. Post add. mus. scar. 


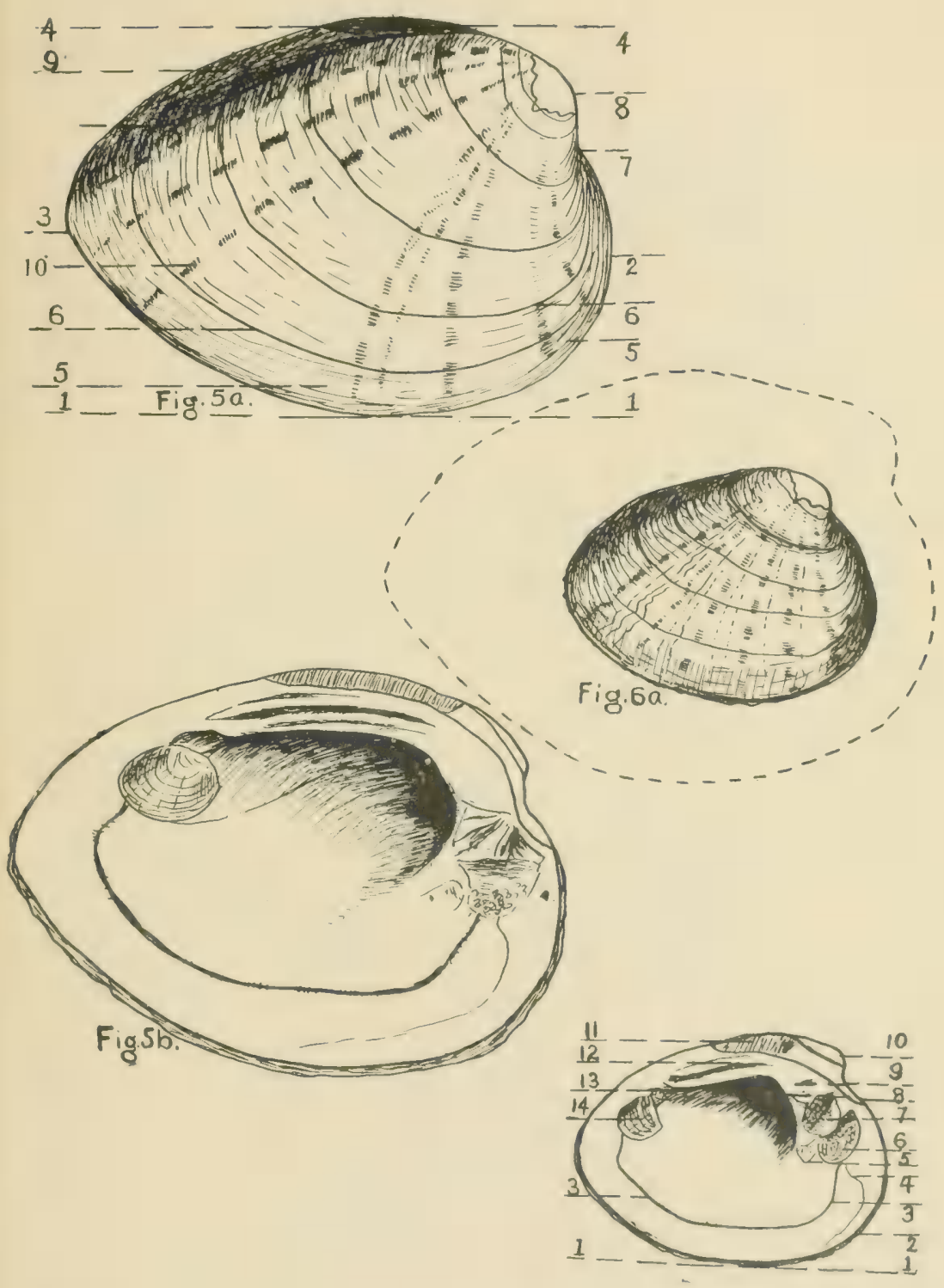

Fig. 6b. 
EXPLANATION ()F PIATE III.

Fig. 7a.-Fixternal structures of Anodontoides ferussacianus (Lea). क (Nat. size).

I. - Ventral extremity.

2.-Dorsal extremity.

6.- Rest lines of growth.

7.-Beak.

3.- Anterior extremity.

8.- Post-dorsal ridge.

4.-Posterior extremity.

9.-Post-umbonal ridge.

5.- Minor lines of growth.

Fig. 7b.- Internal structures of shell of A. ferussacianus. q.

1.-Ventral extremity.

2.-Dorsal extremity.

6.-Mantle line.

3.-Anterior extremity.

7.-Ant, add. scar.

4.- Posterior extremity.

8.-Post. add. scar

5.- Rest lines of growth showing

9.- Beak cavity.

through shell.

10.-Apex of beak.

Fig. 8a.-Dorsal view of A. ferussucianus shell showing Anodontine heak sculpture.

Fig. 8b.-Dorsal view of $P$. coccincum shell showing Unionine beak sculpture.

Fig. 8c.-Dorsal view of $\mathrm{E}$. (C.) para shell showing Lampsiline heak sculpture. 

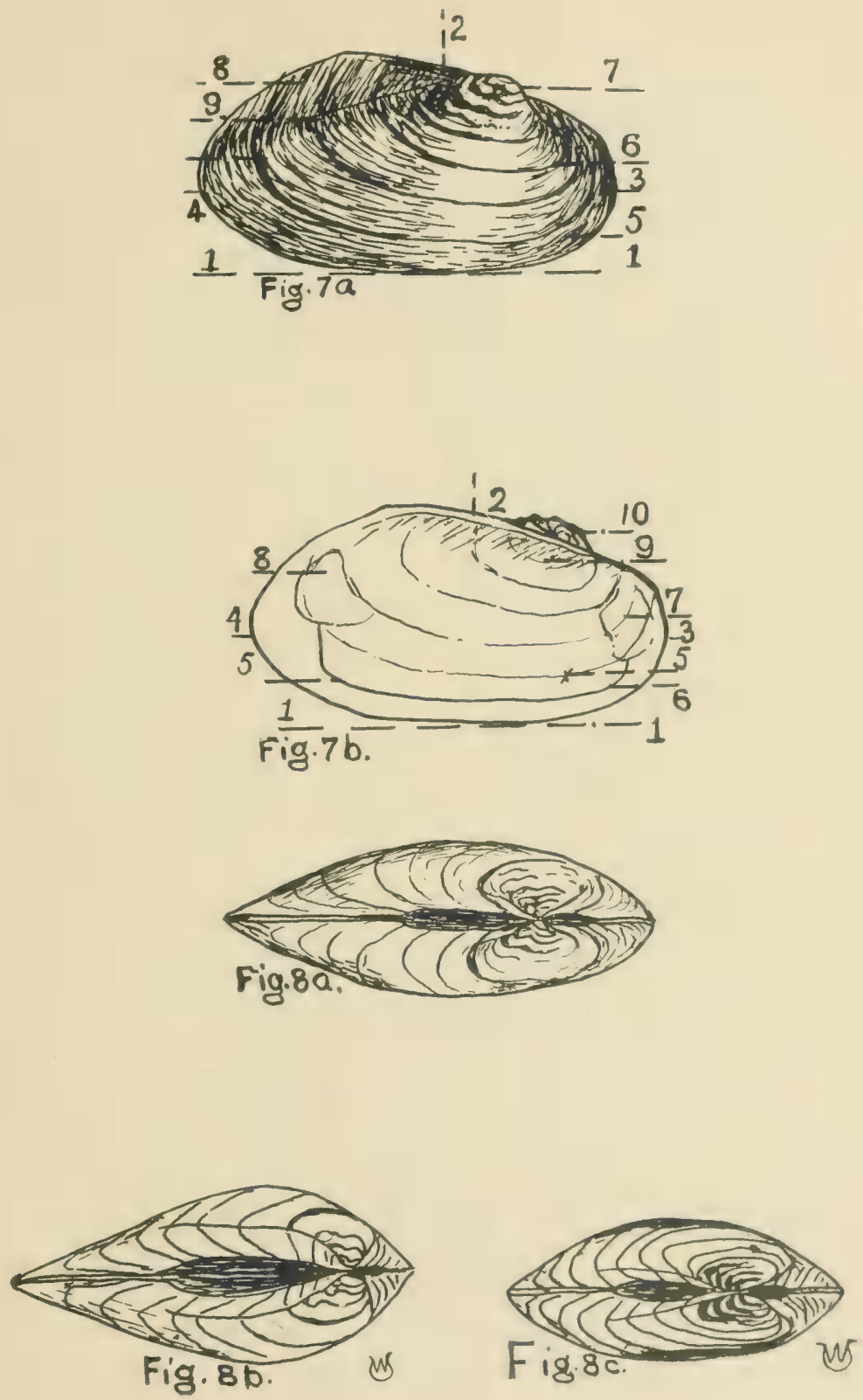

PLATE III.

UTTERBACK ON NAIADES OF MISSOURI 
EXPLANATION OF PLATE IV.

Fig. 9a.-Right gills of Fusconaia undata trigonoides Frierson, showing both marsupial, - a Unionine character.

Fig. gb.-Diagrammatic, vertical section of a Unionine ovisac at ventral margin.

Fig. roa.-Right gills of Lastena suborbiculata (Say) showing entire outer one marsupial,- an Anodontine character.

Fig. Iob.-Diagram of Anodontine ovisac showing lateral water tubes as provision for aeration of embryos.

Fig. 11a.-Right gills of Proptera alata (Say) showing only posterior portion of outer one marsupial,--a Lampsiline character.

Fig. I Ib.-Diagram of Lampsiline ovisac, showing rupture of ventral edge to allow escape of glochidia. 

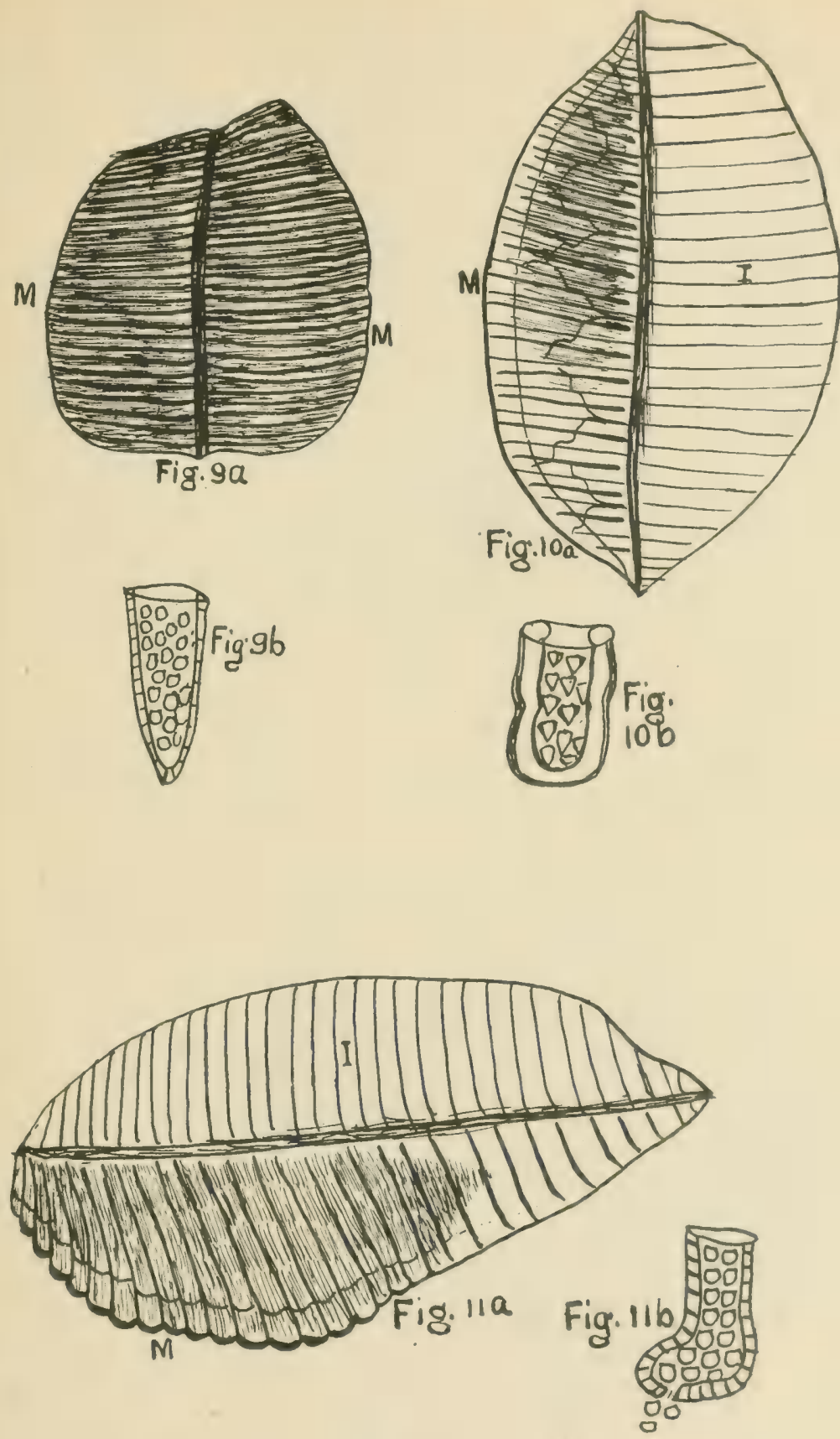

PLATE IV.

UTTERBACK ON NAIADES OF MISSOURI 


\section{FXPLANATION OF PLATE V. \\ (Drawings by G. T. Kline.)}

Fig. I 2a.-External view of left valve of a new species, Plenrobema Utterbackii Frierson. or (Nat. size.)

Fig. I 2 b.--Internal view of right valve of $P$. Ltterbacki. \& 


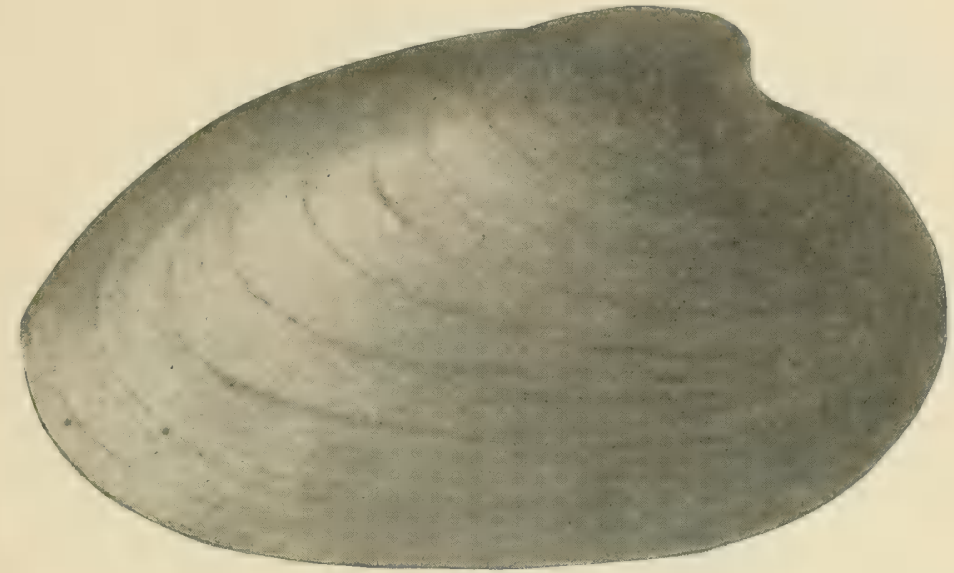

Fig. 12a.

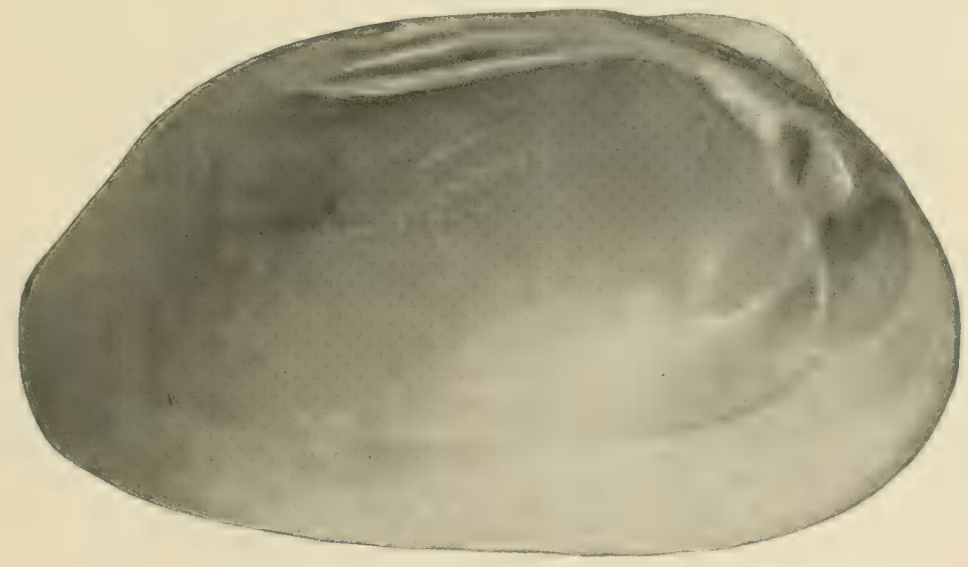

Fig. I $2 b$.

PLATEV. UTTERBACK ON NAIADES OF MISSOURI 
FXPI,ANATION OF PLATE VI.

(Drawings by G. T. Kline.)

Fig. I 3a.-External view of left valve of a new species, Truncilla Leferrei Utterback. or (Nat. size.)

Fig. I 3 b. - Internal view of right valve of $T$. Leferrei. $\sigma^{7}$

Fig.r3c.-External view of left valve of $T$. Leferrei. क

Fig. I3d.-Internal view of right valve of $T$. Leferrei. o

Fig. I 4a.- External view of left valve of a new species, Truncilla Curtisi Frierson and Utterback. or (Nat. size).

Fig. I 4 b. - Internal view of right valve of $T$. Curtisi. $\sigma^{7}$

Fig. 14c--External view of left valve of $T$. Curtisi. ?

Fig. I 4 d.- Internal view of right valve of $T$. Curtisi. \& 


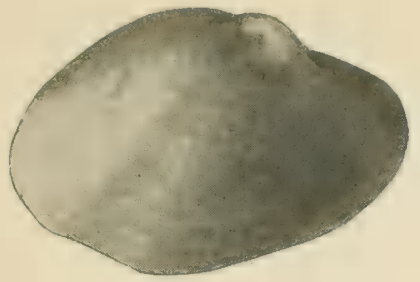

Fig. I $3 \mathrm{a}$.

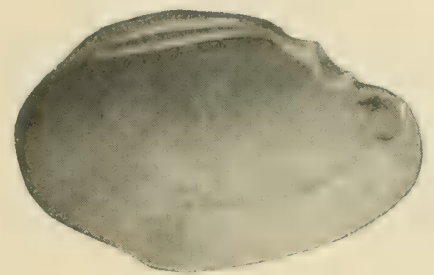

Fig. I 3 b.

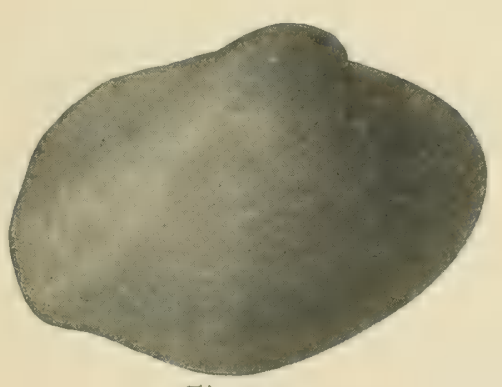

Fig. $14 \mathrm{a}$
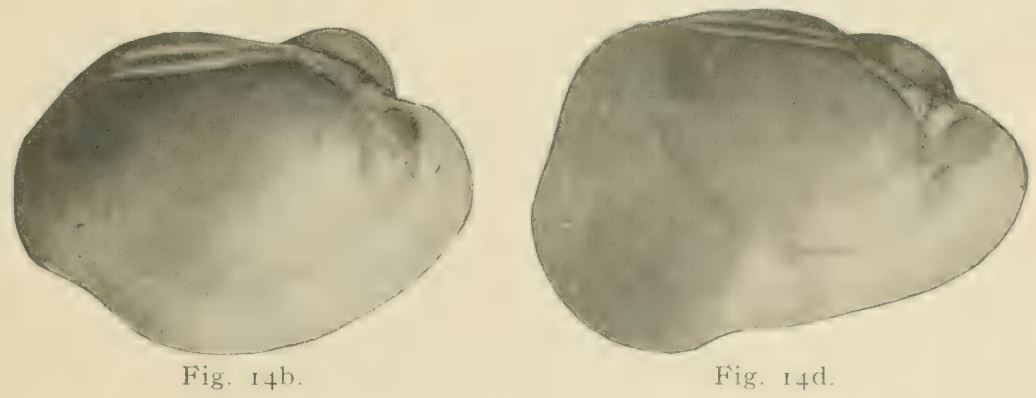

PLATEVI.
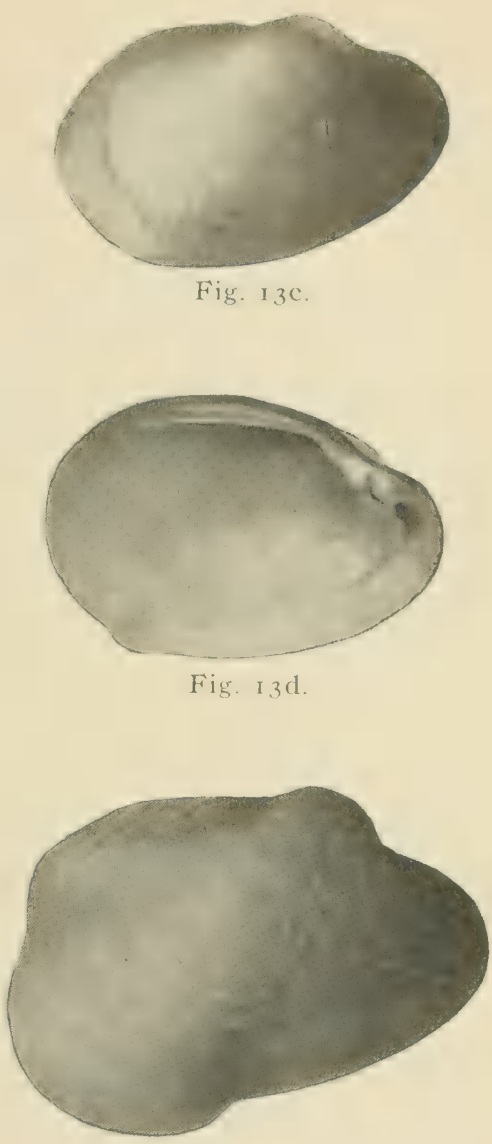

Fig. I 4 C.

Fig. 14 d.
UTTERBACK ON NAIADES OF MISSOURI 
EXPLANATION OF PLATE VII.

Fig. 15.-Anodonta grandis Say o-Actual longi-section of the visceral mass showing entire alimentary tract, protractor muscle and other animal structures in left valve. ( $3 / 4$ Nat. size).

Fig. 16.-Megulonaias heros (Say) \& Photograph of gravid specimen showing animal structure in left valve. ( $3 / 4 \mathrm{Nat}$. size). 


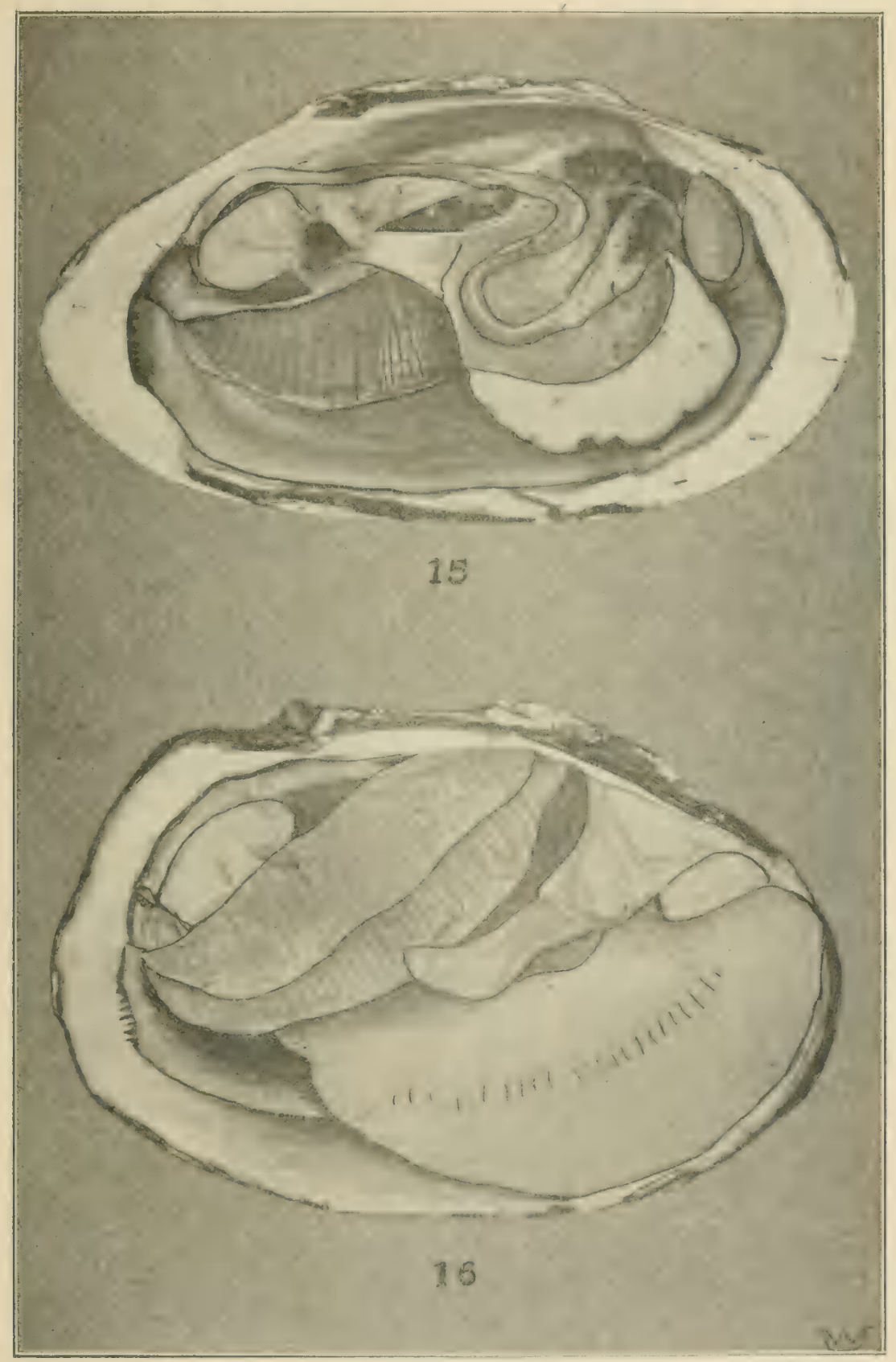

PLATE IIII.

["TTIERBACK ON NAIAI)IS U]' MISSUIRI 


\section{EXPLANATION OF PLATE VIII.}

Fig. I7A.-Lampsilis anodontoides (Lea), of-Extenal view of right valve. ( $3 / 4$ Nat. size $)$.

Fig. i 7 B.-L. anodontoides. $\sigma^{7-I n t e r n a l ~ v i e w ~ o f ~ l e f t ~ v a l v e . ~}$

Fig. r8A-Lampsilis fallaciosa (Smith) Simpson. \&-External view of right valve. (3,4 Nat. size).

Fig. IsB.-L. fullaciosa. $\$-$ Dorsal view showing Lampsiline beak sculpture. 


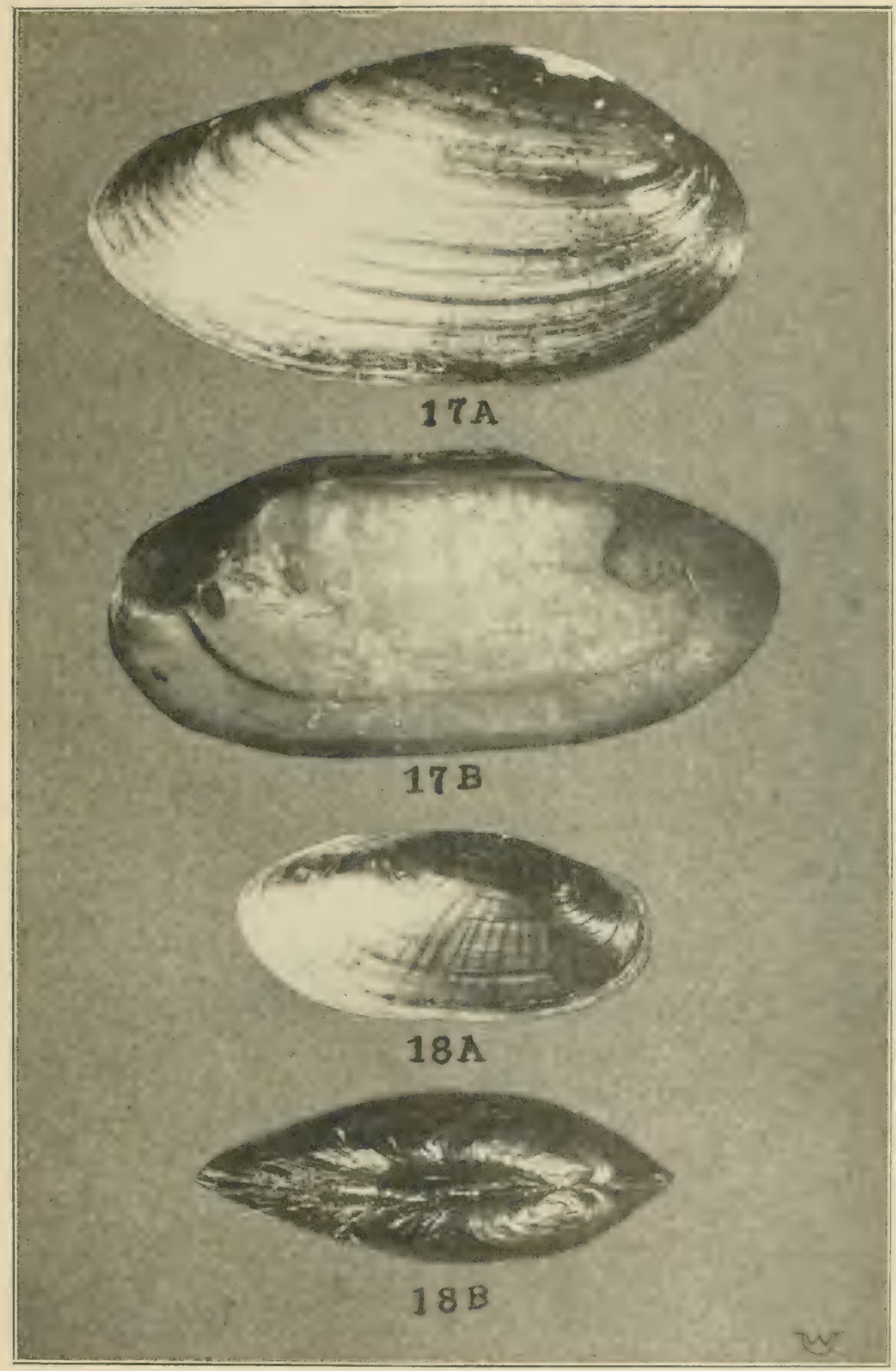




\section{IEXILANATION OF PI,ATE IX.}

Fig. 19.-Posterior views of live mussels in aquarium showing "siphons" open in act of feeding and discharging wastes. Reading from left to right are:- One $P$. laevissima ${ }^{7}, L$. fragilis of (next three) and $L$. suborbiculata of (two at extreme right). Young of $L$. fragilis (lateral view) and Q. quadrula (umbonal view) lie in front.

Fig. 20-Continued aquarium view showing narrowly open "siphons" of .1. rariplicula on the left and the extremely extended "siphons" of $P$. laterissima of on the right (lateral view). 


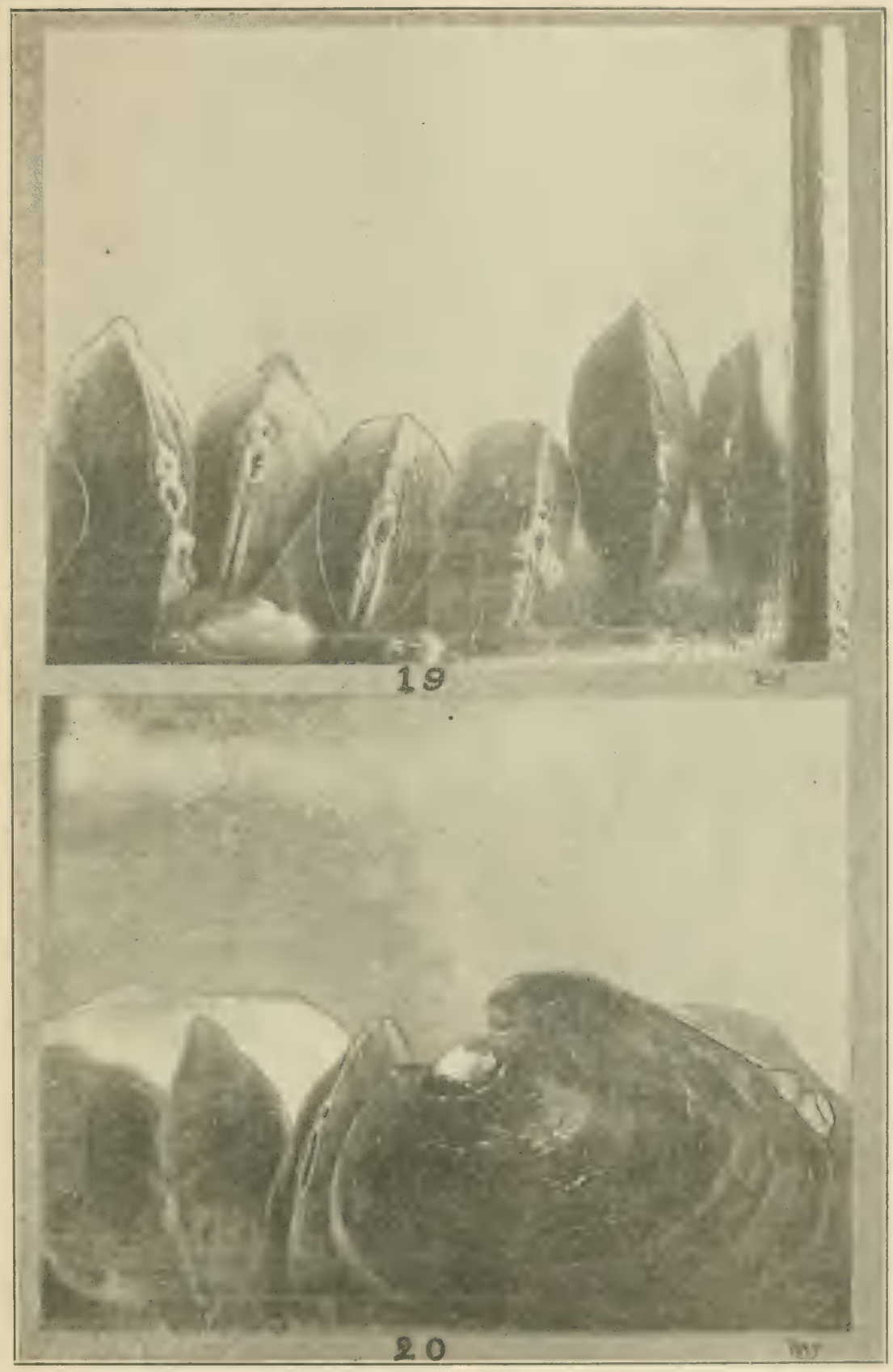

PLATE IX.

UTTERBACK ON NAIADES OF MISSOLRI 
IXPLANATION OF PLATE X.

Fig. 21.-Platte River below a small falls showing a quiet, sheltered "pocket" where juveniles and small species of mussels congregate in great numbers. Note dead shells on the rocky bar. 


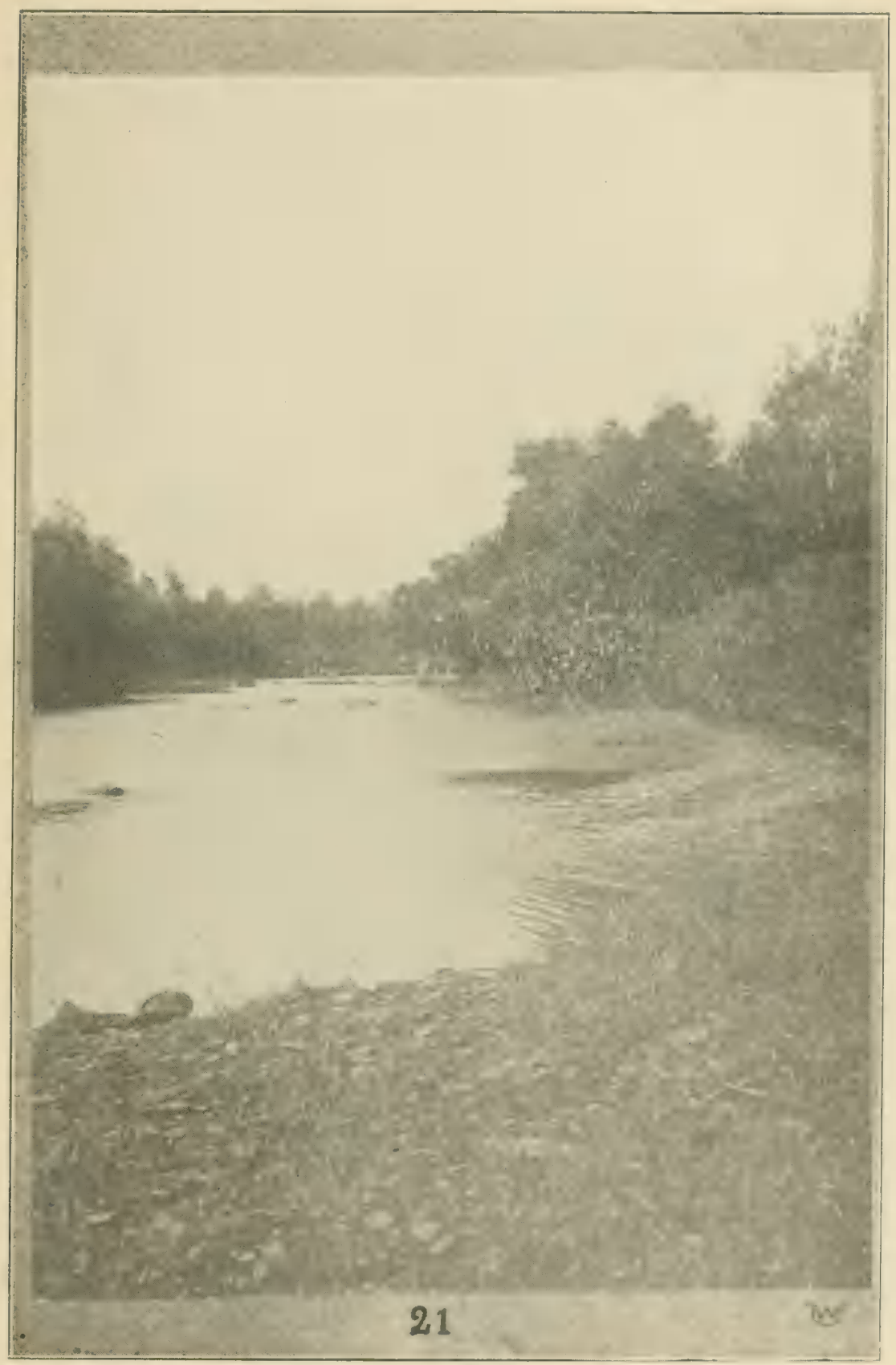

PLATEX.

UTTERBACK ON NAIADISOF MISSOL'RI 


\section{IIXPI,ANATION OF PLATE XI}

Fig. 22.- Limestone clifis and mussel bed at the foot above Dixon Falls, Platte River. Abundance of lime in the water here contributes to the unusual growth of shell.

Fig. 23.- "Fishing" for mussels in the West Bayou of Lake Contrary St. Joseph. A garden rake is used in deep water, but hand, picking, whereever possible, is the most successful. 


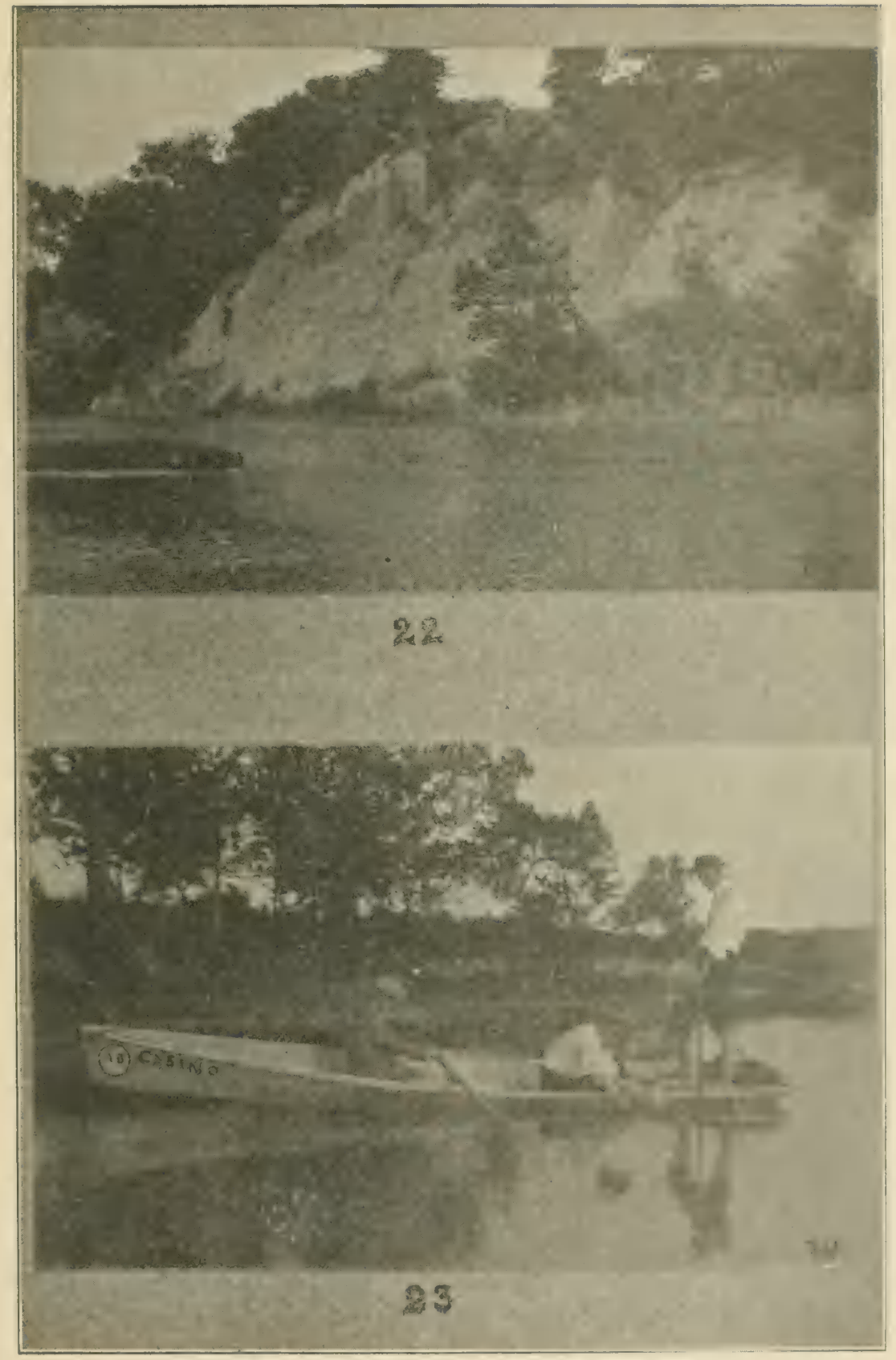

PLATEXI.

UTTERBACK ON NAIADES OF MISSOLRI 


\section{FAPLANATION OF PLATE XII}

Fig. 24.-Beach of a North-West Missouri Lake showing the common sight of a pile of cleaned mussel shells made hy a musk-rat after feeding on the soft parts. These ravages, as well as the receding of the water, tend greatly to deplete the mussel beds. 


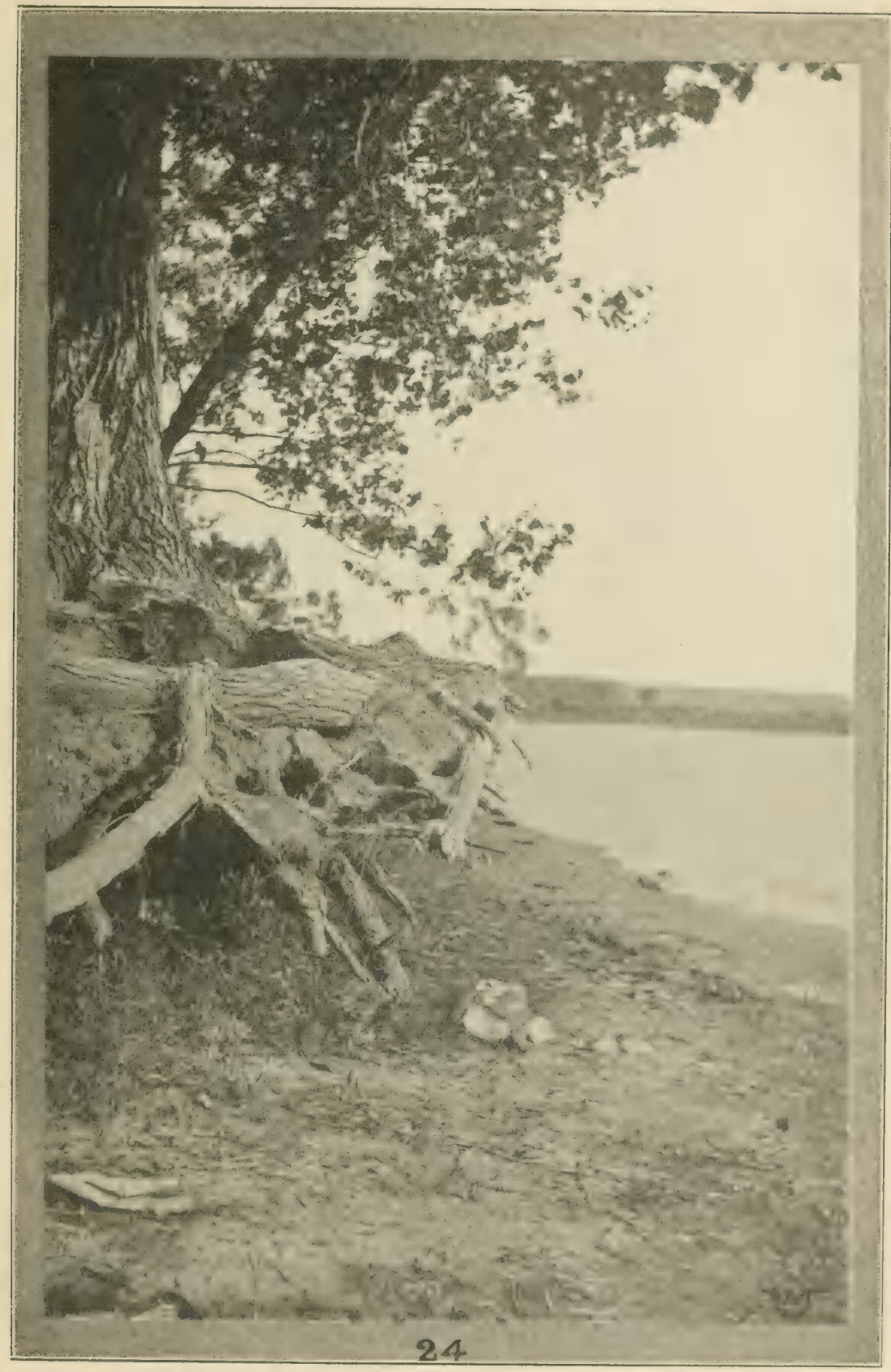

PLATE XII

UTTERBACK ON NAIADES OF MISSOURI 


\section{FXPIANATION UI PLATE XIII}

Fig. 25.- Lake Contrary, (St. Joseph), - the home of the Anodontinae, especially Lastena suborbiculata. Althongh originally the bed of the Missouri River, yet the only river species fonnel here are:- $Q$. quedrula and $P$. laevissima.

Fig. 26.-One-and-Two River, Corby Mill--Above the dam the mussel fauna is different, due to the limitation of the range of certain fish as distributors of mussel life in the parasitic stage. 


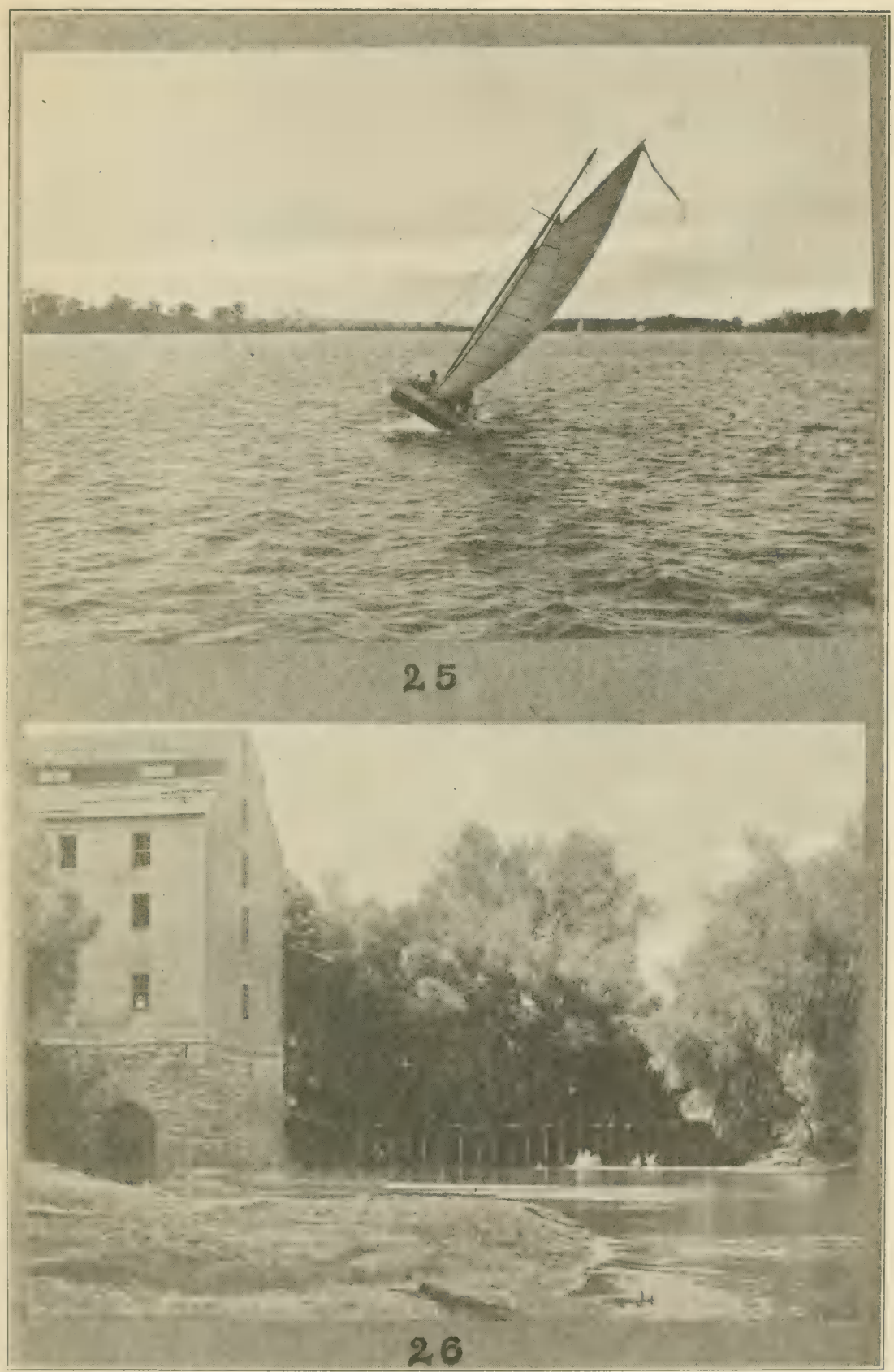

PLATE XIII.

UTTERBACK ON NAIADES OF MISSOURI 
EXPLANATION OI I'LATE XIV

Fig. 27. Shells in situ (above and to right of hat) embedded in a bank along Reck's Slough, St. Joseph. This shows a former mussel life now extinct there. 


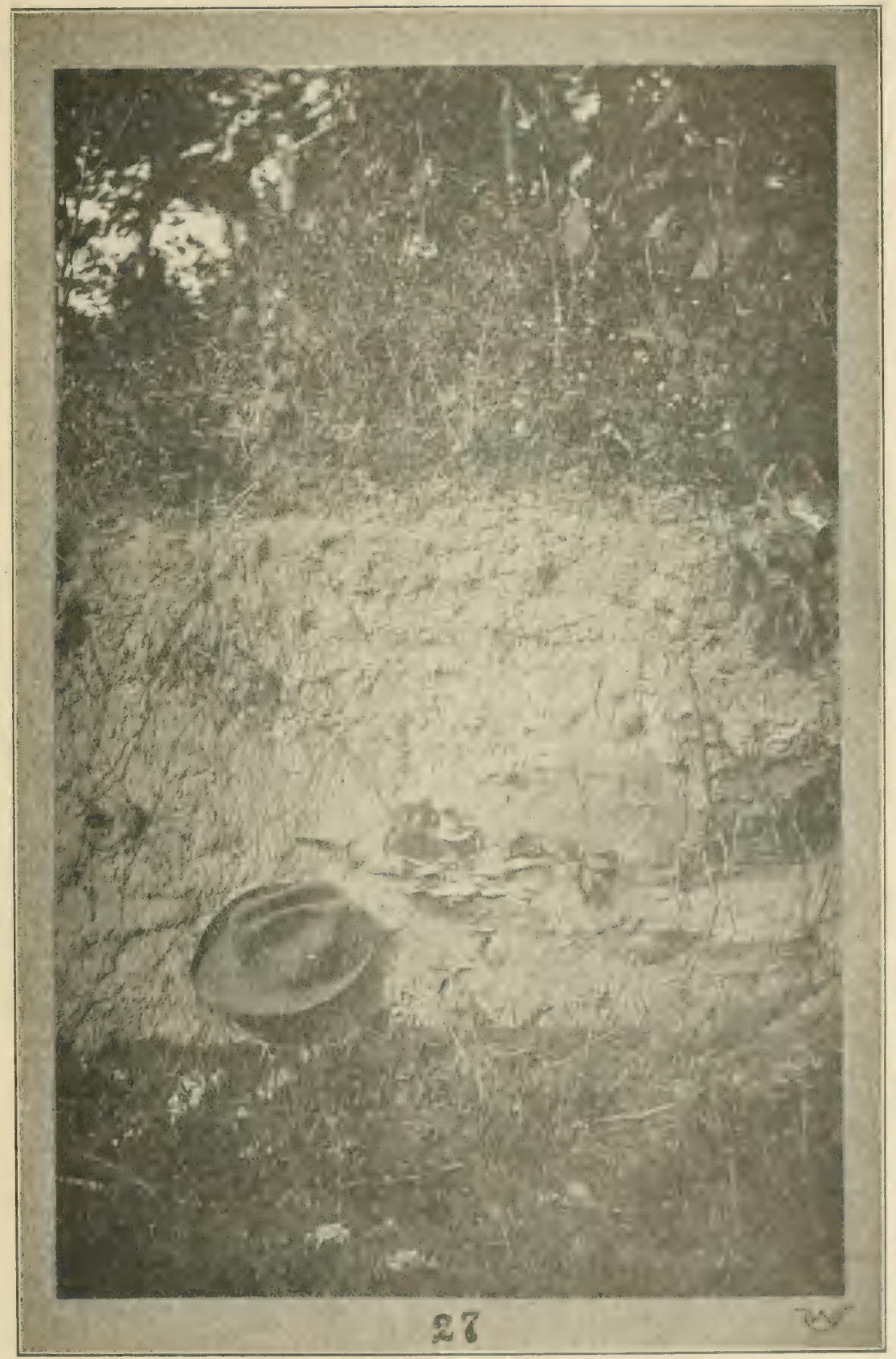

PLATE KIV

UTTERBACK ON NAIADES OF MISSOLRI 


\section{F.XPLANATION OF PLATE XT.}

Fig's. 28.-A and B Cumberlandia monodonta (Say) o, Miss. R. LaGrange.

Fig's. $29 \mathrm{~A}$ and B.--Fusconaia undata (Barnes) , Mis. R., Hannibal Fig's. 30 A and B.-Adult $F$. undata trigonoides Frierson MS. \& Platte R., Agency Ford.

Fig's. $30 \mathrm{C}$ and D.-Juvenile of trigonoides.

Figr's 3: A and B.-F. undate trisona (Lea) o, Osage R., Warsaw.

Fig's. 32 A and B.-Adult F. flare (Raf.) or, White R., Hollister

Fig's $32 \mathrm{C}$ and D.- Young of flava.

Fig's 33 A and B.-F. hebetata (Conrad) of, Osage R., Waraaw

Fig's 34 A and B.-F ebena (Lea) o, Miss. R., LaCrrange. 


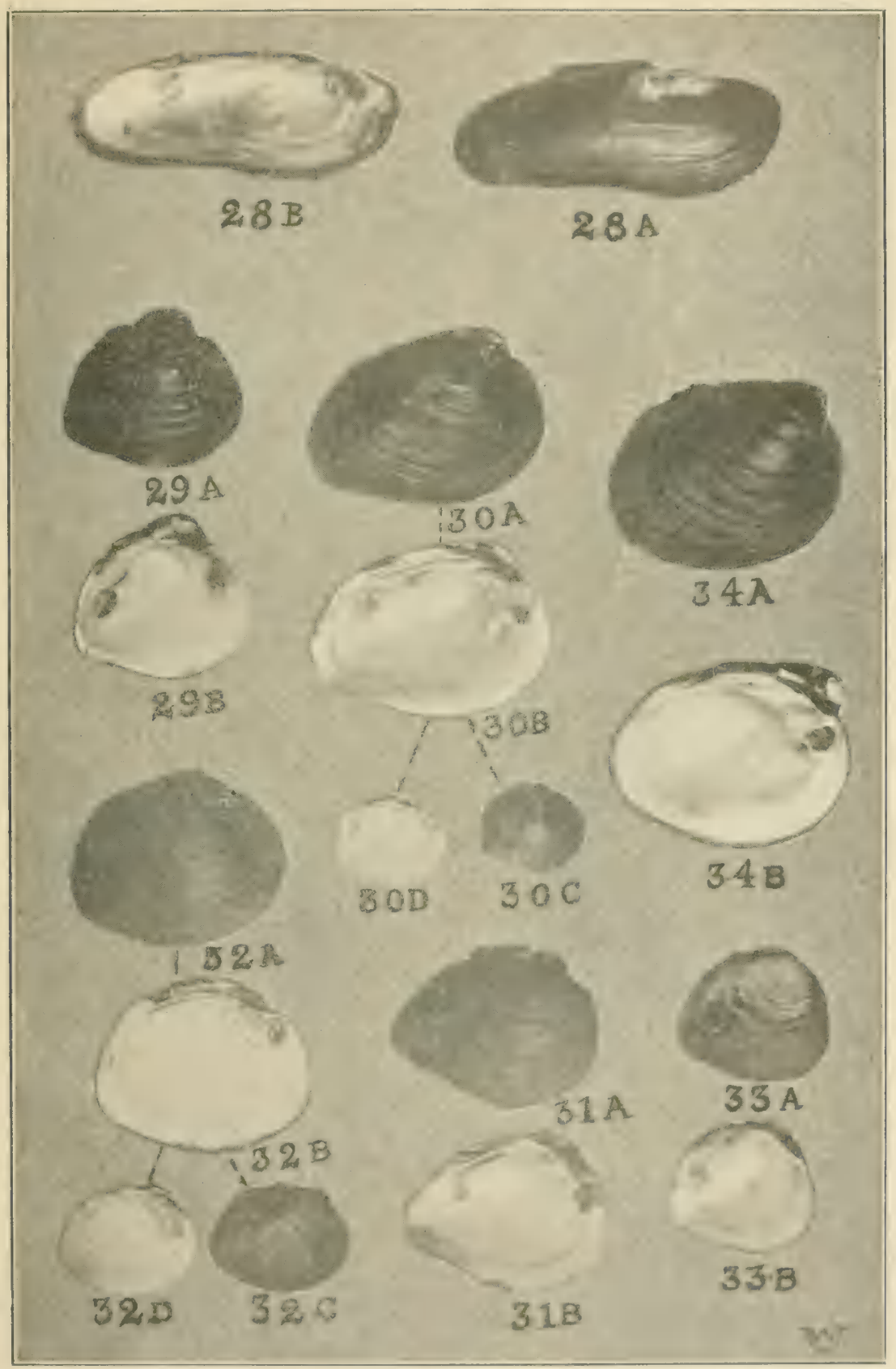

PLATEXI'.

UTTERBACK ON NAIAIFS OF MISSOURI 


\section{EXPLANATION OF PLATE XTI.}

Osceula.

Fig's 35 A and B.-Amblema peruriana (Lamarck) 9 , Osage R.

Fig's 36 A and B.-A rariplicata (Deshayes) 9 , Platte R., Dixon Falls.

Fig's $36 \mathrm{C}$ and D.-A, ruriplicuta (Des) $0^{7}$, Tarkio R., Craig.

Fig's 37 A and B.-A, perplicuta (Conrad) o. St. Francis R., Greenville.

Fig's 38 A and B.-A. perplicata Quintardi (Cragin) o, White R., Hollister.

Fig's $38 \mathrm{C}$ and D.-A. perplicata Quintardi (Cragin) $q$, Osage $\mathrm{R}$ Iructor.

Fig's $39 \mathrm{~A}$ and B.-A. plicata costata (Raf.) $\mathrm{O}^{7}$, Chariton R., Kern

Fig's 39 C and D.-Juvenile of costuta.- Same locality as adult 


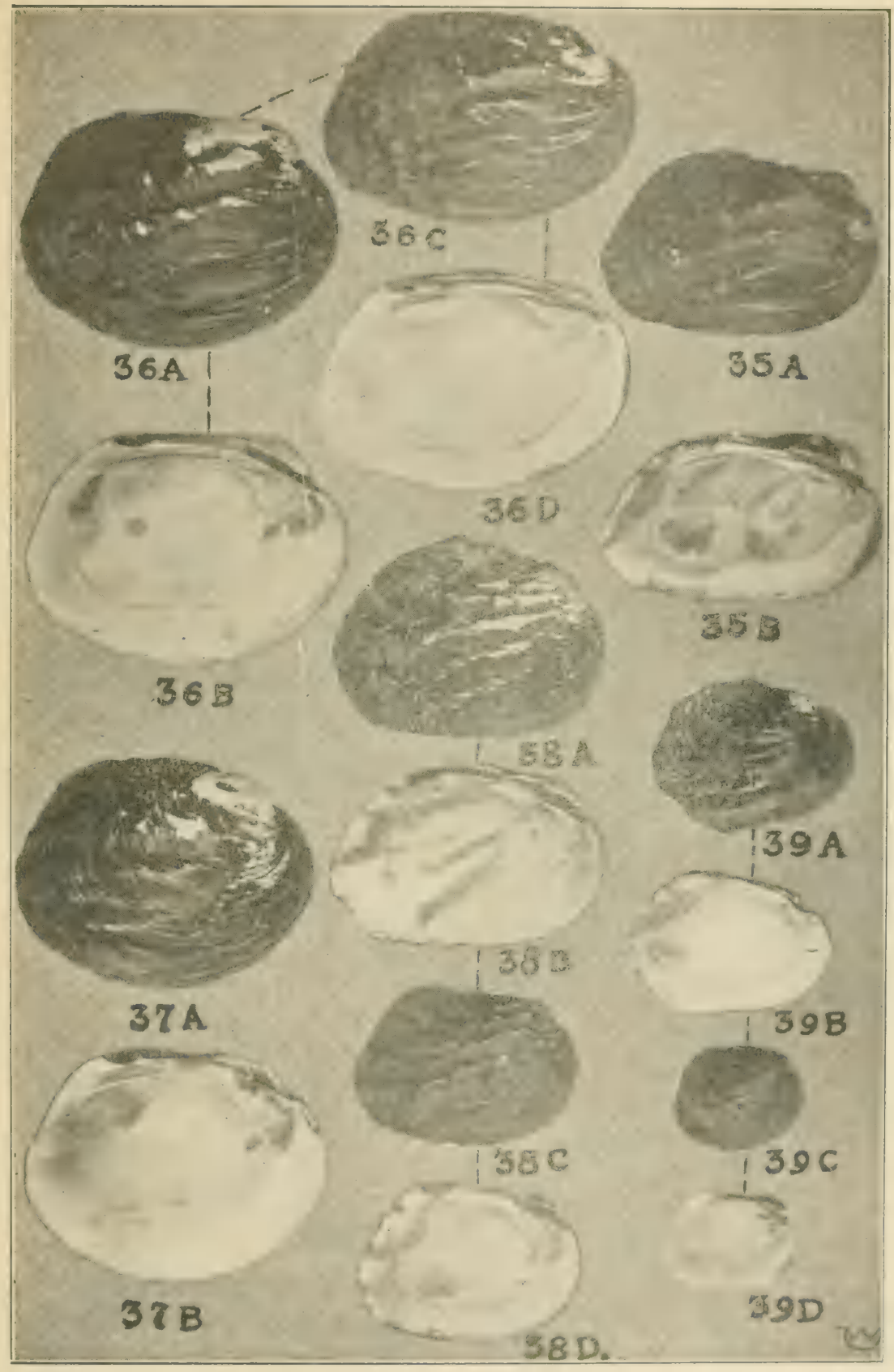

PLATEXIT.

UTTERBACK ON NATADES OF MISSOLRI 


\section{IEXPLANATION OF PLATE XVII}

Fig's 4o A and B.-Adult Megalonaius heros (Say) o, Platte R. Garretsburg.

Fig's to C and D. Juvenile heros, Osage R., Monegaw Springs.

Fig's to E and F. - Young heros, Osage R., Warsaw.

Fig's 4 I A and B. - Ouadrula pustulosa (Lea) q, Miss. R., Hannibal.

Fig's $+2 \mathrm{~A}$ and B.-Adult Q. pustulosa schoolcraftensis (Lea) of, Plat te R., Claire.

Fig's +2 C and I).-Young schoolcraftensis.- Same locality as adult. Fig's 43 A and B.-O. pustulosa asperala (Lea) or. Osage R., Bagnell. Fig's t+ A and B. () norluluta (Raf.) or, Miss. R., Hannibal. 


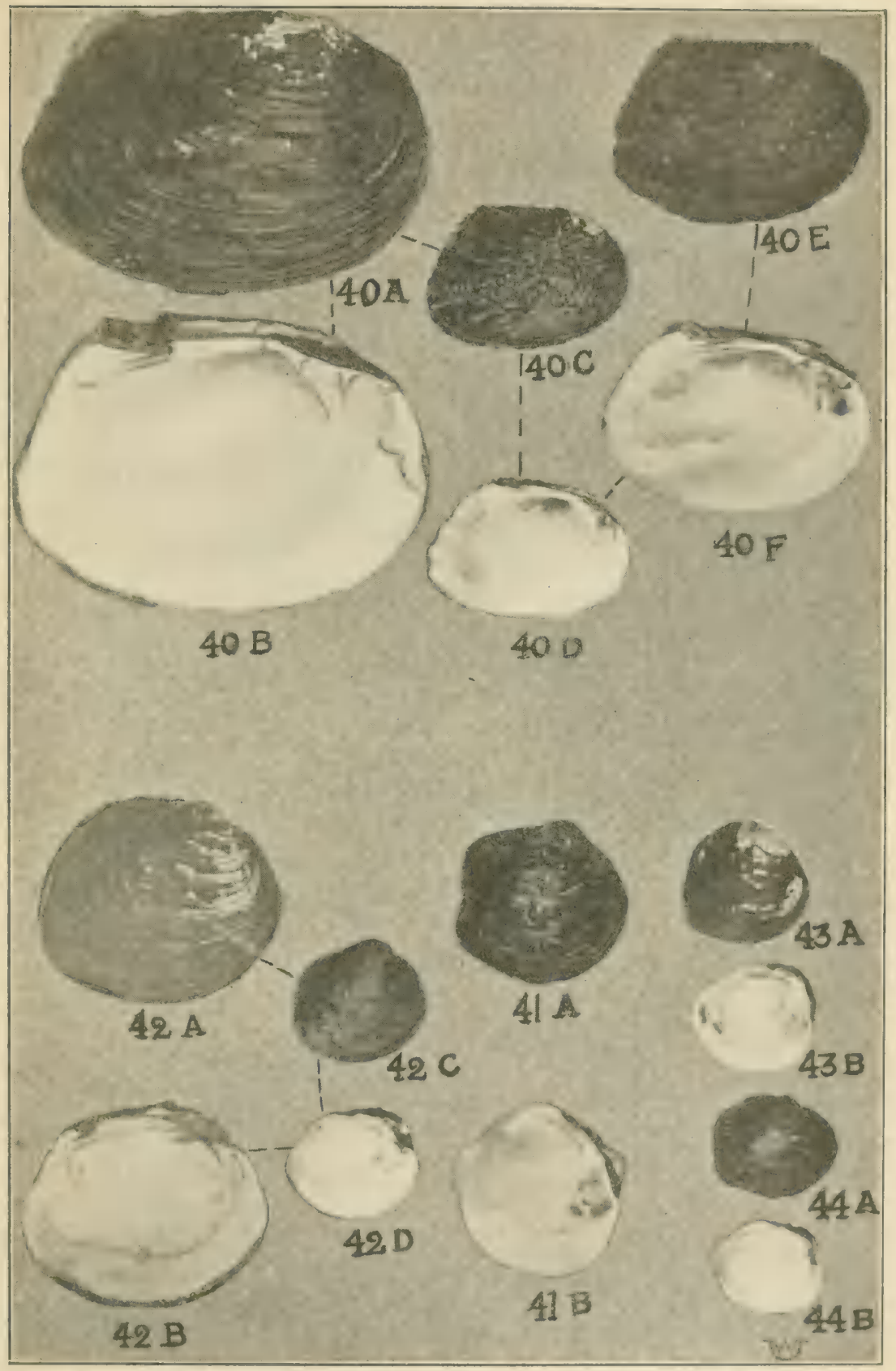

PLATE XVII.

UTTIRBACK ON NAIADI:S OF MISSOURI 
FIXPIANATION OF PIATE XVIII.

Fig's 45 A and B.-Q. quadrula (Raf.) o, Lake Contrary, St. Joseph.

Fig's 45 C and D.-Q. quadrula or. Same locality as female.

Fig's 4.5 Fi and F.-Q. quadrula o ${ }^{7}$, Flat Cr., Sedalia.

Fig's $46 \mathrm{~A}$ and B. - () quadrula o, L. Contrary.-A common pathologic shell found in the N. W. Mo. Lakes.

Fig's 47 A and B.-Q. quadrula contraryensis I'tterback 9, L. Con trary.-A new variely.

Fig's 48 A and B.-Q. fragosa (Conrad) $\odot$, Miss. R., Hannibal.

Fig's 49 A and B.-Q. aspera (Lea) \&, Osage R., Warsaw. 


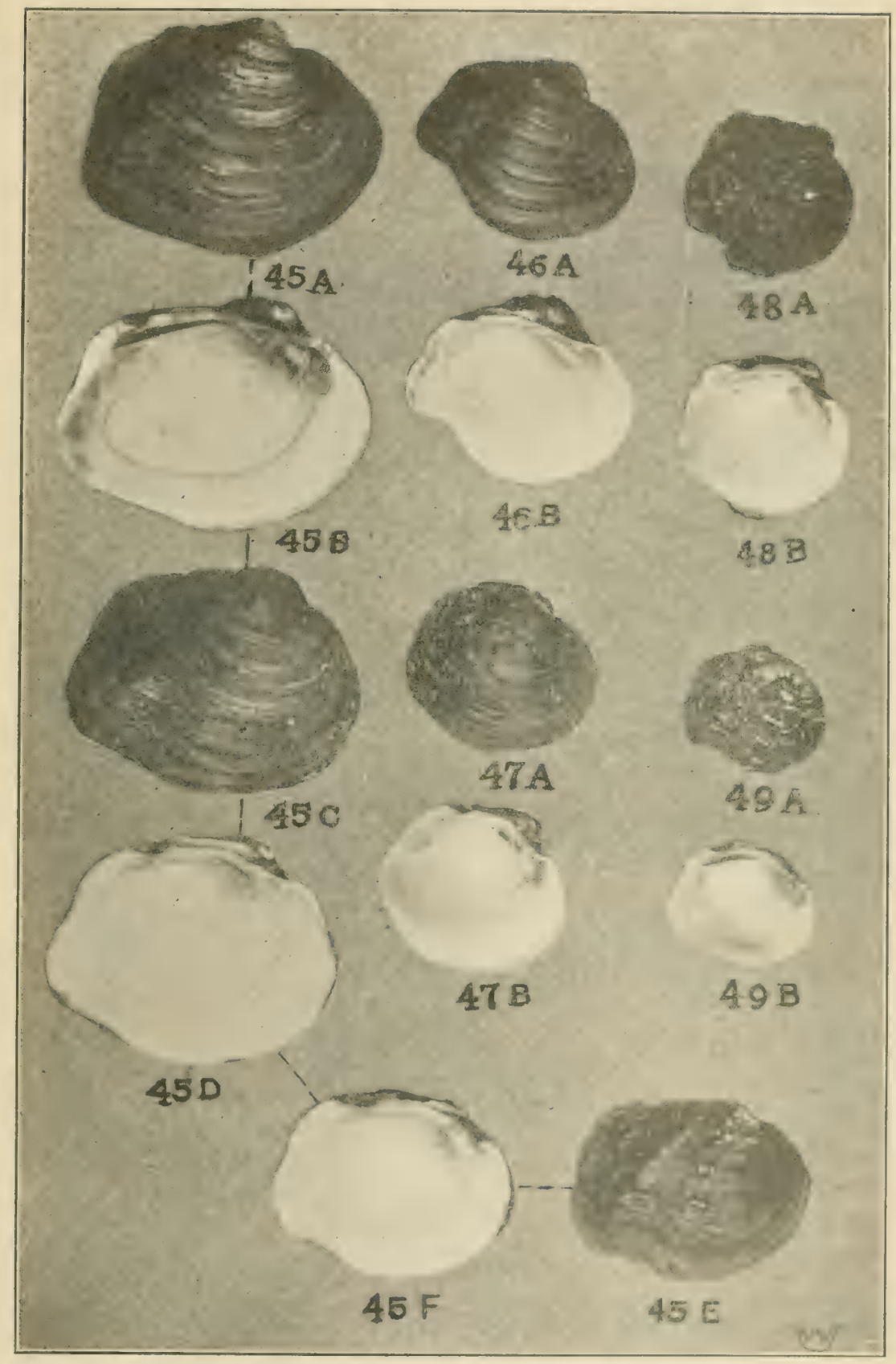

PLATEXVIII.

UTTERBACK ON NAIADISSOF MISSOIRI 
EXPLANATION OF PLATE XIX.

Fig's. 50 A and B.-Q. verrucosa (Raf.) or, Grand R., I)arlington.

Fig's 5o C and D.-Young Q. zerrucosa (Raf.) q, White R., Hollister. Fig's 5 I A and B.-Q. nohilis (Conrad) $ᄋ$, Marais des Cygnes R., Rich Hill.

Fig's 52 A and B.-Q. Cylindirca (Say) $\%$, Black R., Williamsville.

Fig's 53 A and B.-Q. metanevra (Raf.) $0^{7}$, Meramec R., Merance Highlands.

Fig's 54 A and B.-Rotundaria tulerculuta (Raf.) o, Osage R., Schell Citv.

Fig's 55 A and B.-R. granifera (Lea) o, Miss. R., LaGrange. 


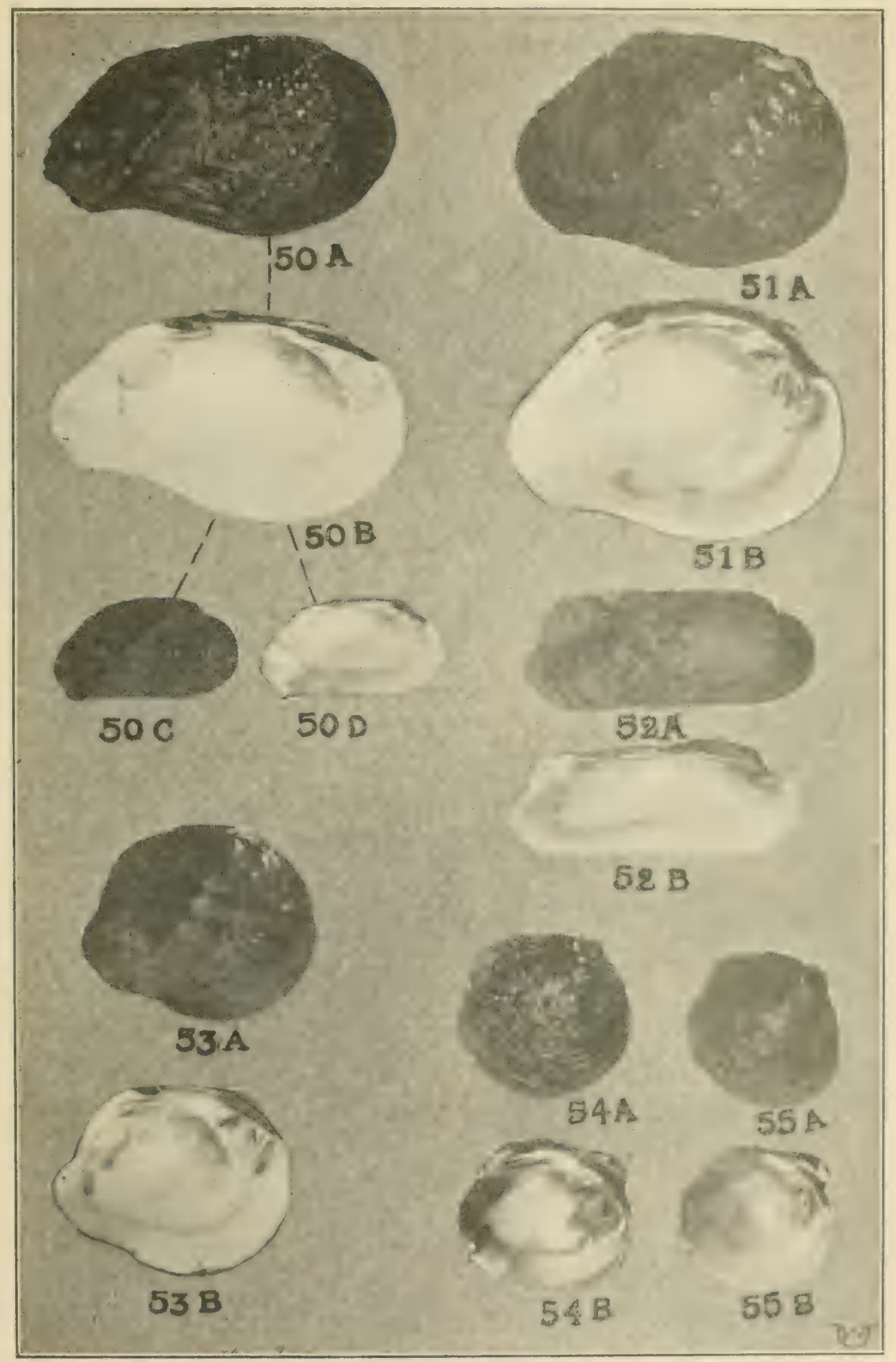

PLATE XIX

UTTERBACK ON NAIADES OI MISSOLRI 
IEXILANATION OF PLATE XX.

Fig's 56 A and B.-Plethobasus aesopus (Green) q, Des Moines R., Dumas.

Fig's $56 \mathrm{C}$ and D.--Juvenile of $P$. aesopus.- Same locality as adult

Fig's $57 \mathrm{~A}$ and B.-P. cooperianus (Lea) $\&$, Gascondy.

Fig's $58 \mathrm{~A}$ and B.-Pleurobema obliquum pyramidatum (Lea) , Osage R., Baker, Mo.

Fig's $59 \mathrm{~A}$ and B.-P. catillus (Conrad) o, Black R., Williamsville.

Fig's $60 \mathrm{~A}$ and B.-P. coccineum (Conr.) \&, White R., Hollister.

Fig's 6 I A and B.-P. obliquum coccineum (Conr.) o, Osage R.. Warsaw.

Fig's $61 \mathrm{C}$ and D.-Young $P$. obliquum coccineum (Conr). Same locality as adult.

Fig's 62 A and B.-P. obliquum catillus (Conr.) 우, Osage R., Colley's Ford.

Fig's 63 A and B.-P. Utterbacki Firierson (n. sp.) o , White R., Hollister. Fig's $63 \mathrm{C}$ and D.-P. Utterbacki $\mathrm{F}$. $\mathrm{O}^{7}$, Jack's Fork of the Current R. 


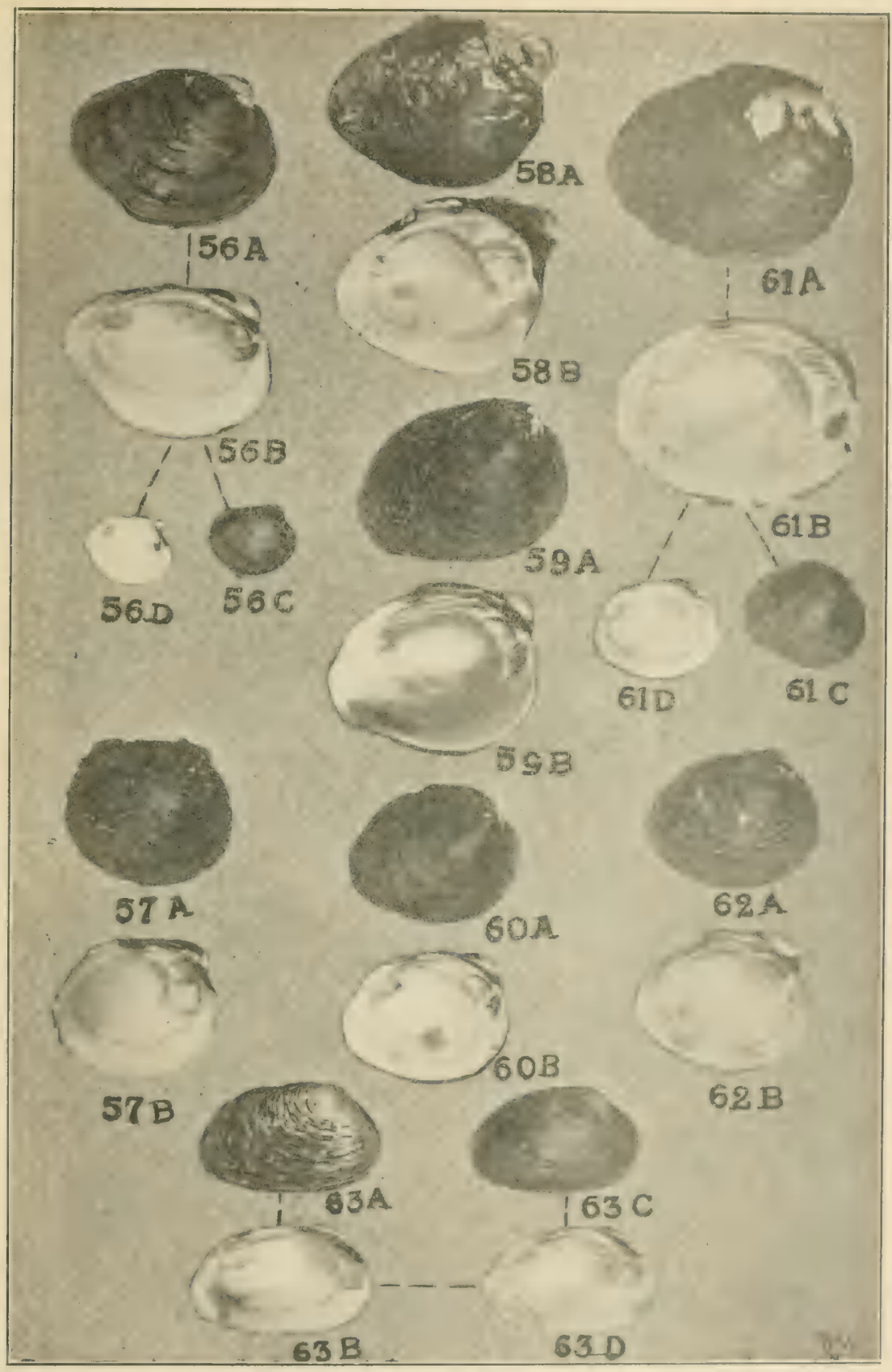

PLATE XX.

UTTIRBACK ON NAIADES OF MISSOURI 


\section{EXPLANATION OH PIATE XXI.}

Fig's 6+ A and B.-Elliptio nigra (Raf.) or. Meramec R., Meramec Highlands.

Fig's $65 \mathrm{~A}$ and B.-E. nigra (Raf.) o, Miss., Hannibal.

Fig's $66 \mathrm{~A}$ and B.-E. dilatata (Raf.) \&, Osage R., Osceola.

Fig's 67 A and B.-E. dilatata delicuta (Simpson) $q$, White R., Hollister.

Fig's $67 \mathrm{C}$ and D.-E. dilatata delicuta (Simp.) or, Black R., Williamsville.

Fig's $68 \mathrm{~A}$ and B.-E. dilatata subgibbosa (Lea) o, Black R., Williamsville. ville.

Fig's $68 \mathrm{C}$ and D.-E. dilatata subgibhosa (Lea) on, Black R., Williams-

Fig's 69 A and B.-Uniomerus tetrulasma (Say) o, Batterton Pond, Columbia. 


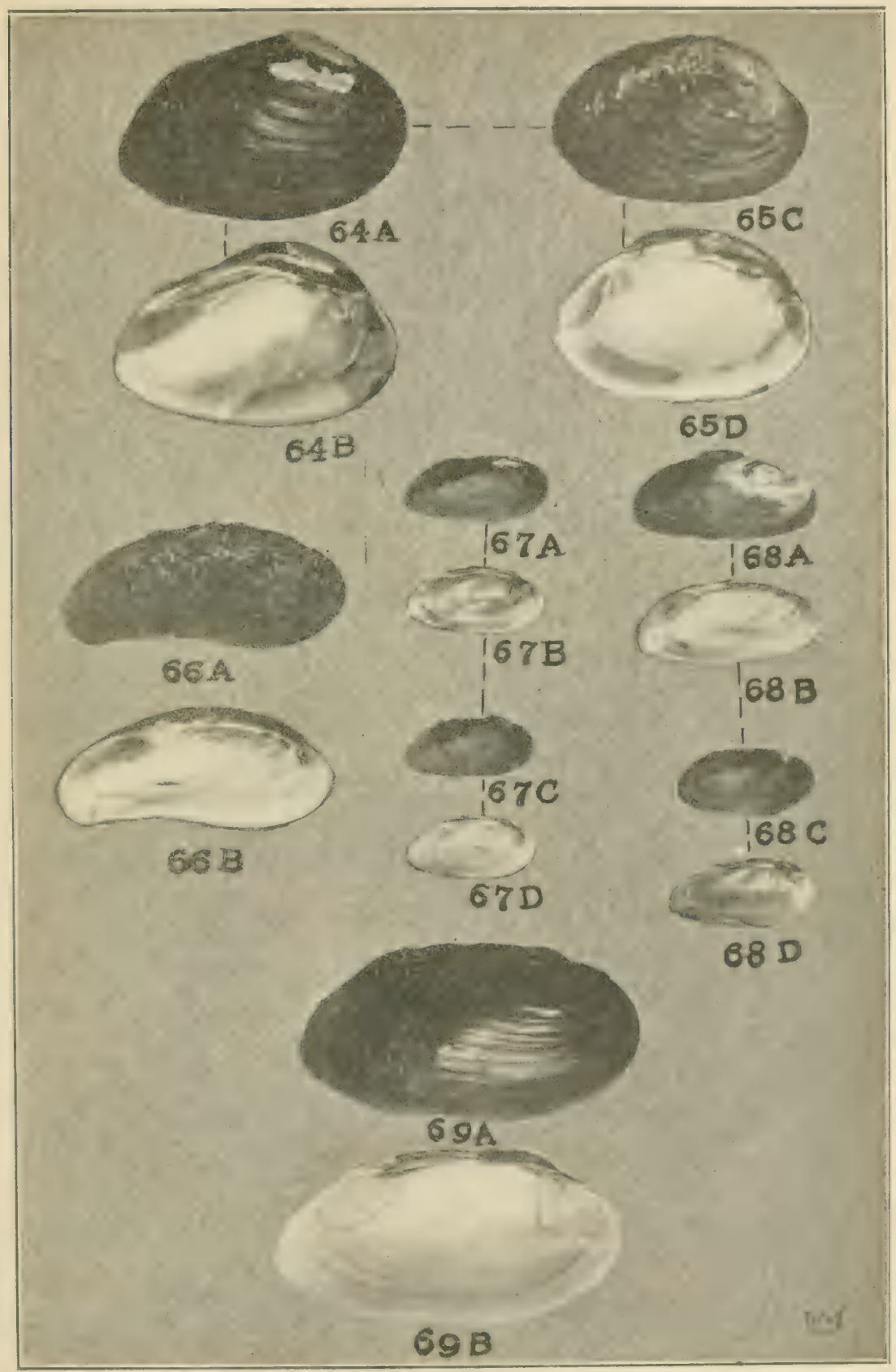




\section{FXPLANATION OF IPATE XXII}

Fig's $7^{\circ} \mathrm{A}$ and B.--Symplinnote complanata (Barnes) o, Big Mud Lake, Kenmoor.

Fig's 71 A and B.-Symphynota costata (Raf.) of, Black R., Williamsville.

Fig's 7 I C ant D.-S. costutu (Raf.) or, Gasconade R., Gascondy.

Fig's 7 I Fi and F.-S. costate (Raf.) o, Miss. R., Hannibal.

Fig's 72 A and B.-Arcidens confrugosa (Say) $q$. Marais des Cygnes R., Papinsville. 


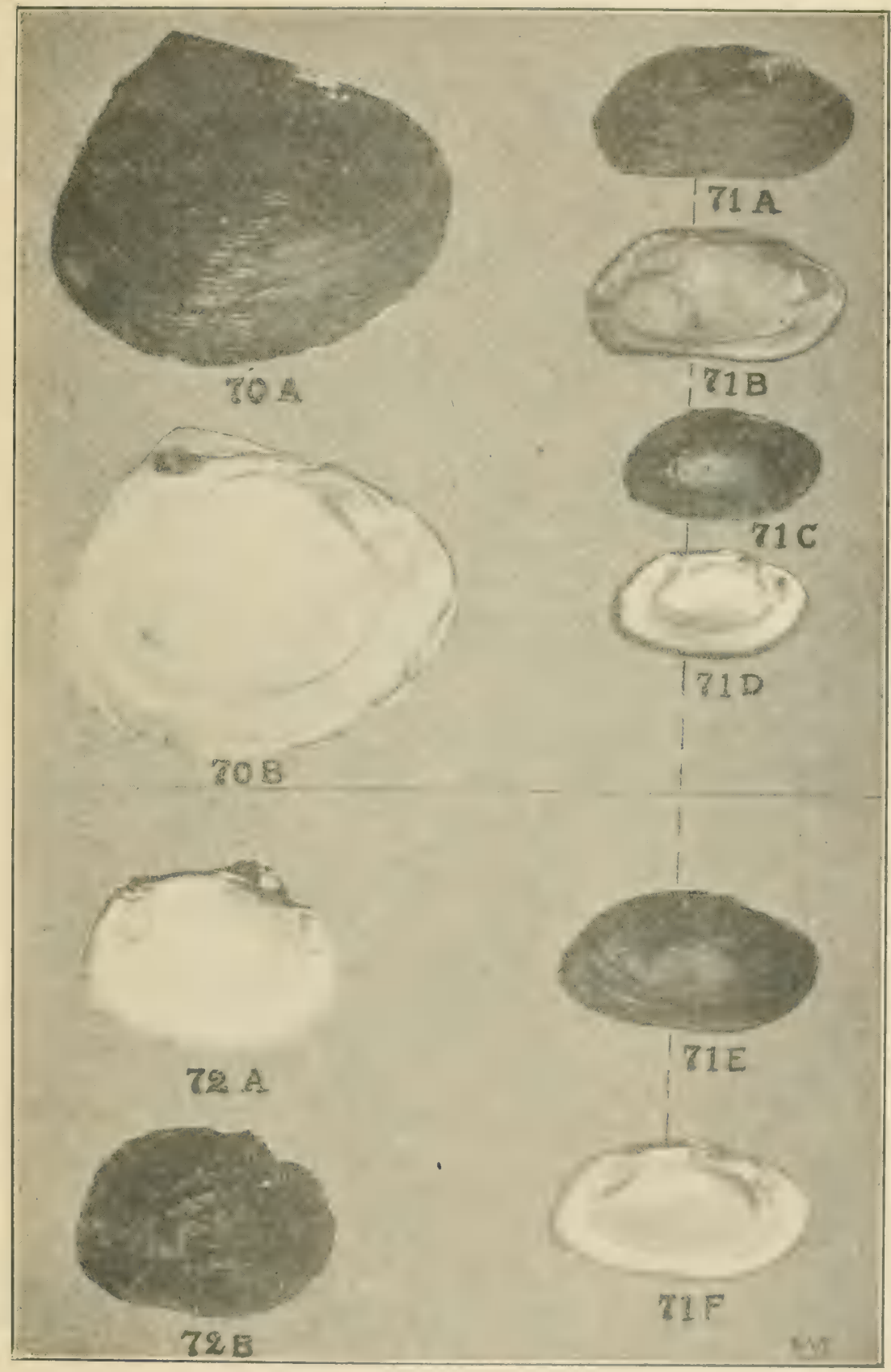

PLATE XXII.

I"TTIRBACK ON NAIADISS OI: MISSOLRI 
FXPLANATION OF PLATL: XXIII.

Fig's $73 \mathrm{~A}$ and B.-Lastena suborbiculuta (Say) o , Lower Lake Contrary. St. Joseph.

Fig's $73 \mathrm{C}-\mathrm{F}$-Juveniles of $L$. suborhiculata.-Upper L. ContraryNote the coarse Anodontine beak sculpture which reaches well down on the disk.

Fig's $7+\mathrm{A}$ and B.-Lastena ohiensis Raf.O. Singleton Iake. Halls.

Fig's $75 \mathrm{~A}$ and B.-Anodonta grandis (Say) o, Mud Latke, Kenmour 


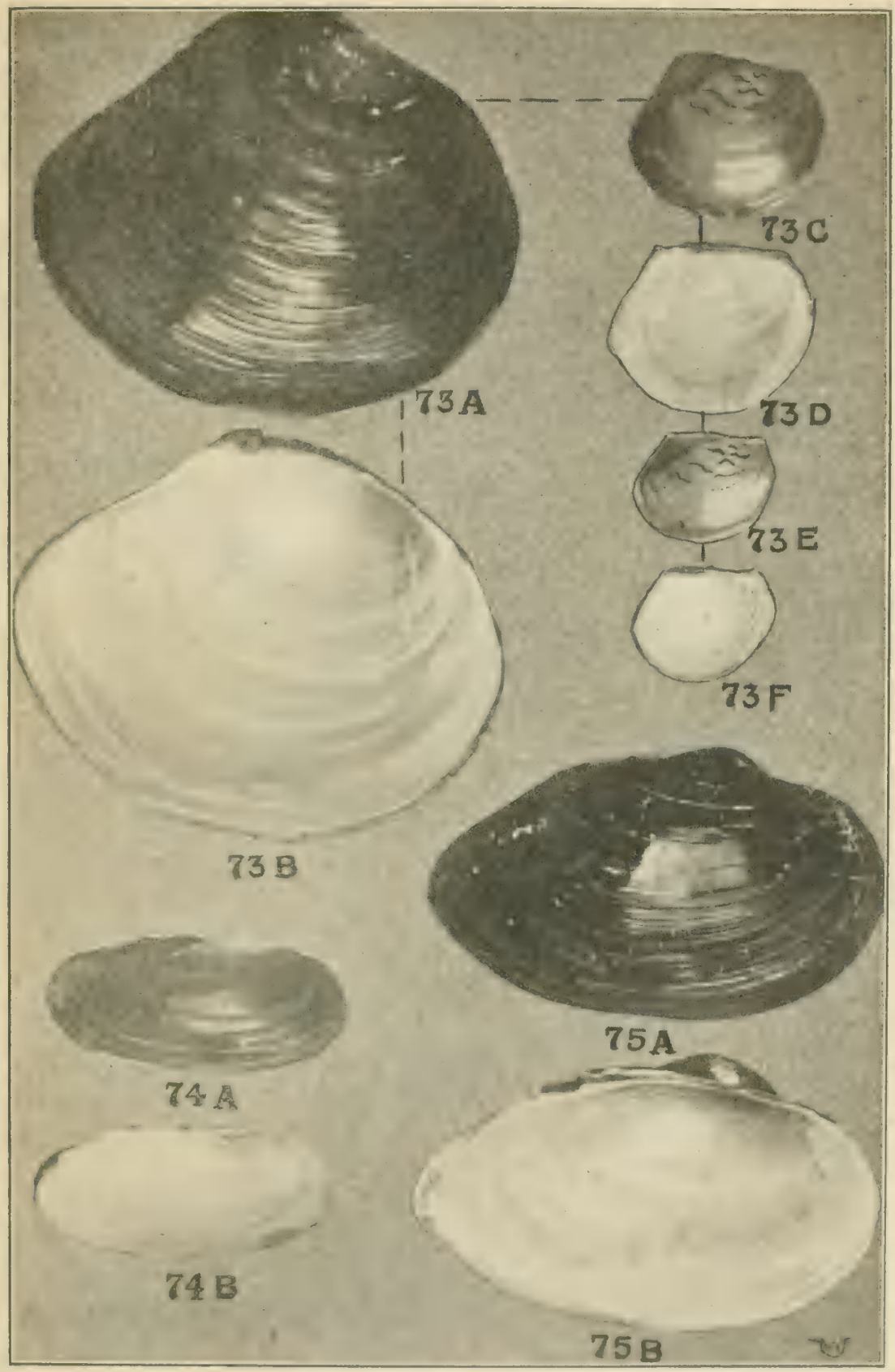

PLATE XYIII.

[TTERBACK ON NAIADES OF MISSOL'RI 
EXPLANATION OF PLATE XXIV

Fig's $76 \mathrm{~A}$ and B.-Anodonta Danielsii Lea o, Lost Cr., Amity. Fig's 77 A and B.-A. dakotana Firierson q. L. Contrary, St. Joseph Fig's $78 \mathrm{~A}$ and B.-Alusmidonta marginata Say $q$, Gasconade $\mathrm{K}$ Gascondy.

Fig's 79 A and B.-A. culceolus (Lea) \&, Jack's Fork, Current R. Fig's $79 \mathrm{C}$ and D.-A. calceolus, $\sigma^{\mathrm{T}}$, White R., Branson.

Fig's 80 A and B.-Strophitus edentulus (Say) o , Osage R., Linn Cr Fig's 80 C and D.-S. edentulus ơ, White R., Branson. 


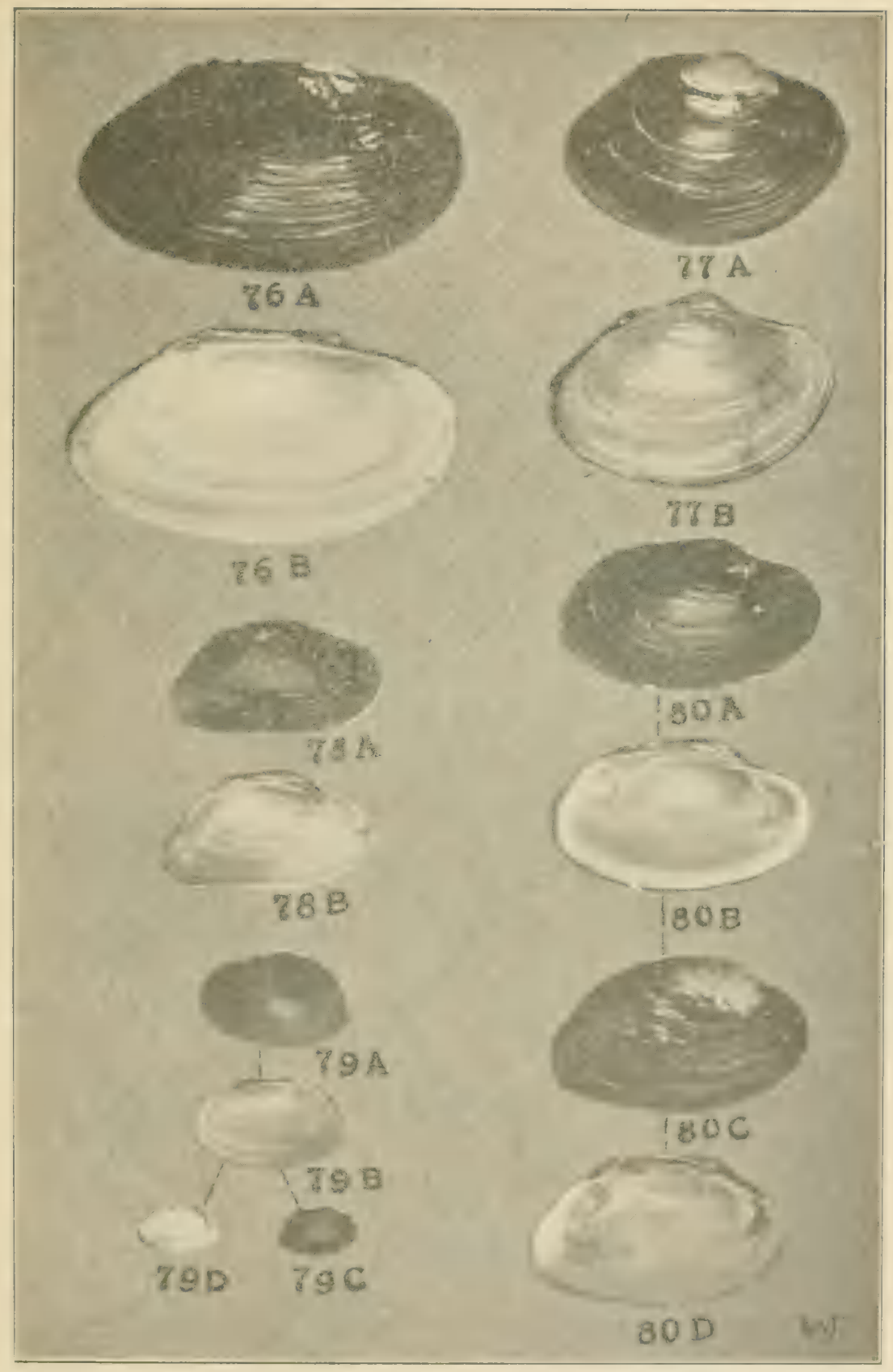

PLATE XXIV.

UTTERBACK ON NAIADES OF MISSOURI 


\section{EXI'LANATION OF' PLATE XXV.}

Fig's $81 \mathrm{~A}$ and B.-Ellipsaria clintonesnsis (Simpson) o, White R., Hollister.

Fig's $8_{2}$ A and B.-Obliquaria reflexa Raf. or, Platte R., Platte R. Sta.

Fig's 82 C and D.,-O. reflexa Ral. F, Osage R., Moregaw Springs.

Fig's 82 I: and F-Juvenile reflexa.-Crow's Fork, Fulton.

Fig's 83 A and B.-Cyprogenia Aberti (Conrad) o, St. Francis R., Greenville.

Fig's 84 A and B.-Oboz'eriu (Pseudoon) eltipsis (Lea) o, Grand R., Sumner.

Fig's $85^{\circ}$ A and B.-Nephronaias ligamentina (Lamarck) \&, Meramec R., Fern Glen.

Fig's $86 \mathrm{~A}$ and B.- $N$. ellisiformis (Comad) on, Osage R., Warsaw.

Fig's 86 C and D.-N. pllipsiformis (Con.) o , Niangua R., Hahatonka.

Fig's 87 A and B.-N. Pleasii (Marsh) q, White R., Branson.

Fig's 87 C and D.- N. Plecisii (Marsh) o', White R., Branson.

Fig's $88 \mathrm{~A}$ and B.-Amygdalonaias truncata (Raf.) o', Osage R., Schell City, Mo.

Fig's 89 A and B.-1. donaciformis (Lea) of, Grand R., Gallatin. Joseph.

Fig's 89 C and I).-A. donaciformis (Lea) o, One-and-Two R., St. 


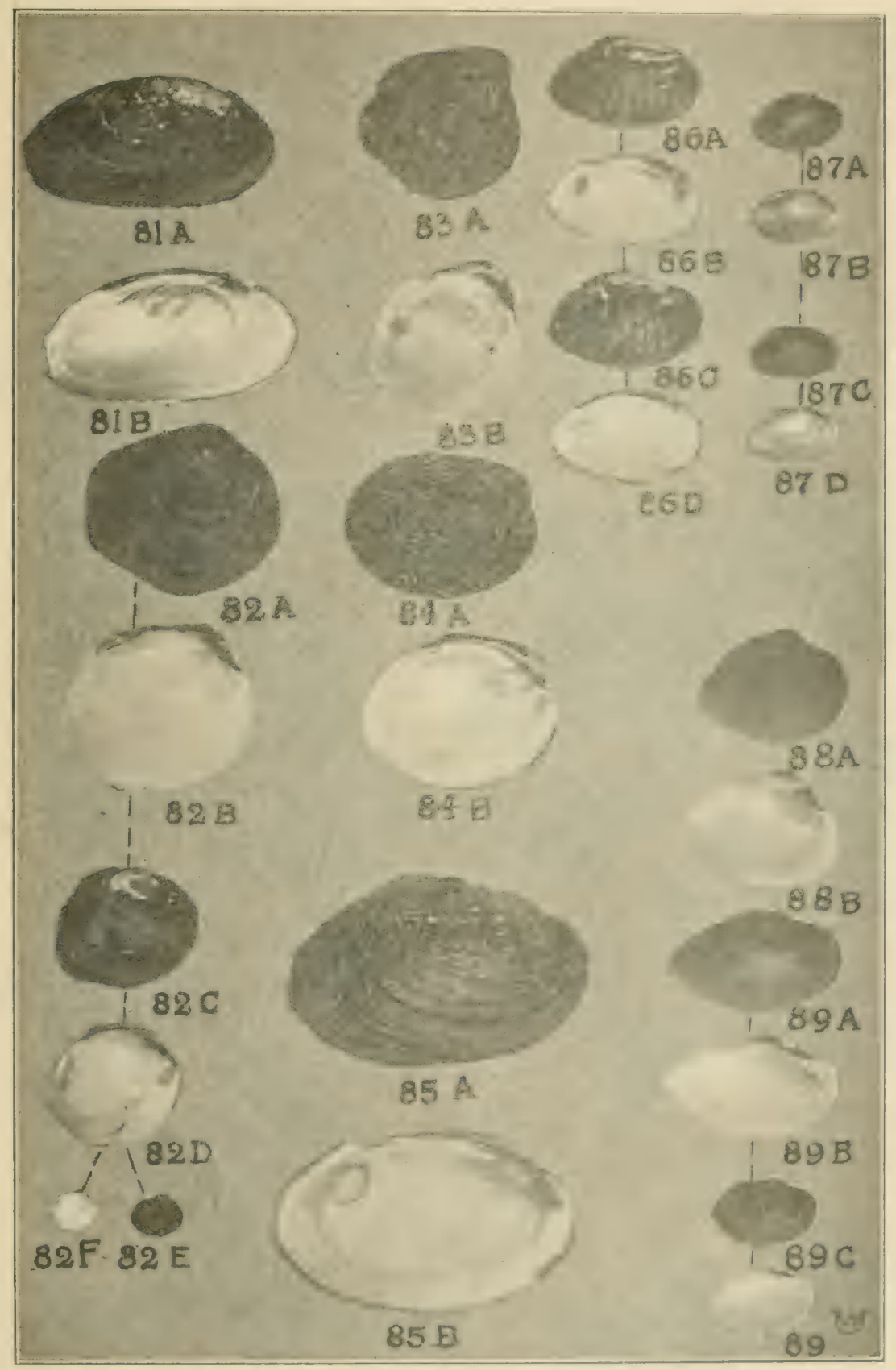

PLATE XXV.

UTTERBACK ON NAIADISS OF MISSOLRI 


\section{EXPLANATION ()F PLATE XXTI}

Fig's $90 \mathrm{~A}$ and B.-Lasmonos fragilis (Raf.) $\odot$, One-and-Two River, St. Joseph. Fig. $90 \mathrm{~B}$ is the photograph of the animal in the left valve showing the gravid marsupium.

Fig's 90 C and D.-L fragilis (Ral.) o ${ }^{7}$, Platte R., Agency Ford.

Fig. go D.-A photograph of soft parts in left valve.

Fig's. 9 r A and B.-Lasmonos Simpsoni (Ferriss) o, White R., Branson

Fig's 92.-A and B.-Proplera purpurata (Lamarck) or, White R., Forsyth.

Fig's $92 \mathrm{C}$ and D.-Proptera purpurata (Lamarck) o, White R., Forsyth.

Fig's 93 A and B.-Prop. capax (Green) o, Miss. R., Hannibal. Fig. 93 b shows photograph of animal with gravid marsupinm. Note non-specialized post-ventral mantle margin.

Fig's 94 A and B.-Prop. laerissima (Lea) o. MI dak Lake, Kenmoor.

Fig's 94 C and I). -Juveniles of laevissima, 1, Contrary, St. Joseph. 


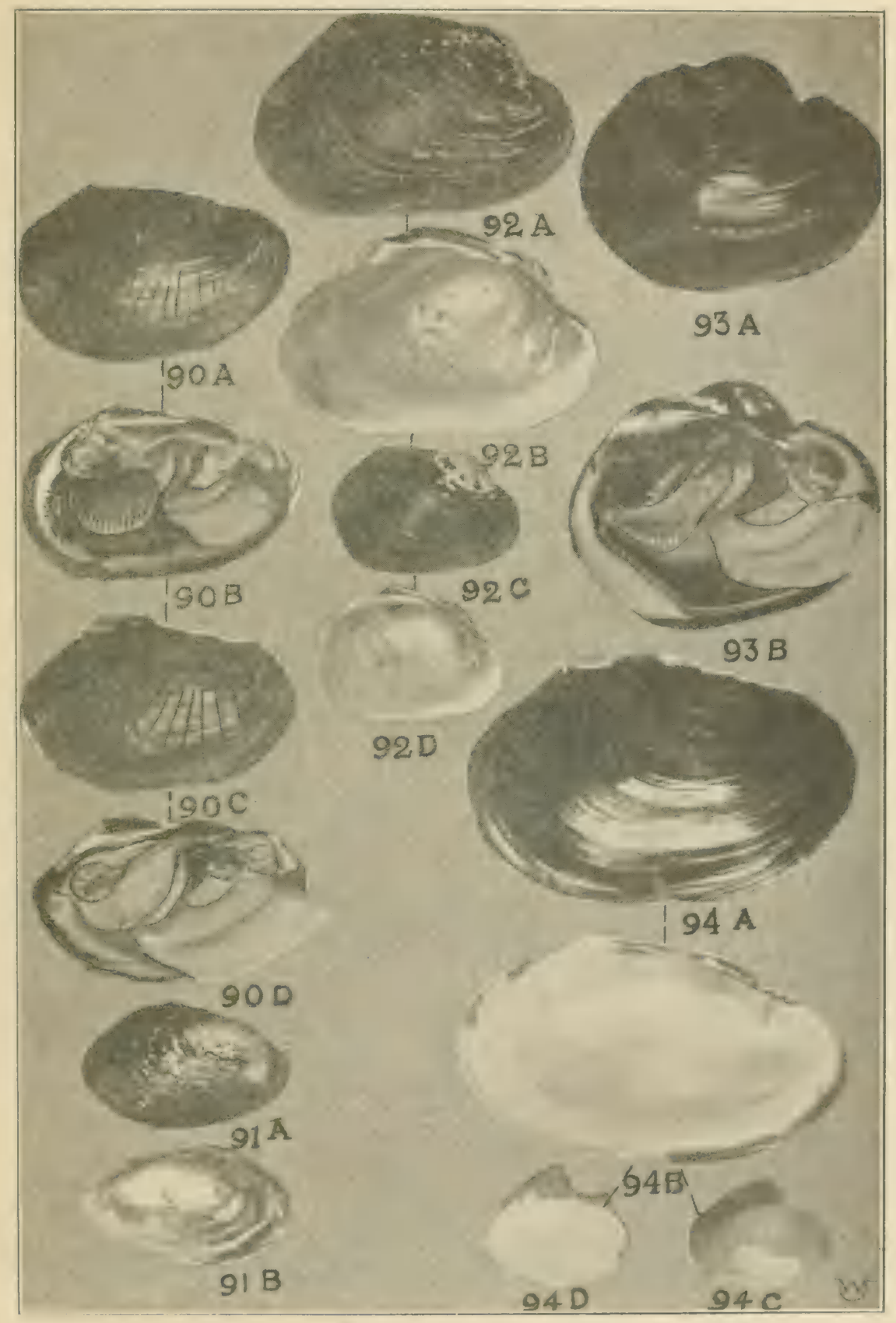

PLATEXIII.

I'TTERBACK ON NAIADISS OF MISSOLRI 


\section{EXPLANATION OF PIATE KXVII}

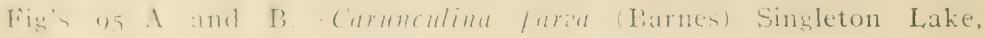
II:all

['ig's 95 ( and 1).- C'. purat (Barnes) o' Artificial Pond, Columbia. Fig's $96 \mathrm{~A}$ and B.-Eurynia (Micromy a) lienosa (Conrad) $\sigma^{7}$, Black R.. Williamsville.

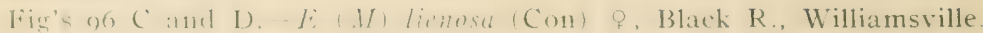
Fig's $97 \mathrm{~A}$ and $\mathrm{B}$. - E. $(M)$ iris (Lea) o, White R., Hollister.

Fig's g.8 A and B.-E ( M.) brevicula (Call) o , White R., Branson.

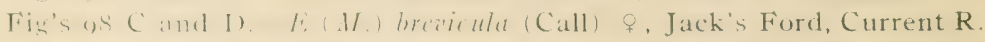

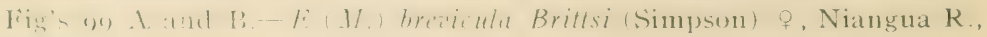
Hahatunka.

Fig's 100 A and B.-E. (Eurynia) recta (Lamarck) on, Osage R., Oseola. Fig's 100 (' and D.-E. (E.) reta (Lam.) \&, Meramee R., Meramec Highlands.

Fign's 10 A and B.-E. (F.) subrostrata (Say) or, Lost Cr., Maysville. Fig's roi (and D.-E. (E.) subrostrulu (Say) o, Flat Cr., Sedalia. 


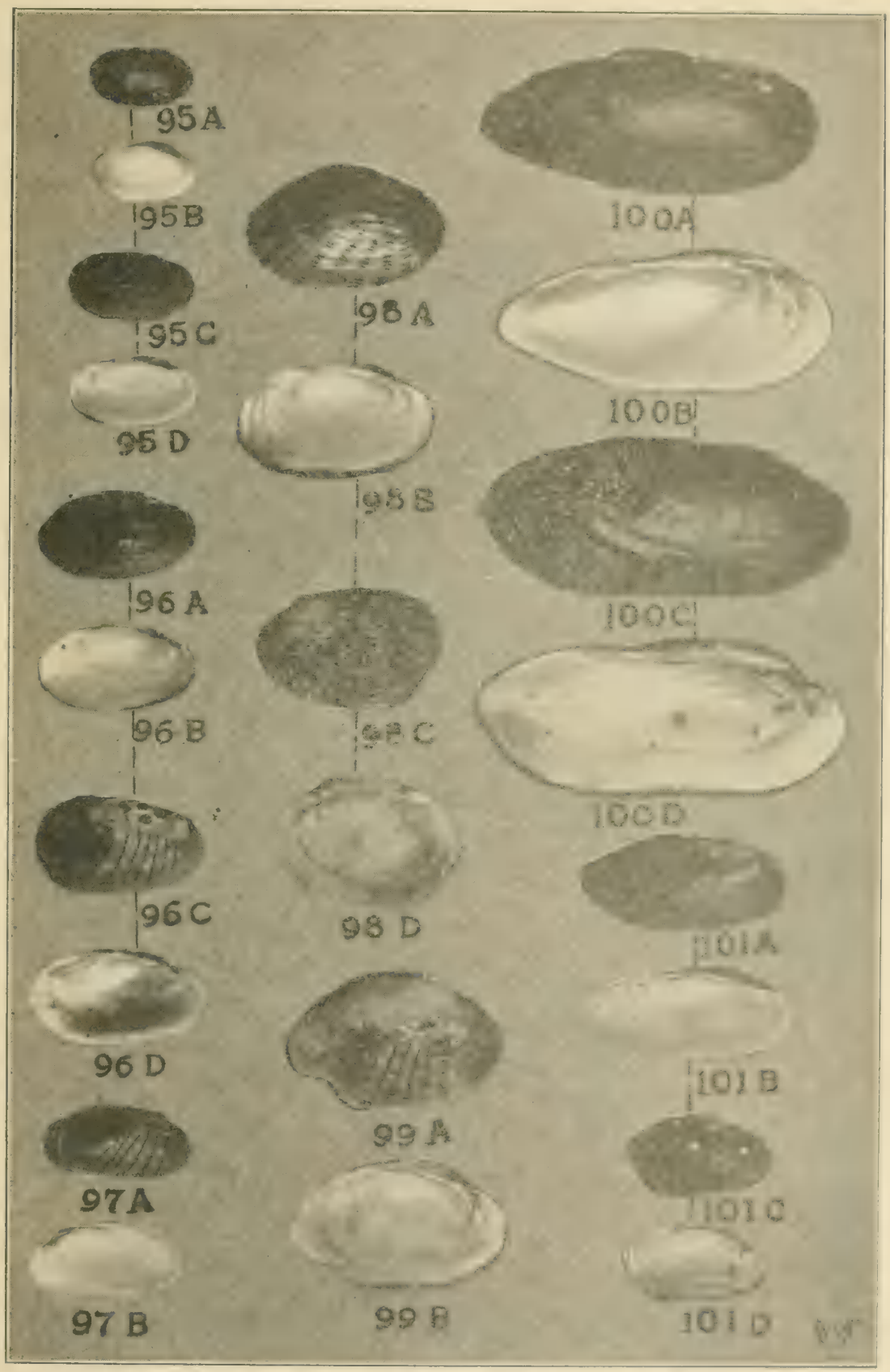

PLATE XXVII.

UTTERBACK ON NAIAIVES OF NISSOIRI 


\section{EXPIANATION OF PLATE XXTIII}

Fig's $102 \mathrm{~A}$ and B.-Lampsilis anodontoides (Lea) on, Chariton R., Kern. Fig's 102 C and D.--L. anodontoides (Lea) of, Chariton R., Kern.

Fig's 103 A and B.-L. Iuteola (Lamarck) or, Black R., Williansville. Fig's 103 C and D.-L. luteole (Lam.) o, Black R., Williamsville

Fig's 103 E and F. - Young L. Iuteola (Lam.) ơ; Black R., Williamsville. Fig's $104 \mathrm{~A}$ and B.-L. Luteola rosacea (Dekay) or. White R., Branson. Fig's 105 A and B.-L. Higginsii (Lea) $\&$, Miss. R., Hannibal.

Fig's $106 \mathrm{~A}$ and $\mathrm{B} .-\mathrm{L}$. ventricose (Barnes) $\sigma^{7}$, Black R., Williamsville. Fig's in6 C and D.-L. ventricose (Barnes) of, Miss. R., Hannibal Fig's $107 \mathrm{~A}$ and B.--L. enentricoas satura (Lea) o. White R., Hollister. Fig's ios A and B.-Truncilla Leferrei Utterback o, Black R., Williamsville.

Fig's $108 \mathrm{C}$ and D.-T. Leferei Utterback o , Black R., Williamsvilte. Fig's Ing A and B.-Truncillu curtisi liricrson and Ltterback of, White R., Hollister.

Fig's $109 \mathrm{C}$ and $\mathrm{D}$. $-T$. Curlisi $\mathrm{H}$. and $\mathrm{U}$. O , White R., Hollister. 


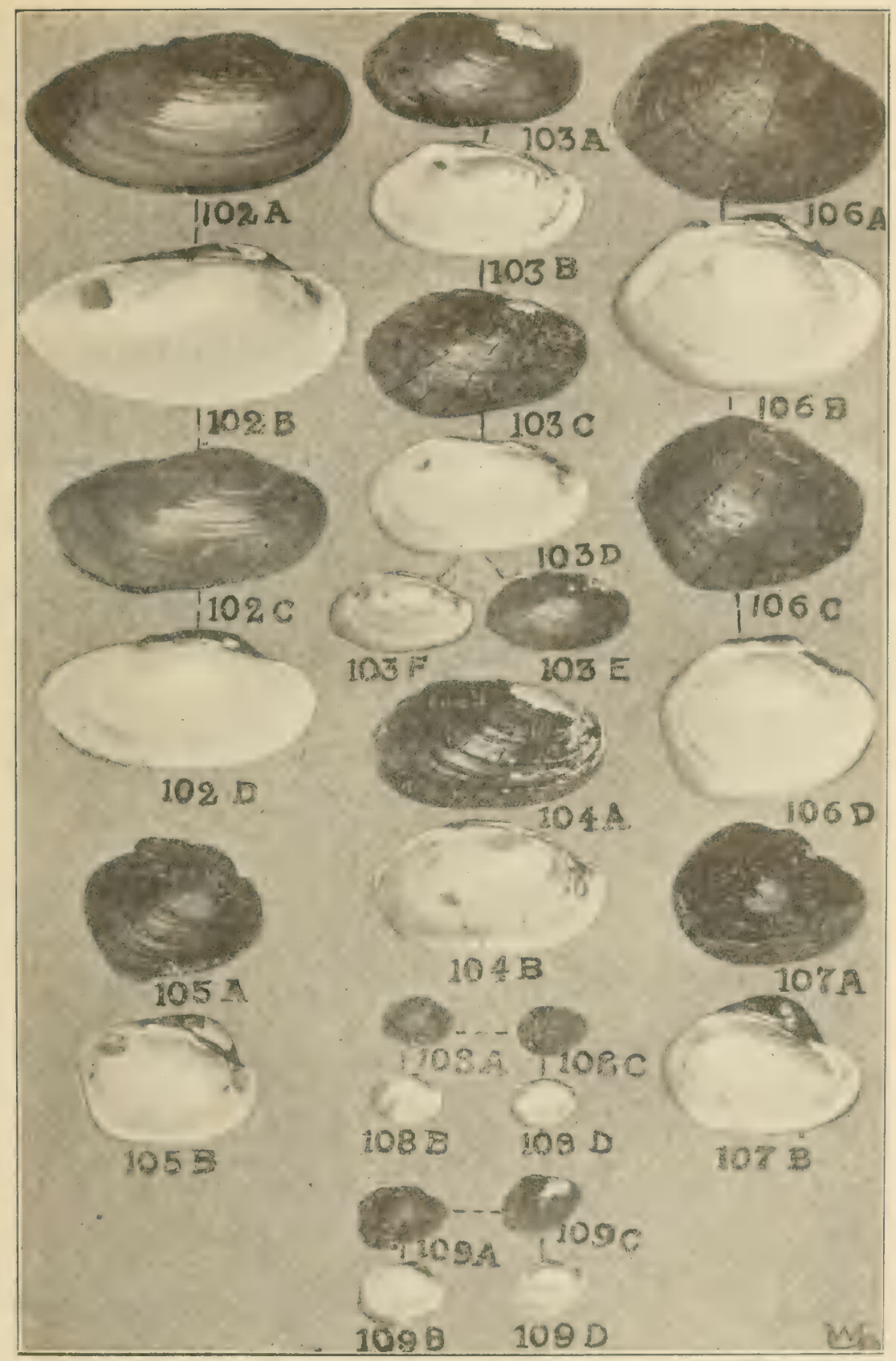

PLATE XXVIII.

UTTERBACK ON NAIAIES OF MISSOLRI 



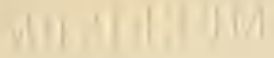

ait at in:

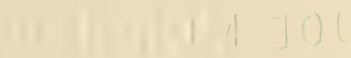





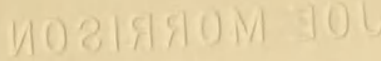

$$
\begin{aligned}
& \text { प0 } 219990 \mathrm{ML}=10 \mathrm{~L}
\end{aligned}
$$

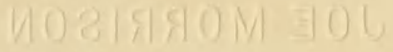


WOE MORRISON

WOE MORRISON

JOE MORRISON 

